
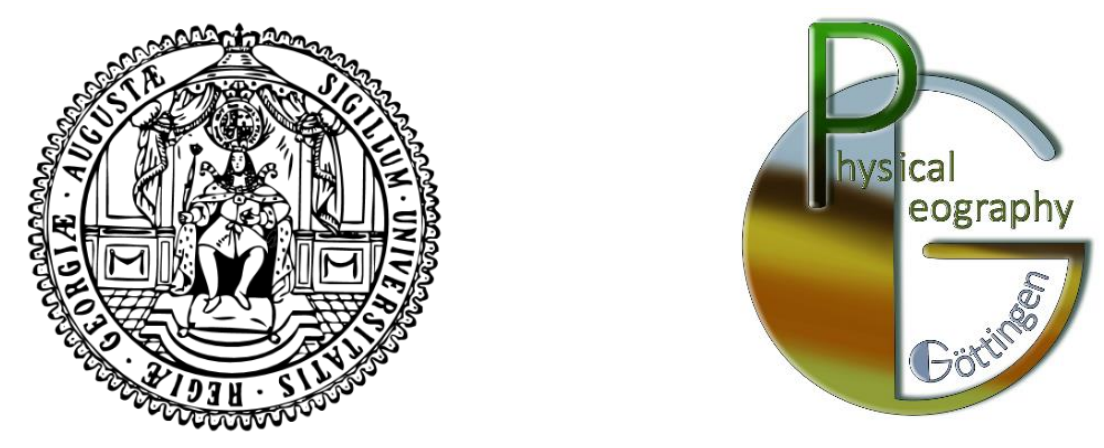

\title{
Geoecological analysis of forest distribution and post-disturbance tree regrowth in the forest-steppe of central Mongolia
}

\section{Dissertation}

Zur Erlangung des mathematisch-naturwissenschaftlichen Doktorgrades

"Doctor rerum naturalium"

der Georg-August-Universität Göttingen

im Promotionsprogramm Geowissenschaften / Geographie

der Georg-August University School of Science (GAUSS)

vorgelegt von

Florian Schneider

aus Görlitz

Göttingen, 2021 


\section{Betreuungsausschuss}

Prof. Dr. Daniela Dauer

(Abteilung Physische Geographie, Georg-August-Universität Göttingen)

Prof. Dr. Hermann Behling

(Abteilung Palynologie und Klimadynamik, Georg-August-Universität Göttingen)

Dr. Michael Klinge

(Abteilung Physische Geographie, Georg-August-Universität Göttingen)

\section{Mitglieder der Prüfungskommission}

\section{Referentin}

Prof. Dr. Daniela Dauer

(Abteilung Physische Geographie, Georg-August-Universität Göttingen)

\section{Korreferent}

Prof. Dr. Hermann Behling

(Abteilung Palynologie und Klimadynamik, Georg-August-Universität Göttingen)

\section{Weitere Mitglieder der Prüfungskommission:}

Prof. Dr. Heiko Faust

(Abteilung Humangeographie, Georg-August-Universität Göttingen)

Dr. Daniel Wyss

(Abteilung Kartographie, GIS und Fernerkundung, Georg-August-Universität Göttingen)

Dr. Michael Klinge

(Abteilung Physische Geographie, Georg-August-Universität Göttingen)

Dr. Stefan Erasmi

(Institut für Betriebswirtschaft, Thünen-Institut Braunschweig)

Tag der mündlichen Prüfung: 29.10.2020 


\section{ACKNOWLEDGEMENTS}

Over the past years, I was fortunate to be in contact with many people who motivated and supported me to achieve my doctoral thesis. At first, I would like to thank Lisa Zwanzig. She encouraged me to apply for the research project position in Göttingen and motivated me to do a PhD. Starting from my arrival in Göttingen 2017 until now, Prof. Dr. Daniela Sauer and Dr. Michael Klinge fundamentally supported my personal and academic development. Thank you very much for all the advice, impressions, critics and opportunities you gave me. You paved my way through this thesis!

I sincerely appreciate the participation of Prof. Dr. Hermann Behling in my thesis. Thank you for the interesting insights during the fieldwork in Mongolia. Special thanks to my former and current colleagues at the Physical Geography Department at the University of Göttingen. From the very beginning, I felt welcome and enjoyed to work together with you. To my former colleagues Stefan, Tino, Kwabena, Wiebke, Daniel, Joscha and Flavia; To my current colleagues Nora, Steffen, Simon, Alexandra, Daniel, Barbara, Harold, Britta, Daniel, Michael and Obaida, I say "thank you". I immensely thank Stephen for his support and fruitful discussions. He always had an ear even when it was getting tough. Furthermore, I sincerely thank Dr. Jürgen Grotheer for his engagement in the laboratory. If there was at any time a problem, he immediately helped to continue the work and kept the process moving. Thanks to Anja, Petra and Eike for the generous support and explanations in the laboratory and the pleasant discussions. I sincerely appreciated the bureaucratic assistance of Marie-France Hesse during my whole time at the department. She made my work more comfortable and let me focus on science without getting stuck in applications and forms. Moreover, I am very grateful to Sören Merkle for his assistance concerning any IT issue and to Lukáš Banyi for the support with $R$. 
My special appreciation to Dr. Choimaa Dulamsuren and Prof. Uudus Bayarsaikhan for their invaluable help in organising and conducting the fieldwork, and to Daramragchaa Tuya for her outstanding support in Mongolia. Thank you to the Mongolian colleagues Amarbayasgalan, Enkhjargal, Enkh-Agar, Munkhtuya, Beck and Bimba; I appreciated their hospitality and help with the fieldwork. My thanks also go to the German students Jannik, Janin, Kim and Tim for their outstanding engagement during the fieldwork. Furthermore, I am deeply grateful to Tino and Jannik for excellent assistance in the laboratory. Thank you to the Deutsche Forschungsgemeinschaft (project number 385460422) for funding this project.

Finally, and most importantly, my deepest gratitude to my family and my friends. Special thanks to Marcel for the mental and academic support since we both started to study geography. He kept motivating me even during the most challenging periods. I am incredibly thankful to my parents. They always pushed me and trusted in what I was doing. This thesis would not be done without the endless support of my wife, Natali. She helped me with everything, from the translation of Russian literature until the deferral of her interests to let me grow. I love you, my dear! 


\section{TABLE OF CONTENTS}

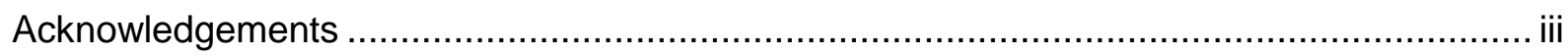

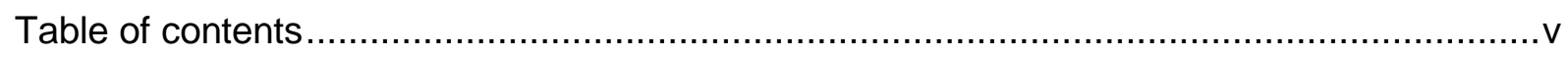

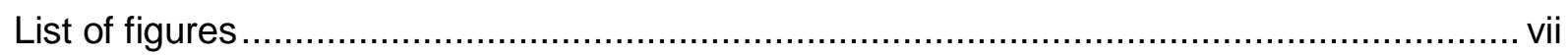

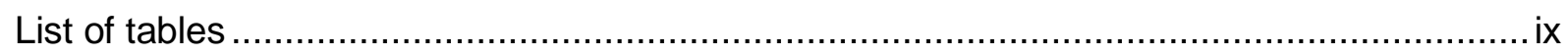

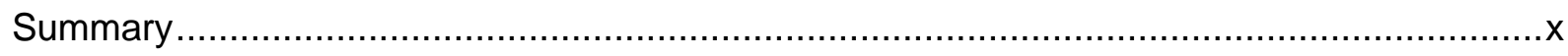

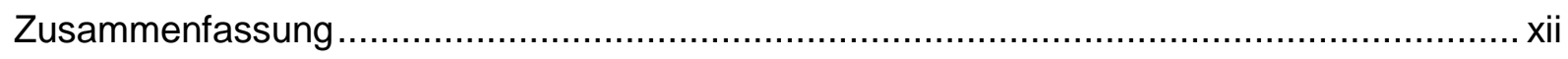

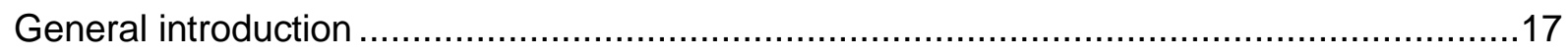

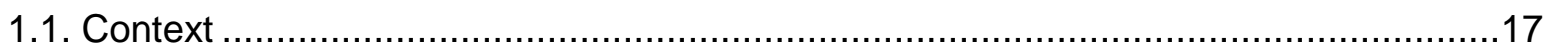

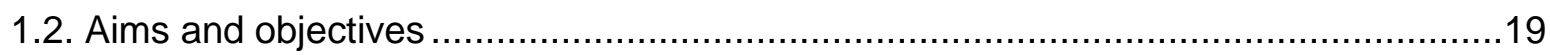

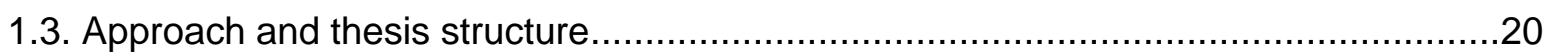

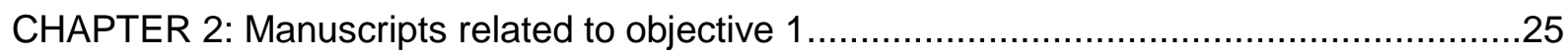

2.1. Geoecological parameters indicate discrepancies between potential and actual forest

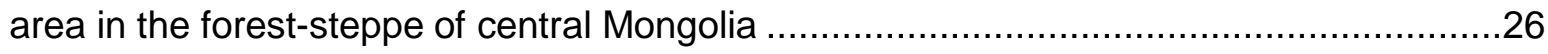

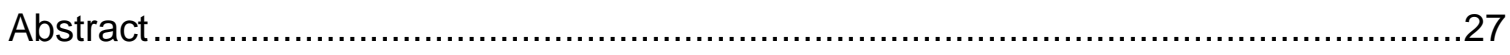

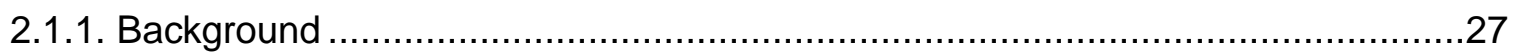

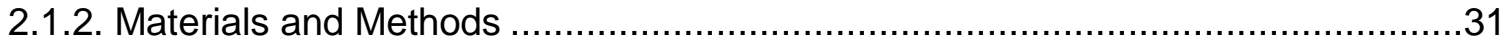

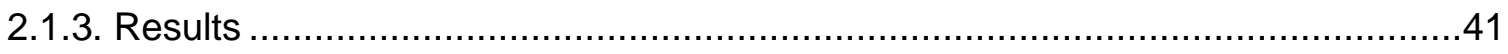

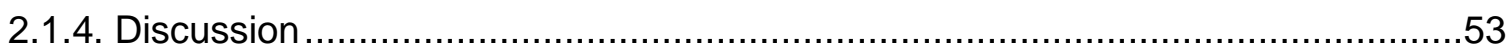

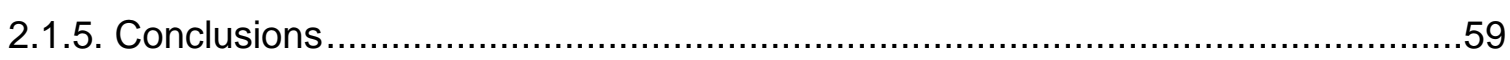

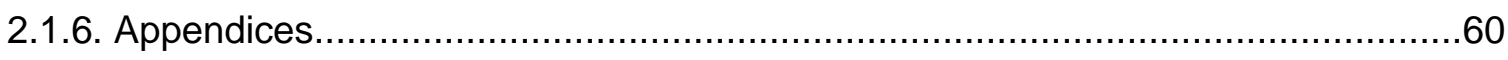

2.2. Modelling the productivity of Siberian larch forests from Landsat NDVI time series in fragmented forest stands of the Mongolian forest-steppe ...........................................62

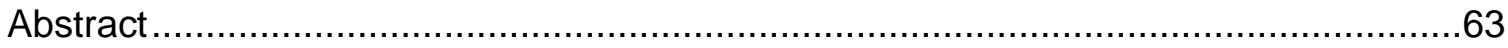

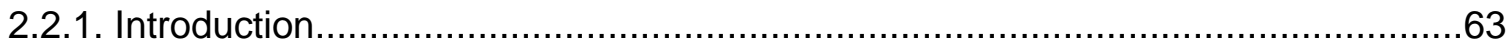

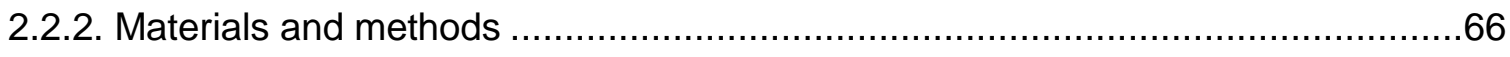

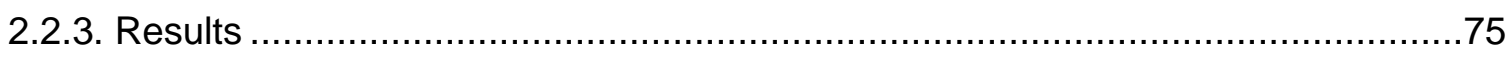

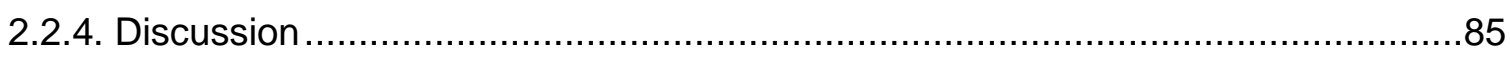

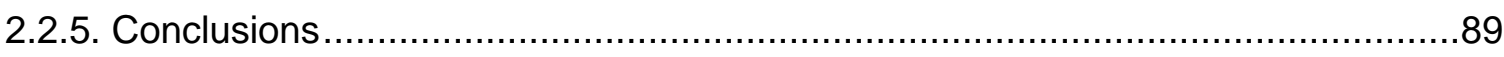

2.3. Siberian larch (Larix sibirica Ledeb.) forests in a changing environment- a systematic review. 


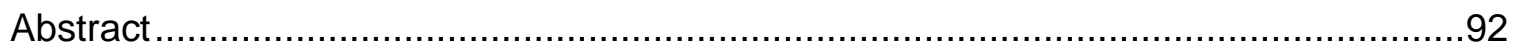

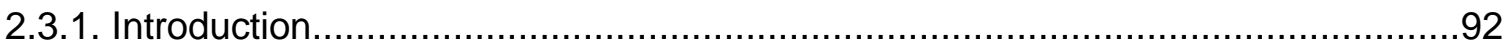

2.3.2. Spatial distribution and ecophysiological characteristics of Larix sibirica .............94

2.3.3. Requirements of Larix sibirica with respect to temperature and light during the

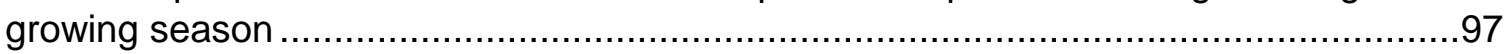

2.3.4. Influence of water scarcity and droughts on Larix sibirica .................................99

2.3.5. The roles of soil properties and permafrost.................................................. 102

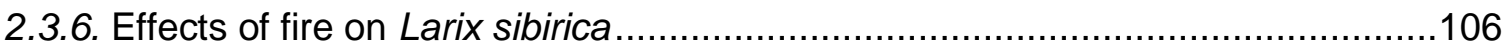

2.3.7. Influence of biotic factors on Larix sibirica..................................................... 109

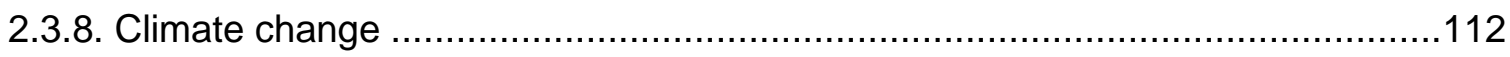

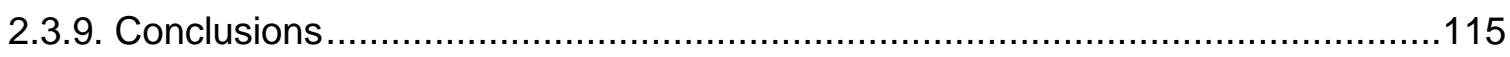

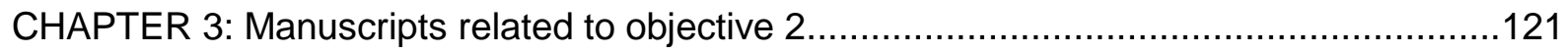

3.1. Hydrological soil properties control tree regrowth after forest disturbance in the forest

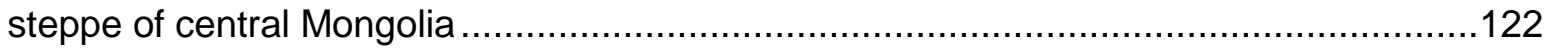

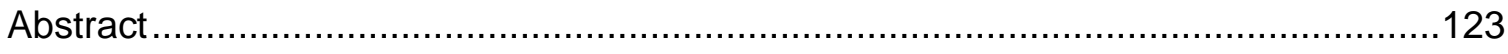

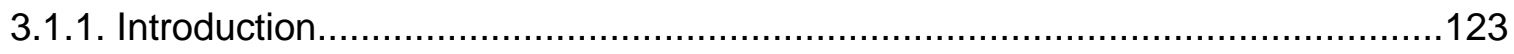

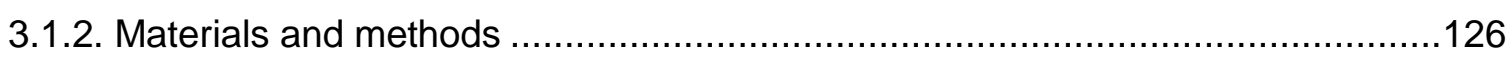

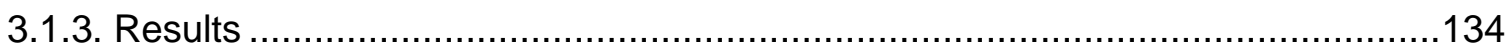

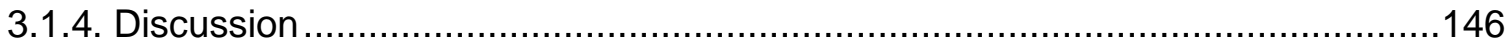

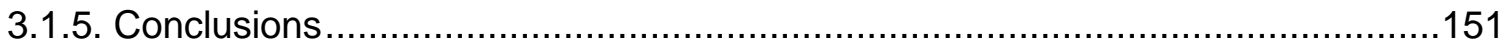

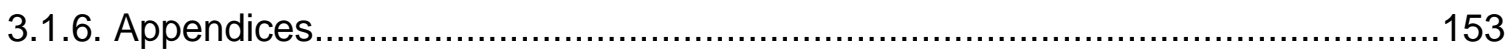

3.2. Interrelations between relief, vegetation, disturbances, and permafrost in the forest-

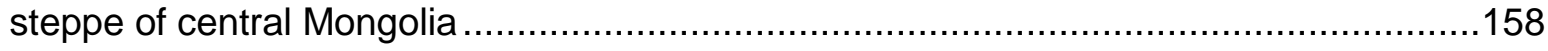

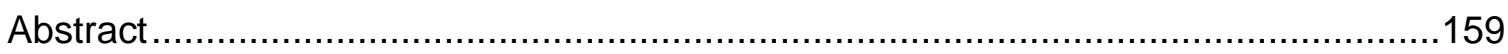

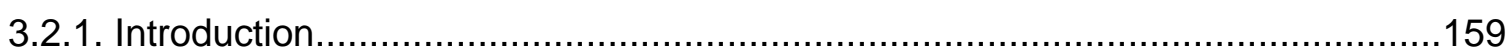

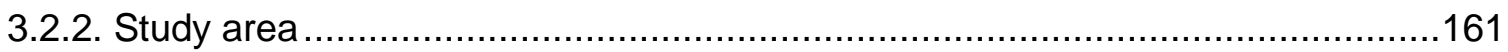

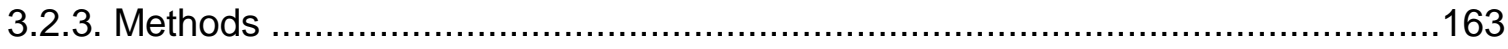

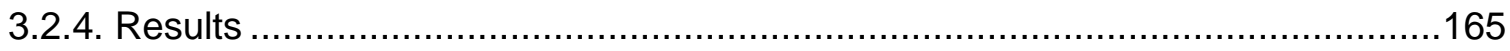

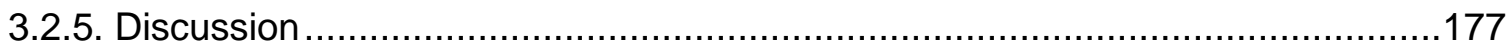

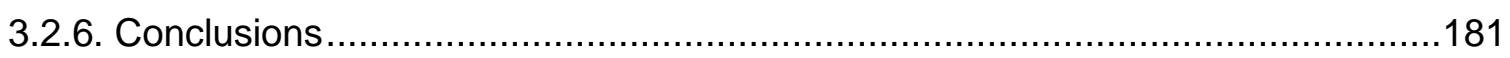

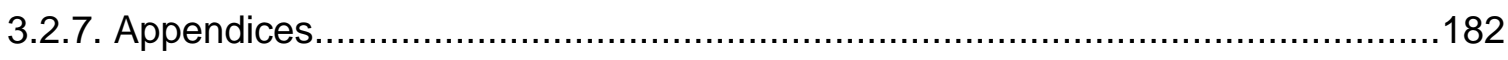

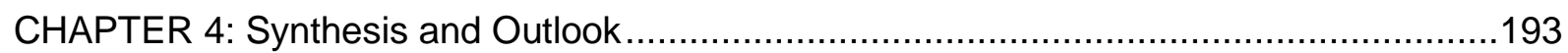

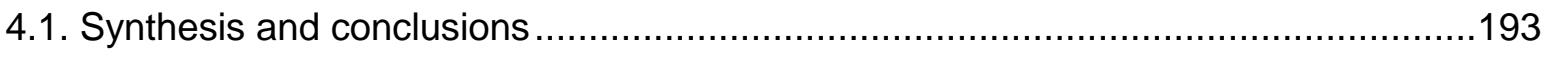

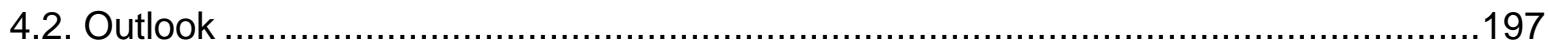

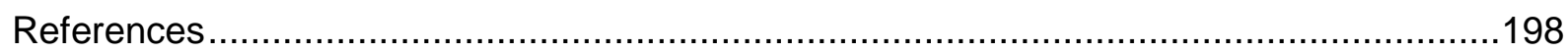




\section{LIST OF FIGURES}

Figure 1.1.1: Forests and disturbed areas in the transition between ..............................18

Figure 1.3.1: Scheme of the study approaches and generated data ...............................21

Figure 2.1.1: Study area. a) Overview of Mongolia with position......................................33

Figure 2.1.2: Climate of the study area around the town Tosontsengel ............................34

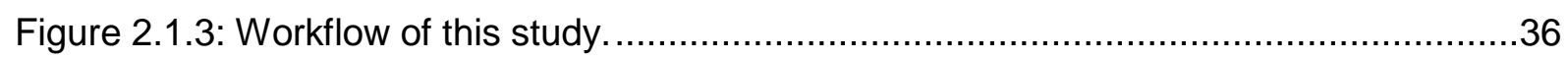

Figure 2.1.4: Landscape units in the study area, with actual forest area............................42

Figure 2.1.5: Top - Change of maximum MGS insolation (left axis) ...............................43

Figure 2.1.6: Forest distribution in 1986 and potential forest areas ................................45

Figure 2.1.7: Frequency-distribution curves of mean growing-season temperature .............46

Figure 2.1.8: Boxplots of tree biomass $\left(\mathrm{Mg} \mathrm{ha}^{-1}\right)$ of forests differing ..............................48

Figure 2.1.9: Relationships between leaf area index (LAl) ........................................49

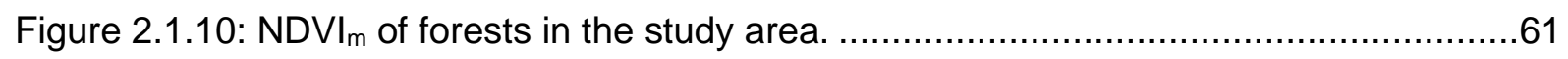

Figure 2.2.1: Study area near Tosontsengel, Mongolia with clusters ................................69

Figure 2.2.2: Variation of monthly precipitation during the summertime .............................70

Figure 2.2.3: Summary of all available Landsat satellite imagery ..................................72

Figure 2.2.4: Temporal profile of standardized peak growing season ...............................77

Figure 2.2.5: Results of the temporal autocorrelation test.........................................

Figure 2.2.6: Relationship between standardized maximum-growing season .....................81

Figure 2.2.7: Relationship between standardized maximum-growing season .....................81

Figure 2.2.8: Standardized maximum-growing season NDVI anomalies..........................84

Figure 2.2.9: Spatial patterns of standardized anomalies of maximum .............................. 85

Figure 2.3.1: Scheme of the environmental factors affecting Larix sibirica........................94

Figure 2.3.2: Spatial distribution of various forest types with and without larch ...................95

Figure 2.3.3: Spatial distribution of studies in central Asia, where .................................101

Figure 2.3.4: The forest area in northern central Asia. The green colour .........................107

Figure 2.3.5: The scatter plot shows the amount of different livestock .............................111 
Figure 2.3.6: Photos from Khangai Mountains, Mongolia. a) Transport

Figure 2.3.7: Schematic description of the relatively weighted environmental.

Figure 3.1.1: Sentinel image (2019/07/31) of the study area

Figure 3.1.2: Typical soil profiles under the four vegetation categories. 130

Figure 3.1.3: Properties of the entire soil profiles. 137

Figure 3.1.4: Properties of the uppermost $10 \mathrm{~cm}$ of the soil profiles. 138

Figure 3.1.5: Top: PCA of the properties of the entire soil profiles 139

Figure 3.1.6: Top: Estimates and $95 \%$ confidence intervals. 142

Figure 3.1.7: Hydraulic conductivities (a) and plant-available field capacities 144

Figure 3.1.8: Calculated plant-available water volume at field capacity 145

Figure 3.1.9: Possible development pathways of disturbed forests 151

Figure 3.1.10: Scatter plots for water repellency..... 155

Figure 3.1.11: Climate diagram for Tosontsengel, Mongolia 156

Figure 3.2.1: Study area. a) Overview of Mongolia. 163

Figure 3.2.2: Soil-temperature depth curves of different geoecological.. 167

Figure 3.2.3: Correlations and $p$ values between O-horizon 168

Figure 3.2.4 GPR images with interpretation of sedimentary structures. 171

Figure 3.2.5: Landscape classification. The shaded relief is based. 172

Figure 3.2.6: Delineated permafrost distribution and calculated depth 176

Figure 3.2.7: Flowchart illustrating input and output data, and the GIS 182

Figure 3.2.8: Relation between measured and calculated depths 183

Figure 3.2.9: (a) Forest with permafrost. The permafrost is indicated 184

Figure 3.2.10: (a) Forest-regrowth pattern after fire: Remaining trees 184

Figure 3.2.11: GPR images with interpretation of sedimentary structures. 188

Figure 4.1.1: Key findings of the conducted studies. Grey boxes represent. 196 


\section{LIST OF TABLES}

Table 2.1.1: Mean living-tree biomass (above and belowground) ..................................40

Table 2.1.2: Thresholds of mean growing-season temperature (MGST) ..........................46

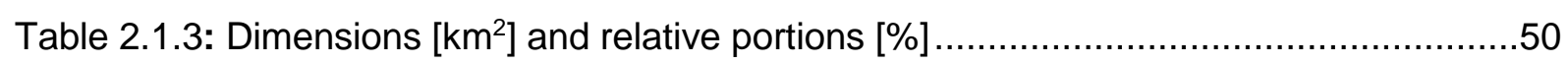

Table 2.1.4: Total living-tree biomass $\left[10^{6} \mathrm{~g}\right]$ in different forest categories .......................52

Table 2.1.5: Potential forest area (PFA) and living-tree biomass ....................................53

Table 2.1.6: Mean living-tree biomass (above and belowground) .................................60

Table 2.2.1: Response of maximum growing season NDVI ........................................76

Table 2.2.2: Results of the correlation analysis between ..........................................79

Table 2.2.3: Results of the correlation analysis between standardized ............................83

Table 2.3.1: Morphological characteristics of Larix sibirica, Larix gmelinii.........................96

Table 2.3.2: Influence of light intensity on carbon assimilation......................................99

Table 3.1.1: General information on the soil profiles................................................154

Table 3.1.2: Applied pedotransfer functions with references......................................157

Table 3.2.1: Average soil-temperature characteristics for different geoecological units. .....168

Table 3.2.2: Correlation statistics of multivariate regressions between ............................173

Table 3.2.3: Geoecological factors controlling soil moisture and permafrost.....................180

Table 3.2.4: Dimensions $\left(\mathrm{km}^{2}\right)$ of the calculated landscape units ................................190 


\section{SUMMARY}

The Mongolian forest-steppe is an ecotone at the transition between the Siberian Taiga in the north and the Gobi Desert in the south. The highly continental, semiarid climate magnifies the importance of water availability for tree vegetation. Forests exclusively appear on northern slopes, due to less evapotranspiration, while the majority of surfaces in the area is covered by grass vegetation. Drought-induced growth reduction and increased tree mortality, intensified by climate change, was frequently observed in the forest-steppe during the last decades. Furthermore, forest fires and forest use, in particular logging and forest grazing, considerably reduced the forest distribution and affected the forest structure. Field investigations showed that severely disturbed forest stands, e.g. by fire or clear-cutting, do not recover equally under apparently similar conditions, ranging from quick tree regrowth to no regrowth of trees at all. It is obligatory to investigate the geoecological factors to understand the recovery pattern and the current development of the forest vegetation in the Mongolian forest-steppe. Therefore, two objectives were aimed in this research as follows: (1) to evaluate the forest vitality, and to determine the forest distribution and the specific requirements for tree growth in the northern Khangai Mountains, situated in the forest-steppe of central Mongolia, (2) to identify the difference in the site-specific conditions, including soil- and permafrost analyses, of healthy forest stands and disturbed forests with and without tree regrowth.

A set of methods on different spatial scales was used to investigate this environment comprehensively. Remote sensing and GIS techniques were applied on Landsat, TanDEM-X and Sentinel satellite images as well as on climate data to characterise the present and potential forest distribution. Those techniques supported the illustration and interpretation of the conducted measurements. A literature review on English, German and Russian literature was carried out to identify the plant-specific needs of Siberian larch, the predominant tree species of the Mongolian forest-steppe. During two field campaigns, 2017 and 2018, 54 soil profiles were analysed, sampled, and hydraulic soil parameters were measured. Moreover, the permafrost depth was analysed using soil profiles, drillings, temperature measurements and ground-penetrating radar. Soil samples were investigated for their physical, chemical and hydrological properties in the laboratory. Statistical procedures were applied to the measured data.

The results indicated that the potential forest area in the northern Khangai Mountains is substantially larger than the present forests. Several fires diminished the forested area by more than $40 \%$ compared to the distribution in 1986. Moreover, logging and grazing livestock opened the forest structure and notably reduced the forest stands at their lower boundary. Based on the findings of the review, fire can be considered as a minor issue for Siberian larch forests due to their quick recovery on burned sites. In contrast, intensified drought events and human impact severely threaten the tree vegetation of the Mongolian forest-steppe by increased tree mortality and hampered tree regrowth.

The soil investigations of the disturbed sites in the study area showed that silt contents of sites with regrowth of trees are significantly higher compared to those without regrowth of trees. Measurements on plant-available field capacity proved this difference by higher capacity in soils of areas with regrowth. Chemical soil properties, such as carbon and nitrogen stocks, effective cation exchange capacity and exchangeable cations, could not prove any significant differences between post-disturbance regrowth and no regrowth. Therefore, soil hydrological properties, which increase the water availability for tree vegetation, are decisive for the tree regrowth on disturbed sites. The permafrost distribution strongly depends on the shadowing of closed vegetation, the thermal isolation by a thick organic layer and the water availability. Dense forest stands contained permafrost within a depth of 50 to $200 \mathrm{~cm}$. On disturbed sites, 
permafrost was not encountered anymore. Thus, the discontinuous permafrost distribution is vanished after severe disturbance and does not influence the tree regrowth pattern.

Based on the findings, it is concluded that water availability is the crucial factor for the tree regrowth pattern after disturbances in the Mongolian forest-steppe. However, the reestablishment of forest vegetation underlies other influences, in particular climate conditions and human impact. Regulating forest management is therefore needed to prevent a dramatic decline of forested areas in future. 


\section{ZUSAMMENFASSUNG}

Die mongolische Waldsteppe bildet den Übergangsbereich zwischen der sibirischen Taiga im Norden und der Wüste Gobi im Süden. Die Baumvegetation in diesem Ökoton ist, aufgrund es hochkontinentalen, semiariden Klimas, in besonderem Maße von Wasserverfügbarkeit abhängig. Waldflächen sind aufgrund des niedrigeren Evapotranspiration auf Nordhängen anzutreffen, während die Mehrheit der Flächen mit Grasvegetation bedeckt ist. Innerhalb der letzten Jahrzehnte haben Dürren zu vermehrter Wachstumsverminderung und erhöhter Baumsterblichkeit in der Waldsteppe geführt. Zudem haben Waldbrände und Waldnutzung, vor allem Abholzung und Waldweide, die Waldverbreitung deutlich reduziert und die Bestandsstruktur beeinflusst. Geländebefunde verdeutlichten, dass sich stark gestörte Waldflächen, verursacht durch Feuer und Kahlschlag, nicht gleichmäßig unter augenscheinlich gleichwertigen Bedingungen erholen. Hierbei wurden Unterschiede von rascher Baumsukzession bis hin zum kompletten Ausbleiben der Baumsukzession dokumentiert. Um diese Vegetationsmuster und die Entwicklung der Waldvegetation in der mongolischen Waldsteppe zu verstehen, ist eine Untersuchung der geoökologischen Steuerungsfaktoren dieses Umweltsystems zwingend erforderlich. Aus diesem Grund hat diese Arbeit folgende Ziele: (1) die Waldverbreitung und die Voraussetzungen für Waldwachstum im nördlichen Khangai Gebirge, welches ein Teil der Mongolischen Waldsteppe bildet, zu bestimmen (2) die entscheidenden Unterschiede in den Standortbedingungen, insbesondere der Bodeneigenschaften und der Permafrostverbreitung, von gesunden Waldstandorten sowie von gestörten Standorten mit und ohne Baumsukzession zu identifizieren.

Eine Vielzahl von Methoden auf verschiedenen räumlichen Skalen wurde genutzt um dieses Umweltsystem weitreichend $\mathrm{zu}$ analysieren. Landsat, TanDEM-X und Sentinel Satellitenaufnahmen sowie Klimadaten wurden mit Hilfe von Anwendungen im Bereich der Fernerkundung und der Geoinformationssysteme genutzt, um die aktuelle und potentielle Waldverbreitung zu ermitteln. Des Weiteren wurden diese Anwendungen genutzt, um die Darstellung und Interpretation der gemessenen Daten zu unterstützen. Eine umfassende Recherche deutscher, englischer und russischer Literatur wurde durchgeführt, um die Anforderungen für das Wachstum der sibirischen Lärche, welche die vorherrschende Baumart in der mongolischen Waldsteppe ist, zu charakterisieren. Während der Geländeaufenthalte 2017 und 2018 wurden 54 Bodenprofilen analysiert, beprobt und hydrologische Bodenparameter gemessen. Zudem wurde die Permafrosttiefe mittels Sondierungen, Bodenprofilen, Temperaturmessungen und dem Einsatz eines Georadars bestimmt. Im Labor wurden die Bodenproben anschließend auf deren chemische, physikalische und hydrologische Eigenschaften untersucht.

Die Ergebnisse weisen darauf hin, dass die potenzielle Waldfläche im nördlichen Khangai Gebirge erheblich größer ist als die aktuelle Waldverbreitung. Mehrere Brände haben die Waldfläche im Vergleich zum Jahr 1986 um 40 \% reduziert. Zudem verringern Abholzung und Waldweide vor allem die untere Grenze der Waldverbreitung und öffnen die Waldstruktur. Basierend auf vorhandener Literatur ist Feuer keine grundsätzliche Bedrohung für die sibirische Lärche, da sie sich auf Brandflächen schnell reetablieren kann. Im Gegensatz dazu gefährden intensive Dürreperioden und der Einfluss des Menschen die Waldverbreitung in der mongolischen Waldsteppe zunehmend, was sich in einer erhöhten Baumsterblichkeit und einem eingeschränktem Baumnachwuchs wiederspiegelt.

Die Untersuchungen der Böden der gestörten Waldflächen haben gezeigt, dass die Flächen mit Baumsukzession signifikant höhere Schluffgehalte im Vergleich zu den Flächen ohne Baumsukzession aufweisen. Messungen der pflanzenverfügbaren Feldkapazität bestätigen diesen Unterschied mit vergleichsweise höheren Werten in Böden unter Baumsukzession 
vergleichen zu Boden, auf denen keine Baumsukzession festgestellt wurde. Bei den bodenchemischen Eigenschaften, wie zum Beispiel Kohlenstoff- und Stickstoffvorräte, effektive Kationenaustauschkapazität und austauschbare Kationen, konnte kein signifikanter Unterschied zwischen den beiden Gruppen ausgemacht werden. Aus diesem Grund wird geschlussfolgert, dass bodenhydrologische Eigenschaften, welche die Wasserverfügbarkeit für Baumvegetation erhöhen, entscheidend für das Aufkommen von Bäumen auf gestörten Waldflächen sind. Die Permafrostverbreitung ist abhängig von der Beschattung durch eine geschlossene Vegetation, von der thermalen Isolation durch eine organische Auflage und von der Verfügbarkeit von Wasser. Im Untersuchungsgebiet wurde Permafrost unter dichten Waldbeständen in einer Tiefe von 50 bis $200 \mathrm{~cm}$ aufgefunden. Im Gegensatz dazu war Permafrost auf den gestörten Waldflächen nicht mehr nachweisbar. Daher hat die diskontinuierliche Permafrostverbreitung keinen Einfluss auf das Wiederaufkommen von Bäumen nach schweren Störungen.

Basierend auf den Erkenntnissen ist zu schlussfolgern, dass die Verfügbarkeit von Wasser der entscheidende Faktor für das Wiederaufkommen von Baumvegetation auf gestörten Waldflächen in der mongolischen Waldsteppe ist. Jedoch unterliegt die Etablierung der Waldvegetation weiterer Einflüsse, insbesondere der klimatischen Bedingungen und des Einflusses des Menschen. Daher ist eine regulierende Forstwirtschaft zwingend nötig, um einen dramatischen Rückgang der Waldflächen in Zukunft zu verhindern. 



\section{GENERAL INTRODUCTION}

\subsection{Context}

Only eight percent of the surface of Mongolia is covered by forest (Tsogtbaatar 2013). These forests concentrate on the northern part of the country and contribute to the southern edge of the Siberian Taiga as well as to the central Asian forest-steppe, an ecotone that represents the transitional zone between boreal forest and steppe. Based on the highly continental, semiarid climate, water is a limited resource in this area. Therefore, the forest-steppe contains forest stands exclusively on north-facing slopes due to less evapotranspiration (Hais et al. 2016). Grass vegetation covers the majority of surfaces in this ecotone with a sparse cover on southern slopes.

The predominant tree species of Mongolian forests is Siberian larch (Larix sibirica Ledeb.) which contributes by $75 \%$ to the standing stock (Tsogtbaatar 2004, 2013). This plant is adapted to the dry conditions by a robust hydraulic architecture which uses the water resources efficiently (Chenlemuge et al. 2015b; Khansaritoreh et al. 2018). Nevertheless, droughtinduced plant stress, leading to growth reduction and tree mortality, is a frequently observed phenomenon in the Mongolian forest-steppe (Dulamsuren et al. 2010c; Dulamsuren et al. 2011). This climate-induced stress further intensives be means of global warming (IPCC 2014). Batima et al. (2005) observed a temperature increase in Mongolia of $1.6{ }^{\circ} \mathrm{C}$ over the last century under equal precipitation. This development leads to higher evapotranspiration loss and, under equal precipitation, to increased drought.

Intensified drought events favour the occurrence of fire. During the 20. Century, the fire frequency in the Taiga and the forest-steppe increased (Kharuk et al. 2008; Hessl et al. 2012). Mongolian forests are widely affected by fire, and the forest distribution is considerably reduced (compare Figure 1.1.1). 


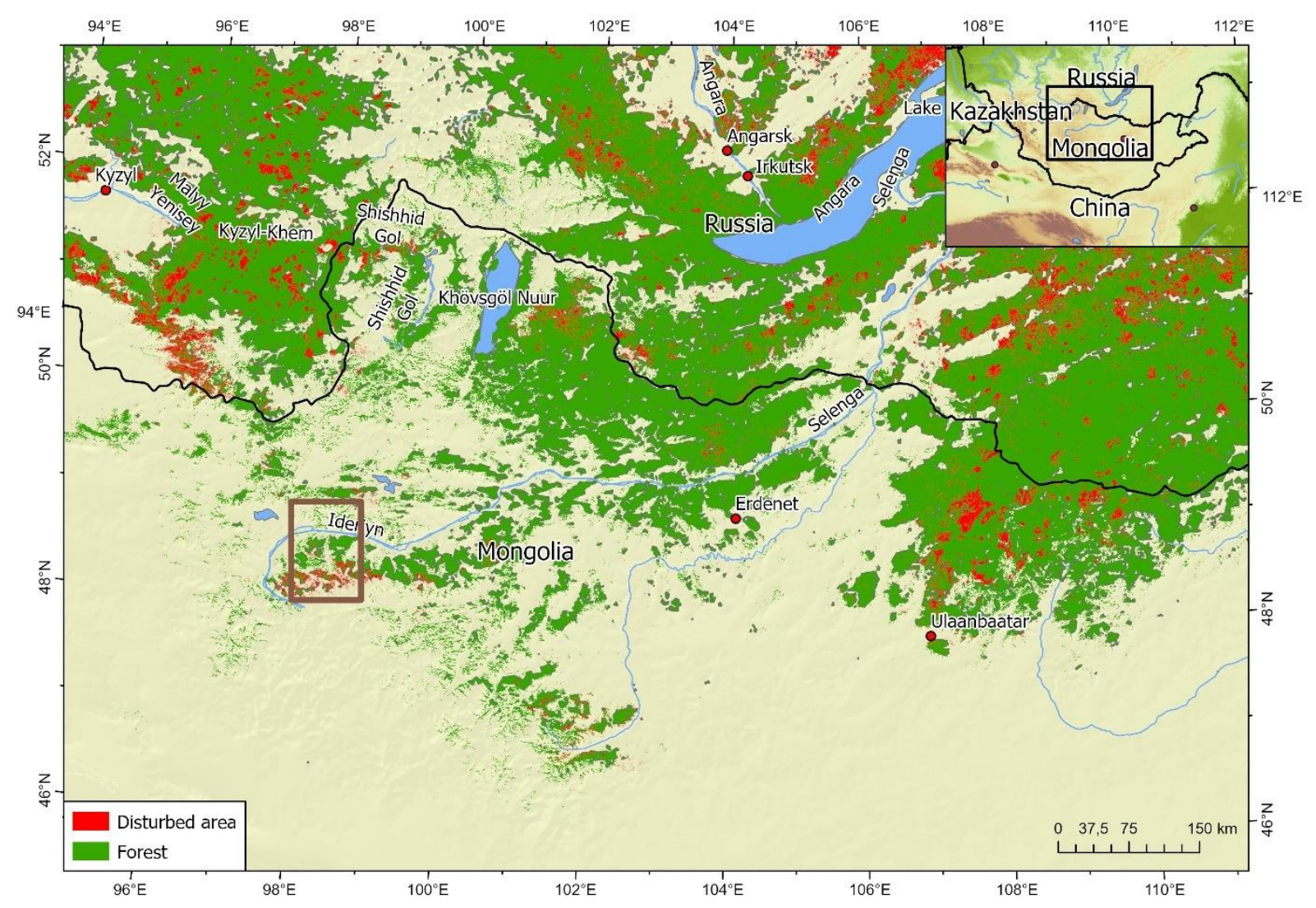

Figure 1.1.1: Forests and disturbed areas in the transition between boreal forest and steppe. The green colour indicates forest areas (FAO, (2006a) and the red colour shows burned, previously forested areas after Hansen et al. (2013). The brown rectangle represents the study area. Right top: Physical map of Mongolia and surrounding countries. The black rectangle shows the position of the map.

Besides the fire, human impact diminishes the forested area to a certain extent. During the Soviet period, selective logging was governmentally organised, and the forest resources were intensively used. Nowadays, logging is restricted to deadwood, but illegal logging is a general issue in Mongolia (Lkhagvadorj et al. 2013a). Moreover, forest grazing, especially by goats, hampers tree regrowth and further opens the forest structure (Hilbig 1987; Sankey et al. 2006; Khishigjargal et al. 2013).

In contrast, the presence of permafrost supports the forest vegetation by additional water supply from the meltwater of the active layer during the summer period (Bonan and Shugart 1989; Zhang et al. 2011; Churakova et al. 2016). The permafrost distribution in Mongolia is discontinuous and strongly connected to the forest distribution due to the shadowing and thermal isolation of the tree vegetation (Dashtseren et al. 2014). As a result of climate change, 
the active layer thickness of permafrost in Mongolia increases by $0.5-2 \mathrm{~cm}$ per year (Sharkhuu and Sharkhuu 2012). This process leads to an enhanced vulnerability of Mongolian forests, in particular to drought events.

Increased drought combined with human impact and the decrease of permafrost substantially threat the distribution of forests in the Mongolian forest-steppe. Field observations showed that severely disturbed forest stands do not recover equally, ranging from quick regrowth to no regrowth at all. Until now, there is a lack of information concerning the controlling factors of this vegetation pattern. Sommer (2000) investigated the ecology of a larch forest in the mountain forest-steppe of north-west Mongolia. The findings proved a clear relation of forest distribution to climate parameters, fire and forest use. Further investigations in this region dealt with soil properties, yet, they do not discuss the connected vegetation pattern (Haase 1963; Krasnoshchekov 2010; Sympilova and Gyninova 2012).

For this reason, a comprehensive analysis is needed to understand the development of this vegetation pattern and to react appropriately to changing environmental conditions. An investigation of the present forest distribution and the post-disturbance tree regrowth pattern will provide crucial information concerning the present limitations and requirements for forests in this ecotone, and may help to identify future trends.

\subsection{Aims and objectives}

In this thesis, it was aimed to investigate the geoecological factors controlling the forest distribution and post-disturbance tree regrowth pattern in the northern Khangai Mountains, central Mongolia. Therefore, the study focused on two broad objectives as follows:

1) To evaluate the forest situation, and to determine the forest distribution and the specific requirements for tree growth in the study area, using; 
i) remote sensing and geographic information system (GIS) techniques, biomass analyses and underground observations to determine the present and the potential forested area - Study 1 ().

ii) remote sensing, geographic information system (GIS) techniques and tree ring growth analyses to connect tree vitality with NDVI time series - Study 2 ().

iii) a comprehensive review of English, German and Russian literature concerning the plant-specific needs of Siberian larch supported by GIS techniques - Study 3 ().

2) To identify the difference in site-specific conditions between forest stands and disturbed forests with and without regrowth of trees. Since several factors are needed to be involved in accomplishing a comprehensive analysis, this objective was further divided into two subthemes as follows;

i) Differences in chemical, physical and hydrological soil properties by field and laboratory measurements - Study 4 (),

ii) Distribution and depth of the discontinuous permafrost under forests and disturbed areas by use of a ground-penetrating radar (GPR) - Study 5 ().

\subsection{Approach and thesis structure}

In order to achieve the objectives, it was essential to work with various methods on different scales of observations, from macro scale to micro scale, and to combine diverse approaches in the conducted studies (Figure 1.3.1). 


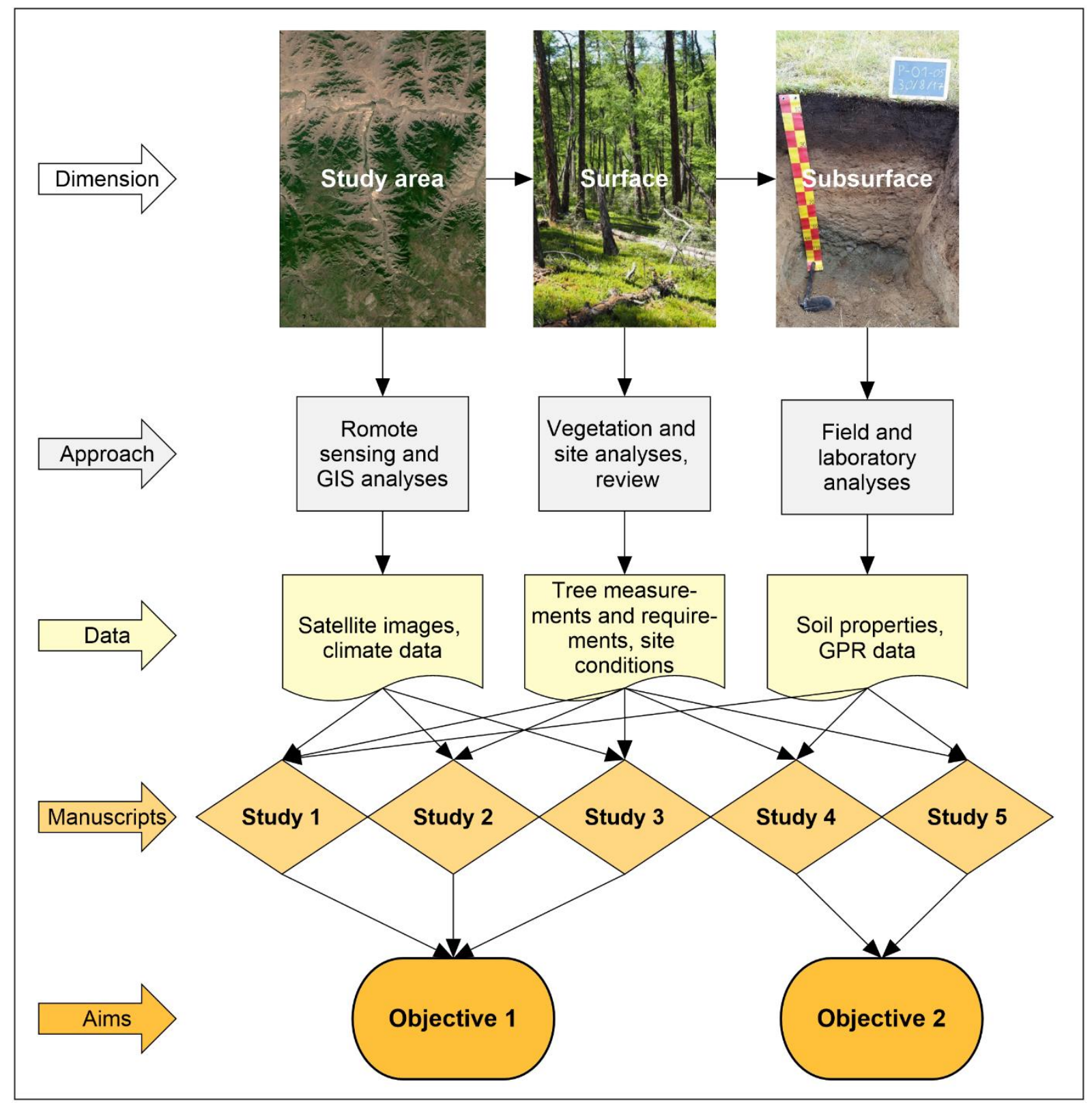

Figure 1.3.1: Scheme of the study approaches and generated data leading to the conducted studies.

The first objective required remote sensing data as well as field observations to determine the present situation properly. Sentinel images and biomass determination were used in study 1 to classify and quantify the forest vegetation and to calculate the potential forest distribution. Study 2 combined field measurements of tree ring growth with NDVI time series from Landsat data to analyse the connection between these parameters and to enable a forest vitality interpretation via remote sensing analysis. Study 3 focused on already conducted investigations on Siberian larch to identify plant-specific limitations and threats in order to 
evaluate the site conditions in the study area. Therefore, a comprehensive literature analysis combined with GIS techniques were used.

The second objective concentrates on the descriptions and results of the field campaigns 2017 and 2018, and the conducted laboratory measurements. In study 4, chemical, physical and hydrological soil properties of 54 soil profiles were analysed and evaluated statistically concerning the vegetation and post-disturbance tree regrowth pattern. GPR measurements combined with soil profiles and drilling cores were the key components of the permafrost investigation. The results were used in study 5 to evaluate the permafrost distribution with the help of GIS techniques.

The thesis structure continues with the conducted studies, which are all presented as scientific manuscripts. These manuscripts are placed in chapter 2 and 3 in order for the objectives. The formatting style of the manuscripts was partly edited to maintain a continuous thesis format. Chapter 4 will synthesise the conducted studies related to the research aim. 

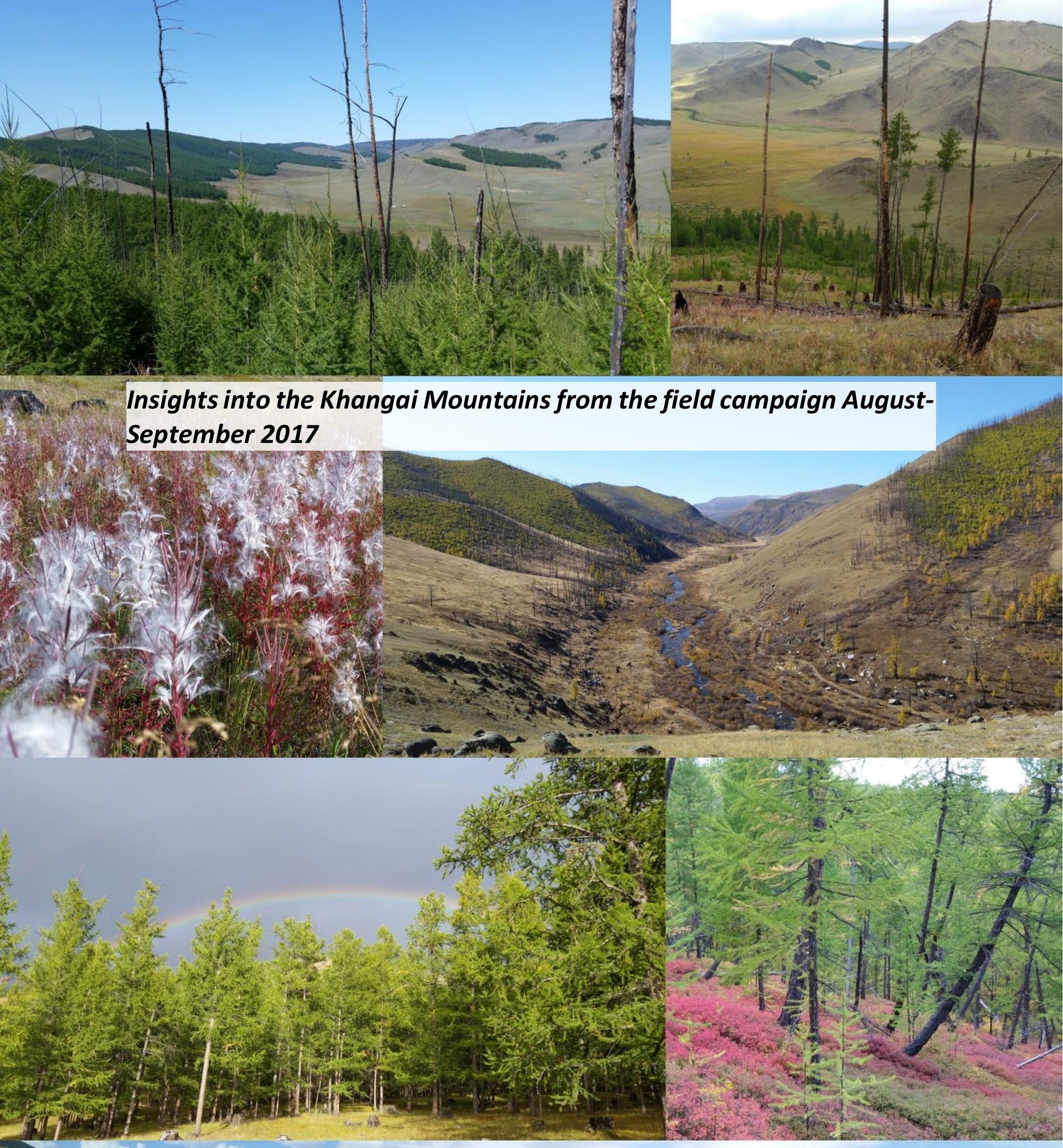

Insights into the Khangai Mountains from the field campaign AugustSeptember 2017 


\section{CHAPTER 2: MANUSCRIPTS RELATED TO OBJECTIVE 1}

This chapter presents three scientific manuscripts in order to achieve the first objective. The first two manuscripts focus on the present and potential forest distribution. The combination of vegetation data and remote sensing data allows insight in forest vitality and potential forest distribution. The third manuscript deals with the plant-specific requirements of Siberian larch to evaluate the potential and risk of Siberian larch forests in the Mongolian forest-steppe under a changing environment. Water scarcity due to climate change and human impact play a primary role in the distribution of larch forests in Mongolia. 


\subsection{Geoecological parameters indicate discrepancies between potential and actual forest area in the forest- steppe of central Mongolia}

Michael Klinge ${ }^{1}$, Choimaa Dulamsuren ${ }^{2}$, Florian Schneider ${ }^{1}$, Stefan Erasmi ${ }^{3}$, Uudus Bayarsaikhan ${ }^{4}$, Daniela Sauer ${ }^{1}$, Markus Hauck ${ }^{2}$

1 Department of Physical Geography, Institute of Geography, University of Göttingen, Goldschmidtstraße 5, 37077 Göttingen, Germany

${ }^{2}$ Applied Vegetation Ecology, Faculty of Environment and Natural Resources, University of Freiburg, Tennenbacher Str. 4, 79106 Freiburg, Germany

3 Institute of Farm Economics, Thünen Institute, Bundesallee 63, 38116 Braunschweig, Germany

${ }^{4}$ Department of Biology, School of Arts and Sciences, National University of Mongolia, Baga toiruu 47, Sukhbaatar duureg, Ulaanbaatar, Mongolia

- Manuscript published in Forest Ecosystems (10. August 2021)

- https://doi.org/10.1186/s40663-021-00333-9

\section{Author contributions:}

M. Klinge conceived the ideas; M. Klinge, CH. Dulamsuren, F. Schneider, M. Hauck, U. Bayarsaikhan and D. Sauer participated fieldwork and collected the data; M. Klinge, S. Erasmi analysed the data; M. Klinge, M Hauck and D. Sauer led the writing.

Keywords: biomass, fire, forest-steppe, geoecological factors, Mongolia, permafrost 


\section{Abstract}

Background: Forest distribution in the forest-steppe of Mongolia depends on relief, permafrost, and climate, and is highly sensitive to climate change and anthropogenic disturbance. Forest fires and logging decreased the forest area in the forest-steppe of Mongolia. The intention of this study was to identify the geoecological parameters that control forest distribution and living-tree biomass in this semi-arid environment. Based on these parameters, we aimed to delineate the area that forest might potentially occupy and to analyse the spatial patterns of actual and potential tree biomass.

We used a combination of various geographic methods in conjunction with statistical analyses to identify the key parameters controlling forest distribution. In several field campaigns, we mapped tree biomass and ecological parameters in a study area within the Tarvagatai Nuruu National Park (central Mongolia). Forest areas, topographic parameters and vegetation indices were obtained from remote sensing data. Significant correlations between forest distribution and living-tree biomass on one hand, and topographic parameters, climate data, and environmental conditions on the other hand, were used to delineate the area of potential forest distribution and to estimate total living-tree biomass for this area.

Results: Presence of forest on slopes was controlled by the factors elevation, aspect, slope, mean annual precipitation, and mean growing-season temperature. Combining these factors allowed for estimation of potential forest area but was less suitable for tree-biomass delineation. No significant differences in mean living-tree biomass existed between sites exposed to different local conditions with respect to forest fire, exploitation, and soil properties. Tree biomass was reduced at forest edges (defined as $30 \mathrm{~m}$ wide belt), in small fragmented and in large forest stands. Tree biomass in the study area was $20 \times 109 \mathrm{~g}(1,086 \mathrm{~km} 2$ forest area), whereas the potential tree biomass would reach up to $65 \times 109 \mathrm{~g}(>3,168 \mathrm{~km} 2)$.

Conclusions: The obtained projection suggests that the potential forest area and tree biomass under the present climatic and geoecological conditions is three times that of the present forest area and biomass. Forest fires, which mostly affected large forest stands in the upper mountains, destroyed $43 \%$ of the forest area and $45 \%$ of the living-tree biomass in the study area over the period 1986-2017.

\subsubsection{Background}

The Mongolian forest-steppe represents the transition zone between the southern limit of the boreal forest in Central Asia and the dry region of the Gobi Desert. It is characterized by semiarid climate and is highly vulnerable to climate change and land-use intensification (Poulter et al. 2013; Yang et al. 2016; Khansaritoreh et al. 2017b). Various ecological stress factors have recently reduced Mongolia's forest area and thus most likely tree biomass as well (Dulamsuren et al. 2010b; Dulamsuren et al. 2010a; Hansen et al. 2013). Mongolia's boreal forests harbor a unique biodiversity of forest species, which is regionally obliterated due to deforestation 
(Hauck et al. 2014). Moreover, conversion of boreal forests to steppe grassland is estimated to reduce the organic carbon stock density by roughly $40 \%$ not only due to the removal of biomass, but also as the result of carbon losses from the organic layer (Dulamsuren et al. 2016).

Drought stress and resulting declines in wood production and forest regeneration were repeatedly reported, especially for Siberian larch (Larix sibirica Ledeb.), which makes up approximately $80 \%$ of the total forest area (Dulamsuren et al. 2009c; 2010c; 2010a; Liu et al. 2013). Mongolia's mean annual air temperature has increased by $0.27 \mathrm{~K}$ per decade (in total $1.7 \mathrm{~K}$ ) from 1940 to 2001 (Batima et al. 2005), which is clearly above the global average of $0.12 \mathrm{~K}$ per decade from 1951 to 2012 (IPCC 2013). For the period 1940-2006, Dagvadorj et al. (2009) reported a seasonal differentiated temperature increase of $0.11 \mathrm{~K}$ per decade in summer and of $0.51 \mathrm{~K}$ per decade in winter. For the same period, the authors stated spatially varying trends of increasing and decreasing precipitation.

In addition, devastating forest fires disturbed large forest areas in Mongolia over the past decades (Goldammer 2002; Nyamjav et al. 2007; Hansen et al. 2013). Local authorities of the Tarvagatai Nuruu National Park in our study region stated that forest fires became more frequent since the 1990s, whereby the most severe fires occurred in 1996 and 2002. Goldammer (2002) reported that fire fighters with an air fleet were installed from 1969 until the 1990s, when financial support from Russia ended. Thus, the extensive fire events in 1996 and 2002 could not be fought as effectively as previous fires. Furthermore, a lack in systematic forest management, insufficient control of logging and forest pasture in the vicinity of grasslands contributed to forest degradation and decrease of forest area (Tsogtbaatar 2004; Dulamsuren et al. 2014). Widespread logging activities after forest fires with the target to extract the remaining wood from the forest are thought to delay reforestation due to mechanical damage to young trees (Sakamoto et al. 2021).

Boreal forests represent an important organic carbon pool and are thus important for the global climate (Goodale et al. 2002; Pan et al. 2011). Although most of the organic carbon in the 
boreal zone is stored in soils (Deluca and Boisvenue 2012; Shvidenko and Schepaschenko 2014; Mukhortova et al. 2015), a considerable amount of carbon is also stored in the livingtree biomass. Typically, carbon stocks in the total tree biomass of boreal forests amount to 4080 Mg C ha-1 (Jarvis et al. 2001; Luyssaert et al. 2007; Thurner et al. 2014). Investigations on tree biomass in the Mongolian forest-steppe have been carried out in the Altai Mountains, southern Khangai Mountains (Dulamsuren et al. 2016), northern Khangai Mountains (Dulamsuren et al. 2019a), and Khentei Mountains (Danilin 1995; Danilin and Tsogt 2014). Obtained tree biomass values were in the range of $123-397 \mathrm{Mg} \mathrm{ha}^{-1}$ and thus (due to Mongolia's position in the southernmost boreal zone) in and beyond the higher range typical for boreal forests Altogether, these studies point to a decrease of average tree biomass from the more humid north to the drier south of the Mongolian forest-steppe. At local scale, tree biomass in the interior of $L$. sibirica forests exceeds that at the forest edges (Dulamsuren et al. 2016). No consistent significant differences in tree biomass were found between forest stands of varying sizes and between forests growing in grassland- and forest-dominated areas of the forest-steppe (Dulamsuren et al. 2019a).

Logging, other kinds of forest use such as forest pasture, and fire-setting have reduced the forest area and tree biomass in Central Asia since prehistoric times (Miehe et al. 2007a; 2014; Unkelbach et al. 2017; 2019). The impact of these activities can be evaluated by estimating the potential extent of forest area based on climatic and topographic parameters (Klinge et al. 2015). The parameters precipitation, temperature and evaporation control the spatial pattern of forest and steppe distribution in the semi-arid forest-steppe (Nyamjav et al. 2007; Dulamsuren and Hauck 2008; Klinge et al. 2018). In addition, topographic position plays an important role, as forests are generally limited to north-facing slopes (Klinge et al. 2015; Hais et al. 2016). Thus, relief is an important factor for the existence, vigour and tree density of forests. In addition to natural factors, the present forest distribution is strongly influenced by human impact that increased since prehistoric times. Logging is done in an unsystematic manner for timber and fuelwood and pervasive in the forest-steppe. Its intensity has often increased after the transition from planned to market economy in the 1990s (Dulamsuren et al. 
2014). Livestock kept by pastoral nomads influences forest regeneration at forest margin and in the interior of small forests. In the Mongolian Altai, increased livestock densities promoted the establishment of $L$. sibirica seedlings due to the creation of gaps in the ground vegetation, but later reduced the density of tree regeneration in the sapling stage, as the seedlings are a preferred diet of goats (Khishigjargal et al. 2013). Goat numbers in Mongolia have multiplied since the 1990s owing to the high economic significance of cashmere wool for the herder households (2013b; Lkhagvadorj et al. 2013a). Relative to livestock, browsing by wild ungulates is of subordinate importance due to lower densities and a large hunting pressure. The regeneration success of $L$. sibirica is primarily dependant on moisture availability and herbivory (Dulamsuren et al. 2008; Khishigjargal et al. 2013). It is only loosely related to fire in the Mongolian forest steppe, as the dry climate (supported by livestock) generates gaps in the ground vegetation where seedlings can establish (Danilin 1995; Dulamsuren et al. 2010b). Tree-ring chronologies often show annual tree establishment over longer periods with moist climate, but unrelated to fire (2010c; Dulamsuren et al. 2010a; Khansaritoreh et al. 2017a).

Based on the state of knowledge described above, we addressed the following hypotheses:

(I) Climatic and topographic parameters limiting the general distribution of larch forests in the study area can be deduced by spatial analysis of remote sensing data.

(II) The combined effect of additional environmental factors (differing from the topo-climatic factors controlling forest distribution) control the actual living-tree biomass in the study area.

(III) Frequent forest fires, logging, and wood pasture strongly reduced the forest area and living-tree biomass since prehistorical time. Thus, forests only partially cover the potential forest area that can be deduced from climatic and topographic conditions. 


\subsubsection{Materials and Methods}

\subsubsection{Study area}

The study area is located on the northern edge of the Khangai Mountains near the town Tosontsengel in northern central Mongolia $\left(98^{\circ} 16^{\prime} \mathrm{E}, 48^{\circ} 46^{\prime} \mathrm{N}\right)$ (Fig. 2.1.1). The region has continental climate with cold semi-arid conditions (Fig. 2.1.2). The monthly mean temperatures at Tosontsengel range between $-31.7^{\circ} \mathrm{C}$ in January and $14.7^{\circ} \mathrm{C}$ in July. Most of the annual precipitation occurs during summer, from low-pressure cells brought by the westerlies (Batima et al. 2005). In contrast, the Siberian High during winter causes mostly dry conditions. The cold climate promotes discontinuous permafrost, with permafrost mainly occurring in valley bottoms, upper mountains, and partially on slopes. The existence of permafrost ice requires some soil moisture, whereas dry soil conditions lead to dry permafrost, i.e., perennially frozen ground without ice.

The maximum altitudes of the study area of up to 3,200 $\mathrm{m}$ a.s.l. occur in its southern part. They are characterised by mountain plateaus with cryoplanation terraces (Richter et al. 1963; Kowalkowski and Starkel 1984). These highest regions above the upper treeline at approx. 2,500 $\mathrm{m}$ a.s.l. belong to the periglacial belt, with alpine vegetation and bare, rock-debris covered land surfaces (Klinge et al. 2018). In the northern part, the mountains are lower, and mountain forest-steppe covers the north-facing slopes up to the summits. The main valleys run from south to north, leading into the east-west running valley of the Ider Gol (Gol: Mongolian for River) at an elevation of 1,600 m a.s.I.. The geological basement consists of Permian metamorphosed sedimentary and acid plutonic rock, and Carboniferous mafic rock (Academy of Sciences of Mongolia, Academy of Sciences of USSR 1990). Coarse detritus of these bedrocks forms slope debris, which is often mixed with and covered by sandy to silty aeolian deposits. 
Dense, extensive forests occur south of the Ider Gol, whereas north of the river, forests are more fragmented and steppe vegetation is dominant (Dulamsuren et al. 2019a). A clear spatial pattern of forests (made up of L. sibirica) on north-facing slopes and steppe on south-facing slopes is typical in the forest-steppe of Mongolia (Hilbig 1995; Treter 1996). This vegetation pattern is generally controlled by low precipitation $(<300 \mathrm{~mm})$, high evapotranspiration and relief-controlled differences in insolation in the mid-latitudes (Schlütz et al. 2008; Hais et al. 2016). Riverine forests consist of willow (Salix), poplar (Populus), and larch (L. sibirica). Since these alluvial forests are supported by groundwater, they are rather independent from local precipitation. Pleistocene dune fields with scattered individual old larch trees are abundant in the basins. Many local forest and steppe fires occur during summer (Goldammer 2007; Hessl et al. 2012). Severe forest fires in 1996 and 2002 destroyed extensive forests. Many of these former forest areas have not yet regrown. A timber factory and forest tracks were established in the Tosontsengel region during Soviet times to facilitate intensified forest exploitation since the 1960s. Former clear-cutting is still documented by rotted tree stumps inside the forests. Industrial logging was abandoned after the political change in the early 1990s, but has been resumed to some extent. Illegal logging happens selectively inside of forests and affects individual remnants in burnt areas, but no extensive clear-cutting occurs. In addition, the local population extracts selectively fuelwood from the forests. 

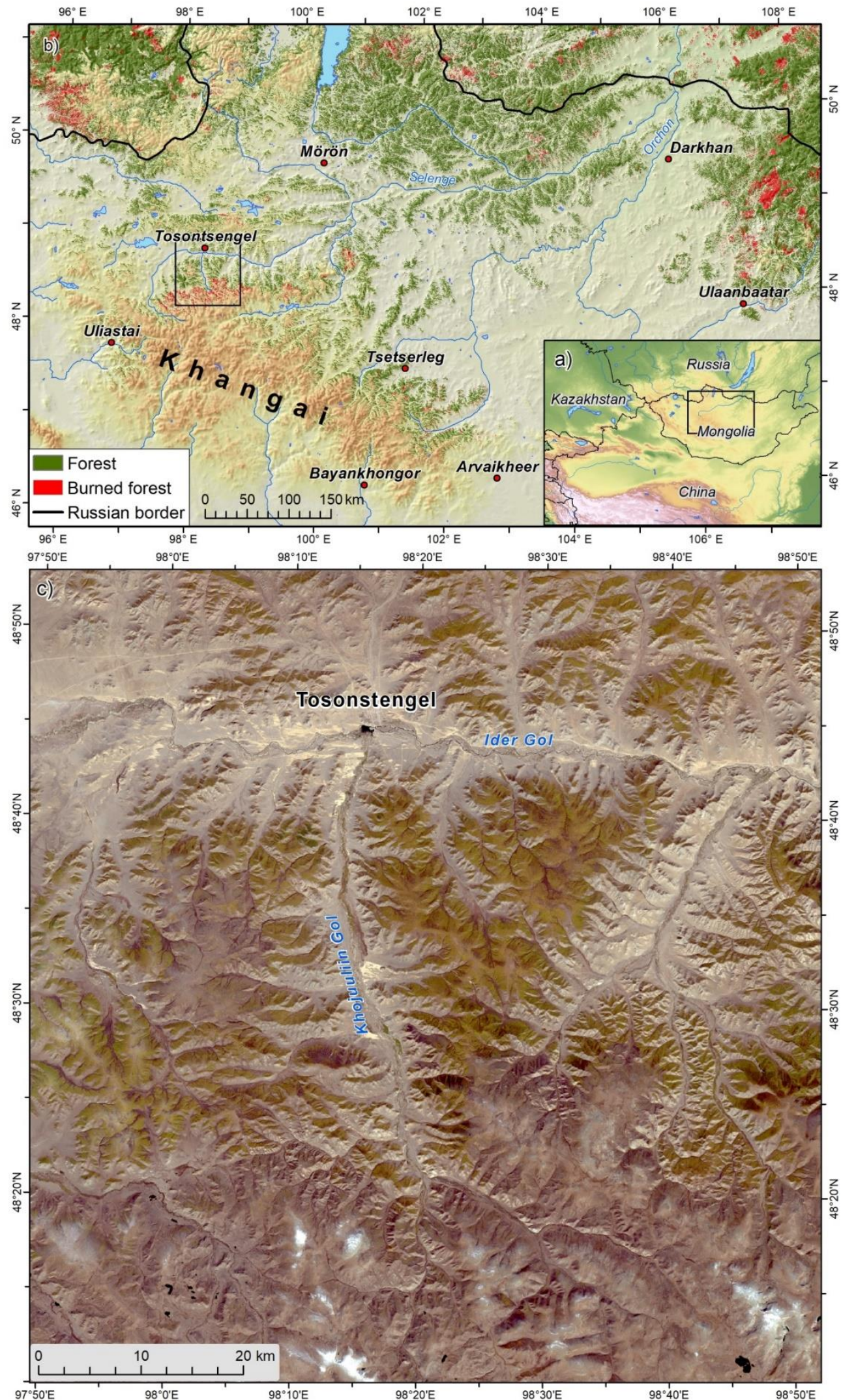

Figure 2.1.1: Study area. a) Overview of Mongolia with position of the map shown in b) (black rectangle). b) Location of the study area in the forest-steppe of northern central Mongolia. Forest distribution was adapted from Klinge et al. (2018), burnt forest area (2000-2018) was adapted from Hansen et al. (2013). The digital elevation model (DEM) was created from SRTM (Shuttle Radar Topography Mission) data. The black rectangle in b) indicates the position of 
the image shown in c). c) True-colour satellite image of the study area near Tosontsengel (Landsat 8, September 22, 2014).
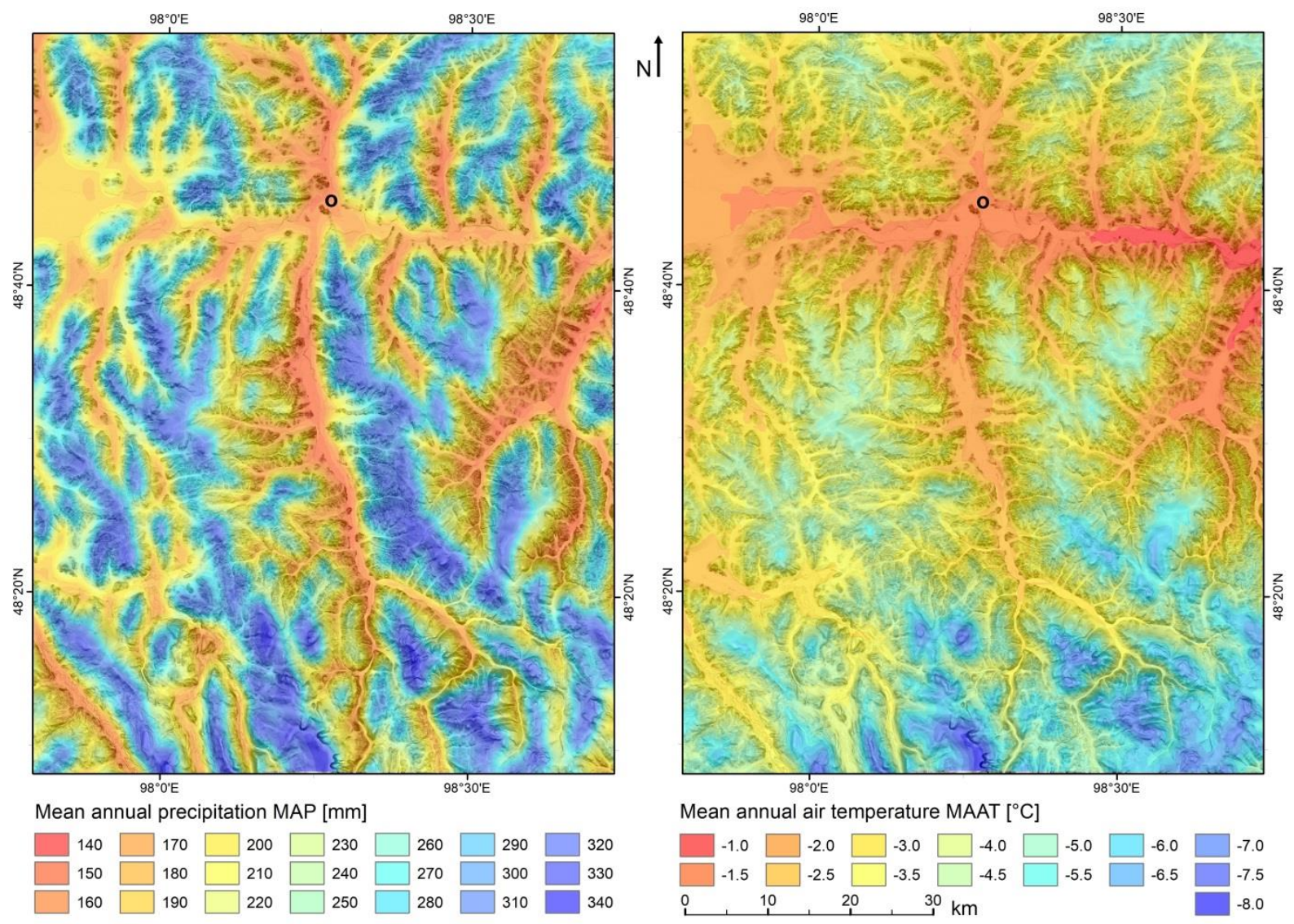

Figure 2.1.2: Climate of the study area around the town Tosontsengel (black circle). Data from the CHELSA V1.2 dataset, measuring period 1979-2013 (Karger et al. 2017), the shaded relief illustration is based on TanDEM-X data.

\subsubsection{Remote sensing analysis of forest distribution, forest categories and landscape units}

This work step was crucial, as the main aim of this study was to identify a possible mismatch between actual and potential forest area. Input data for this work step included Landsat 5 , Landsat 8 and Sentinel 2 images (Fig. 2.1.3, first line). For the mapping of forest areas, we applied a semi-automatic approach after Klinge et al. (2015). The manual mapping of forest stands from satellite imagery was supported by a previous supervised maximum likelihood classification, where training samples were distinguished for forest, steppe and water bodies. We used a Landsat 5 satellite image from September 23, 1986 to delineate the distribution of forest prior to extensive forest destruction through fires. This image from 1986 was the best 
image for the period before the onset of extensive forest fires. We determined the actual forest area by integrating several scenes of Landsat 8 (May 14, 2013; June 20, 2015) and Sentinel 2 (Sep 14, 2016; Sep 19, 2017). After the intersection of the classification, we went through an intensive visual check of all forest polygons to delete and edit wrong classified areas. In the forest-steppe, distinct boundaries between forest patches and grassland allowed for highly accurate forest maps. As shown by Klinge et al. (2015), image classification combined with manual post-editing leads to an overall accuracy of $>0.99$. We used the difference in forest area between the images of 1986 and 2017 to work out the burnt forest area for this period. Because of the different spatial resolutions of the satellite images, divergences less than $20 \mathrm{~m}$ at the forest edges were neglected.

We distinguished several forest categories that occur in different landscape units. Based on the proportion between forest and steppe, we differentiated between forest stands in forestdominated area and steppe-dominated area. The area, where the mountain tops reach above the upper treeline, was defined as high-mountain area. Forests in flat areas $\left(<2^{\circ}\right)$ along rivers were interpreted as alluvial forests. Forest stands on dunes were directly identified in the satellite images. Furthermore, we distinguished four forest-size classes in the forest-dominated and steppe-dominated areas, respectively: $\mathrm{F} 1, \mathrm{G} 1=<0.1 \mathrm{~km}^{2} ; \mathrm{F} 2=0.1-1 \mathrm{~km}^{2} ; \mathrm{F} 3=1-5 \mathrm{~km}^{2}$; $\mathrm{F} 4=>5 \mathrm{~km}^{2}$, using a spatial buffer of $30 \mathrm{~m}$ to distinguish the forest edges from the interior. These classification schemes were adapted from Dulamsuren et al. (2016; 2019a).

\subsubsection{Determination of suitable topographic conditions and topographic thresholds for forest growth}

Relief leads to variations of local climate, which is a particularly important aspect in semiarid central Asia (Klinge et al. 2015). Therefore, we created a digital elevation model (DEM) based on TanDEM-X data (Fig. 2.1.3, first line). Due to high horizontal $(10 \times 10 \mathrm{~m})$ and vertical $(<1$ m) resolution of the DEM, the calculated terrain surface was distorted by the forest canopy, 
especially at the edges of the forest stands. Therefore, we used the map of the actual forest area obtained from satellite imagery to correct the DEM in forests.

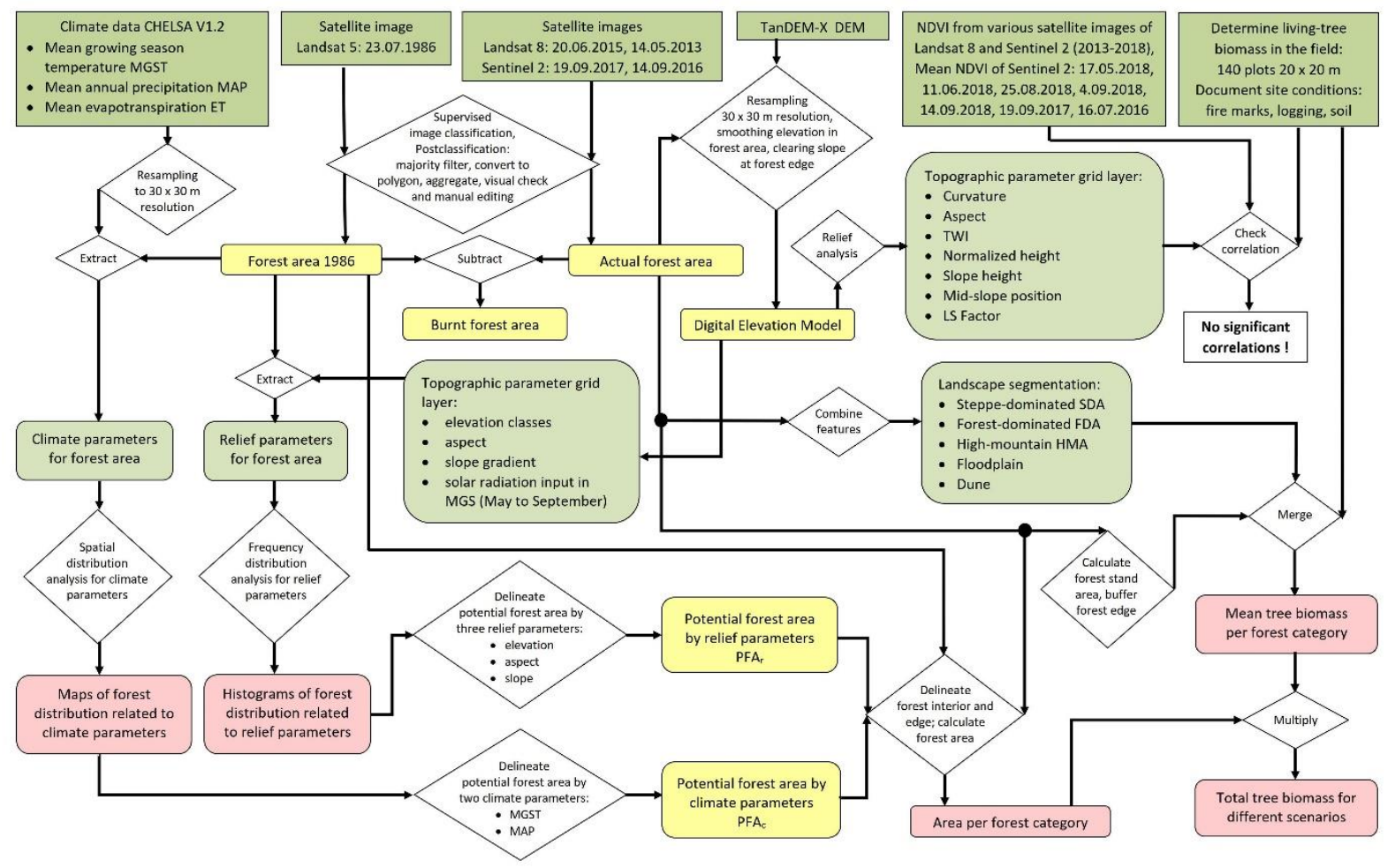

Figure 2.1.3: Workflow of this study.

The corrected DEM allowed us to extract various topographic parameters, including elevation, aspect, slope, and insolation. We applied a GIS tool to estimate the cumulative solar radiation input for the period Mai-September 2017, which served as mean growing season (MGS). These parameters were extracted for forest area using the forest map of 1986, in order to identify relationships between potential forest distribution and relief. This approach allowed us to determine suitable topographic conditions and topographic thresholds for forest growth from the respective value range. We produced a map of potential forest area based on relief parameters (PFA $)$, assuming that forest growth is possible in all areas within the topographic thresholds for forest growth, applying the approach of Klinge et al. (2015). 


\subsubsection{Determination of suitable climatic conditions and climatic thresholds for forest growth}

Similarly to the determination of PFA, described above, we also analysed PFA based on relationships between forest distribution and climatic parameters $\left(P F A_{c}\right)$. For this purpose, we used climate data from the CHELSA V1.2 dataset (Karger et al. 2017), which we resampled from the originally 30 -arcsec resolution to obtain $30 \mathrm{~m}$ resolution (Fig. 2.1.3, first box). This reanalysed climate dataset enabled us to consider terrain parameters and wind effect, and thus allowed us to obtain an improved representation of climate conditions in relief terrain (Karger et al. 2017). We calculated mean annual precipitation (MAP), mean annual potential evaporation, and mean growing-season temperature (MGST, as the average of the monthly mean temperatures between May and September) for the period 1973-2013. Temperature and precipitation were largely independent (Fig. 2.1.2), whereby temperature followed a vertical gradient, and precipitation showed an additional longitudinal gradient caused by the westerlies. Potential evaporation was so closely correlated with MGST that we did not include it as an additional parameter for delineating PFA.

The climatic parameters were extracted for forest area using the forest classification of 1986 , in order to identify relationships between potential forest distribution and climate, and to determine suitable climatic conditions and climatic thresholds for forest growth. The intention was to produce a map of potential forest area based on climatic parameters (PFA $A_{c}$ ), assuming that forest growth is possible in all areas within the climatic thresholds for forest growth, thus, using the same approach as for the PFA map.

\subsubsection{Tree-biomass analysis}

During fieldwork in the years 2014-2018, we determined living-tree biomass on $20 \times 20 \mathrm{~m}$ plots (Fig. 2.1.3, last box in first line), by measuring tree diameter at breast height (dbh) and tree height of all living trees exceeding a height of $4 \mathrm{~m}$. In addition, we counted seedlings, saplings 
and trees $<3 \mathrm{~m}$, whereas we did not include the dead biomass. We used either a Vertex IV ultrasonic clinometer and T3 transponder (Haglöf, Långsele, Sweden) or a True Pulse 200 laser rangefinder (Laser Technology, Inc., USA) for measuring tree height. Stem diameter was calculated from stem circumference as measured with a measuring tape. Plot dimensions were determined by measuring tape, and plot-corner positions were measured by GPS at an accuracy of $\sim 3 \mathrm{~m}$. For spatial reference of the plot data, the centre between the four plot corners was calculated. For statistical correlation analysis between biomass and remote sensing data, mean values were interpolated of the pixels located within a $400 \mathrm{~m}^{2}$ circle around this point (Fig. 2.1.3, upper left side). In this way, we analysed 140 plots, including forest- and steppe-dominated landscapes, forest edges and interiors, toe slopes, mid-slopes, upper slopes, pristine and exploited forests, as well as forest stands on slopes of different aspects and of different forest-stand sizes. We selected the biomass plots according to their representativeness for a larger surrounding area, to minimise discrepancies between field data and remote sensing data.

We applied the two allometric functions for Siberian larch (L. sibirica) in Mongolia published by Battulga et al. (2013) and Dulamsuren et al. (2016), and used the mean of the results of both equations to estimate the aboveground and belowground living-tree biomass. Differences in the estimates of the two functions are discussed in Dulamsuren et al. (2016). We presumed that the increase of total tree biomass over the four-year period of biomass-data collection in the field was less than the precision of the allometric method. Forest stands where tree stumps indicated logging, were mapped as forests with "logging", whereas forest stands without tree stumps were mapped as forests with "no logging". Forest stands, where burnt bark and/or charred wood indicated former fire events, were mapped as having "fire indicators", those without as having "no fire indicators". Ground vegetation structure, soil profiles and detection of permafrost provided auxiliary data. Ground-vegetation structure was important for assessing, which portion of the NDVI of the forest sites was contributed by ground vegetation, because tree-canopy closure was less than $53 \%$. In 24 of the plots, we measured leaf area index (LAI) using a LI-COR Plant Canopy Analyzer LAI-2200 C (Licor Biosciences, USA). Soil 
profiles were used to distinguish soils developed in sandy sediment and slope debris, and to detect permafrost, as permafrost is a crucial factor for forest distribution due to its impounding effect for meltwater from seasonal ground ice, keeping the meltwater available for trees. Permafrost distribution was not used for biomass and PFA delineation, but its ecological feedback represents a relevant secondary parameter as shown by Klinge et al. (2021)(2021).

Classification of the plot data according to other influencing factors (Table 2.1.1) in addition to relief and climate, allowed for extracting effects of these factors on tree biomass through statistical analysis.

Dulamsuren et al. (2019) already analysed tree biomass in the interior of larch forests on slopes in the same study area, thereby focusing on larch stands in the optimum stage of the forest development cycle (Jacob et al. 2013; Feldmann et al. 2018) and excluding disturbances from fire or logging. Complementary to that study, we also included larch stands influenced by various factors, in order to also address the response of tree biomass to these factors. In doing so, we also tested the potential of remote sensing techniques for upscaling plot-based data to the landscape level. We used tree-biomass data of $30 \mathrm{~L}$. sibirica plots on slopes from Dulamsuren et al. (2019) and added tree-biomass data from forest edges and further L. sibirica plots of different forest-stand sizes (classes F1/G1 to F4) and forest-to-grassland ratios (forestdominated area with classes F1 to F4 vs. steppe-dominated area with class G1).

In addition to these forests on slopes, we also analysed larch forests on alluvial sand in floodplains. However, their limited size did not allow for obtaining separate datasets for forest interior and edge. Altogether, we distinguished 12 larch-stand categories, including the additional influencing factors forest interior / forest edges of the slope-forest categories F1, F2, F3, F4 and G1, and the floodplain forests as independent variables, and differentiating between logged / not logged and burnt / not burnt forest stands as covariates, based on the presence / absence of tree stumps and fire scars. Usual windthrow that creates single deadwood inside natural forests was not considered as disturbance. 
We calculated the mean living-tree biomass for each forest category (as affected by the diverse factors), considering, e.g., logging, fire indicators, and topsoil conditions (Table 2.1.1, Table 2.1.6). We checked the tree-biomass data of each forest category for normal distribution and tested the differences in living-tree biomass between the forest categories for statistical significance using Duncan's multiple range test calculated in SPSS.

We multiplied the area of each forest category with the mean tree biomass of that forest category, using three scenarios, namely i) the actual forest area, ii) the forest area of 1986, and iii) the potential forest area (PFA). Delineation of potential alluvial-forest area was not feasible, because the alluvial-forest distribution pattern was largely controlled by the erosiondeposition dynamics of the braided rivers.

Table 2.1.1: Mean living-tree biomass (above and belowground) for different forest categories affected by various factors. Plots, where a possible influence of a certain factor could not be assured, were excluded from the respective part of the analysis. SE = standard error, $n=$ number of plots.

\begin{tabular}{|c|c|c|c|c|c|c|c|c|c|c|c|c|c|c|c|}
\hline & $\mathrm{F} 1$ & SE & $n$ & $\mathrm{~F} 2$ & SE & $n$ & F3 & SE & $n$ & F4 & SE & $n$ & G1 & SE & $n$ \\
\hline total & 198.7 & 11.2 & 29 & 208.0 & 11.8 & 31 & 212.5 & 13.9 & 31 & 182.0 & 12.9 & 34 & 142.2 & 10.7 & 10 \\
\hline forest interior & 219.3 & 14.0 & 18 & 218.2 & 12.6 & 26 & 220.6 & 13.4 & 26 & 181.7 & 13.8 & 30 & 145.4 & 15.0 & 7 \\
\hline forest edge & 165.1 & 13.7 & 11 & 155.2 & 21.0 & 5 & 170.7 & 46.2 & 5 & 184.3 & 35.2 & 4 & 134.8 & 2.7 & 3 \\
\hline difference & 54.2 & & & 63.0 & & & 49.9 & & & -2.6 & & & 10.6 & & \\
\hline $\begin{array}{l}\text { no fire indicators; } \\
\text { no logging }\end{array}$ & 211.5 & 22.3 & 2 & 210.7 & 18.1 & 5 & 219.0 & 12.8 & 4 & 170.7 & 14.3 & 15 & & & \\
\hline no fire indicators & 204.8 & 18.7 & 14 & 206.2 & 12.8 & 14 & 194.3 & 17.4 & 21 & 168.3 & 13.3 & 23 & 122.1 & 2.7 & 2 \\
\hline fire indicators & 179.5 & 15.2 & 9 & 171.6 & 20.9 & 11 & 231.3 & 14.4 & 6 & 175.5 & 39.7 & 5 & 154.9 & & 1 \\
\hline difference & 25.2 & & & 34.6 & & & -36.9 & & & -7.2 & & & & & \\
\hline no logging & 211.5 & 22.3 & 2 & 234.3 & 11.9 & 8 & 238.8 & 23.8 & 6 & 180.4 & 13.7 & 18 & 134.1 & 4.0 & 2 \\
\hline logging & 197.8 & 11.9 & 27 & 198.9 & 14.4 & 23 & 207.4 & 16.6 & 24 & 183.8 & 22.7 & 16 & 144.3 & 13.2 & 8 \\
\hline difference & 13.7 & & & 35.4 & & & 31.4 & & & -3.4 & & & & & \\
\hline slope debris & 211.0 & 18.4 & 13 & 207.8 & 16.5 & 18 & 196.3 & 18.5 & 19 & 176.7 & 14.3 & 28 & & & \\
\hline sand layer & 188.8 & 13.3 & 16 & 204.5 & 15.8 & 14 & 238.3 & 18.3 & 12 & 214.4 & 24.5 & 7 & & & \\
\hline difference & 22.2 & & & 3.4 & & & -42.0 & & & -37.7 & & & & & \\
\hline
\end{tabular}




\subsubsection{Results}

\subsubsection{Spatial patterns of forest-fire and permafrost distribution}

\section{Forest-fire distribution}

The high-mountain area in the southern part of the study area lost the largest portion of forest through fire over the past decades (Fig. 2.1.4). Its formerly large forests turned into numerous small and fragmented forest remnants. In the forest-dominated central and north-eastern parts of the study area, the most extensive burnt forest areas were in the upper mountains. Only few forest stands burnt down in the steppe-dominated areas in the north-western and eastern parts of the study area.

\section{Permafrost distribution}

Permafrost was restricted to large forest stands on slopes in the forest-dominated area and high-mountain area, as observed in our soil profiles (Klinge et al. 2021). Under large forest stands (forest-size class F4) on north-facing slopes, the permafrost was rich in ice and occurred already at shallow depth, whereas east- and west-facing slopes had only small patches of permafrost that started at depths of more than $1 \mathrm{~m}$. There was no field evidence for permafrost under fragmented forest stands (G1, F1, F2) and burnt forests (Klinge et al. 2021). 


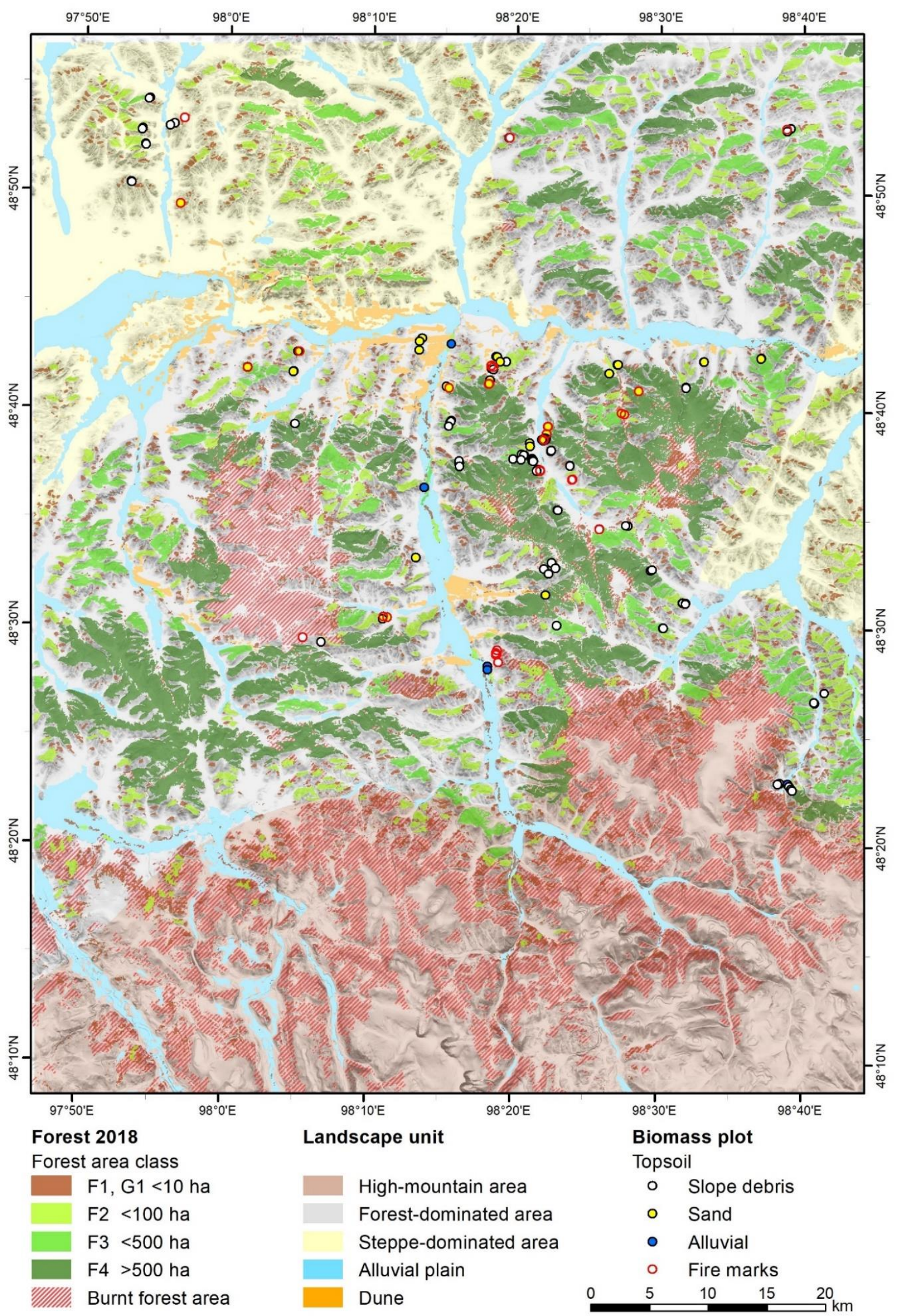

Figure 2.1.4: Landscape units in the study area, with actual forest area and burnt forest area (reference year 2018). The shaded relief illustration is based on TanDEM-X data. 


\subsubsection{PFA delineation based on relief parameters (PFAr)}

The upper treeline in the study area rises from 2,400 $\mathrm{m}$ in the north to $2,600 \mathrm{~m}$ a.s.l. in the south (Klinge et al. 2018). Since 1986, forest fires in the upper mountains led to a decline in the mean elevation range of forests $(95 \%)$ to $1,600-2,400 \mathrm{~m}$ a.s.I.. South-facing slopes in the forest-steppe are generally covered by steppe vegetation; they may be partially forested above 2,100 m a.s.I. (Fig. 2.1.5). Forests also occur in areas of maximum MGS insolation, which demonstrates that insolation is no limiting factor for forest growth in the study area.

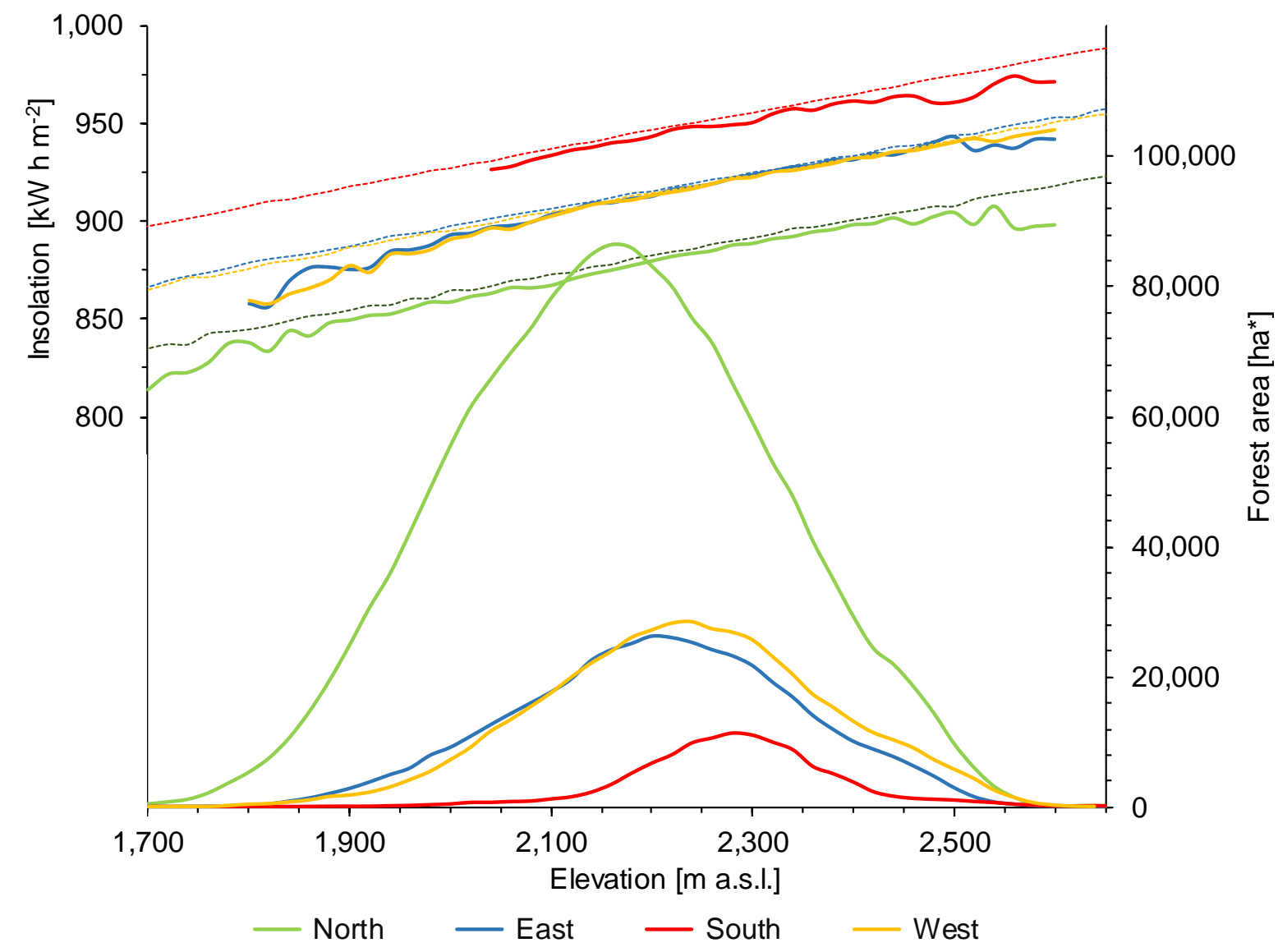

Figure 2.1.5: Top - Change of maximum MGS insolation (left axis) with elevation (MGS = mean growing season, May-September). Solid lines = MGS insolation on forest area, dashed lines = MGS insolation on the total land surface. Bottom - Forest area in hectares (right axis) in 1986 plotted against elevation. ${ }^{*}$ The forest area on south-exposed slopes is shown in ha $\times 10$.

We delineated the PFA $r$ by clipping the area, where all three parameters 'aspect' (no forest below $2,100 \mathrm{~m}$ a.s.I. on slopes with aspect $\left.135^{\circ}-225^{\circ}\right)$, 'slope gradient' (0-25 $)$, and 'elevation' (upper treeline: 2,400 $\mathrm{m}$ a.s.I. in the north, 2,600 $\mathrm{m}$ a.s.I. in the south) allowed for tree growth 
(Fig. 2.1.3). The most striking outcome of this $\mathrm{PFA}_{r}$ projection was a much more extensive forest cover on toe slopes and pediments, which are at present generally covered by steppe vegetation (Fig. 2.1.6). In the high-mountain area, the estimated PFA $A_{r}$ exceeded the presently forested area on steep slopes, from the valleys up to the upper treeline at 2,600 $\mathrm{m}$ a.s.I..

\subsubsection{PFA delineation based on climatic parameters (PFAc)}

The spatial resampling of the climate data by linear interpolation produced some noise, because small topographic variations could not be considered. Therefore, we did not use the obtained climate dataset to deduce the climatic thresholds for forest growth by histogram analysis. Instead, we derived these thresholds from stepwise adjustment of the climatic thresholds until the spatial pattern of temperature and precipitation with positive conditions for tree growth included all forest stands of 1986. The climatic thresholds obtained from this approach are listed in Table 2.1.2. The obtained PFA $A_{c}$ showed larger forest areas on the upper south-facing slopes and small flat summits. It matched well with the upper treeline in the highmountain area (Fig. 2.1.7). Compared to the $P F A_{r}$, the PFA did not extend as far down into the basins, which may be due to low precipitation there. 


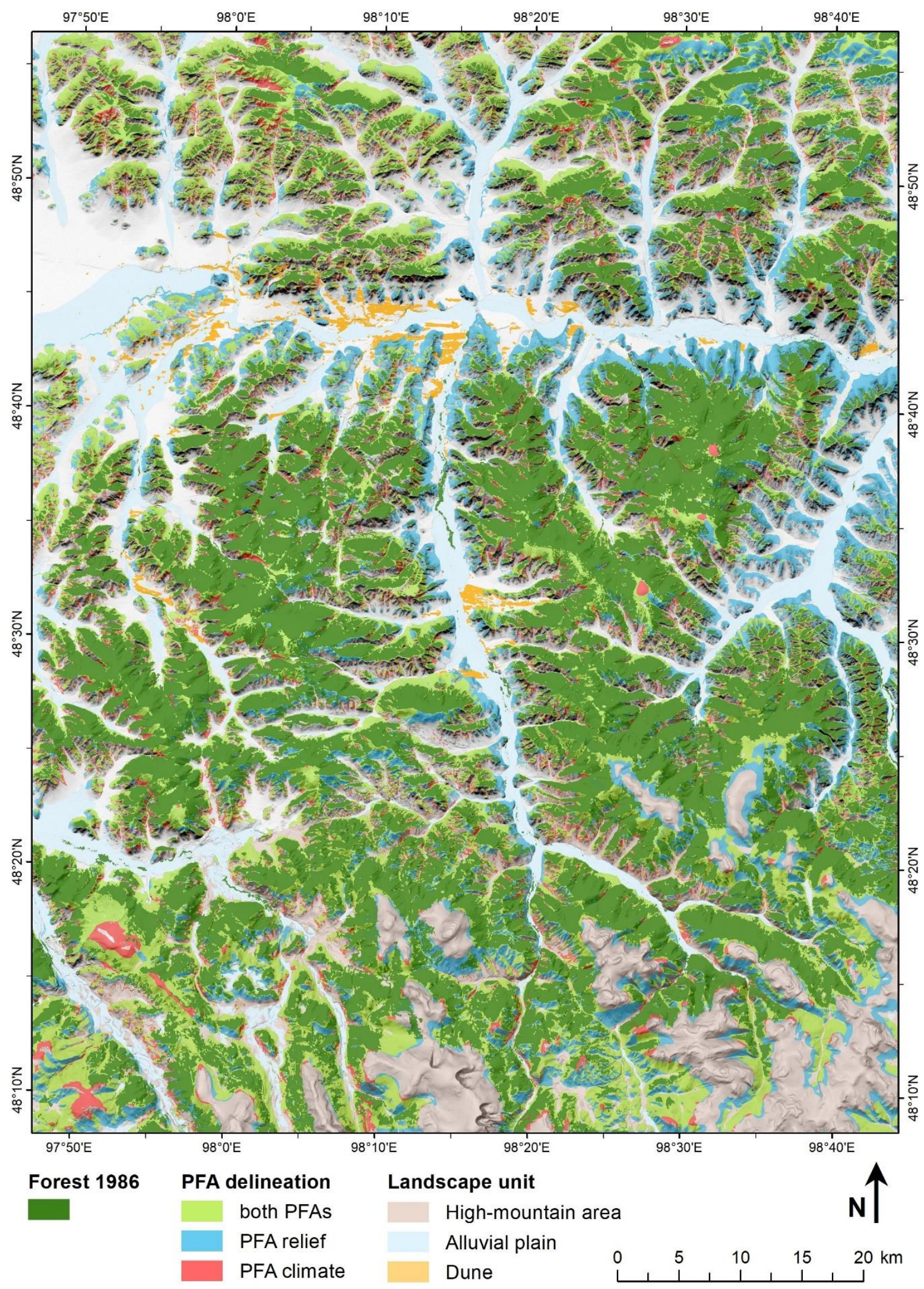

Figure 2.1.6: Forest distribution in 1986 and potential forest areas (PFA) delineated based on climate and relief. The shaded relief illustration is based on TanDEM-X data. 

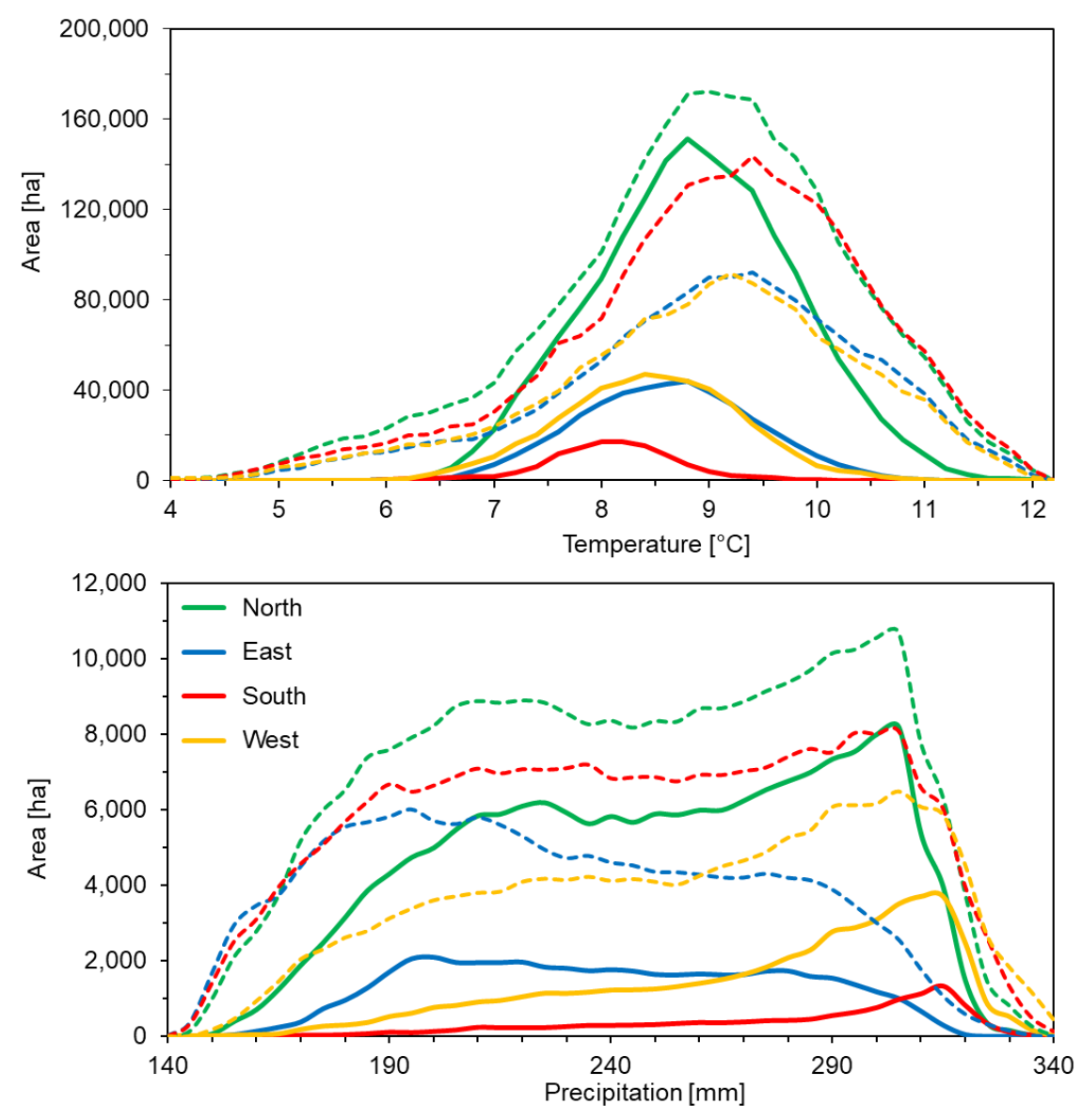

Figure 2.1.7: Frequency-distribution curves of mean growing-season temperature (MGST) and mean annual precipitation (MAP) in the study area. Solid lines = forest area, dashed lines = total area. Climate data source: CHELSA V1.2 (Karger et al. 2017), period 1979-2013, spatially resampled to $30 \mathrm{~m}$ by linear interpolation.

Table 2.1.2: Thresholds of mean growing-season temperature (MGST) and mean annual precipitation (MAP) used for $P F A_{c}$ delineation.

\section{Aspect}

North East South West

Maximum MGST

$\left[{ }^{\circ} \mathrm{C}\right]$

$\begin{array}{llll}10.8 & 10.4 & 8.6 & 10.0\end{array}$


Minimum MGST $\left[{ }^{\circ} \mathrm{C}\right] \quad 6.5 \quad 6.5 \quad 6.5 \quad 6.5$

Maximum MAP [mm] $320 \quad 310 \quad 340 \quad 340$

Minimum MAP [mm] $\quad \begin{array}{llll}160 & 170 & 290 & 165\end{array}$

\subsubsection{Plot-based tree-biomass data}

Mean tree height ranged between $12 \mathrm{~m}$ and $20 \mathrm{~m}$, whereas the maximum heights of single trees reached up to $32.7 \mathrm{~m}$. Stand basal area ranged from 5 to $91 \mathrm{~m}^{2} \mathrm{ha}^{-1}$, with an average of $38.8 \mathrm{~m}^{2} \mathrm{ha}^{-1}$. Mean tree ages were 100-200 years, whereby maximum tree ages reached up to $380-413$ years. Living-tree biomass in larch forests on slopes ranged between $25 \mathrm{Mg} \mathrm{ha}^{-1}$ and $380 \mathrm{Mg} \mathrm{ha}^{-1}$. Maximum tree biomasses of $440-688 \mathrm{Mg} \mathrm{ha}^{-1}$ were found in forests on floodplains, whereas larch trees on sand dunes only formed open woodlands with less tree biomass (48 $\mathrm{Mg} \mathrm{ha}^{-1}, n=1$ ). In all stand-size classes of the forests of the forest-dominated area, tree-biomass means and medians were within the range $180-220 \mathrm{Mg} \mathrm{ha}^{-1}$; maximum tree biomass exceeded $320 \mathrm{Mg} \mathrm{ha}^{-1}$ (Table 2.1.1). Duncan's multiple range test did not proof statistically significant differences between the forest categories, except for a difference of the G1 forest edge plots to the F1 and F2 interior plots (Fig. 2.1.8). Forests of the size classes F1, F2, and F3 had 50-63 $\mathrm{Mg} \mathrm{ha}^{-1}$ less living-tree biomass at forest edges than in their interiors; only the forest-size class F4 showed no distinct difference in tree biomass between forest edges and interior (Table 2.1.1). Small fragmented forests $\mathrm{G} 1$ in the steppe-dominated area had up to $70 \mathrm{Mg} \mathrm{ha}^{-1}$ less tree biomass than those in the forest-dominated area. Logging, forest fire and sediment type did not significantly influence living-tree biomass. The large proportion of forest with logging in the categories of small fragmented forests (size classes F1 and G1) pointed to a higher exploitation pressure on these small forests compared to larger stand sizes. 


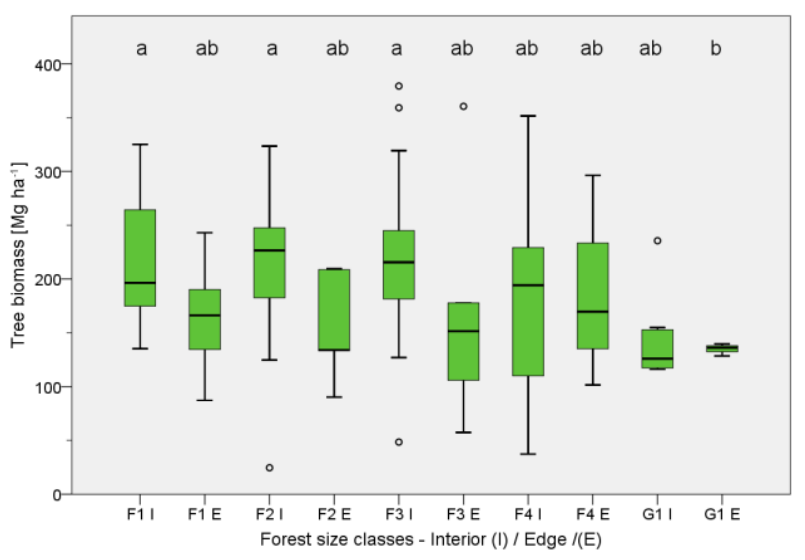

Tree biomass at forest interiors and edges.

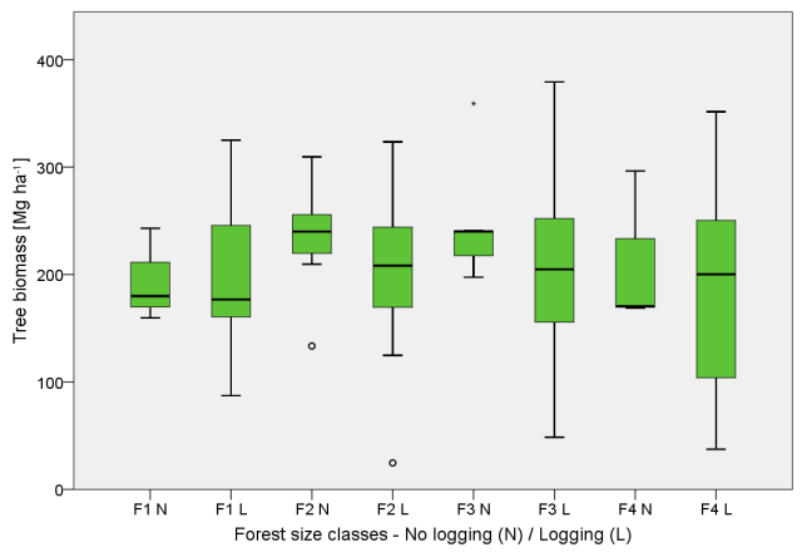

Tree biomass of forests with and without logging.

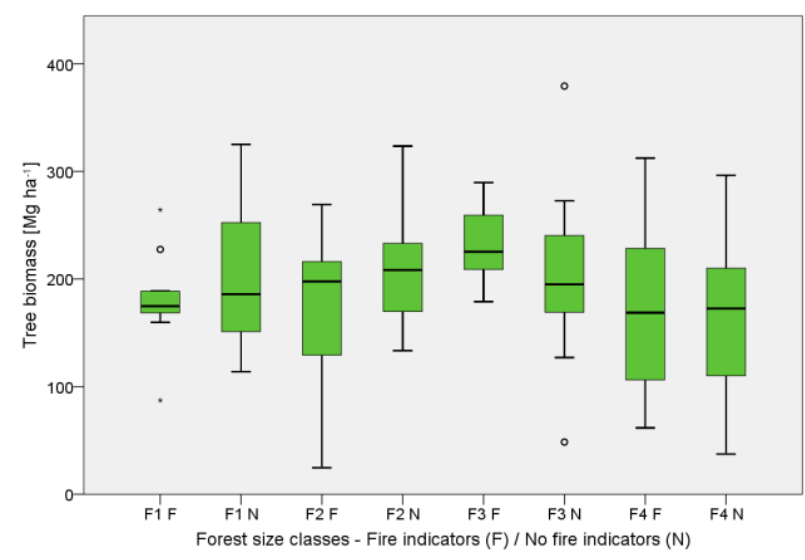

Tree biomass of forests with and without fire indicators.

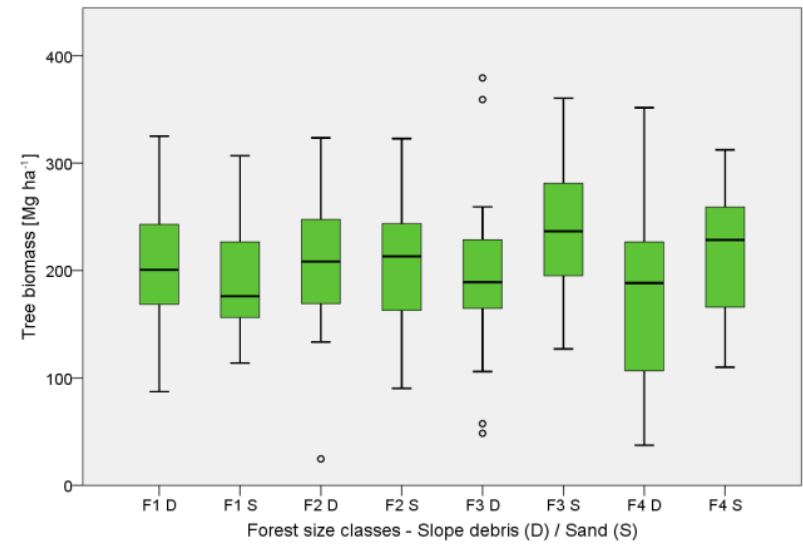

Tree biomass of forests on slope debris and sand.

Figure 2.1.8: Boxplots of tree biomass $\left(\mathrm{Mg} \mathrm{ha}^{-1}\right)$ of forests differing with respect to edge effects, influence of fire, logging and sediment type. Horizontal line = median, bars = quartiles, whiskers $=$ range, dots $=$ outliers. Means sharing a common letter, do not differ significantly (Duncan's multiple range test, $p \leq 0.05$ ).

\subsubsection{Remote-sensing analysis based on tree-biomass estimates}

We tested several NDVI datasets and various topographic parameters for significant single or multi-correlations with measured tree biomass, as such correlations would allow for interpolating tree biomass to landscape scale. However, we found no statistically significant correlations $(r>0.5, p<0.05)$. One problem for NDVI analysis was the low number of 
multispectral satellite images with $<10 \%$ cloud cover taken during summer. Another problem was the weak correlation between needle volume and tree biomass, as leaves and needles provide the chlorophyll signal in multispectral satellite images. Danilin and Tsogt (2014) stated that needle biomass is independent of the average age of a larch stand, whereas tree biomass increases with tree age. The absence of a significant correlation between leaf area index ( $\mathrm{LAl})$ and tree biomass measured on 24 plots confirmed this statement (Fig. 2.1.9). Overall, the statistical relationships between NDVI, needle volume and tree biomass were poor.

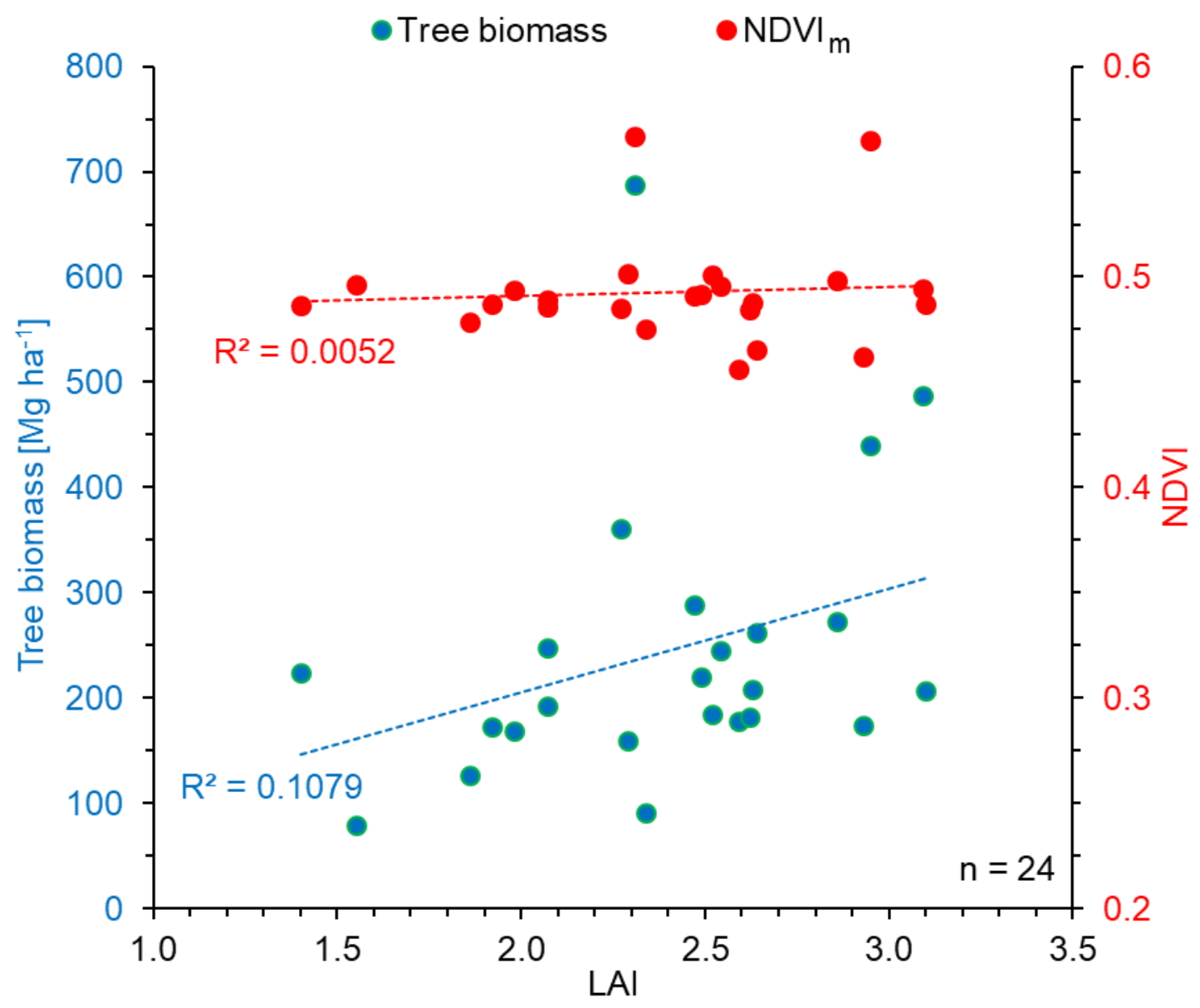

Figure 2.1.9: Relationships between leaf area index (LAl) and living-tree biomass (left axis, blue dots), and between $L A I$ and $N D V I_{m}$ (right axis, red dots) of 24 plots. $N D V I_{m}=$ mean NDVI obtained from seven Sentinel 2 images (Fig. 2.1.3). 


\subsubsection{Synthesis of the results of the forest-distribution and tree-biomass assessments}

The size of the study area was $6,355 \mathrm{~km}^{2}$. A closed third of the total area $\left(1,898 \mathrm{~km}^{2}\right)$ was still forested in 1986. Since then, the forested area declined to $1,086 \mathrm{~km}^{2}$ (actual forest area). The delineated PFA yielded 3,168 (PFA $)$ and $3,553 \mathrm{~km}^{2}\left(P F A_{r}\right)$, respectively. Details on the differences between actual forest area, forest area in 1986, and PFA, are listed in Table 2.1.3. The largest portion of the actual forest area falls into the forest-size class F4 (8.6\%) in the forest-dominated area. Prior to the large fire events, this forest-size class was also widespread in the high-mountain area (9.2\%). Altogether, a forest area of $812.5 \mathrm{~km}^{2}(12.8 \%$ of the total study area and $42.8 \%$ of the formerly forested area) was destroyed by fire since the end of the last century. The burnt forest area was negligible in the steppe-dominated area and small in the forest-dominated area, but it amounted up to $95 \%$ of the formerly forested area in the highmountain area. The ratios between forest interior and forest edge $\left(F_{i} / F_{e}\right)$ for each forest-size class were relatively consistent for the different landscape units (Table 2.1.3).

Table 2.1.3: Dimensions $\left[\mathrm{km}^{2}\right]$ and relative portions [\%] of different forest categories and landscape units in the study area at present (actual forest area) and in 1986, prior to the large forest fires.

\begin{tabular}{|c|c|c|c|c|c|c|c|c|c|c|c|}
\hline & \multicolumn{5}{|l|}{ Actual forest area } & \multirow{2}{*}{$\begin{array}{l}\text { Burnt } \\
\text { forest }\end{array}$} & \multicolumn{5}{|c|}{ Forest distribution in 1986} \\
\hline & forest-size class & 1 & 2 & 3 & 4 & & 1 & 2 & 3 & 4 & Steppe \\
\hline & \multicolumn{11}{|c|}{ Steppe-dominated area } \\
\hline$\widetilde{\widetilde{E}}$ & Interior & 4.74 & 18.25 & 21.51 & 7.29 & \multirow{3}{*}{3.88} & 5.59 & 19.65 & 22.90 & 7.92 & \multirow{3}{*}{1042.29} \\
\hline ֻ & Edge & 11.07 & 12.33 & 7.65 & 1.69 & & 10.28 & 16.19 & 6.92 & 1.37 & \\
\hline 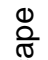 & Ratio I/E & 0.43 & 1.48 & 2.81 & 4.32 & & 0.54 & 1.21 & 3.31 & 5.80 & \\
\hline 空 & \multicolumn{11}{|c|}{ Forest-dominated area } \\
\hline 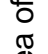 & Interior & 12.66 & 82.93 & 144.04 & 440.35 & \multirow{2}{*}{115.25} & 13.90 & 87.52 & 120.78 & 606.55 & \multirow{3}{*}{1907.62} \\
\hline $\begin{array}{l}\overline{\widetilde{D}} \\
\Phi\end{array}$ & Edge & 43.55 & 52.56 & 44.21 & 107.34 & & 32.10 & 42.10 & 32.12 & 105.36 & \\
\hline 总 & Ratio I/E & 0.29 & 1.58 & 3.26 & 4.10 & & 0.43 & 2.08 & 3.76 & 5.76 & \\
\hline & \multicolumn{11}{|c|}{ High-mountain area } \\
\hline 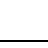 & Interior & 1.73 & 7.51 & 6.40 & & 693.33 & 3.74 & 29.70 & 65.66 & 491.08 & 1021.74 \\
\hline
\end{tabular}




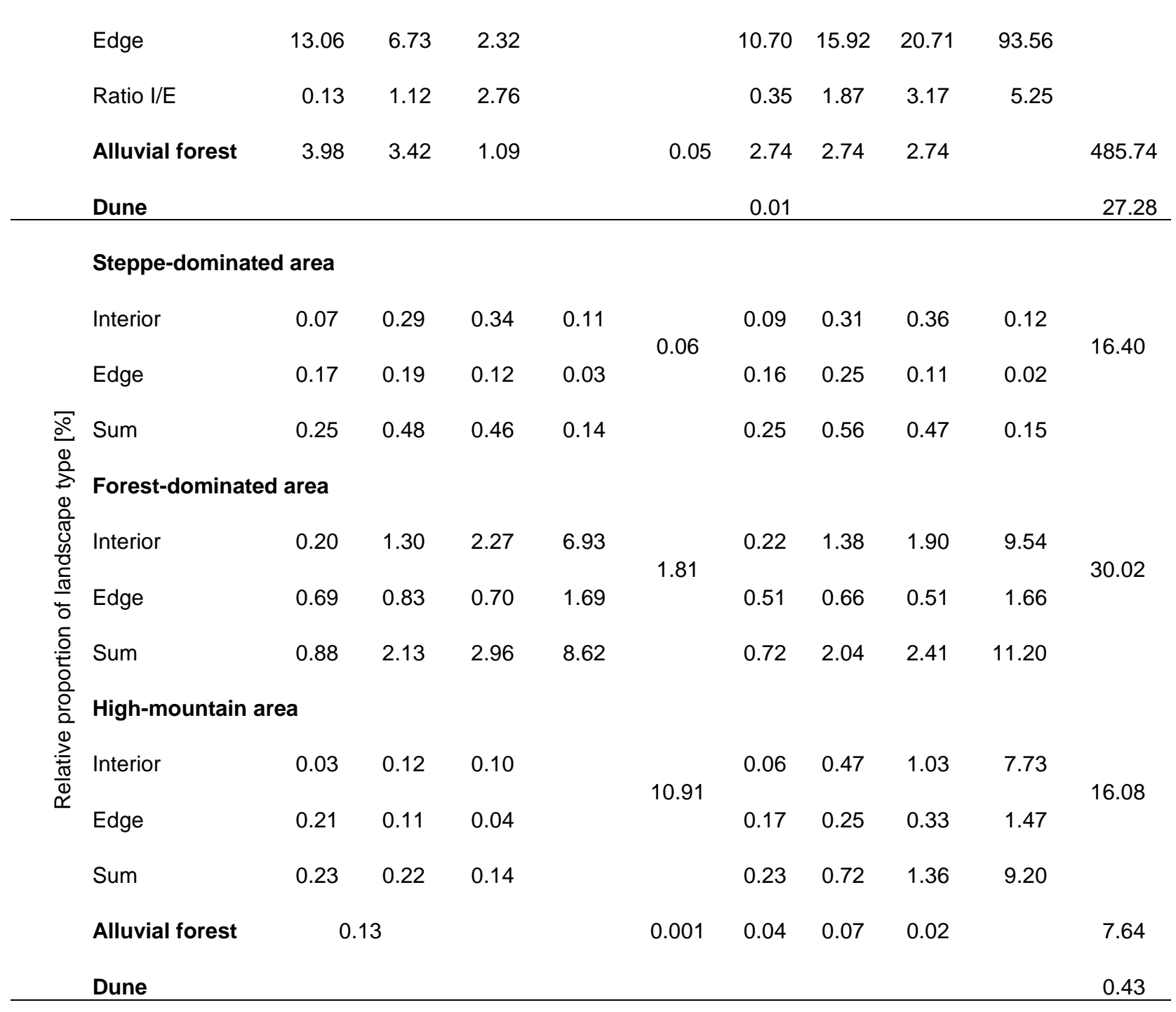

Due to the low correlation between topographic parameters, NDVI and living-tree biomass (Fig. 2.1.9), estimation of the total living-tree biomass in the study area by use of regression functions was not feasible. Therefore, we estimated the total living-tree biomass by multiplying the specific mean tree biomass of each forest category by the area of that forest category in 1986 and 2018 (Tables 2.1.3-5). The total living-tree biomass of the PFA was calculated based on the mean living-tree biomass of forest-dominated area, because both PFA projections had resulted in forest-dominated landscapes (Table 2.1.5). The actual tree biomass in the study area was $57 \%$ of the one in 1986 , corresponding to $30 \%$ and $34 \%$ of the tree biomass estimated for the PFA and PFA, respectively (Table 2.1.5). The greatest losses of living-tree biomass due to forest fires since 1986 were detected in the large forests (size class F4) of the 
forest-dominated area and high-mountain area, whereas tree-biomass losses through fire were less severe in the steppe-dominated area and alluvial forests.

Table 2.1.4: Total living-tree biomass $\left[10^{6} \mathrm{~g}\right]$ in different forest categories of the study area.

\begin{tabular}{|c|c|c|c|c|c|c|c|c|c|c|}
\hline \multirow{2}{*}{$\begin{array}{r}\text { Actual forest area } \\
\text { forest-size class } \\
\end{array}$} & \multirow[b]{2}{*}{1} & \multirow[b]{2}{*}{2} & \multicolumn{8}{|c|}{ Forest distribution in 1986} \\
\hline & & & 3 & 4 & Sum & 1 & 2 & 3 & 4 & Sum \\
\hline \multicolumn{11}{|c|}{ Steppe-dominated area } \\
\hline Interior & 68,892 & 398,195 & 474,487 & 132,398 & $1,073,972$ & 81,348 & 428,835 & 505,209 & 143,948 & $1,159,341$ \\
\hline Edge & 149,217 & 191,236 & 130,499 & 31,053 & 502,005 & 138,668 & 251,237 & 118,171 & 25,152 & 533,229 \\
\hline Sum & 218,109 & 589,431 & 604,986 & 163,450 & $1,575,976$ & 220,016 & 680,073 & 623,380 & 169,100 & $1,692,569$ \\
\hline \multicolumn{11}{|c|}{ Forest-dominated area } \\
\hline Interior & 277,732 & $1,809,560$ & $3,177,481$ & $8,000,534$ & $13,265,306$ & 304,883 & $1,909,714$ & $2,664,408$ & $11,020,218$ & $15,899,224$ \\
\hline Edge & 718,971 & 815,498 & 754,423 & $1,977,866$ & $4,266,758$ & 530,041 & 653,229 & 548,092 & $1,941,327$ & $3,672,689$ \\
\hline Sum & 996,703 & $2,625,058$ & $3,931,904$ & $9,978,400$ & $17,532,064$ & 834,925 & $2,562,943$ & $3,212,500$ & $12,961,545$ & $19,571,913$ \\
\hline \multicolumn{11}{|c|}{ High-mountain area } \\
\hline Interior & 37,963 & 163,881 & 141,084 & 0 & 342,928 & 82,118 & 648,002 & $1,448,389$ & $8,922,284$ & $11,100,793$ \\
\hline Edge & 215,657 & 104,498 & 39,519 & 0 & 359,674 & 176,719 & 247,038 & 353,449 & $1,723,920$ & $2,501,126$ \\
\hline Sum & 253,620 & 268,379 & 180,603 & 0 & 702,602 & 258,837 & 895,041 & $1,801,838$ & $10,646,204$ & $13,601,919$ \\
\hline Alluvial forest & & & & & 350,149 & & & & & 353,095 \\
\hline Total Sum & & & & & $20,160,791$ & & & & & $35,219,497$ \\
\hline \multicolumn{11}{|c|}{ Comparison of tree biomass } \\
\hline Sum 1986 & $1,313,778$ & $4,138,056$ & $5,637,718$ & $23,776,849$ & $34,866,401$ & & & & & \\
\hline Sum 2018 & $1,468,432$ & $3,482,868$ & $4,717,493$ & $10,141,850$ & $19,810,642$ & & & & & \\
\hline Loss by fire & $-154,655$ & 655,189 & 920,225 & $13,634,999$ & $15,055,759$ & & & & & \\
\hline$\%$ & -11.8 & 15.8 & 16.3 & 57.3 & 43.2 & & & & & \\
\hline
\end{tabular}


Table 2.1.5: Potential forest area (PFA) and living-tree biomass as controlled by climate (PFA $\left.A_{c}\right)$ and relief $\left(P F A_{r}\right)$.

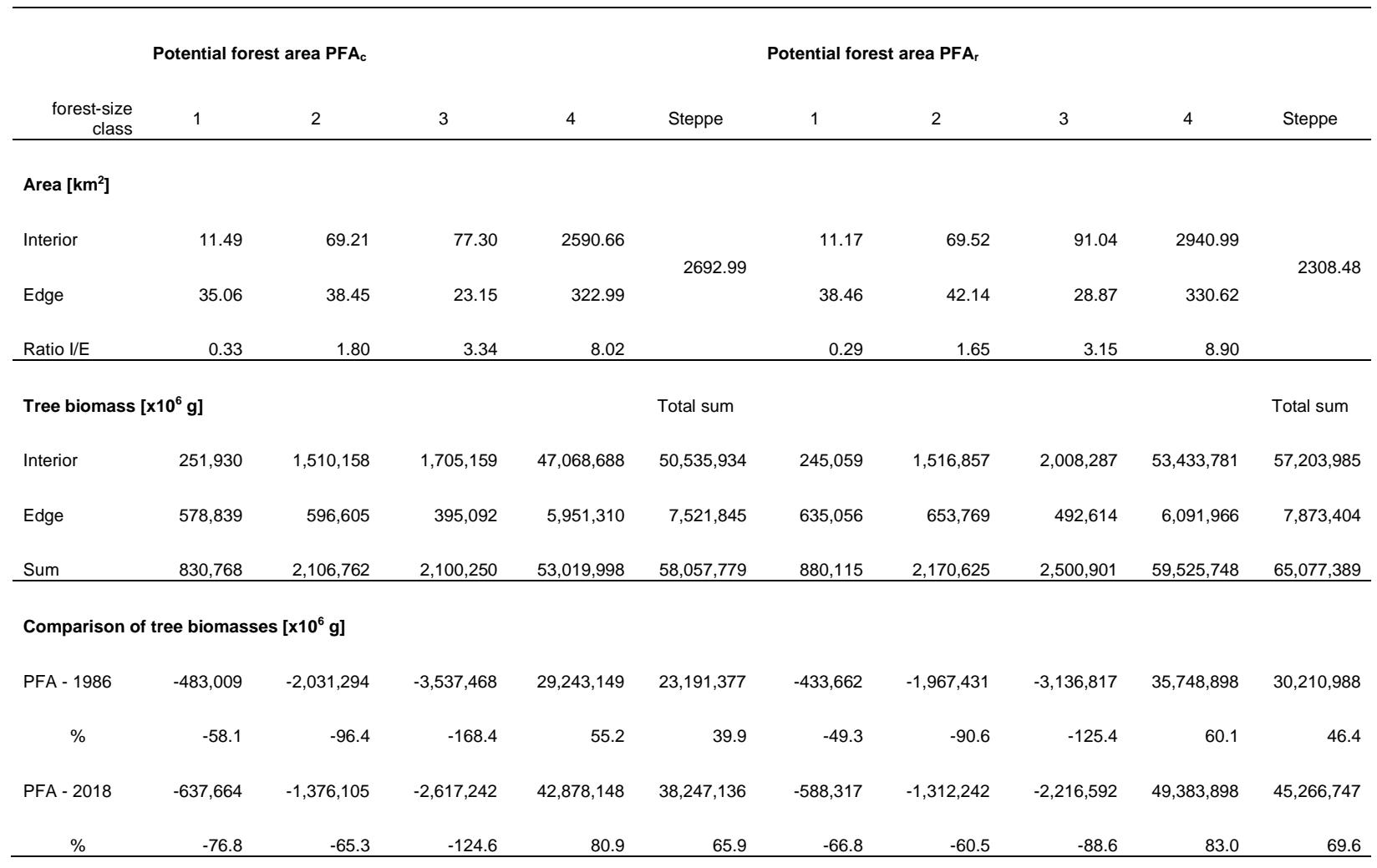

\subsubsection{Discussion}

\subsubsection{Forest distribution}

The main natural factors that control the spatial distribution and vigour of forests in the Mongolian forest-steppe are low precipitation and high evapotranspiration. The latter depends on insolation, which in turn varies with relief, resulting in a lack of forests on south-facing slopes (Dulamsuren and Hauck 2008; Hais et al. 2016; Klinge et al. 2018). Where forests occur, the forest canopy fosters dense ground vegetation and an organic surface layer that insulates the soil from warm air during summer (Dashtseren et al. 2014). In this way, forests support discontinuous permafrost (Klinge et al. 2021). In turn, permafrost helps trees to survive summer droughts, as it prevents meltwater that is released above the permafrost table from percolating below the rooting zone (Sugimoto et al. 2002). Recognising these mutual relationships is crucial for understanding the patterns of forest distribution and tree biomass in 
the Mongolian forest-steppe. However, this causal network alone cannot explain the present forest-distribution pattern, as it is additionally influenced by other - mostly anthropogenic factors that may lead to a discrepancy between the actual and potential forest area (PFA).

\subsubsection{Potential forest area (PFA)}

The relief-limited potential forest area (PFA $)$ obtained from this study suggests a potential for forest expansion, both downslope towards the basins, and upslope towards the high-mountain area. Pediments that widely cover the toe slopes in the study area generally provide suitable geoecological conditions for tree growth, as confirmed by several existing small forest stands there. Nevertheless, steppe vegetation predominates on the pediments, mainly because of herbivore grazing (Hilbig 1995). The climate-limited potential forest area (PFA ${ }_{c}$ obtained from this study yielded a lower treeline where dry conditions of the basins prevent tree growth, coinciding with the present lower forest boundaries. Existence of forests below the threshold of $160 \mathrm{~mm}$ MAP can be explained by additional water supply through lateral water fluxes, cumulating in concave positions and toe slopes (Klinge et al. 2021). The PFA moreover suggests a potential for greater forest areas on south-facing slopes. This mismatch reconfirms that MAP and MGST alone cannot explain forest distribution, which is a result of a more complex causal network as explained in the beginning of this chapter. Short growing seasons and long-lasting snow cover prevent the expansion of forests into upper valleys and onto the mountain plateaus of the high-mountain area in the south. Another limiting factor there is the extensive use of alpine meadows as summer pastures. The upper treeline rises from 2,400 m a.s.I. in the north to $2,600 \mathrm{~m}$ a.s.I. in the south of the study area. Thereby, small treeless areas on the flat summits of the northern mountains may result from the so-called "summit effect" (Körner 2012), i.e., particularly harsh conditions near summits, rather than from a true upper treeline. The projected PFAs suggest more large forests and considerably less small, fragmented forest stands in the steppe-dominated area in the northern part of the study area, assuming potential forest-dominated area there. A shift from potential forest-dominated area 
to the presently observed steppe-dominated area may have been partially triggered by natural factors such as fire, windbreak, insect calamities, and drought, but logging and forest pasture most likely caused major forest losses in this area. Given the permafrost-promoting effect of large forests, the proposed forest-dominated area scenario for the northern part of the study area would involve also greater abundance of permafrost in this area.

\subsubsection{Impact of fire}

The forest area that burnt down between 1986 and 2017 amounts to $12.8 \%$ of the total study area. The loss of living-tree biomass since the last century adds up to roughly 15 million tons, which represents more than $45 \%$ of the former tree biomass. Nyamjav et al. (2007) stated that $95 \%$ of the actual forest destruction was caused by forest fires, whereas $5 \%$ was due to logging. The authors reported an increase of fire events in Mongolia during the past decades. Goldammer (2002) assumed that most of the fires were caused by human activities. Hessl et al. (2012) investigated fire history over the past 450 years based on tree ring analysis. In agreement with results from the Tuva region in southern Siberia (Ivanova et al. 2010), the authors did not detect an increase in fire frequency during the last decades, but fires became more severe due to drier conditions. The limited contemporaneity of fire events at different sites pointed to fire-raising by humans (Hessl et al. 2012). On the other hand, human impact may also lead to reduced destructiveness of fires, as wood gathering and intensive grazing of livestock reduce available fuel for fires (Umbanhowar et al. 2009; Hessl et al. 2012).

Although the most extensive forest fires in this area occurred already in 2002, forests have not yet re-established in many burnt forest areas. The most extensive burnt forest areas are located in the large forests of the high-mountain area and in the upper mountains in the forestdominated area. In contrast, only few burnt forest areas occur in the small and fragmented forests of the steppe-dominated area. We conclude that forest fragmentation in the steppedominated area prevents forest fires from passing over into neighbouring forest stands and keeps fires rather isolated. The decrease of large forests (size class F4) by fire led to an 
increase in small, fragmented forest stands (size class F1), representing remnants of the former large forests. This change induced loss of permafrost in these areas. Surviving larch trees in the remaining forest remnants show enhanced fructification (Danilin and Tsogt 2014). Their important role as nuclei for forest regeneration is demonstrated by numerous seedlings and saplings growing in the direct surrounding of the forest remnants, in the shade of the old trees. Thus, a slow but steady re-immigration of larch trees into the burnt area proceeds from these forest remnants. It may take up to 200 years until a forest regenerates to its state prior to a fire (Nyamjav et al. 2007).

Fires occur frequently in semi-arid environment (Hessl et al. 2012). Thus, L. sibirica is fireadapted to a certain degree. Its survival of a fire depends on the type of fire (crown, surface or ground fire), fire intensity, season, and soil moisture. The prevalent survival of forest stands in depressions, erosion channels, and on toe slopes demonstrates the importance of soil moisture for tree survival.

\subsubsection{Living-tree biomass}

In contrast to the close relationships of forest distribution with relief and climate, living-tree biomass showed no significant correlation with topographic parameters. It turned out that forests of the Mongolian forest-steppe have highly variable living-tree biomass. In addition to natural impacts on forests (e.g., fire, windbreak, insect calamities, and drought), logging and forest pasture may affect living-tree biomass. Alluvial forests exist where river channels hamper wood pasture, logging, and forest fires. These alluvial forests usually consist of old larch trees and have large tree biomass. Open larch forests on dunes are also made up by very old trees, but have low stand density and tree biomass.

In attempts to assess biomass at landscape scale, the NDVI is commonly used as a biomass proxy. However, its suitability depends on the scale and data resolution. Dulamsuren et al. (2016) successfully applied NDVI at regional scale for biomass estimation in Mongolia. 
However, in our local-scale analysis we did not obtain a statistically significant correlation between NDVI and living-tree biomass. Instead, the NDVI proved to be a suitable indicator of the growing conditions for the entire forest vegetation (Erasmi et al. 2021).

The differences in mean tree biomass between the forest categories distinguished in our study were up to $85 \mathrm{Mg} \mathrm{ha}^{-1}$. Our field measurements showed that the least mean tree biomasses occurred in the forest-size class $\mathrm{G} 1\left(142 \mathrm{Mg} \mathrm{ha}^{-1}\right)$ of the steppe-dominated area and in the class F4 (182 Mg ha-1) of the forest-dominated area. The reduced living-tree biomass of the small, fragmented forests in the steppe-dominated area (G1) can be explained by enhanced forest use, reducing the stand basal area. As therefore solar irradiation on the ground is increased, there is no permafrost under these forests. The reduced living-tree biomass of the largest forests (size class F4) has a different reason. There, the permafrost table approaches the surface and hinders deep rooting of trees. Trees are therefore highly prone to windthrow, which explains the reduced living-tree biomass in this forest category.

Furthermore, forest edges showed reduced living-tree biomass. Forest edges represent natural zones of forest expansion and retreat (Sommer and Treter 1999), whereby temporal climatic variations control these fluctuations. Forest edges may have a fringe of dead trees at their outer boundary, and their outer boundary may also be dissected. In addition, logging and pasture is more intensive at the forest edges than in the interiors. Due to the lower tree density, the living-tree biomass is generally lower at the forest edges than in the interiors. However, we found exceptions to this rule in the forest-size classes $\mathrm{G} 1$ and F4, where the forest interiors and edges had similar tree biomasses. In the class $\mathrm{G} 1$, the tree biomasses of the small interior forest areas are similarly low as those of the forest edges. In the class F4, the forest edges have large tree biomasses compared to all other forest edges. This can be explained by the effect of permafrost. A shallow permafrost table in the interior part of F4 forests causes reduced tree biomass in the forest interior as described above. Towards the forest edges, the depth of the permafrost table increases. There, during summer permafrost supplies meltwater to the trees that are otherwise close to the climatic threshold of tree growth at the drier forest edges. 
This effect, together with higher precipitation in the upper mountains may also explain the existence of forests on south-facing slopes in the higher mountains (Fig. 2.1.5).

Interestingly, forest stands that experienced non-lethal fire events or selective logging had similar tree biomasses as pristine forests. A possible explanation is that moderate thinning of forests may improve the growing conditions for the remaining trees, as it leads to reduced competition for water and increased nutrient supply from ash, and the melting permafrost leads to a temporary increase of soil moisture and allows for deeper rooting.

The estimated maximum tree biomass of the PFA $\left(58-65 \times 10^{9} \mathrm{~g}\right)$ was twice the tree biomass in $1986\left(35 \times 10^{9} \mathrm{~g}\right)$ and three times the actual tree biomass of $20 \times 10^{9} \mathrm{~g}$. However, several relevant factors could not be considered in the PFA projection. For example, large forests (size class F4), as predominantly obtained from the PFA delineation, are more prone to severe fires than fragmented forest stands. In addition, due to the long-lasting human influence, reconstructing the natural proportion between steppe and forest in this region remains a major research challenge (Klinge and Sauer 2019). Human impact already started with the extinction of large herbivores like elephantine, and the reduction of wild animal herds since the Mesolithic period. It continued with the breeding of domestic animals and the development of pasture since the Neolithic period, which started around 4.7 ka BP with the Afanasievo culture in the Altai Mountains (Kovalev and Erdenebaatar 2009).

Tchebakova et al. (2009b) modelled potential vegetation changes across Siberia based on climate-change scenarios projecting warmer and drier climate. The authors forecast an increase of forest-steppe and grassland areas. They assume that drier conditions and larger amounts of fuel due to enhanced tree mortality will lead to an increase in frequency and destructiveness of fires. 


\subsubsection{Conclusions}

A combination of tree-biomass determination, permafrost detection in soil profiles, remote sensing and climate-data analysis allowed us to identify factors controlling larch-forest distribution and living-tree biomass in the northern Khangai Mountains, central Mongolia. The identified topographic and climatic thresholds for forest growth enabled us to delineate the potential forest area (PFA), which was much larger than the actual forest area. Forest fires destroyed $43 \%$ of the forest area and $45 \%$ of the living-tree biomass in the study area over the period 1986-2017. They mostly affected large forest stands in the upper mountains. Permafrost, which was widespread under large forests, disappeared soon after the destruction of a large forest stand.

In contrast to forest distribution, living-tree biomass showed no correlation with topographic and climatic parameters. We found neither significant differences in living-tree biomass between forests with different fire history, degree of exploitation, and soil properties, nor between most forest-size classes. Only forest edges and small, fragmented forest stands had significantly less tree biomass than all other forest categories. Neither non-lethal fires nor selective logging seriously reduced living-tree biomass. We conclude that these impacts remove tree biomass, but also stimulate growth of the remaining trees by reducing competition.

Based on relief thresholds for forest growth, we obtained a PFA of $3,552 \mathrm{~km}^{2}$ with $65 \times 10^{9} \mathrm{~g}$ tree biomass, and based on climatic thresholds a PFA $A_{c}$ of $3,113 \mathrm{~km}^{2}$ with $58 \times 10^{9} \mathrm{~g}$ tree biomass, corresponding to $323 \%$ and $288 \%$ of the actual tree biomass, respectively. However, these estimates do not consider several relevant factors such as herbivore grazing and plant competition. In addition, long-lasting human impact (at millennial timescale) plays an important role for the vegetation pattern as well, which needs further investigation. 


\subsubsection{Appendices}

\section{Additional files:}

Table 2.1.6: Mean living-tree biomass (above and belowground) for different forest categories and site conditions. Plots, where site conditions were not clearly identified, were excluded from the respective part of the analysis. The two lower and higher forest-size classes in the forestdominated area were combined for the statistical analysis, because of the small dataset for forest edges. $S E=$ standard error, $n=$ number of plots. Underlined data are not representative because of insufficient size of the respective dataset.

\begin{tabular}{|c|c|c|c|c|c|c|c|c|c|c|c|c|c|c|c|}
\hline & F1 & SE & $n$ & $\mathrm{~F} 2$ & SE & $n$ & F3 & SE & $n$ & $\mathrm{~F} 4$ & SE & $n$ & G1 & SE & $n$ \\
\hline total & 198.7 & 11.2 & 29 & 208.0 & 11.8 & 31 & 212.5 & 13.9 & 31 & 182.0 & 12.9 & 34 & 142.2 & 10.7 & 10 \\
\hline difference interior - edge & 54.2 & & & 63.0 & & & 49.9 & & & -2.6 & & & 10.6 & & \\
\hline forest interior & 219.3 & 14.0 & 18 & 218.2 & 12.6 & 26 & 220.6 & 13.4 & 26 & 181.7 & 13.8 & 30 & 145.4 & 15.0 & 7 \\
\hline \multicolumn{16}{|l|}{ no fire indicators; } \\
\hline no logging & & & 0 & 236.9 & 4.4 & 3 & 232.8 & 6.3 & 3 & 161.1 & 13.1 & 13 & & & \\
\hline no fire indicators & 242.0 & 27.2 & 7 & 212.0 & 13.5 & 12 & 201.7 & 17.3 & 16 & 165.1 & 13.5 & 20 & $\underline{122.1}$ & 2.7 & 2 \\
\hline fire indicators & 194.4 & 15.9 & 5 & 181.9 & 25.8 & 8 & 231.3 & 14.4 & 6 & 177.2 & 49.5 & 4 & $\underline{154.9}$ & & 1 \\
\hline difference & 47.6 & & & 30.1 & & & -29.6 & & & -12.0 & & & & & \\
\hline no logging & & & & 255.2 & 10.9 & 6 & 251.0 & 25.2 & 5 & 174.1 & 14.4 & 15 & & & \\
\hline logging & 219.3 & 14.0 & 18 & 207.1 & 15.2 & 20 & 215.1 & 15.6 & 20 & 189.3 & 23.5 & 15 & 145.4 & 15.0 & 7 \\
\hline difference & & & & 48.1 & & & 35.9 & & & -15.2 & & & & & \\
\hline slope debris & 236.5 & 25.4 & 7 & 216.2 & 18.8 & 15 & 215.8 & 19.8 & 15 & 175.2 & 15.0 & 25 & & & \\
\hline sand layer & 208.4 & 15.2 & 11 & 220.9 & 15.2 & 11 & 227.2 & 16.3 & 11 & 214.1 & 31.7 & 5 & & & \\
\hline difference & 28.1 & & & -4.7 & & & -11.4 & & & -38.9 & & & & & \\
\hline forest edge & 165.1 & 13.7 & 11 & 155.2 & 21.0 & 5 & 170.7 & 46.2 & 5 & 184.3 & 35.2 & 4 & 134.8 & 2.7 & 3 \\
\hline \multicolumn{16}{|l|}{ no fire indicators; } \\
\hline no logging & 211.5 & 22.3 & 2 & 171.5 & 26.9 & 2 & 177.8 & & 1 & 233.4 & 44.6 & 2 & & & \\
\hline no fire indicators & 167.5 & 16.0 & 7 & 171.5 & 26.9 & 2 & 170.7 & 46.2 & 5 & 189.4 & 46.6 & 3 & & & \\
\hline fire indicators & 160.9 & 24.9 & 4 & 144.3 & 28.3 & 3 & & & & 168.7 & & 1 & & & \\
\hline difference & 6.6 & & & 27.2 & & & & & & 20.7 & & & & & \\
\hline no logging & 211.5 & 22.3 & 2 & $\underline{171.5}$ & 26.9 & 2 & $\underline{177.8}$ & & 1 & 211.8 & 34.5 & 3 & $\underline{134.1}$ & 4.0 & 2 \\
\hline logging & 154.8 & 13.8 & 9 & 144.3 & 28.3 & 3 & 168.9 & 57.8 & 4 & $\underline{101.6}$ & & 1 & $\underline{136.3}$ & & 1 \\
\hline difference & $\underline{56.7}$ & & & $\underline{27.2}$ & & & $\underline{9.0}$ & & & $\underline{110.3}$ & & & & & \\
\hline slope debris & 181.2 & 20.9 & 6 & $\underline{171.5}$ & 26.9 & 2 & 123.2 & 22.9 & 4 & 189.4 & 46.6 & 3 & & & \\
\hline sand layer & 145.8 & 11.7 & 5 & 144.3 & 28.3 & 3 & 360.5 & & 1 & $\underline{168.7}$ & & 1 & & & \\
\hline difference & 35.5 & & & $\underline{27.2}$ & & & $\underline{-237.3}$ & & & $\underline{20.7}$ & & & & & \\
\hline combined classes & & F1 / F2 & SE & $n$ & & F2 / F3 & SE & $n$ & F3/F4 & SE & $n$ & & & & \\
\hline forest edge & & 162.0 & 11.5 & 16 & & 162.9 & 25.5 & 10 & 176.7 & 30.2 & 9 & & & & \\
\hline \multicolumn{16}{|l|}{ no fire indicators; } \\
\hline no logging & & 191.5 & 20.1 & 4 & & 173.6 & 18.0 & 3 & 214.9 & 33.3 & 3 & & & & \\
\hline no fire indicators & & 168.4 & 13.8 & 9 & & 170.9 & 33.9 & 7 & 177.7 & 33.9 & 8 & & & & \\
\hline fire indicators & & 153.8 & 18.9 & 7 & & 144.3 & 28.3 & 3 & $\underline{168.7}$ & & 1 & & & & \\
\hline difference & & 14.6 & & & & 26.6 & & & $\underline{9.0}$ & & & & & & \\
\hline no logging & & 191.5 & 20.1 & 4 & & 173.6 & 18.0 & 3 & 203.3 & 26.9 & 4 & & & & \\
\hline logging & & 152.2 & 12.6 & 12 & & 158.3 & 35.5 & 7 & 155.4 & 33.3 & 3 & & & & \\
\hline difference & & 39.3 & & & & 15.3 & & & 47.9 & & & & & & \\
\hline slope debris & & 169.9 & 14.9 & 10 & & 139.3 & 20.0 & 6 & 151.6 & 26.9 & 7 & & & & \\
\hline sand layer & & 144.2 & 11.5 & 9 & & 198.3 & 51.4 & 4 & $\underline{264.6}$ & 67.8 & 2 & & & & \\
\hline difference & & 25.7 & & & & -59.0 & & & -113.0 & & & & & & \\
\hline
\end{tabular}




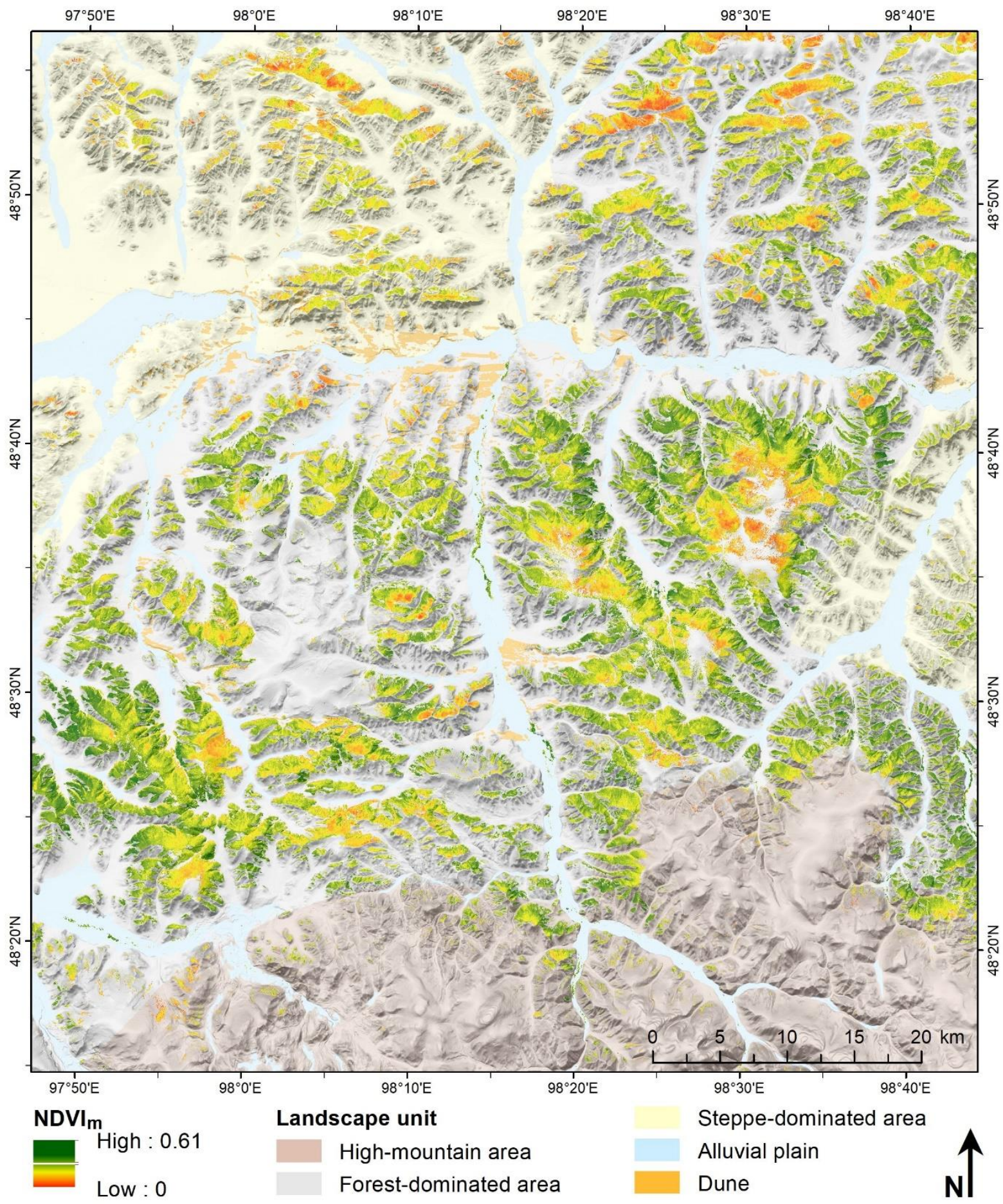

Figure 2.1.10: $N D V I_{m}$ of forests in the study area. Arithmetic means of NDVI from seven Sentinel 2 satellite images (17.05.2018, 11.06.2018, 25.08.2018, 4.09.2018, 14.09.2018, 19.09.2017, 16.07.2016). The shaded relief illustration is based on TanDEM-X data. 


\subsection{Modelling the productivity of Siberian larch forests from Landsat NDVI time series in fragmented forest stands of the Mongolian forest-steppe}

Stefan Erasmi ${ }^{1}$, Michael Klinge ${ }^{2}$, Choimaa Dulamsuren ${ }^{3}$, Florian Schneider ${ }^{2}$, Markus Hauck $^{3}$

${ }^{1}$ Thünen Institute of Farm Economics, Bundesallee 63, D-38116 Braunschweig, Germany

2 Department of Physical Geography, Institute of Geography, University of Goettingen, Goldschmidtstraße 5, 37077 Göttingen, Germany

${ }^{3}$ Applied Vegetation Ecology, Faculty of Environment and Natural Resources, University of Freiburg, Tennenbacher Str. 4, 79106 Freiburg, Germany

- Manuscript published in Environmental Monitoring and Assessment (18. March 2021)

- https://doi.org/10.1007/s10661-021-08996-1

Author contributions:

Stefan Erasmi: Conceptualization, Data curation, Methodology, Formal analysis, Validation, Visualization, Writing - original draft. Michael Klinge: Conceptualization, Funding acquisition, Project administration, Visualization, Writing - review \& editing. Choimaa Dulamsuren: Writing - review \& editing. Florian Schneider: Methodology, formal analysis, visualization, writing, review and editing. Markus Hauck: Funding acquisition, Writing - review \& editing

Keywords: forest-steppe, NDVI, tree productivity, tree ring, remote sensing, dendrochronology 


\section{Abstract}

The monitoring of the spatial and temporal dynamics of vegetation productivity is important in the context of carbon sequestration by terrestrial ecosystems from the atmosphere. The accessibility of the full archive of medium-resolution earth observation data for multiple decades dramatically improved the potential of remote sensing to support global climate change and terrestrial carbon cycle studies. We investigated a dense time series of multisensor Landsat Normalized Difference Vegetation Index (NDVI) data at the southern fringe of the boreal forests in the Mongolian forest-steppe with regard to the ability to capture the annual variability in radial stemwood increment and thus forest productivity. Forest productivity was assessed from dendrochronological series of Siberian larch (Larix sibirica) at 15 plots in forest patches of different ages and stand sizes. The results revealed a strong correlation between the maximum growing season NDVI of forest sites and tree ring width over an observation period of 20 years. This relationship was independent of the forest stand size and of the landscape's forest-to-grassland ratio. We conclude from the consistent findings of our case study that the maximum growing season NDVI can be used for retrospective modelling of forest productivity over larger areas. The usefulness of grassland NDVI as a proxy for forest NDVI to monitor forest productivity in semi-arid areas could only partially be confirmed. Spatial and temporal inconsistencies between forest and grassland NDVI are a consequence of different biophysiological and ecological vegetation properties. Due to coarse spatial resolution of available satellite data, previous studies were not able to account for small-scaled land-cover patches like fragmented forest in the forest-steppe. Landsat satellite-time series were able to separate those effects and thus may contribute to a better understanding of the impact of global climate change on natural ecosystems.

\subsubsection{Introduction}

Terrestrial carbon of aboveground biomass plays a major role in the global carbon cycle. Knowledge about productivity and spatial distribution of aboveground carbon stocks in forests is essential for global biogeochemical scenarios and modelling (Goodale et al. 2002; Pan et al. 2011). Assessing the spatial and temporal variability of vegetation productivity remains a challenge and is a function of numerous environmental factors. Changing climate is assumed to have a considerable impact on vegetation growth and hence, tree productivity, especially in areas that are considered as hotspots of global climate change, like the eastern part of Central Asia (Turco et al. 2015). Direct measurements of tree productivity on historical scales are available from dendrochronological studies that use the annual radial stem increment (tree ring width; TRW) as a measure of tree growth and thus are able to produce time series of ecosystem productivity. Depending on the climatic conditions, annual stem increment in boreal of forest can either be limited by low temperatures or drought during the growing season (Beck 
et al. 2011; Hauck et al. 2020; Zhou et al. 2020). As the result of climate warming, boreal forests are increasingly switching from temperature-limited to drought-limited ecosystems (D'Arrigo et al. 2004; Buermann et al. 2014). Especially the forest-steppe related to the semiarid regions of Central Asia is more and more subjected to forest disturbance by fire and windthrow (Nyamjav et al. 2007). These forests often show decreases in productivity (Dulamsuren et al. 2010c; Dulamsuren et al. 2013a).

Tree ring studies can cover centuries but only deliver local information. The uneven and sparse distribution of available tree ring information cannot represent larger areas. By contrast, remote sensing data are able to monitor and quantify ecological parameters that affect plant productivity over large areas. The basic concept relies on the establishment of relations between the absorbed and reflected solar radiation in the visible and near infrared (VNIR) spectrum and the specific index of plant productivity in question, such as tree ring increment (Eitel et al. 2020). The vast majority of such studies use regression analyses to parameterize the relationship between the target variable and the remote sensing observations (Powell et al. 2010; Lu et al. 2015; Rodríguez-Veiga et al. 2019). In most cases when long time series of satellite data are investigated, the Normalized Difference Vegetation Index (NDVI) serves as a proxy variable (Fensholt and Proud 2012; Eckert et al. 2015; Testa et al. 2018; Ivanova et al. 2021). The NDVI is calculated as the ratio between the difference and the sum of the spectral reflectance in the red and near infrared region (Rouse et al. 1974).

Combining temporal series of ground-measured tree-ring and remote-sensing data enables the generation of a data pool for the assessment of the spatial and temporal variability in forest productivity for the last four decades since operational satellite earth observations became available. Several studies exist that have demonstrated the potential of satellite remote sensing time series for tree productivity monitoring. Bunn et al. (2013) used time series of biweekly NDVI data for the estimation of tree growth and revealed best correlations for July NDVI data together with the first principal component of tree-ring data from different sites of the 
Siberian taiga. Comparable results were reported from juniper woodlands of the Tibetan Plateau by He and Shao (2006) who also used the first principal component of the tree-ring data together with NDVI time series. Kaufmann et al. (2004) and Xu et al. (2019) underlined the importance of the summer greenness of the canopy (June / July) for the prediction of TRW. D'Arrigo et al. (2000a) and Wang et al. (2004) also highlighted the potential of satellite-time series for the prediction of forest productivity. However, not all studies confirmed a general positive relationship between dendrochronological sampling and annual or seasonal NDVI composites. A recent study by Brehaut and Danby pointed out that relations are inconsistent and might be a function of forest type and also be affected by climatic variables (Brehaut and Danby 2018).

All mentioned studies have in common that they were based on data from coarse spatial resolution sensors (e.g. AVHRR, MODIS) and cannot account for small-scaled land-cover patches and landscape heterogeneity. Due to this limitation in resolution and the highly fragmented forests in Central Asia, some studies used NDVI time series over larger grassland areas as a proxy for forest productivity (He and Shao 2006). Only few and recent studies made use of the potential of higher spatial resolution time series available from the Landsat missions for mapping spatial and temporal variations in forest productivity (Liu 2016). Coops et al. (1999) was the first to evaluate the potential of annual Landsat data stacks for the estimation of the annual increment of forest-stand volume. Powell et al. (2010) compared different regression techniques to estimate biomass from time series of Landsat data. Main-Knorn et al. (2013) and Thomas et al. (2011) monitored forest disturbance and regrowth patterns from biennial time series stacks. The only study that used a multi-year series of Landsat for the estimation of tree ring width so far was published by Sangüesa-Barreda et al. (2014). They used single Landsat5 images for 15 irregularly distributed years within a 25-year span to monitor the consequences of insect outbreaks on the annual increment of the stand basal area in Mediterranean pine forests. A major issue with such approaches is the proper determination of a consistent time of the year when dealing with long annual time series. All known studies that are related to 
predicting forest productivity from Landsat time series only manually selected the optimal annual acquisition based on quality criteria (cloud coverage, peak of growing season) and only made use of a single sensor.

In the present study, we investigated the applicability of Landsat based growing season NDVI time series as a proxy of TRW of Siberian larch (Larix sibirica) at the southern border of the boreal forests in Mongolia. Landsat data covered a range of 32 years from 1986 to 2017 . In addition to existing studies, we used data from a full dense Landsat time series (LTS) of all available acquisitions from the Landsat-sensors Landsat-5/TM, Landsat-7/ETM+ and Landsat8/OLI. We computed annual-monthly metrics of NDVI data for the growing season over all sensors as a proxy for tree productivity. Besides the evaluation of the technical potential of the LTS, the central hypothesis of the study was that vegetation greenness is a function of tree ring width and hence, NDVI LTS are able to capture temporal anomalies and trends in forest productivity due to climate variations. Based on the findings of Khansaritoreh et al. (2017b) that the forest-steppe occurs in a dominantly drought-limited environment, our main hypothesis referred to the general assumption that long time series of high-resolution satellite data indicate the temporal variations in vegetation greenness that are related to climate variations. Furthermore, we postulated that the spatial patterns of those trends are related to forest fragmentation, i.e. that the reduction of forest areas (i.e. the forest-to-grassland ratio) has an impact on the vulnerability to climate variations and thus tree productivity. Further, it was tested, if steppe-grassland areas surrounding the forest stands can serve as a proxy for the monitoring of tree growth when the resolution of the satellite data and the size of the forest patches is not large enough for the analysis of homogeneous areas.

\subsubsection{Materials and methods}

The study area is located at the northern slope of the Khangai Mountains near the city of Tosontsengel in central Mongolia $\left(98^{\circ} 16^{\prime} \mathrm{E} / 48^{\circ} 46^{\prime} \mathrm{N}\right)$ about $600 \mathrm{~km}$ to the west of Ulan Bator 
(Figure 2.2.1). The high continental climate of the region is reflected by cold and semi-arid conditions. The monthly mean temperatures at Tosontsengel range between $-31.7{ }^{\circ} \mathrm{C}$ in January and $14.7^{\circ} \mathrm{C}$ in July (National Agency for Meteorology and Environment Monitoring of Mongolia, Ulan Bator). The main precipitation occurs during the summer season and is related to the circulation of the westerlies (Batima et al. 2005). Summer precipitation is subject to high inter-annual variations (Figure 2.2.2), making the area vulnerable to droughts. In contrast, the Siberian high during the winter season produces mostly dry conditions. The area is part of the southern boreal forests of Mongolia with altitudes ranging from 1,600 to 2,500 m a.s.l. Forest stands are strongly dominated by Siberian larch (Larix sibirica) and occur mainly on northern slopes whereas grassland steppe is found on the southern slopes (Hilbig 1995; Treter 1996). The major factors limiting tree growth is the shortage of precipitation $(<300 \mathrm{~mm} / \mathrm{a})$ together with high evapotranspiration as a function of incoming solar radiation and terrain parameters (Schlütz et al. 2008; Hais et al. 2016). Forest stands in the study area show considerable impact from industrial timber harvest activities in the second half of the twentieth century until 1990. After the end of the socialistic period in Mongolia, activities changed to predominantly unsystematic selective logging by the rural population (Nyamjav et al. 2007). Today, the foreststeppe area is home to mobile pastoralists, who keep mixed herds of sheep, goats, cattle, yak, and horses on common pastures. Livestock is not much herded and animals preferentially graze on grassland, but also move into the forests along the edges and further into the interior, when the forest islands are small (Lkhagvadorj et al. 2013a).

\subsubsection{Field data}

Field data of wood cores were taken in August 2014 in monospecific L. sibirica forest stands in sub-plots of $20 \times 20 \mathrm{~m}$ size (Khansaritoreh et al. 2017b). Wood cores from all L. sibirica trees (1755 individuals) with a stem diameter of $\geq 3 \mathrm{~cm}$ were collected at breast height $(1.3 \mathrm{~m}$ above the ground) using an increment borer with an inner diameter of $5 \mathrm{~mm}$. From the wood cores, the tree ring width was measured to an accuracy of $10 \mu \mathrm{m}$ using a Lintab 5 measuring system 
(Rinntech, Heidelberg, Germany). All sampled trees were classified into four age classes including "very old trees" (>160 years), "old trees" (101-160 years), “middle-aged trees" (61100 years), and "young trees" ( $\leq 60$ years). The forest stands were selected by a stratified random sampling approach in the core areas of forests (i.a. avoiding a $30 \mathrm{~m}$ forest edge buffer). Stratification was based on a supervised classification between forest and non-forest area (Landsat 8 OLT/TIRS of September 19, 2013). All forest patches were subsequently classified into four different size classes $\left(1:<0.1 \mathrm{~km}^{2} ; 2: 0.1-1.0 \mathrm{~km}^{2} ; 3:>1.0-5.0 \mathrm{~km}^{2} ; 4:>5.0 \mathrm{~km}^{2}\right)$ that serve as a proxy for forest fragmentation. Based on the forest-to-grassland ratio we distinguished between grassland-dominated $(\mathrm{G})$ and forest-dominated $(\mathrm{F})$ sub-regions. Forest patches in the grassland-dominated subregion mostly consisted of the smallest patch size class (G1). For each patch class (F1 to F4; G1), three replica were sampled. In each forest stand, two independent nearby sub-plots of $20 \times 20 \mathrm{~m}$ were sampled. For this study, the data from the sub-plots were aggregated at the stand level. This yielded a total of 15 forest plots distributed over the study area (Figure 2.2.1) that were investigated for the impact of patch size and isolation on the forest productivity. 


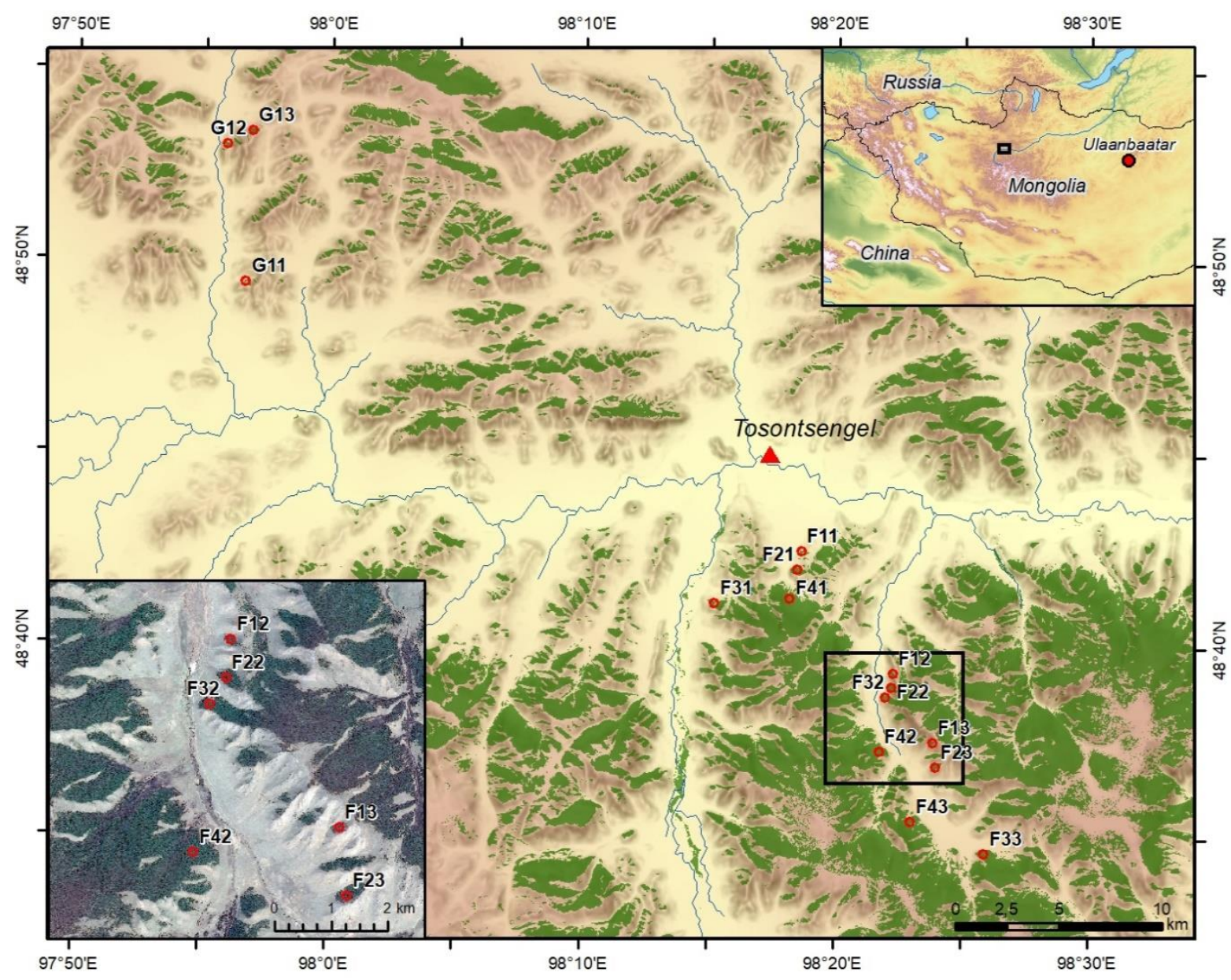

Figure 2.2.1: Study area near Tosontsengel, Mongolia with clusters of forest stands of different size (increasing from F1/G1 to F4) in subregions with high (F1-F4, south-eastern part of the study area) or low (G1, north-western part) forest-to-grassland ratio. The red points indicate the plot positions and the first digit defines the patch size class, whereas the second digit numbers the replica. The small rectangle in the overview map (top right) shows the location of the study area (main map). The rectangle in the main map shows the position of the detailed map (bottom left). 


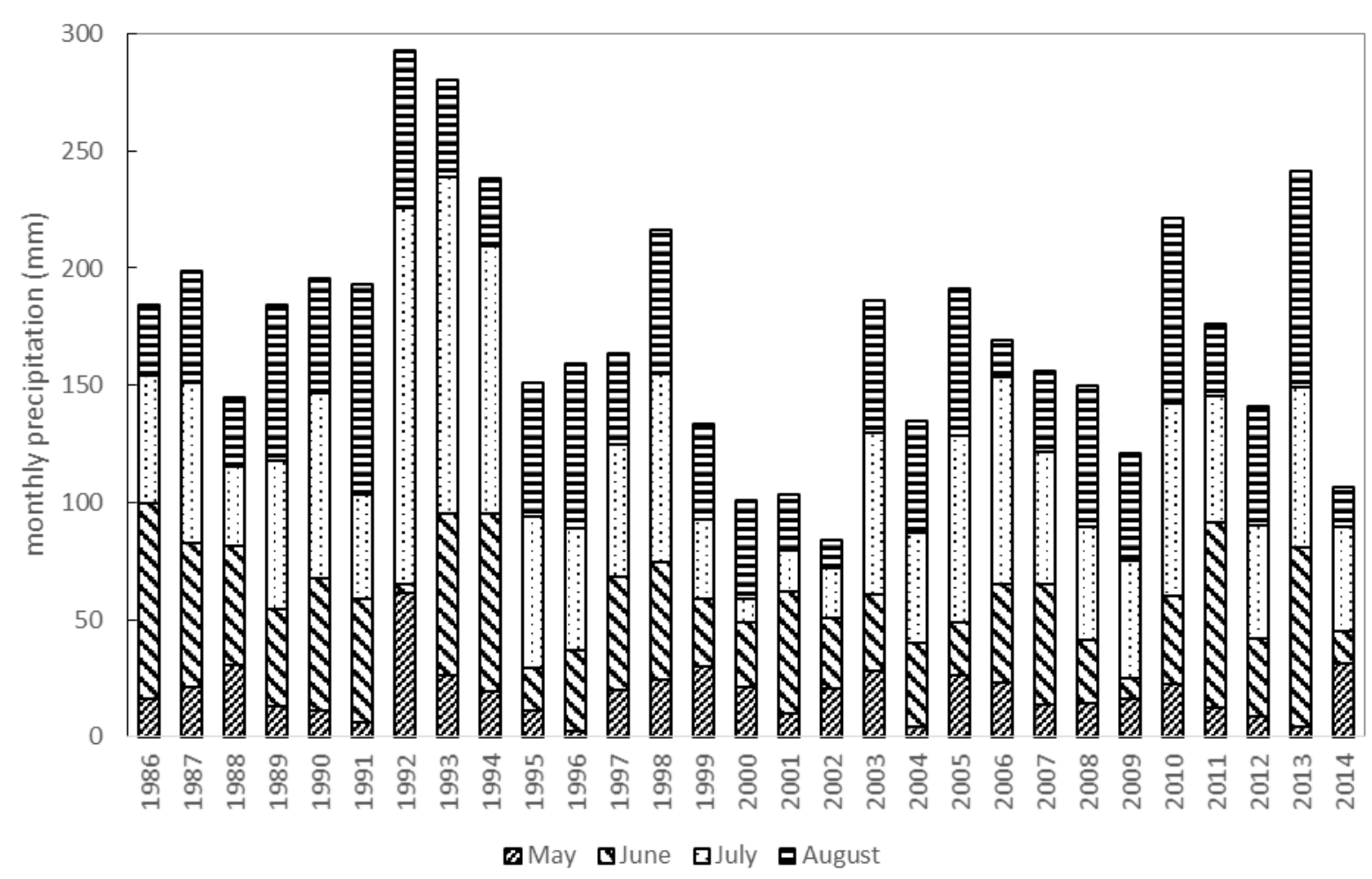

Figure 2.2.2: Variation of monthly precipitation during the summertime in the study area from 1986 to 2014 (daily data for Tosontsengel, aggregated to monthly sums and cumulated for the period May to August) Climate data were obtained from the National Agency for Meteorology and Environment Monitoring of Mongolia, Ulan Bator.

\subsubsection{Satellite data}

Landsat data were collected from U.S. Geological Survey (USGS) Earth Resources Observation and Science (EROS) Center from the Landsat sensors Thematic Mapper (TM), Enhanced Thematic Mapper+ (ETM+) and Operational Land Imager (OLI) at a 30-meter spatial resolution (U.S. Geological Survey, Earth Resources Observation and Science Center 2012a, 2012b; U.S. Geological Survey, Earth Resources Observation Science Center 2014). The "Collection 1 Level-2" scenes are processed to surface reflectance. Landsat-8 OLI surface reflectance data are computed using the Landsat Surface Reflectance Code (LaSRC). Landsat 5 TM and Landsat 7 ETM+ surface reflectance are generated using the Landsat Ecosystem Disturbance Adaptive Processing System (LEDAPS) algorithm. Both algorithms make use of the Moderate Resolution Imaging Spectroradiometer (MODIS) for the estimation of climate and atmospheric parameters but build on two different radiative transfer models to retrieve surface 
reflectance. LaSRC in addition uses the coastal aerosol spectral band from Landsat-8 OLI to perform aerosol inversion as input for the radiative transfer modelling. Details about the processing of the surface reflectance for the three sensors can be found in the respective product guides (U.S. Geological Survey 2019b, 2019a). The output from the two processing systems is a compilation of all spectral bands in the solar reflectance domain (Bands 1-5 and 7 for Landsat 5 TM and Landsat 7 ETM+; Bands 2-7, 9 for Landsat 8 OLI) together with a pixel quality assessment layer ("pixel_qa") that stores a bit index that later is used for cloud masking in the LTS processing. It should be noted that, depending on the surface reflectance processing algorithm, this bit index stores different values for clear pixels. On demand, the processor also delivers a collection of ready to use vegetation indices like the NDVI and others.

For the purpose of time-series analysis, only highest quality data with a root mean square error of less than or equal to $12 \mathrm{~m}$ in geometric accuracy (referred to as "Tier 1" Landsat data) were used in the present study according to the recommendations of the U.S. Geological Survey (U.S. Geological Survey 2019c). All Landsat scenes (path 137 / row 26) from beginning of April until end of September were selected for the 31-year time period 1986 to 2017, from which at least a subset of 20 years was used (see below). This resulted in an overall collection of 216 scenes from the TM sensor, 123 from ETM+ and 55 from OLI. An overview of all Landsat data for this study is given in Figure 2.2.3. 


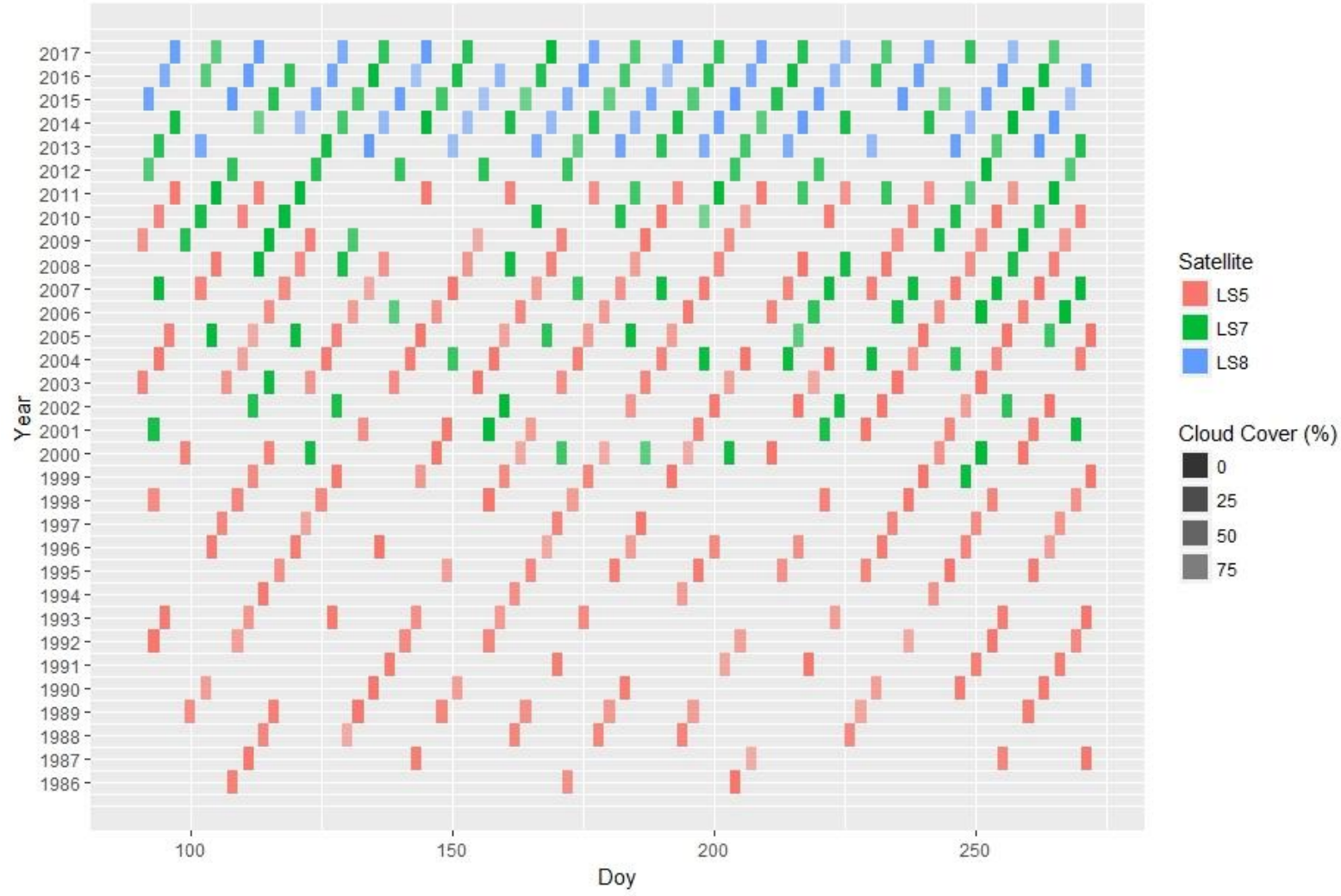

Figure 2.2.3: Summary of all available Landsat satellite imagery for the study area between 1986 and 2017 (Landsat path 137 / row 26; colour of the bars shows the three Landsat systems, red $=$ Landsat -5 TM, green $=$ Landsat 7 ETM+, blue = Landsat $8 \mathrm{OLI}$; opacity of the bars indicates amount of cloud coverage).

\subsubsection{Data analysis}

The collection of Landsat satellite data for the study area was processed to a time series layer stack of NDVI images. First, the NDVI was computed for every single Landsat scene based on the well-known ratio of high absorption in the Red and high reflectance of incoming solar radiation in the NIR part of the electromagnetic spectrum as an indicator for "green" vegetation and vegetation productivity (Tucker 1979):

$$
N D V I=\frac{N I R-R e d}{N I R+R e d}
$$

Cloud, cloud-shadow, snow and ice affected pixels were masked for each NDVI layer based on the pixel quality assessment layer of the respective Landsat acquisition. Differences in 
reflectance wavelength and hence, NDVI, between the OLI and the other two sensors have been observed for stable land surface targets. These differences are a result of the improved calibration, radiometric and spectral resolution of the OLI sensor. In order to produce a consistent LTS, we accounted for this issue based on ordinary least squares (OLS) regression transformations of the NDVI from Landsat $8 \mathrm{OLI}$ to Landsat $7 \mathrm{ETM}+$ and Landsat $5 \mathrm{TM}$ that are suggested by Roy et al. (2016).

After masking and transformation, the Landsat NDVI data were aggregated using a maximum value compositing (MVC) approach (Holben 1986) for all data that were acquired within the long-term growing season between mid of May and mid of September for every single year. The MVC approach selects for every pixel the maximum NDVI value from a satellite dataset recorded during the growing season of one year. Therefore, these aggregated annual values are referred to as the "maximum growing season NDVI (MGS-NDVI)" in this study. Data availability within the compositing period may produce a bias in the MGS-NDVI when only few images are available. Further, strong rainfall during the summer months around the peak of growing season may introduce artefacts in the composited seasonal NDVI time series. E.g., during 1992 and 1994 climate records show extreme precipitation sums during the summer months (especially in July, see Figure 2.2.2). These issues restricted the processing of the MGS-NDVI to a minimum of three cloud free observations (at the pixel level) per season. As a consequence, considerable parts of the study area were masked out, especially for the first ten years of the Landsat collection where only Landsat-5 images are available and at irregular temporal intervals with a considerable lack of data at the peak of the growing season where NDVI is at its maximum (Figure 2.2.3). Thus, the final time series included only the years from 1995 to 2017 . With regard to the availability of the tree ring data, only the period from 1995 to 2014 could be evaluated. 
The two-time series of annual data (TRW and MGS-NDVI) from 1995 to 2014 were finally corrected for seasonal effects and adjusted to a comparable data range by computing the standardized anomalies:

$$
M G S-N D V I_{a}=\frac{M G S-N D V I-\mu_{M G S-N D V I}}{\sigma_{M G S-N D V I}}
$$

where $\mu_{M G S-N D V I}$ is the mean value of the MGS-NDVI observations in the time period 1995 to 2014 and $\sigma_{M G S-N D V I}$ is its standard deviation. The standardized anomalies of TRW are calculated as $\mathrm{TRW}_{\mathrm{a}}$, respectively.

The analysis concept of the relations between MGS-NDVI $a$ and $\mathrm{TRW}_{\mathrm{a}}$ built on a correlation analysis at the level of the sub-categories (F1-F4; G1) that are defined above. The relationships were investigated for every single forest plot (with $n=$ no. of available years) and for the mean values of the standardized anomalies across the three forest plots within each patch size category (F1-F4, G1). Further, the TRW data were separated by tree-age class and the MGS-NDVI $-\mathrm{TRW}_{\mathrm{a}}$ relationship was analyzed at the level of age classes. The general idea behind these stratifications was that the tree productivity and hence, the NDVI, is affected by the forest patch size and shows differences even within a patch size depending on the age of the trees as has been reported by Khansaritoreh et al. (2017b). Further, it is assumed from previous work, that variations in tree productivity are related to variations in climate (Dulamsuren et al. 2010c; Dulamsuren et al. 2011; Khansaritoreh et al. 2018). Based on this rationale, the hypotheses that are stated in the introduction were tested at the plot level. Mean seasonal MVC NDVI anomalies were extracted for the plot coordinate and the surrounding 3 $x 3$ pixel neighbourhood in order to ensure that all pixels that contribute to the $20 \times 20 \mathrm{~m}$ plots are covered. With regard to the hypothesis that grassland NDVI can serve as a proxy for the monitoring of tree productivity ( $\mathrm{He}$ and Shao 2006), every forest plot was assigned a corresponding grassland plot. The grassland plots were determined by calculating the shortest distance from the forest plot to the forest border and then measuring a distance of $100 \mathrm{~m}$ 
perpendicular to the forest border outside the forest. Only unmanaged grassland sites were selected.

Statistical analysis was executed with IBM SPSS Statistics 26.0 and R (4.0.3-1). All statistical analysis was carried out at the level of the 15 plots for the 20 -year time period. The statistical results based on the calculation of the Pearson correlation coefficient $r$ in order to be able not only to evaluate the strength but also the direction of the relations between NDVI and TRW data. The overall significance of the linear models was estimated from an F-test and the definition of critical p-values at $99 \%, 95 \%$ and $90 \%$ significance level. The results of the statistical analysis were used as input for spatial modelling of annual standardized TRW anomalies for the entire study area. Temporal autocorrelation in the TRW as well as in the NDVI time series observations was tested with the autocorrelation function as described in Venables and Ripley (2011).

\subsubsection{Results}

\subsubsection{Landsat time series of peak growing season NDVI and climate variability}

The MGS-NDVI ${ }_{a}$ followed the variations in climate conditions for the studied time period of 1995 to 2014 (Table 2.2.1). Higher precipitation during the summer (May-August) was associated to higher NDVI values of the growing season. This correlation could be observed at the plot level for the majority of the 15 forest plots. The highest number of significant relations were found for June precipitation of the same year and seasonal NDVI. Further, the precipitation of the year prior to the NDVI measurement also was correlated with vegetation greenness in terms of NDVI. Here, the significant relations could be observed for the months July and August (Table 2.2.1).

The temporal profile of the MGS-NDVI for the studied time period appeared to reflect these variations quite similarly for the different patch sizes and the separation by grassland- and 
forest-dominated landscapes (Figure 2.2.4). The general behaviour was similar for all classes with negative standardized anomalies for periods that are linked to years of low summer precipitation (compare to Figure 2.2.2). For single years (e.g. 2012) small forest patches (F1/G1) showed higher anomalies compared to the larger patches (F2 to F4).

Table 2.2.1: Response of maximum growing season NDVI (MGS-NDVla) to precipitation standardized anomalies of the same year and the previous year (period of analysis: 19952014). $F=$ forest-dominated area, $G=$ steppe-dominated area. The first digit defines the forestpatch size, whereas the second digit numbers the single replicas. Plots without second digits represent the summarized classes.

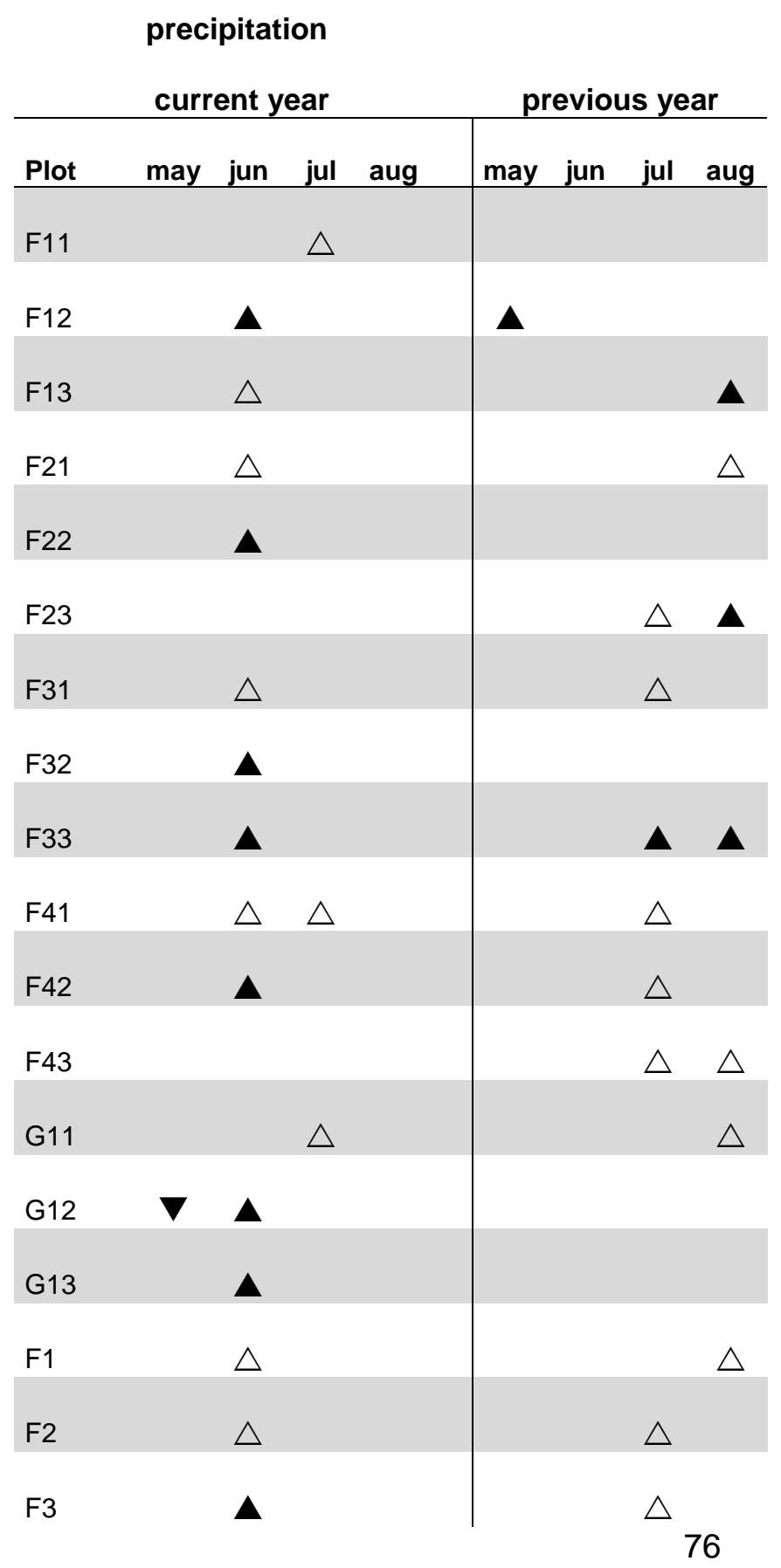




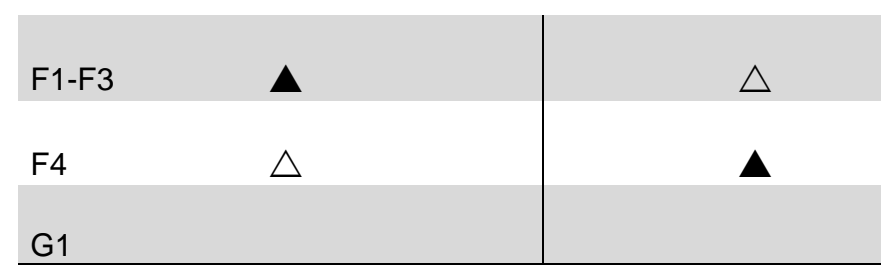

- significant positive $(\mathrm{p}<0.05)$

$\boldsymbol{\nabla}$ significant negative $(p<0.05)$

$\triangle \quad$ marginally significant positive $(p<0.1)$

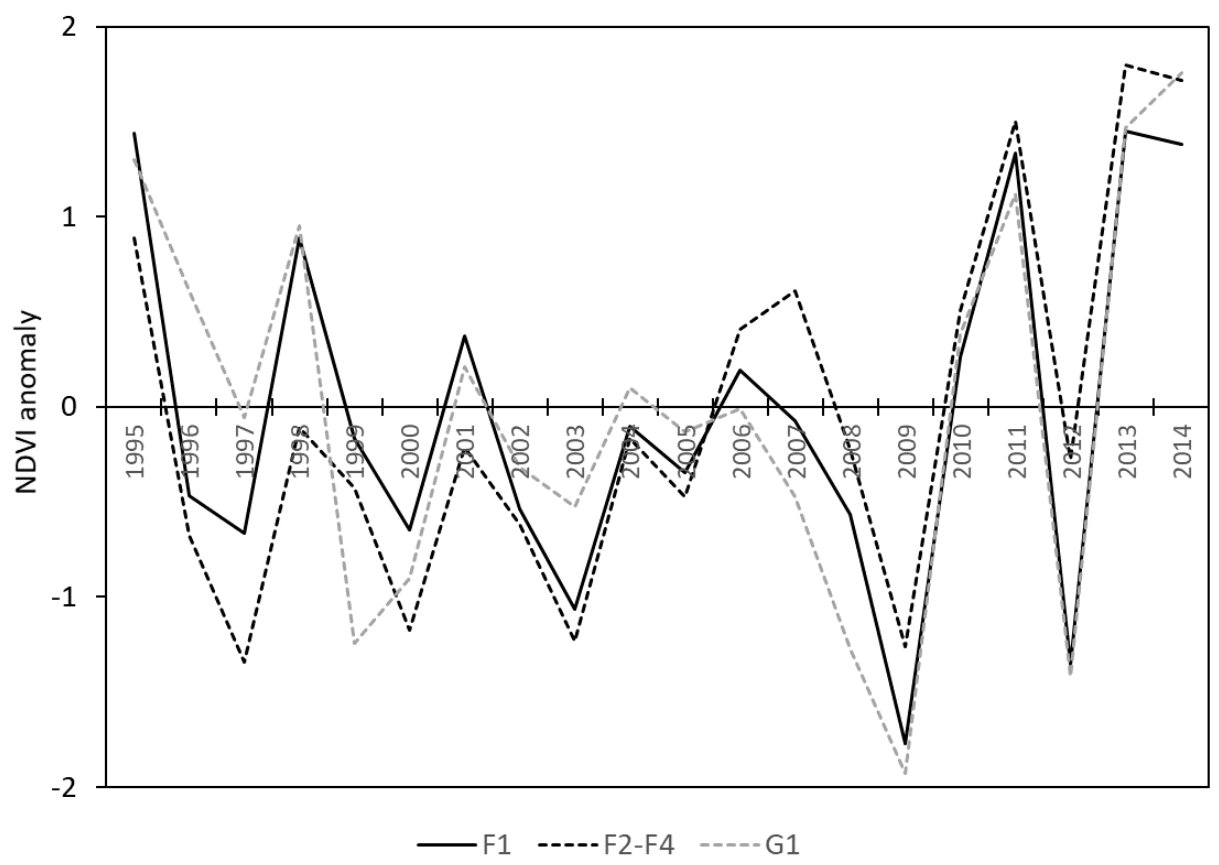

Figure 2.2.4: Temporal profile of standardized peak growing season NDVI anomalies for the reference period 1995 to 2014 grouped by patch size (F1, F2-F4) and forest-to-grassland ratio $(F, G)$.

\subsubsection{Landsat time series of peak growing season NDVI and tree ring width}

The interannual variability of the MGS-NDVI showed overall significant correlations with $\mathrm{TRW}_{\mathrm{a}}$ (Table 2.2.2). The relation between NDVI and TRW was always positive, i.e. positive standardized anomalies of NDVI were associated with positive anomalies of TRW. Temporal 
autocorrelation of annual NDVI and TRW observations could be neglected based on the results from the autocorrelation-function test (Figure 2.2.5). Graph (a) in Figure 2.2.5 shows the autocorrelation between TRW of the year under investigation and the previous years $(\mathrm{t}-1$ and $\mathrm{t}-2)$. High values indicate a strong effect of the past on the current year. It is obvious that past year's (t-1) TRW has an effect on productivity of trees in the current year. This is in line with other studies that revealed a spill-over effect of growing conditions of the previous year on current productivity (Vaganov et al. 2009; Babushkina and Belokopytova 2014). In contrast to the TRW time series, in general, no effect of past NDVI observations on the current year could be found. This is mainly a consequence of the annual aggregation of the NDVI data that eliminates the seasonal cycle and the inherent correlation structure of seasonal data (Forkel et al. 2013) and thus enables a regression analysis on the annual level. Only NDVI of large forest patches (F4) indicated an effect of the past on the current year. This can be due to the stable microclimate of large forest patches that is less effected by climate variability. Annual NDVI values of grassland showed no overall temporal autocorrelation.

Significant correlations $(p<=0.05)$ between MGS-NDVI $I_{a}$ and $\mathrm{TRW}_{\mathrm{a}}$ were found for the majority of forest plots over all age classes as well as for the mean of all trees within a plot and therefore also independent of forest-patch size (Table 2.2.2). Only two plots (F11, F41) did not show any significant relationships, at neither of the three investigated levels. The highest share of highly significant correlations was found for the age class "old trees" $(\mathrm{O})$. Note that the results for young trees $(\mathrm{Y})$ are less robust for interpretation across plots due to missing data in almost 50 $\%$ of the plots. The introduction of a one-year lag in the NDVI-TRW relationship reduced the overall significance of the correlations considerably. Then significant relations $(p<=0.05)$ were only found for small forest patches in grassland dominated landscapes (G1).

Based on the significant relations between MGS-NDVIa and $\mathrm{TRW}_{\mathrm{a}}$, the slope of the linear regression of TRW from NDVI was further investigated (Figure 2.2.6). The underlying assumption that the forest patch size and forest-grassland ratio have an impact on the slope 
of the regression line was not confirmed. The slopes are not notably different for the different forest-patch size classes.
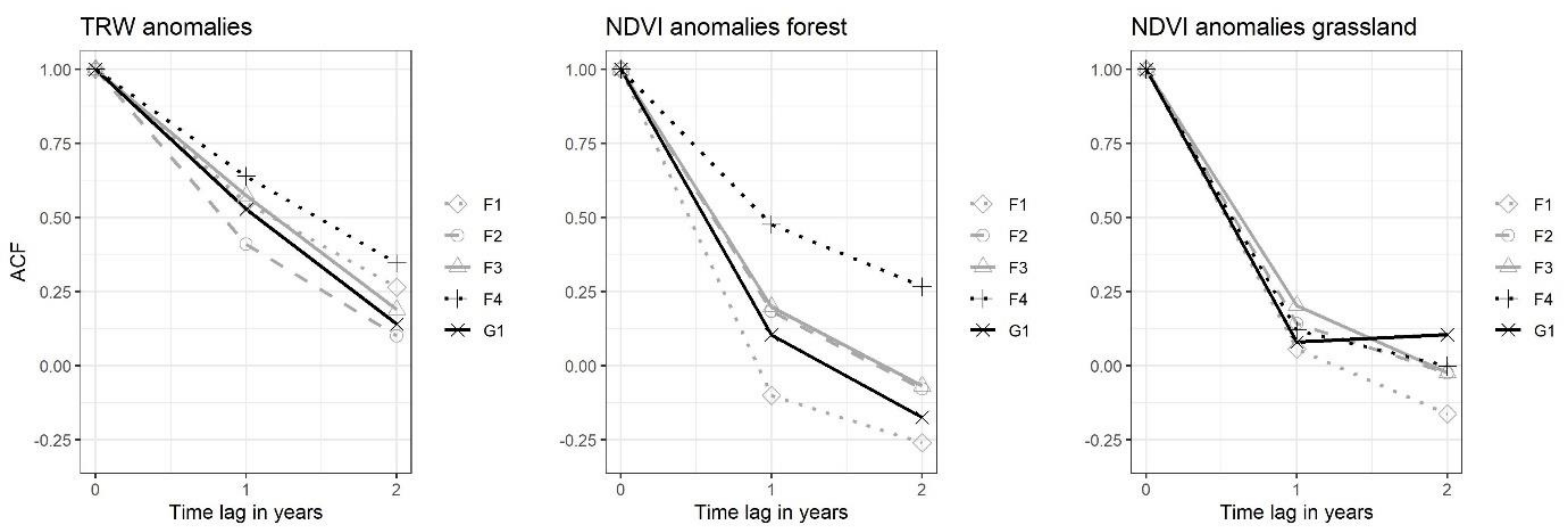

Figure 2.2.5: Results of the temporal autocorrelation test. Autocorrelation of annual TRW anomalies (a), autocorrelation of annual NDVI anomalies over forest (b) and autocorrelation of annual NDVI anomalies over associated grassland plots (c). The $X$-axis displays the time lag in years between two observations, the $Y$-axis shows the value of the autocorrelation function. Values below 0.50 indicate no autocorrelation between the observations.

Table 2.2.2: Results of the correlation analysis between standardized maximum growing season NDVI anomalies (MGS-NDVIa) and standardized anomalies of the tree-ring width (TRWa) for different forest-patch size classes and tree age classes.

\section{tree age class}

\begin{tabular}{|c|c|c|c|c|c|}
\hline $\begin{array}{l}\text { patch size } \\
\text { class / plot }\end{array}$ & ( $\leq 60$ years) & $\begin{array}{c}\text { M } \\
\text { (61-100 years) }\end{array}$ & $\begin{array}{c}0 \\
\text { (101-160 years) }\end{array}$ & $\begin{array}{c}\text { vo } \\
\text { (>160 years) }\end{array}$ & mean \\
\hline F11 & & & 0.33n.s. & $0.40+$ & $0.37 n . s$. \\
\hline F12 & & $0.66+++$ & $0.49++$ & $0.64+++$ & $0.60+++$ \\
\hline F13 & & $0.69+++$ & $0.78+++$ & $0.82+++$ & $0.76+++$ \\
\hline F1 & & $0.58+++$ & $0.56++$ & $0.65+++$ & $0.61+++$ \\
\hline F21 & 0.4 & $0.48++$ & $0.61+++$ & $0.63+++$ & $0.58++$ \\
\hline F22 & & $0.40+$ & $0.70+++$ & $0.71+++$ & $0.69+++$ \\
\hline F23 & & $0.77+++$ & $0.85+++$ & $0.86+++$ & $0.84+++$ \\
\hline F2 & $0.53++$ & $0.74+++$ & $0.82+++$ & $0.82+++$ & $0.81+++$ \\
\hline F31 & & $0.68+++$ & $0.64+++$ & $0.73+++$ & $0.74+++$ \\
\hline F32 & & 0.27 n.s. & $0.75+++$ & $0.59+++$ & $0.58++$ \\
\hline
\end{tabular}




\begin{tabular}{|c|c|c|c|c|c|}
\hline F33 & $0.52++$ & $0.65+++$ & $0.53++$ & $0.61+++$ & $0.60+++$ \\
\hline F3 & $0.69+++$ & $0.68+++$ & $0.77+++$ & $0.76+++$ & $0.75+++$ \\
\hline F41 & -0.03n.s. & -0.23 n.s. & -0.11 n.s. & 0.03n.s. & -0.08 n.s. \\
\hline F42 & $0.73+++$ & $0.73+++$ & $0.76+++$ & $0.72+++$ & $0.75+++$ \\
\hline F43 & $0.50++$ & $0.55++$ & $0.57++$ & $0.62+++$ & $0.57++$ \\
\hline F4 & $0.58++$ & $0.70+++$ & $0.64+++$ & $0.69+++$ & $0.66+++$ \\
\hline G11 & $0.64+++$ & $0.61+++$ & $0.68+++$ & $0.60+++$ & $0.70+++$ \\
\hline G12 & $0.66+++$ & $0.67+++$ & $0.64+++$ & $0.47++$ & $0.66+++$ \\
\hline G13 & & -0.20 n.s. & $0.54++$ & $0.55++$ & $0.42+$ \\
\hline G1 & $0.67+++$ & $0.54++$ & $0.69+++$ & $0.63+++$ & $0.66+++$ \\
\hline+++ & \multicolumn{5}{|c|}{ correlation highly significant ( $p<=0.01$ ), positive } \\
\hline++ & \multicolumn{5}{|c|}{ correlation significant $(p<=0.05)$, positive } \\
\hline+ & \multicolumn{5}{|c|}{ correlation marginally significant $(p<=0.1$ ), positive } \\
\hline n.s. & \multicolumn{5}{|c|}{ no significant correlation } \\
\hline
\end{tabular}




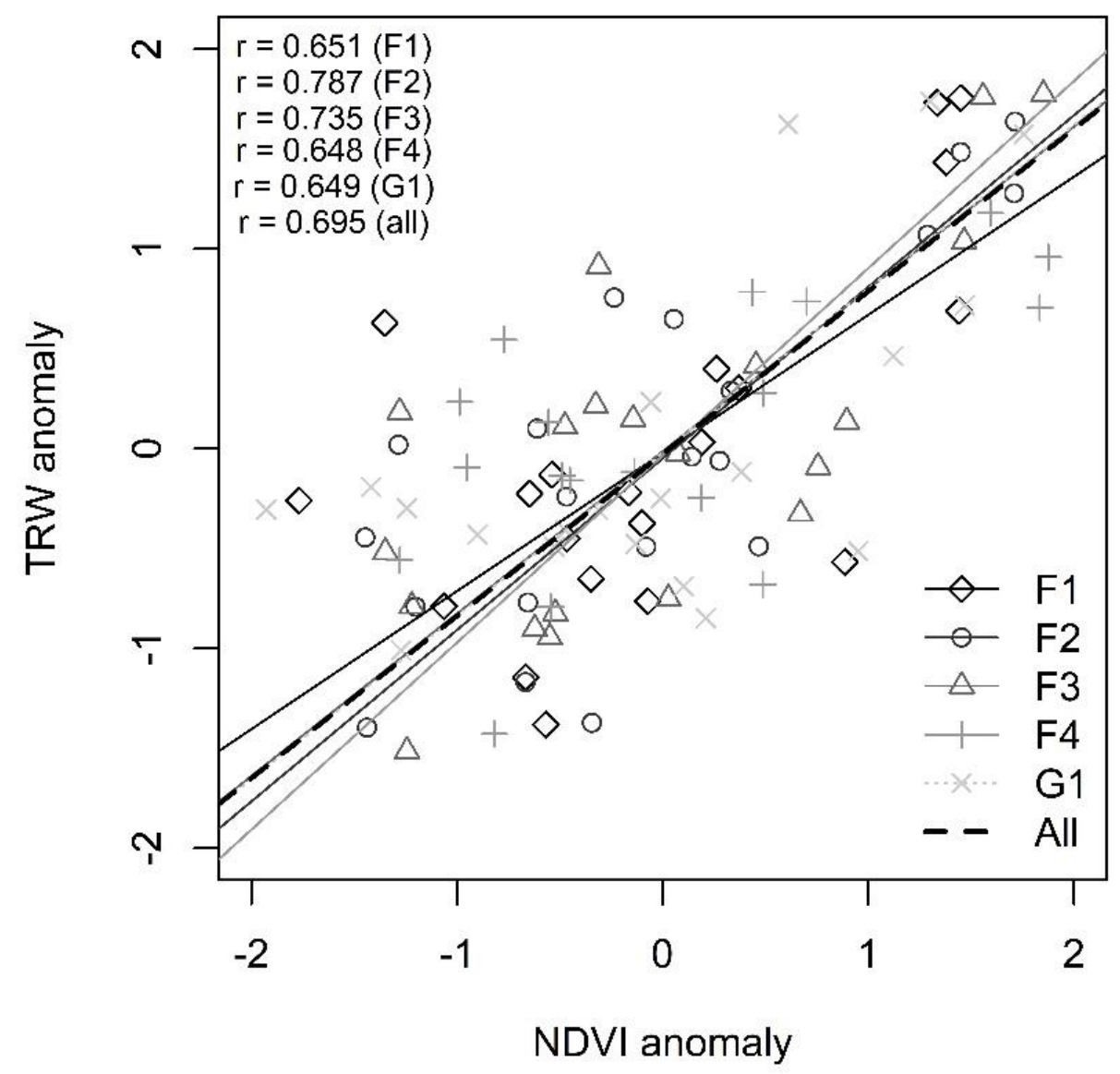

Figure 2.2.6: Relationship between standardized maximum-growing season NDVI anomalies (MGS-NDVIa) and standardized tree-ring width anomalies (TRWa) for different forest-patch size classes (grey lines) and overall correlation for all plot types (black dashed line). Reference period is 1995 to 2014.
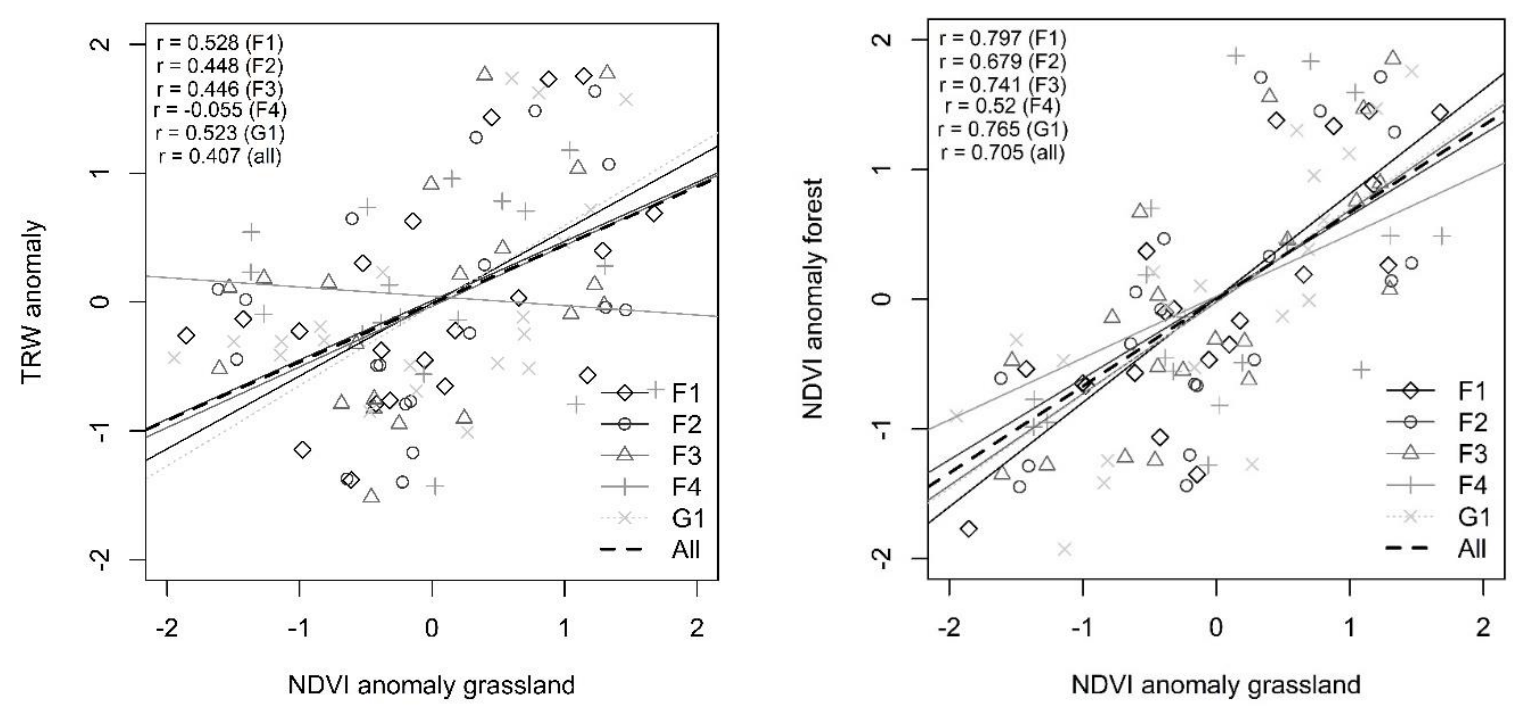

Figure 2.2.7: Relationship between standardized maximum-growing season NDVI anomalies (MGS-NDVIa) of grassland plots and standardized tree-ring width anomalies (TRWa) for 
corresponding forest-patches (a) and relationship between MGS-NDVla of forest patch and corresponding grassland plots (b) for different patch size classes (grey lines) and the overall correlation (black dashed line). Reference period is 1995 to 2014Grassland NDVI as a proxy for tree productivity.

\subsubsection{Grassland NDVI as a proxy for tree productivity}

With regard to the hypothesis that steppe-grassland NDVI can be used as a proxy for forest NDVI in the assessment of anomalies and trends in forest productivity, significant correlation between MGS-NDVI ${ }_{a}$ of the steppe and $\mathrm{TRW}_{\mathrm{a}}$ could be found for all patch-size classes except F4 (Table 2.2.3, Figure 2.2.7a). However, the significance levels were generally lower compared to the use of forest NDVI. In many cases, at patch class level and at plot level, no significant relation was observed. The largest forest patches (F4) showed weak correlations and no significance at all. Accordingly, the correlation analysis between grassland and forest MGS-NDVI $l_{a}$ revealed highly statistically significant relations $(p<=0.01)$ at all forest-patch size classes except for F4 ( $p<=0.05$ ) (Figure 2.2.7b). Here again, the slopes of the linear regression functions for the patch-size classes (F1-F3, G1) are not statistically different, whereas MGS-NDVI ${ }_{a}$ and $\mathrm{TWR}_{\mathrm{a}}$ of the largest patch size class $\mathrm{F} 4$ are completely uncorrelated.

A closer look at the temporal signatures of grassland and forest NDVI anomalies (Figure 2.2.8) confirms the generally uniform behaviour of the two time series for small forest patches ( $F 1$, G1). However, it can also be seen that the general response of forest NDVI in some years is different from grassland NDVI, especially in large forest patches and their surroundings (F4). The large discrepancies between forest and steppe NDVI anomalies become obvious, especially in drought years, which is exemplarily shown in Figure 2.2.9. 
Table 2.2.3: Results of the correlation analysis between standardized maximum growing season NDVI anomalies (MGS-NDVIa) and standardized anomalies of the tree-ring width (TRWa) for different forest-patch size classes and tree age classes. NDVI anomalies refer to the corresponding grassland plot at the forest border of the respective patch.

tree age class

\begin{tabular}{|c|c|c|c|c|c|}
\hline $\begin{array}{l}\text { patch size } \\
\text { class / plot }\end{array}$ & ( $\leq 60$ years) & $\begin{array}{c}\mathbf{M} \\
\text { (61-100 years) } \\
\end{array}$ & $\begin{array}{c}0 \\
\text { (101-160 years) }\end{array}$ & $\begin{array}{c}\text { vo } \\
(>160 \text { years })\end{array}$ & mean \\
\hline F11 & & & $0.41+$ & $0.47++$ & $0.45++$ \\
\hline F12 & & $0.48++$ & 0.31n.s. & $0.49++$ & $0.44+$ \\
\hline F13 & & $0.44+$ & $0.51++$ & $0.58+++$ & $0.51++$ \\
\hline F1 & & $0.48++$ & $0.47++$ & $0.57+++$ & $0.52++$ \\
\hline F21 & & 0.04n.s. & 0.16 n.s. & 0.22 n.s. & 0.15 n.s. \\
\hline F22 & & 0.18n.s. & $0.48++$ & $0.49++$ & $0.45+$ \\
\hline F23 & & $0.46+$ & $0.58++$ & $0.59++$ & $0.55++$ \\
\hline F2 & 0.23n.s. & 0.39n.s. & $0.53++$ & $0.56++$ & $0.51++$ \\
\hline F31 & 0.61 & $0.66+++$ & $0.46++$ & $0.46++$ & $0.58+++$ \\
\hline F32 & & 0.37n.s. & $0.55++$ & $0.43+$ & $0.43+$ \\
\hline F33 & $0.19 n . s$. & 0.39n.s. & 0.30n.s. & 0.20n.s. & 0.28n.s. \\
\hline F3 & $0.46+$ & $0.43+$ & $0.51++$ & $0.46+$ & $0.48++$ \\
\hline F41 & $-0.23 n . s$ & -0.02 n.s. & -0.24 n.s. & -0.29 n.s. & $-0.23 n . s$ \\
\hline F42 & $0.12 \mathrm{n} . \mathrm{s}$. & 0.09n.s. & 0.13 n.s. & 0.18 n.s. & 0.12 n.s. \\
\hline F43 & -0.15 n.s. & $-0.16 n . s$ & -0.01 n.s. & $-0.13 n . s$ & $-0.13 n . s$ \\
\hline F4 & $-0.15 n . s$. & -0.08 n.s. & $-0.13 n . s$ & $-0.18 n . s$ & $-0.14 n . s$ \\
\hline G11 & $0.43+$ & $0.42+$ & $0.53++$ & $0.45++$ & $0.50++$ \\
\hline G12 & $0.69+++$ & $0.64+++$ & $0.55++$ & $0.41+$ & $0.61+++$ \\
\hline G13 & & -0.35 n.s. & 0.31n.s. & 0.37n.s. & 0.19n.s. \\
\hline G1 & $0.59+++$ & $0.43+$ & $0.54++$ & $0.47++$ & $0.53++$ \\
\hline
\end{tabular}



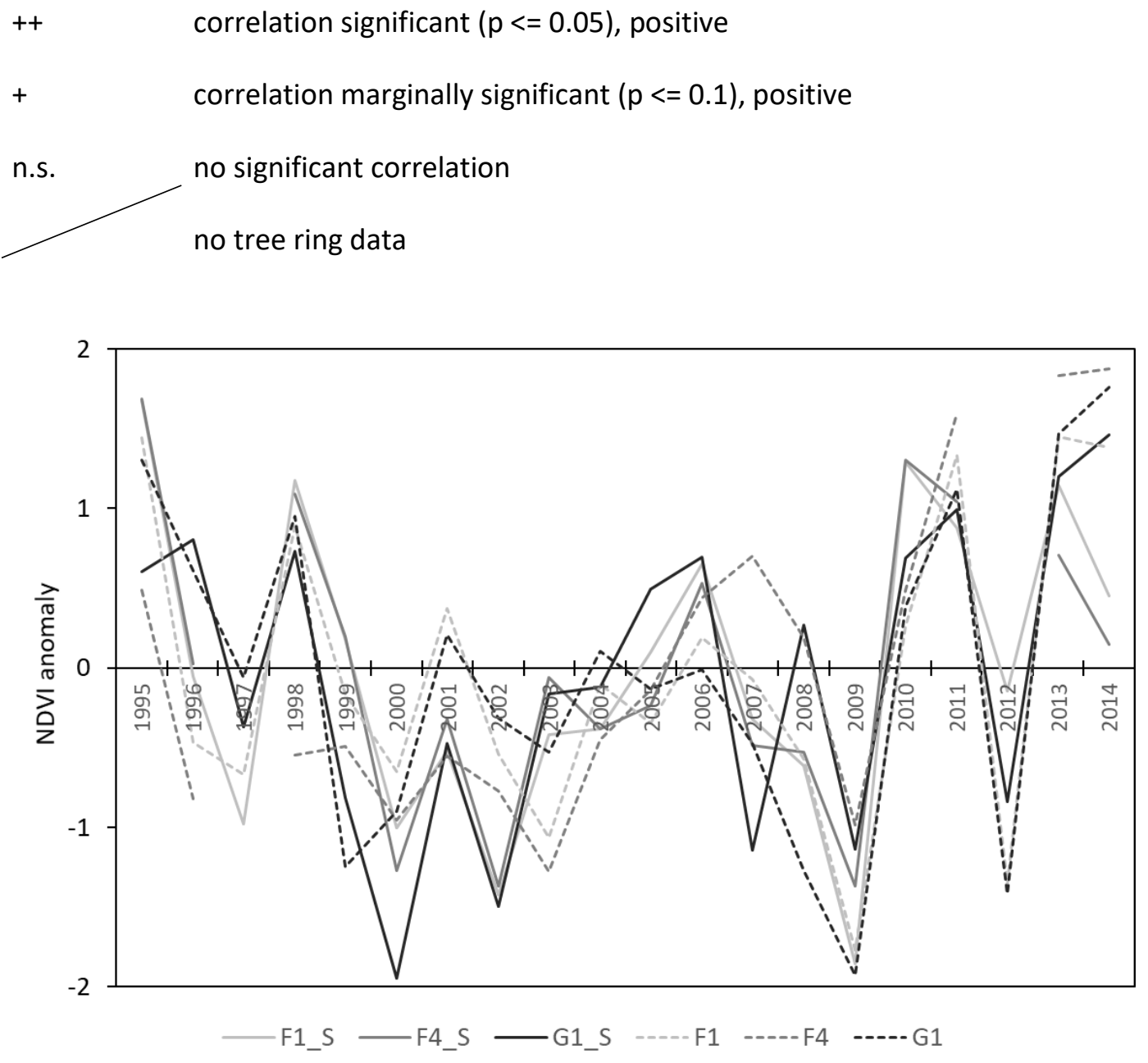

Figure 2.2.8: Standardized maximum-growing season NDVI anomalies (MGS-NDVIa) for forest-patch size classes (F1, F4, G1) compared to corresponding steppe plots (F1_S, F4_S, G1_S) (reference period 1995 to 2014). 


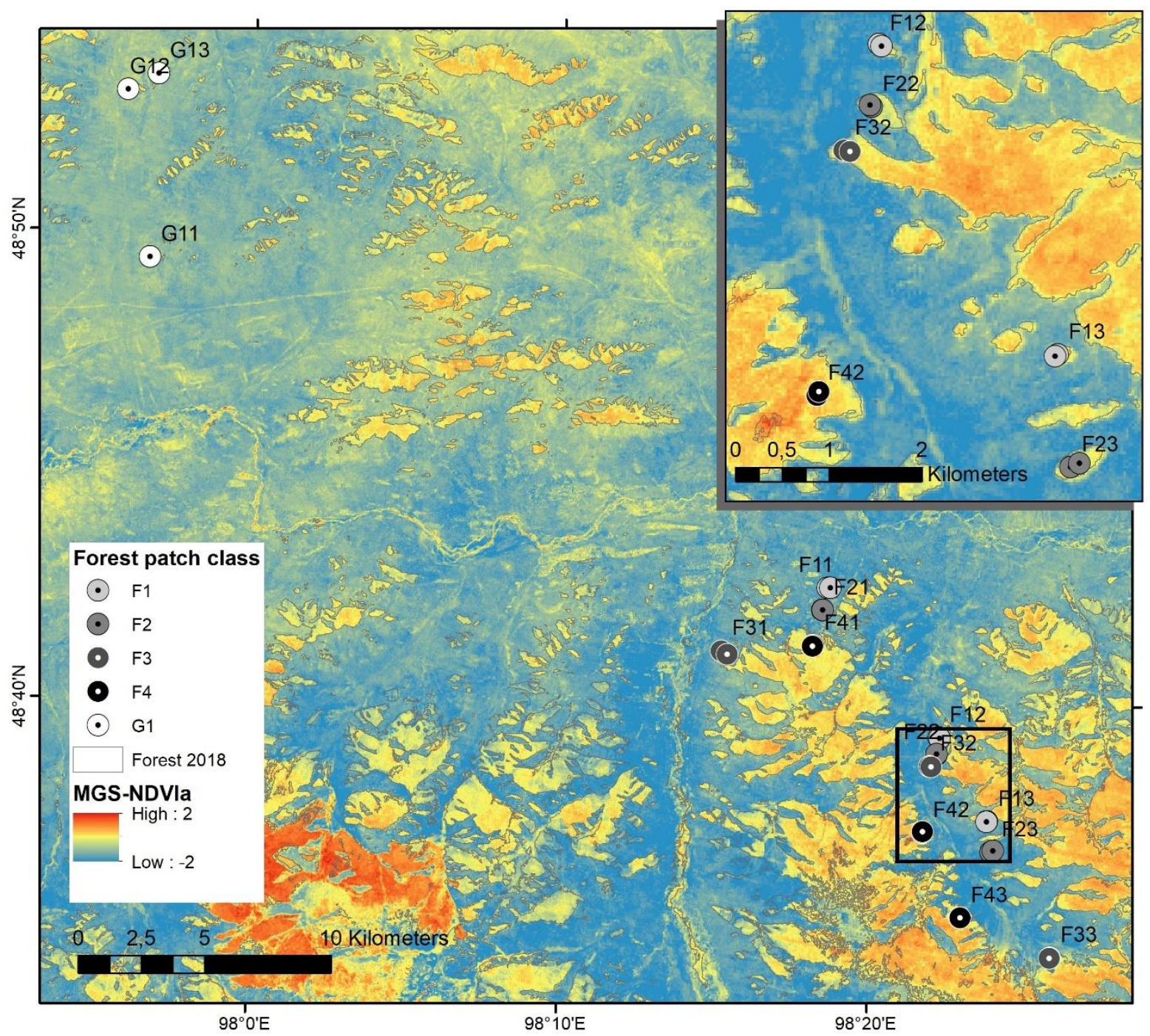

Figure 2.2.9: Spatial patterns of standardized anomalies of maximum growing season NDVI (MGS-NDVIa) for the year 2002. Outline shows the extend of forest patches, dots illustrate the location of the sample plots for the different forest patch classes.

\subsubsection{Discussion}

We used a compilation of dendrochronological records from 15 plots of Siberian larch in the southern boreal forests of Mongolia together with a dense time series of Landsat satellite images for 20 years to investigate the relations between annual radial stem increment and maximum NDVI composites of the growing season. The study concept followed the evidence from previous literature about the general similarity of temporal patterns from NDVI as an indicator of vegetation greenness and tree-ring width (TRW) as a proxy of biomass accumulation. Hence, both signals represent the vegetation vitality and can indicate variations 
in forest productivity (D'Arrigo et al. 2000a; Kaufmann et al. 2004). Our results confirmed the correlations of NDVI to annual variations in climate during the growing season and thus TRW for the mountainous forests in the study area.

The seasonal maximum of vegetation greening in terms of NDVI is closely linked to the precipitation in the summertime (most frequently in June) of the corresponding year of observation. Late summer and spring rainfall did not affect the maximum growing season NDVI. This is in accordance with other studies (Kaufmann et al. 2004; Bumann 2017) that also reported a close relation of growing-season precipitation to the maximum of NDVI. On the other hand, He and Shao (2006) did not reveal any significant relations for Qilian juniper stands in central China. In comparison to the NDVI-precipitation relationship, Khansaritoreh et al. (2017b) pointed out that the TRW-precipitation relationship is more correlated by applying a one-year time lag between summer precipitation and TRW. Nevertheless, like other authors, they found significant precipitation-TRW relationships for both the current and previous year summer months (Bumann 2017; Khansaritoreh et al. 2017b). In accordance with these findings, we could show both a relation between NDVI and precipitation of the same year as well as a weaker but still significant relation for NDVI and previous year July precipitation.

In opposite to our finding of significant correlation of data from the same year, Wang et al. (2004) reported a one-year lag in the correlation between NDVI and TRW for oak forests in North America. The maximum growing season NDVI was found to be a valuable indicator of tree productivity whereas the sizes of the forest patches and the landscape type (grassland vs. forest dominated landscapes) did not have an impact on the NDVI-TRW relationship. The General relationship between NDVI and TRW was reported by other authors, too (Coops et al. 1999; He and Shao 2006; Bumann 2017). Further, Khansaritoreh et al. (2017b) found that TRW in small forests compared to larger forests correlated more with climatic variability, suggesting that small stands show a higher variability also in NDVI. Indeed, small stands showed higher amplitudes of NDVI over the observed time period in both forest-dominated and 
grassland-dominated forest-steppe areas (Figure 2.2.4). Dulamsuren et al. (2019a) reported that the humus content of the organic layer, which improves the moisture availability, increased simultaneously with forest stand size. In addition, Klinge et al. (2021) have shown that permafrost is promoted by a thick organic layer and permafrost is mostly absent in small forest stands. The authors stated that permafrost supports soil-moisture conditions, which influences tree growth in the forest-steppe. This geoecological factor decreases drought stress in large forest stands, whereas small fragmented forest patches are subjected more to climate variability. Nevertheless, this increased climate sensitivity of TRW and NDVI in small forest stands did not obliterate the general correlation between the two variables across all studied forest stands.

Due to data quality issues and availability in the early years of Landsat $5 \mathrm{TM}$, the time series in our study had to be reduced from 31 to 20 years of overlapping dendrochronological records and annual NDVI composites. This is in line with the majority of comparable studies that investigated the sensitivity of NDVI time series to tree productivity based on dendrochronology (D'Arrigo et al. 2000a; Kaufmann et al. 2004; Wang et al. 2004; Bunn et al. 2013; VicenteSerrano et al. 2016; Brehaut and Danby 2018). The major drawback of the Landsat based studies is that they were solely based on single acquisitions that represent a full growing season (Coops et al. 1999) or on data from a single sensor, e.g. Landsat 5 TM (Bumann 2017). This constraint and also the usage of pre-composited products limited the proper delineation of the maximum of growing season NDVI in the earlier studies. Kaufmann et al. (2004) underlined that only the summer peak in NDVI represents the physiological status of the forest stand. Thus, the approach in the present study used the full archive of Landsat data for the delineation of the seasonal maximum NDVI as a proxy for tree productivity. The highly significant results of the correlation analysis confirmed the adequacy of this approach. However, the mentioned issues in the MVC processing for the first ten years of the time series also reveal the still existing challenges for long time series of satellite data. Bunn et al. (2013) pointed to the fact that despite the major progress in satellite-time series availability and 
processing, the major restriction of satellite-time series for monitoring tree physiology parameters still is the relatively short record compared to the variation of tree growth at decadal or even multi-decadal time scales. Despite this fact, the present study underlines the indisputable value of high-resolution dense time series for monitoring and retrospective modelling of tree productivity.

A major issue in the NDVI-TRW analysis in highly fragmented forest landscapes is that the forest patch size cannot always be covered and depicted accurately by the spatial resolution of the available satellite-time series. This is why in previous studies, grassland NDVI time series have been used as a proxy to monitor temporal variations in tree productivity (Wang et al. 2004; He and Shao 2006; Bumann 2017). This principle builds on the assumption that forests and grasslands grow under similar climatic conditions and presumes a similar response of different vegetation-cover types on variations in those climate conditions ( $\mathrm{He}$ and Shao 2006). In this case, forest NDVI can be replaced by grassland NDVI in modelling productivity. In our study, we generally confirmed the overall significant relation between grassland and forest NDVI over the investigated time period. However, in some years, the overall spatial patterns of NDVI and thus TRW standardized anomalies show opposed responses of grassland and forest patches to climate conditions. E.g., for the year 2002, we observed strong negative anomalies for steppe-grassland areas whereas the forest areas showed no deviation to the long-term mean (Figure 2.2.9). This year was at the end of a long, severe drought with very low summer rainfall in the Khangai Mountains (compare Figure 2.2.2). Thus, the results support the hypothesis that forests are better adapted to changing climate compared to grassland areas and that undisturbed, large forest patches show a higher resilience to climate extremes compared to small, highly fragmented forest sites. For the specific site conditions in our study area, this can be linked to various environmental factors where the most obvious one is the strong association of forest occurrence with topography. Forest patches are mainly present on north-facing slopes where evapotranspiration is reduced compared to south-facing slopes, resulting in higher soil water availability and relative humidity that support tree growth 
(Klinge et al. 2018). During drought periods, soils in the forested areas are favoured by canopy shading and are able to maintain necessary hydrological conditions over longer periods. The higher resilience of large forest patches compared to small patches in the study area is also associated to the permafrost distribution that modifies the soil hydrological regime in larger, closed forest stands (Klinge et al. 2018; Klinge et al. 2021). Here, seasonal ice above the permafrost layer can compensate the deficiency in drought years by accumulating soil water in moist years and releasing water to the tree roots in dry and warm periods (Sugimoto et al. 2002). Summarizing, the analysis of the grassland NDVI-TRW relationship shows a potential for monitoring tree productivity in highly fragmented grassland-steppe-forest landscapes. It also reveals that this relationship is not uniform but shows spatial and temporal inconsistencies that are a function of complex, site-specific ecological parameters and processes. Thereby, the availability of higher spatial resolution satellite time series as exemplified in this study is a prerequisite to separate those effects.

\subsubsection{Conclusions}

Seasonal composites of NDVI data from a 20-year multi-sensor Landsat time series were tested for correlations with dendrochronological tree ring growth of Siberian larch in the southern boreal forests of northern Mongolia. The analysis concept was based on the hypothesis that the general vegetation greenness is correlated with ecosystem productivity and thus productivity can be captured by satellite-based vegetation indices like the NDVI. Our results confirmed the general ability of NDVI time series to capture anomalies in forest productivity. We could also demonstrate that the nature of the relation between the NDVI signal and tree ring width is comparable for different forest types (e.g., age, patch size, forest-steppe ratio). However, our analysis revealed that the NDVI of grasslands is less suitable as a proxy to monitor forest productivity due to the different response patterns of grasslands and forests to climate conditions. Our study should therefore contribute to a better understanding of longterm dynamics in forest-steppe ecosystems and their relation to climate change. Overall, the 
observed patterns and relations between satellite data time series and dendrochronological records form the basis for a retrospective modelling of tree ring growth over larger areas and thus may provide a key parameter for global climate change and terrestrial carbon cycle studies as well as for the calibration of global carbon models. 


\subsection{Siberian larch (Larix sibirica Ledeb.) forests in a changing environment- a systematic review}

Florian Schneider ${ }^{1}$, Michael Klinge ${ }^{1}$, Daniela Sauer ${ }^{1}$

${ }^{1}$ Physical Geography, Institute of Geography, University of Göttingen, Goldschmidtstraße 5, 37077 Göttingen, Germany

- Manuscript unpublished

\section{Author contributions:}

Florian Schneider wrote the manuscript with contributions from all authors. Michael Klinge designed the maps with contributions from Florian Schneider.

Keywords: Siberian larch, forest-steppe, climate change, drought, human impact, permafrost, fire, central Asia 


\section{Abstract}

Siberian larch (Larix sibirica) is a stand-building tree species in the eastern Siberian taiga and central Asian forest-steppe. However, climate warming, extensive forest fires, and human impact have considerably reduced the area occupied by Siberian larch forests in central Asia over the past decades. The Mongolian forest-steppe may serve as an example of an ecotone, where Siberian larch forests are at the dry edge of their distribution area, and are particularly suffering from climate change, logging and pastoral pressure. Thereby, some Siberian larch forests respond more sensitively then others. In order to understand the reasons for these differences, we reviewed existing literature for the current knowledge on the influence of various ecological factors on Larix sibirica. Based on this review, we point to existing knowledge gaps, the probable development of Siberian larch forests under climate change and human impact, as well as possible measures.

Our review focuses on the geoecological requirements of Siberian larch and on the influence of insolation, water supply, soil conditions, fire and biotic factors. This knowledge is essential for understanding the differentiated response of Siberian larch forests to environmental changes. Enhanced drought stress is a well-documented threat for Siberian larch in southern Siberia and the central Asian forest-steppe. Climate warming will progressively lead to intensification of droughts and, thus, reduce the vitality and extent of Siberian larch forests. Most likely, steppe vegetation will replace many larch-forest stands in the forest-steppe, if the ongoing environmental changes, especially the thawing of permafrost, will continue with the predicted intensity. Furthermore, increased logging and pasture have reduced tree regrowth after forest disturbance, and have enhanced the sensitiveness of larch forests to environmental changes. As a result, the larch-forest area in central Asia has already decreased.

The outcomes of this review stress the importance of forest management in the forest-steppe, especially in areas where forests are already at risk because of climate change. Without improved forest management in the Mongolian forest-steppe, its forest stands that are mainly composed of Siberian larch, will continue to decrease dramatically.

\subsubsection{Introduction}

Larch trees are mainly distributed in the boreal zone of Eurasia and North America. They contribute to mixed forests and dominate ecozones with harsh conditions such as the eastern Siberian taiga and the central Asian forest-steppe, whereby the latter represents the transitional zone between boreal forest and steppe (Abaimov 2010). Due to this transitional character, the forest-steppe ecotone in Mongolia, where forest patches are usually dominated by Siberian larch (Larix sibirica Ledeb.) is highly prone to environmental change. The sensitivity of larch forests to climate change and human impact is thereby influenced by the geoecological factors that determine the site-specific growth conditions. Hansen et al. (2013) reported a forest loss of $13.5 \%$ for Mongolia between 2000 and 2012, which is much higher than the global 
forest loss that amounted to about 3 \% from 1990 to 2015 (Keenan et al. 2015). Thereby, climate change is currently leading to increased tree mortality almost worldwide (Allen et al. 2010). Furthermore, fires, insect infestations and human impact often cause disturbances that contribute to global forest decline (van Lierop et al. 2015).

Around $35 \%$ of the Russian and more than $75 \%$ of the Mongolian forests are made up of pure or mixed larch stands (Abaimov et al. 1998; Tsogtbaatar 2013). Especially in Mongolia, but also in Russia, Siberian larch is of considerable economic importance. There is a high demand for larch timber because of its weathering resistance (Maksis and Haruk 2002; Venäläinen et al. 2006). The average carbon stock density of a Larix sibirica (L. sibirica) forest in Mongolia amounts to $215 \mathrm{Mg} \mathrm{C}$ ha $^{-1}$ with an mean aboveground tree biomass of $134 \mathrm{Mg} \mathrm{C}^{-1}$ and a trunk growth of 2-8 $\mathrm{m}^{3} \mathrm{ha}^{-1} \mathrm{y}^{-1}$ (Danilin and Tsogt 2014; Dulamsuren et al. 2016). These amounts are above of those of eastern Siberian Larix gmelinii (L. gmelinii) and Larix cajanderi (L. cajanderi) forests (Kajimoto et al. 2006). Thus, sustainable management of L. sibirica forests is not only an important measure against climate warming (Ripple et al. 2019) but provides also economic benefits.

It is important to understand the ecological requirements of L. sibirica in order to implement an appropriate forest management and prevent major losses of Siberian larch forests in central Asia. Thus, the aim of this review is, firstly, to provide a comprehensive state-of-the-art knowledge on the requirements of $L$. sibirica and, secondly, to assess the effects of the following factors on the growth of Siberian larch: insolation, water supply, soil conditions, fire, biotic environment, and climate change (comp. Figure 2.3.1), as we suppose that the combined effects of these factors are the key to identify present and future threats for L. sibirica. 


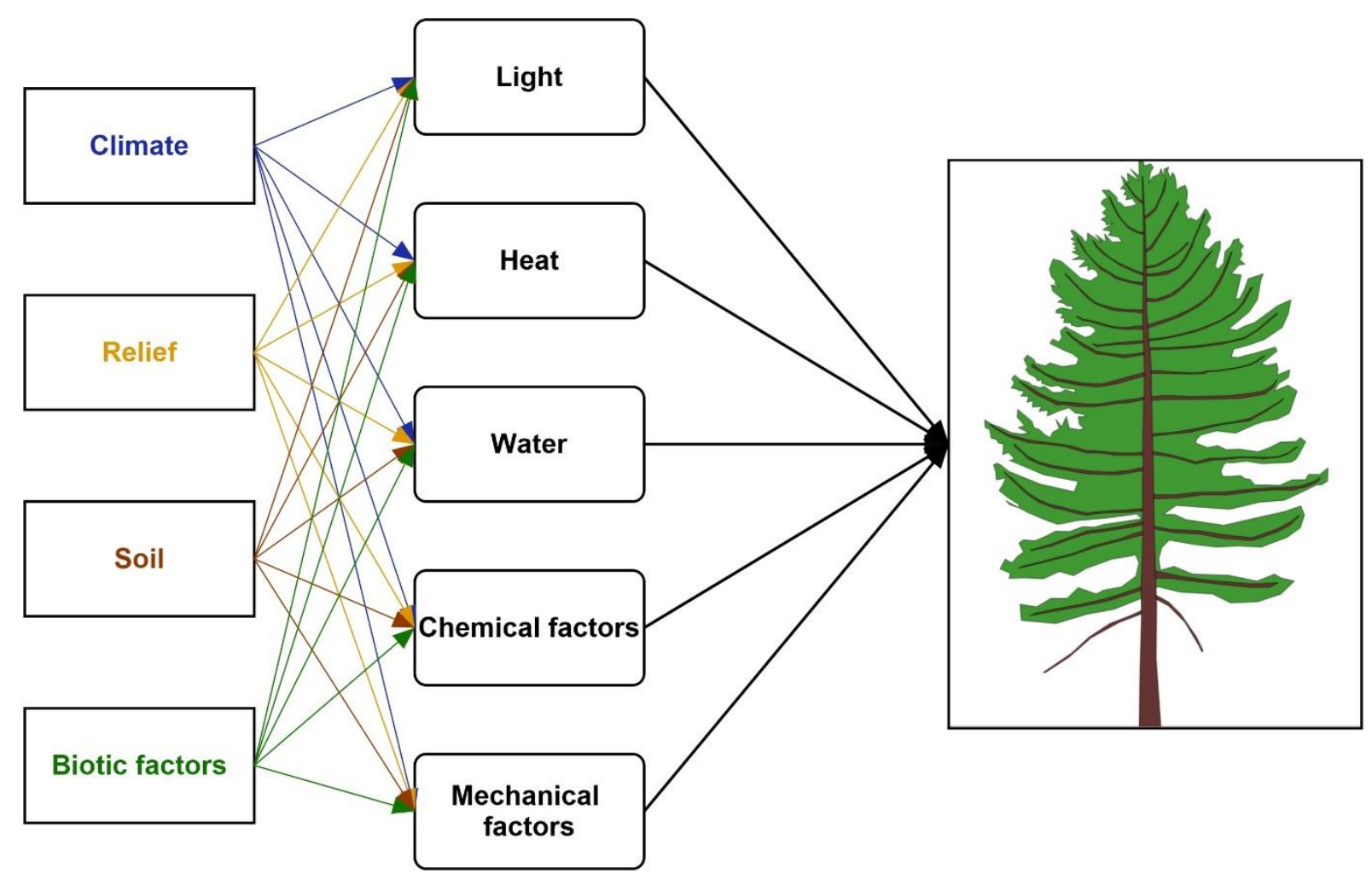

Figure 2.3.1: Scheme of the environmental factors affecting Larix sibirica, after Glaser et al. (2017).

\subsubsection{Spatial distribution and ecophysiological characteristics of Larix sibirica}

Various larch species occur in different ecozones of Eurasia, as illustrated in Figure 2.3.2 for north and central Asia. The distribution area of L. sibirica extends from the taiga-tundra transition in north-central Siberia into the central Asian forest-steppe. In the taiga, L. sibirica only contributes subordinately to various forest communities, whereas it is the dominant tree species of the forest-steppe. Other larch species occur further west- and eastwards, partly in mixed forests and partly as dominating trees. 


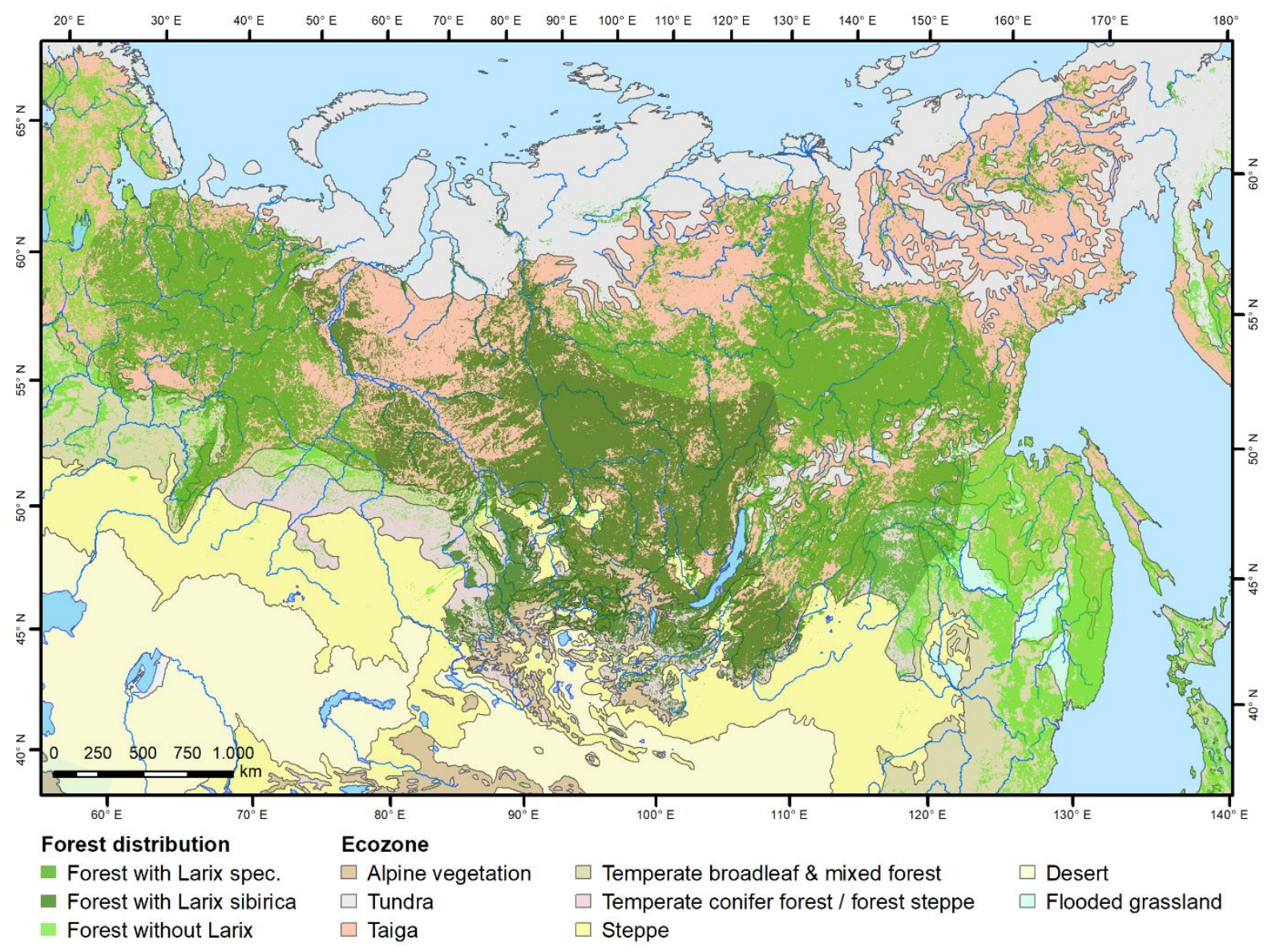

Figure 2.3.2: Spatial distribution of various forest types with and without larch (Abaimov et al. 1998) in Eurasia (Davis and Holmgren 2000; Hansen et al. 2013) and adjacent ecozones (Walter and Breckle 1999; Tchebakova et al. 2009a; Dinerstein et al. 2017; Klinge et al. 2018; Klinge and Sauer 2019).

Siberian larch persists under harsh conditions, both near the latitudinal and the altitudinal tree line. Plantations in Scandinavia and on Iceland proved its cold hardiness (Bjarnadottir et al. 2007; Lukkarinen et al. 2010). Siberian larch is classified as frost resistant (Abaimov et al. 1998), drought tolerant (Karaseva et al. 2003; Pavlov and Mironov 2003), fire tolerant (Kharuk et al. 2011), light demanding and fast growing (Abaimov et al. 1998; Abaimov 2010). L. sibirica has a higher potential growth rate, and larger needles and seeds than L. gmelinii and $L$. cajanderi, which are also widespread in Siberia (Table 2.3.1). The photosynthetic rates of larch needles are up to twice as high as those of evergreen conifers. Larch trees invest less mass to build up the same leaf surface as evergreen conifers do (Gower and Richards 1990). $L$. sibirica is supposed to reach the highest biomass production at a mean day temperature of 16 ${ }^{\circ} \mathrm{C}$ and a precipitation of 2.3-2.5 mm per day (Antonova and Stasova 1997). Kapper (1954) 
assumed a mean monthly temperature of $11.5-13.5^{\circ} \mathrm{C}$ from May until September and 300 $400 \mathrm{~mm}$ precipitation over this period as optimal climatic conditions. Siberian larch is also able to grow in regions, where the growing season is extremely short, for example 65-80 days at the northern treeline (Abaimov et al. 1998). Its cambial activity already starts when the daily mean air temperature reaches $6-8^{\circ} \mathrm{C}$ and the upper $20 \mathrm{~cm}$ of the soil have been thawed for a 10 days period (Kalinina et al. 2019). Gavrilova (1996) detected the end of root growth during autumn, when the temperature of the uppermost $20 \mathrm{~cm}$ soil dropped below $+5^{\circ} \mathrm{C}$.

Table 2.3.1: Morphological characteristics of Larix sibirica, Larix gmelinii and Larix cajanderi. Data from Abaimov et al. (1998).

\begin{tabular}{|c|c|c|c|}
\hline Properties Unit & Larix sibirica & Larix gmelinii & Larix cajanderi \\
\hline \multicolumn{4}{|l|}{ Tree } \\
\hline Height & $>40$ & $35-40$ & $35-40$ \\
\hline \multicolumn{4}{|l|}{ Needles } \\
\hline Length $\quad \mathrm{mm}$ & $5-600$ & Apr 42 & Jun 33 \\
\hline Needles per $n$ & Okt 50 & Aug 58 & Dez 59 \\
\hline \multicolumn{4}{|l|}{ Cones } \\
\hline Size (length mm & $10-50 / 10-50$ & $8-35 / 5-25$ & $9-25 / 10-28$ \\
\hline \multicolumn{4}{|l|}{ Seeds } \\
\hline Size (length mm & $5-17 / 5-17$ & $6-15 / 5-13$ & $6-17 / 5-15$ \\
\hline Seeds per cn & Sep 44 & Jul 30 & Okt 30 \\
\hline Weight per $g$ & 04. Okt & 01.05 .2005 & $1.1-6.5$ \\
\hline Germination \% & $24-73$ & $18-77$ & $45-81$ \\
\hline
\end{tabular}

Seed production of $L$. sibirica depends on the environmental conditions. In open areas, young trees start to produce seeds after 10-15 years, whereas in dense stands seed production starts after 25-30 years. At this stage, mast years occur every 4 to 5 years (Abaimov 2010). Germinability varies not only between species but also within a species (Table 2.3.1). In mountainous areas, germinability is lower due to the harsh climatic conditions (Barchenkov et al. 2012). Batkhuu et al. (2010) found a strong negative correlation of seed quality with altitude, which they interpreted as a result of increasingly unfavourable environmental conditions. In a greenhouse experiment, Lukkarinen et al. (2009) tested the growth of L. sibirica and L. gmelinii from seeds originating from various regions of Siberia. Under same conditions, the individuals from higher latitudes ended their annual growing period earlier, resulting in thin tree rings, 
whereas those from southern areas utilised the given greenhouse conditions more efficiently. The vertical and lateral development of the root system of larch trees depends on soil properties. Kapper (1954) reported a rooting depth of $150 \mathrm{~cm}$ and more for Siberian larch, whereas Albenskiy et al. (1956) measured larch roots reaching more than 2 meters depth in a Chernozem. In contrast, root development of larch on permafrost-affected soils proceeds dominantly lateral and can exceed several meters in width (Kajimoto et al. 2003; Kajimoto et al. 2007).

\subsubsection{Requirements of Larix sibirica with respect to temperature and light during the growing season}

Tree growth in Siberia is generally limited by decreasing temperature towards the north and by decreasing water supply towards the south (Furyaev et al., (2001). Growth of L. sibirica at the northern timberline is strongly related to temperature during the growing season as confirmed by several studies (Sudachkova et al. 2003; Hantemirov et al. 2008; Vaganov and Kirdyanov 2010). Gurskaya (2019) identified a development of poorly developed latewood, called light rings, in different larch species growing in northern Siberia. L. sibirica showed light rings with mean August temperatures below $9.5^{\circ} \mathrm{C}$ whereas L.gmelinii formed light rings below $7.7^{\circ} \mathrm{C}$ leading to a better adaptation of L.gmelinii to low temperatures. The dominance of $L$. sibirica over L.gmelinii in a certain area of northern Siberia might be caused by a higher sensitivity of the latter species to water availability (Sidorova et al. 2008; Sidorova et al. 2010). As an adaption mechanism to unfavourable conditions, Siberian larch is able to accumulate metabolic products in its stem and woody root tissue during favourable periods, which helps it to persist subsequent harsh climatic conditions (Sudachkova et al. 2003).

Also, in central and southern Siberia, summer temperature is a limiting factor for larch trees, but the importance of water limitation increases southward, whereby topographic position and soil properties modify water availability at a site (Velisevich and Kozlov 2006; Velisevich and Khutornoy 2009; James 2011; Kuznetsova and Kozlov 2011; Kalinina et al. 2019). Forests 
close to the upper treeline are mainly temperature-limited, as shown by several studies in the Altai Mountains, where higher summer temperatures at altitudes of $2000-2500 \mathrm{~m}$ a.s.l. led to enhanced tree growth (Bocharov 2009; Chen et al. 2012; Fonti et al. 2013; Dulamsuren et al. 2014; Taynik et al. 2016).

Steady temperature increase during spring has a positive effect on the reproduction of Siberian larch, which starts producing pollen when daily mean temperatures exceed $0{ }^{\circ} \mathrm{C}$. Frost events during pollen development lead to reduced pollen quality and thus, decreased seed production (Pavlov and Mironov 2003; Noskova and Romanova 2013).

Light is of fundamental importance for Siberian larch (Dylis 1947; Abaimov et al. 1998; Abaimov 2010). In several studies, Karaseva et al. (2003) observed a strong decline in the activity of $L$. sibirica subjected to light reduction, and total inactivity when the light was reduced below $10 \%$ of its approximate light demand. (Kapper 1954) found that pine and larch reached their maximum assimilation only with full sun light, whereas spruce and fir showed maximum assimilation already at $30 \%$ light (Table 2.3.2). Therefore, in the dark taiga, L. sibirica is outcompeted by other conifers such as Picea obovata, Abies sibirica and Pinus sibirica, which are the predominant tree species in the dark taiga. In contrast, the light taiga, with more open canopy, is dominated by larch and pine species (Dulamsuren et al. 2005). Furthermore, due to its ability to occupy also unfavourable sites, Siberian larch is able to grow at sites, where competition with other tree species is low, and thus enough light is available. 
Table 2.3.2: Influence of light intensity on carbon assimilation of four conifers (data from (Kapper 1954).

\begin{tabular}{llcc}
\hline \multicolumn{4}{c}{ Light intensity (in \% of full sunlight) } \\
& 1 & 30 & 100 \\
\hline & \multicolumn{4}{c}{ Carbon assimilation per gram of } \\
& \multicolumn{3}{c}{ green needles } \\
\hline Larch & -0.06 & 3.1 & 4.4 \\
Pine & -0.08 & 2.4 & 3.3 \\
Spruce & 0.06 & 1.6 & 1.7 \\
Fir & 0.13 & 3.4 & 2.6 \\
\hline
\end{tabular}

\subsubsection{Influence of water scarcity and droughts on Larix sibirica}

Plant stress due to lack of water is well-documented for boreal forests in North America (Peng et al. 2011; Ma et al. 2012), as well as for forest-steppe in South America (Villalba and Velben 1997). Similarly, water is a major limiting factor for the distribution of forest at the southern fringe of the Siberian taiga and in the forest-steppe of central Asia (Walter and Breckle 1999; Furyaev et al. 2001). Droughts are common in semiarid environments, including the foreststeppe of Mongolia (Davi et al. 2010). During droughts, sap flow is rather controlled by vapor pressure deficit than by water availability (Benkova et al. 2019). L. sibirica is adapted to dry environments and drought events through several mechanisms. It develops a high hydraulic conductivity that enables it to deal with porewater resistance under dry conditions and to absorb water efficiently after strong rainfall events (Chenlemuge et al. 2015b; Chenlemuge et al. 2015a). L. sibirica can adjust its tracheid diameters, tracheid density and hydraulic conductivity to the water supply at a site (Khansaritoreh et al. 2018). After exceptionally strong drought events, Siberian larch shows an extensive fine-root dieback. This has been interpreted as an adaption to minimize the risk of cavitation in coarse roots leading to increased tree mortality (Chenlemuge et al. 2013).

Nevertheless, lack of water leads to reduced tree-ring thickness of $L$. sibirica, as frequently shown by various studies in Mongolia, eastern Kazakhstan, southern Russia and northwestern China and it intensified during the last decades (Davi et al. 2006; Velisevich and 
Kozlov 2006; Velisevich and Khutornoy 2009; Dulamsuren et al. 2010a; Dulamsuren et al. 2010c; Dulamsuren et al. 2011; Kuznetsova and Kozlov 2011; Dulamsuren et al. 2013a; Kovylina et al. 2013a; Liu et al. 2013; Babushkina and Belokopytova 2014; Khishigjargal et al. 2014; Abramenko 2015; Chen et al. 2015; Chenlemuge et al. 2015b; Jiao et al. 2015; Fonti and Babushkina 2016; Babushkina et al. 2017; Khansaritoreh et al. 2017a). Similar relationships and trends, such as increased numbers of thin latewood formations during the last decades compared to the last 200 years, were observed for other tree species in central Asia including Abies fargesii, Abies spectabilis, Betula platyphylla, Betula utilis, Larix cajanderi, Larix gmelinii, Picea schrenkiana, Pinus tabulaeformis, Pinus sibirica, Pinus sylvestris, Populus davidiana and Ulmus pumilla (Rigling et al. 2001; Dulamsuren et al. 2009a; Velisevich and Khutornoy 2009; Grandpré et al. 2011; Liu et al. 2012; Liu et al. 2013; Tei et al. 2014; Fonti and Babushkina 2016; Müller et al. 2016; Gradel et al. 2017). Frequently recorded shoot water potentials close to zero turgor reflect the water deficit in soil of Mongolia (Dulamsuren et al. 2009c). Also, remote sensing data combined with climatological observations confirmed drought stress on trees, especially in the Mongolian forest-steppe (Poulter et al. 2013; Klinge et al. 2018). Lack of water causes the main limitation for L. sibirica and other tree species, except for mountain areas close to the upper treeline (Figure 2.3.3). 


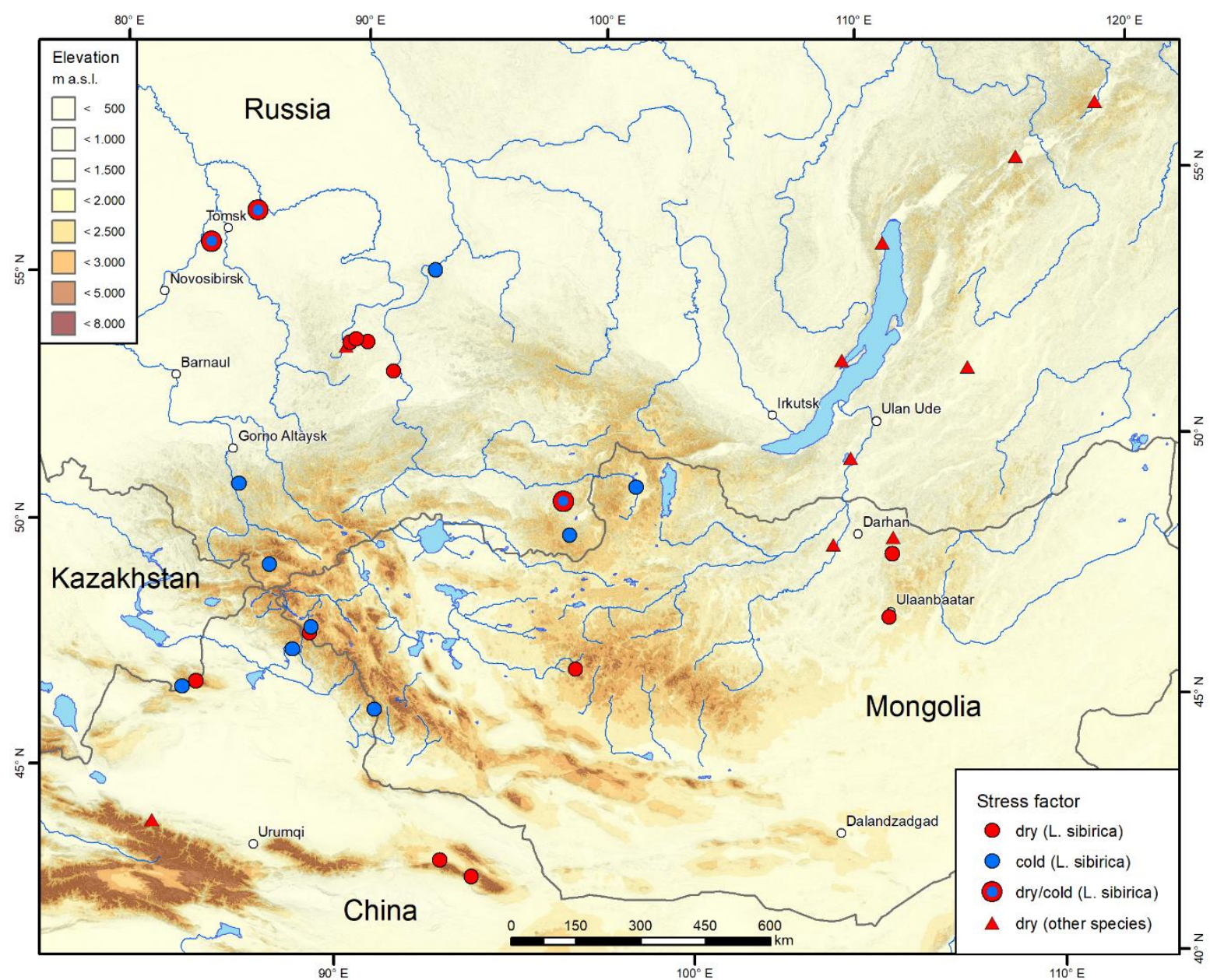

Figure 2.3.3: Spatial distribution of studies in central Asia, where main climatic stress factors for Larix sibirica and other tree species have been identified (including studies of (Rigling et al. 2001; Velisevich and Kozlov 2006; Bocharov 2009; Dulamsuren et al. 2009a; Velisevich and Khutornoy 2009; Dulamsuren et al. 2011; Grandpré et al. 2011; James 2011; Kuznetsova and Kozlov 2011; Chen et al. 2012; Dulamsuren et al. 2013a; Liu et al. 2013; Babushkina and Belokopytova 2014; Dulamsuren et al. 2014; Abramenko 2015; Chen et al. 2015; Chenlemuge et al. 2015b; Chenlemuge et al. 2015a; Jiao et al. 2015; Fonti and Babushkina 2016; Taynik et al. 2016; Babushkina et al. 2017; Gradel et al. 2017; Kalinina et al. 2019).

Forest fragmentation can enhance drought stress, as it causes disruption of the forest microclimate, leading to increased climate sensitivity of shrinking forest stands (Khansaritoreh et al. 2017b). During the last decades, the authors proved a significant increase of missing ring frequencies of $L$. sibirica stands which are smaller than $5 \mathrm{~km}^{2}$. Moreover, younger trees are more strongly affected than older ones due to their less developed root system (Dulamsuren et al. 2013a). This study showed that trees older than 120 years had higher radial growth rates compared to younger trees of the same stand. Thus, tree regrowth after disturbance is impeded in the absence of a forest microclimate. Also, further expansion of larch forest into 
steppe areas seems to be impossible under the actual climatic conditions (Dulamsuren and Hauck 2008). Similarly, lack of water hinders the establishment of seedlings of $L$. sibirica and Pinus sylvestris on sun-exposed slopes (Dulamsuren et al. 2008; Dulamsuren et al. 2013b).

Water stress also increases the vulnerability of $L$. sibirica to other impacts. Thus, an increase in water scarcity can either cause a reduction of the forest area or a replacement of larch by other species such as Pinus sylvestris, which can survive droughts by high shoot-water potential and low stomatal conductance (Dulamsuren et al. 2009b; Anenkhonov et al. 2015). This species is able to strongly reduce the $\mathrm{CO}_{2}$ assimilation leading to a minor dependence on soil moisture compared to $L$. sibirica. In contrast, birch species of the forest-steppe, such as Betula platyphylla and Betula pendula, have higher potential hydraulic conductivities, due to greater vessel diameters, leading to a higher vulnerability to cavitation compared to larch species and are thus not likely to replace larch under decreasing water availability (Gradel et al. 2017; Dulamsuren et al. 2019b).

\subsubsection{The roles of soil properties and permafrost}

\subsubsection{Soil chemistry}

In general, Siberian larch is able to grow on many different soils from all kinds of parent materials, including also nutrient-poor and juvenile soils (Dylis 1947); Timoshok et al., 2014). Larch forests are common on acidic soils but also produce thick tree rings on alkaline soils (Kovylina et al. 2013b). L. sibirica absorbs nutrients quantitatively in the order $\mathrm{Ca}>\mathrm{Mg}>\mathrm{N}>$ $\mathrm{K}>\mathrm{P}$ and is able to adapt to low nutrient supply by enhanced root development (Lebedev $2012,2013)$. In this case, it reduces the production of aboveground biomass for the benefit of belowground biomass to extract sufficient amounts of nutrients from the soil. Nevertheless, lack in nutrients can limit larch growth as well. In nutrient-poor soils at the taiga-tundra boundary, Liang et al. (2014) proved a positive correlation between the growth of L. gmelinii 
and nitrogen availability, and Lebedev (2010) showed that nitrogen fertilisation increased biomass production of $L$. sibirica in western Siberia, demonstrating that increased nutrient supply enhances larch productivity. The fertilisation with $\mathrm{P}$ and $\mathrm{K}$ improved the biomass production of about $20 \%$ whereas the fertilisation with $\mathrm{N}, \mathrm{P}$ and $\mathrm{K}$ lead to a increase of up to $75 \%$ compared to the control group. On the other hand, Carter (1980) reported a very low tolerance of $L$. sibirica to chloride salinity and a moderate tolerance to sulphate salinity. A sulphate salinity with an electrical conductivity of up to $8 \mathrm{mS} / \mathrm{cm}$ leads to a significant growth reduction but not to tree mortality. In contrast, a mixed salinity with chloride and sulphate of $9.2 \mathrm{mS} / \mathrm{cm}$ causes a mortality of $70 \%$. Therefore, soil salinity can even prevent larch species from occupying areas.

\subsubsection{Soil hydrology}

Under semi-arid climate conditions, soil moisture is an important factor for tree growth and reforestation potential (Anenkhonov et al. 2015; Bazha et al. 2016; Müller et al. 2016). Park et al. (2009) found a difference in topsoil moisture between forested areas and severely disturbed forests without tree regrowth of 5 to $7 \%$. Therefore, soil hydrology is particularly important for disturbed forests in the central Asian forest-steppe. Soil moisture is also the key for carbon fluxes in the Mongolian steppe as it limits the respiration of soils and grass vegetation (Sharkhuu et al. 2016). However, low hydraulic conductivity may lead to waterlogging what negatively affects the growth of $L$. sibirica (Velisevich and Kozlov 2006; Kuznetsova and Kozlov 2011).

Larch trees do not grow on permanently waterlogged soils. An oversupply of soil water, e.g., due to relief position and dense subsoil horizons reduces tree growth leading to negative correlation of tree ring width with precipitation under semi-arid conditions (Kuznetsova and Kozlov 2011; Chen et al. 2012; Abramenko 2015). L. sibirica and L. gmelinii are not adapted to anoxic soil conditions which promotes reduced root activity and tree growth (Sudachkova et 
al. 2003; Miyahara et al. 2011). They produce predominantly horizonal root systems where volumetric soil water content exceeds $25 \%$ or groundwater table occur (Abaimov et al. 1998; Takenaka et al. 2016). In the tundra-taiga transition zone, L. gmelinii occupies mounds, where the distance to the water table is somewhat increased (Liang et al. 2014). In eastern Siberian forests, L. cajanderi suffers from waterlogging caused by thawing permafrost (lijima et al. 2014). Ohta et al. (2014) reported that waterlogging in eastern Siberian larch forests led to a reduction of living trees of about $15 \%$ from 1998 to 2011.

In Russia, soil properties of the forested areas are well-documented (Stolbovoi 2000). The potential distribution of Siberian larch in the taiga can therefore be analysed and managed based on the given information. In contrast, soil properties of the Mongolian the forest-steppe have been less investigated. Several studies have been conducted in the mountain and steppe areas, providing a certain understanding of the site conditions. (Haase 1963; Sommer 2000; Krasnoshchekov 2008, 2010; Sympilova and Gyninova 2012; Wecking 2017; Undarmaa et al. 2018). Haase (1963) and Krasnoshchekov (2010) investigated physical and chemical soil properties in the Khangai mountains, Mongolia. Krasnoshchekov (2008), Sympilova and Gyninova (2012) and Undarmaa et al. (2018) analysed soils in other mountain regions and steppe areas using similar methods. However, a lack of information exists, especially with respect to soil-hydrological properties and theirs connection to the vegetation pattern. Sommer (2000) and Wecking (2017) connected soil properties and vegetation patterns in the TurgenCharchiraa mountains and the Khentey mountains. Beside soil properties, climate conditions and human impact appeared to dominantly influence the forest structure and distribution.

\subsubsection{Permafrost}

Since the permafrost table is impermeable, in early summer, soil water flows down above the permafrost table and accumulates in flat positions or valley bottoms. Bonan and Shugart (1989) defined a mean annual air temperature (MAAT) of $-6.7^{\circ} \mathrm{C}$ or less for the occurrence of 
continuous permafrost. Higher MAATs of up to $-1.1^{\circ} \mathrm{C}$ lead to discontinuous permafrost. Its spatial pattern is determined by additional conditions, such as vegetation cover, relief and aspect. Thereby, forest and permafrost support each other. On one hand, forest vegetation reduces heat flux by shading the ground and supports the development of an organic layer, which again applies a thermal isolation. In addition, this organic layer increases the refreezing rate in winter which supports the maintenance of permafrost (Dashtseren et al. 2014). On the other hand, the forest benefits from meltwater of the permafrost ice in the active layer during the summer season (Bonan and Shugart 1989; Zhang et al. 2011).

Several forested areas in central Asia require this additional water from the active layer of the permafrost due to an annual precipitation below $250 \mathrm{~mm}$ (Chenlemuge et al. 2013; Dulamsuren et al. 2014). $\delta^{13} \mathrm{C}$ and $\delta^{18} \mathrm{O}$ measurements proved the uptake of meltwater in summer by different larch species in Siberia (Sugimoto et al. 2002; Churakova et al. 2016). With the same method, Li et al. (2006) determined water uptake from lower soil layers by Siberian larch in Mongolia, which identified the permafrost as the potential water source. Nevertheless, permafrost can also have a negative influence on forests. Waterlogging (Ohta et al. 2014) as well as a shallow root system can lead to a higher tree mortality and high risk of wind throw.

The areal share of permafrost decreases with increasing MAAT from the taiga to the foreststeppe. Therefore, the discontinuous permafrost in Mongolia concentrates on forested northfacing slopes and basins (Ishikawa et al. 2005; Kopp et al. 2014). On south-facing slopes as well as recently burned areas, permafrost is absent (Kopp et al. 2014). Furthermore, the active layer thickness of the discontinuous permafrost in Mongolia increases by $0.5-2 \mathrm{~cm}$ per year caused by the influence of global warming (Sharkhuu and Sharkhuu 2012). The comprehensive land use, in particular overgrazing and logging, intensifies this process by a reduction of shading and thermal isolation of permafrost during summer. Based on dynamic vegetation models, a further increase in air temperature of more than $2{ }^{\circ} \mathrm{C}$ can destroy the mutual support between larch forests and permafrost (Zhang et al. 2011). The resulting 
reduction of permafrost would lead to a water deficit during the growing season that could destabilise the dominance of larch (Dulamsuren et al. 2014). Zhang et al. (2011) used different models to forecast the development of larch forests in the taiga under a temperature increase of up to $4^{\circ} \mathrm{C}$. The results strongly suggest a replacement of larch by other boreal and subboreal tree species. Tsogtbaatar (2013) found that according to an Mongolian ecosystem survey $16 \%$ of the forest ecosystems has replaced by non forest ecosystems during the last 100 years.

\subsubsection{Effects of fire on Larix sibirica}

Fire is a common phenomenon in boreal forests and forest-steppe areas. Approximately $10 \%$ of the larch-dominated forests in Siberia were burned from 1992 to 2016 (Chen et al. 2016). Figure 2.3.4 illustrates the forest area and burned forests in central Asia. There is considerable effect of fires on the forested area. In central Siberia, fire repeats on average every 80 years in L. gmelinii and L. sibirica dominated forests (Kharuk and Ponomarev 2017). South-facing slopes show shorter intervals than north-facing slopes due to higher insolation (Kharuk et al. 2008). Furthermore, drought affected forests are prone to fires. Forkel et al. (2012) investigated the relation between fires and soil moisture conditions at the soil surface. They found that the fire severity is enhanced by low soil moisture conditions during the present year and previous summer.

The duration of fire return intervals increases northwards. Kharuk et al. (2011) and Ponomarev et al. (2016) described an average fire return interval at $71^{\circ} \mathrm{N}$ of $300-320$ years caused by low insolation and temperatures as well as by less human influence. Kuosmanen et al. (2014) received similar results in north-western Siberia. In Comparison, fire frequencies in NorthAmerican boreal forest range between an average of 50 and 200 years (Bonan and Shugart 1989). 


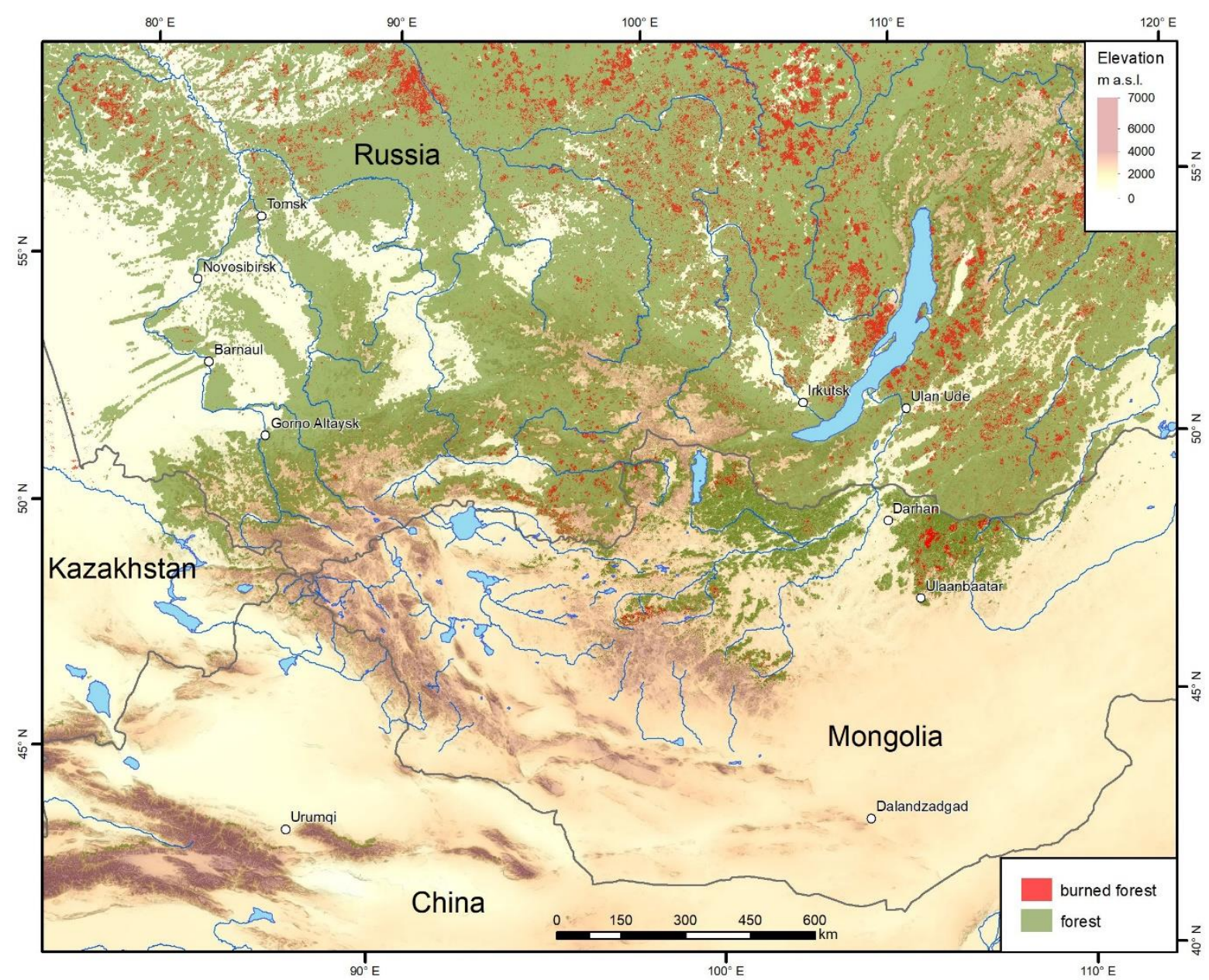

Figure 2.3.4: The forest area in northern central Asia. The green colour indicates forest (FAO, (2006a) and the red colour shows burned, previously forested areas after Hansen et al. (2013).

In general, conifers of the light taiga (larch, pine) are more resistant against fire than conifers of the dark taiga due to their structure and thick bark (Furyaev 1996). Korovin (1996) provided evidence for a higher fire frequency in conifer stands of the light taiga compared to dark taiga. Increasing fire frequency can lead to a forest transformation to more fire-adapted species. Alexander et al. (2018) described a positive effect of fire on the reproduction of $L$. cajanderi. The authors found a strongly increased number of germinations per square meter after fire induced by the destruction of the thick organic layer. A certain fire frequency supposed to maintain and improve the distribution of this so-called "pyrophytic" larch species (Kharuk et al. 2011). In general, L. sibirica establish on sites which were disturbed by fire (Timoshok and Skorokhodov 2014). Analyses on the burn severity in Siberian larch forests indicated a strong regrowth after moderate fires, whereas weak and severe fires led to lower larch regrowth rates 
(Chu et al. 2016b, 2016a). Nevertheless, Siberian larch can be replaced by birch trees after severe burning or clear cutting (Abaimov et al. 1998; Abaimov 2010). It takes up to 100 years until larch dominates those sites again.

The time span between fire events decreased during 20th century in the taiga and the foreststeppe (Kharuk et al. 2008; Hessl et al. 2012). The temperature increase, causing more drought events, and the ignition by human activity are the reasons for this trend (Kovacs et al. 2004; Miehe et al. 2007b; Hessl et al. 2012). Ignition by lightning plays a minor role and is more relevant in areas where human activity is rare (Korovin 1996; Kovacs et al. 2004). In southern Siberia and Mongolia, most fires occur during spring and autumn separated by the main precipitation period in summer (Valendik 1996; Kharuk and Ponomarev 2017). The number of fire events increases especially in years with low precipitation. Thus, more than one fourth of Mongolian forests are currently burned or affected by fire (FAO 2006a; Mongolian Ministry of Environment and Tourism 2019). However, intense grazing and fuel collection reduced the fire connectivity resulting in a moderate fire activity in Mongolia since the beginning of 21 st century (Saladyga et al. 2013; Hessl et al. 2016).

Fire does not necessarily reduce the overall area occupied of $L$. sibirica. Larch species even benefit from fire due to better germination rates and new potential growing areas after a forest fire. However, when fire changes the site conditions and soil properties, the burned area can turn unsuitable for larch as well. In the discontinuous permafrost zone, a fire can vanish the vegetation cover and the increased insolation combined with less thermal isolation reduces the distribution of the frozen ground. This loss of permafrost leads to reduced water supply (Shur and Jorgenson 2007; Kopp et al. 2014). The water deficit is likely to disable the tree's ability to re-establish at this location. Furthermore, fire can cause an understory change to grass dominated vegetation (Park et al. 2009). The disturbance in the organic layer accompanied with a different understory vegetation can reduce a refreezing of permafrost due to less isolation. 


\subsubsection{Influence of biotic factors on Larix sibirica}

\subsubsection{Competition with other species}

Larch species are in strong competition in Siberian taiga with evergreen conifers due to the longer $\mathrm{CO}_{2}$ assimilation period of evergreen conifers, extending into spring and autumn and the photosynthetic adaption to favourable periods during the growing season (Suvorova et al. 2009). Evergreen conifers dominate large parts of the taiga and are able to replace larch after disturbances (Schulze et al. 2005). Therefore, L. sibirica occupies unfavourable sites with extreme climate conditions such as drought-affected areas of the forest-steppe or extremely cold sites at the treelines.

Beside competitors, granivores, such as birds, and herbivores, such as grasshoppers and small mammals, diminish the growth and distribution of larch forests (Pavlov and Mironov 2003; Dulamsuren et al. 2008). Field experiments illustrated that especially seedlings and young trees suffer from those animals leading to a reduced regrowth on open sites. Furthermore, the gypsy moth (Lymantria dispar) can strongly reduce the tree growth of $L$. sibirica by consuming up to $90 \%$ of the tree's needles (Hauck et al. 2008; Dulamsuren et al. 2010b). Particularly the forest edge and single trees suffer from this parasite infestation. The amount of gypsy moth populations correlates positively to winter precipitation. A thicker snow cover protects the eggs from frost which leads to higher survival rates (Dulamsuren et al. 2013a). Climate warming and urban influences can even aggravate this effect due to milder temperatures (Dulamsuren et al. 2011; Hauck et al. 2016).

\subsubsection{Human activity}

In Central Asia, human-induced forest destruction took already place more than 6000 years ago (Miehe et al. 2007b). Thus, the influence of human activities on the vegetation lasts already for millennia and is typically driven by logging, burning and livestock grazing. The lower treeline 
is hereby a frequently disturbed place (Miehe and Miehe 2000). Air pollution by industry and traffic is an additional, recently increasing impact. Chlorosis of needles, reduced tree growth, higher frequency of missing rings, and reduced seed production are frequently documented consequences for $L$. sibirica especially close to cities and agglomerations such as Ulaanbaatar and Krasnojarsk (Avdeeva and Kuzmichev 2007; Noskova and Romanova 2013; Abramenko 2015; Hauck et al. 2016).

In general, pastoral pressure, caused by browsing and trampling, clearly reduces the establishment of larch trees in the forest-steppe (Hilbig 1987; Dulamsuren et al. 2013a; Khishigjargal et al. 2013). Especially goats enter the forest patches and eat saplings as well as branches from young trees (Sankey et al. 2006). However, cashmere wool from goat husbandry contribute up to $70 \%$ to Mongolian nomads income (Lkhagvadorj et al. 2013a). Therefore, the number of goats in the nomad's livestock increased in the last 30 years leading to an aggravated pastoral pressure (Lkhagvadorj et al. 2013b). Figure 2.3.5 illustrates the development of the common livestock in Mongolia. Since the $1990^{\text {th }}$, the total amount of livestock has extremely increased. Especially the number of goats raised from 5.1 to 27.1 million animals in the period from 1990 to 2018 (National Statistical Office of Mongolia). This enormous expansion has a considerable impact on the vegetation. Next to the consequences for the forests, overgrazing by increased numbers of livestock caused a change in the grass vegetation density and an ecological degradation of many steppe areas (van Staalduinen et al. 2007; Bazha et al. 2012). 


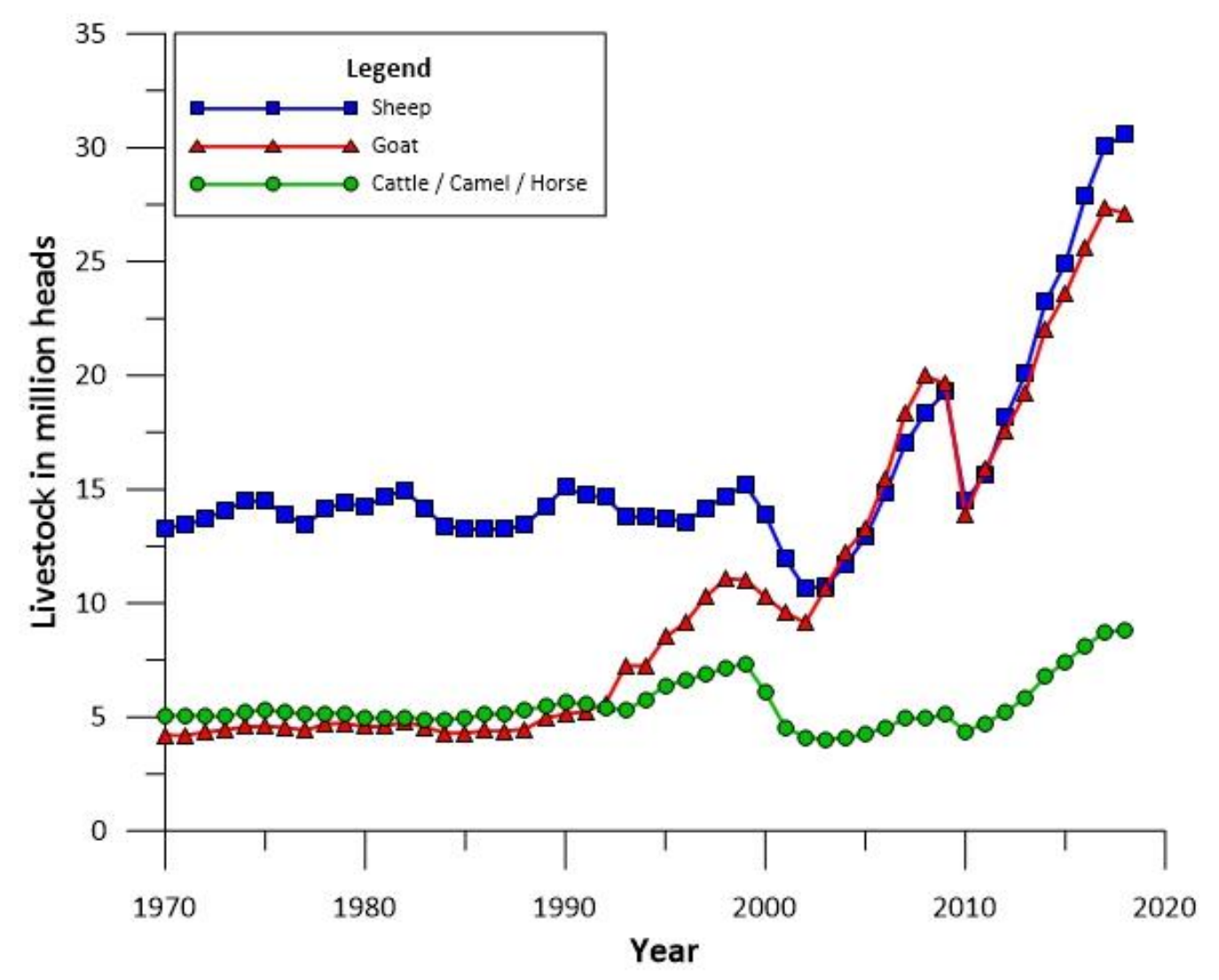

Figure 2.3.5: The scatter plot shows the amount of different livestock in Mongolia from 1970 to 2018 in million heads based on surveys from (National Statistical Office of Mongolia).

Beside overgrazing, intensive logging and fuel collection led to a decline of forested area in the forest-steppe (Hilbig 1987; Dulamsuren et al. 2014; Khansaritoreh et al. 2017a). Clear cutting effects the soil properties, such as bulk density and water content, more negatively than forest fires (Park et al. 2009). The caused site degradation can lead to insufficient properties, such as water supply, for the reestablishment of larch trees. Approximately 250.000 ha of clear logged areas do not show a reforestation anymore (Tsogtbaatar 2013). Furthermore, illegal cutting plays a significant role, especially in Mongolia (Lkhagvadorj et al. 2013a). The authors calculated that only the fuel wood consumption of a Mongolian household in western Mongolia is about $8 \mathrm{~m}^{3}$. It is not possible to achieve this amount exclusively with dead wood. However, the registered violations concerning tree cutting in the observed area (Bayan-Ulgii) was in sum 72 from 2006 to 2009. Figure 2.3.6 illustrates the intensity of the forest use in the Khangai Mountains of Mongolia. A further site effect is a decrease in biodiversity in the forest-steppe (Hauck et al. 2012). 

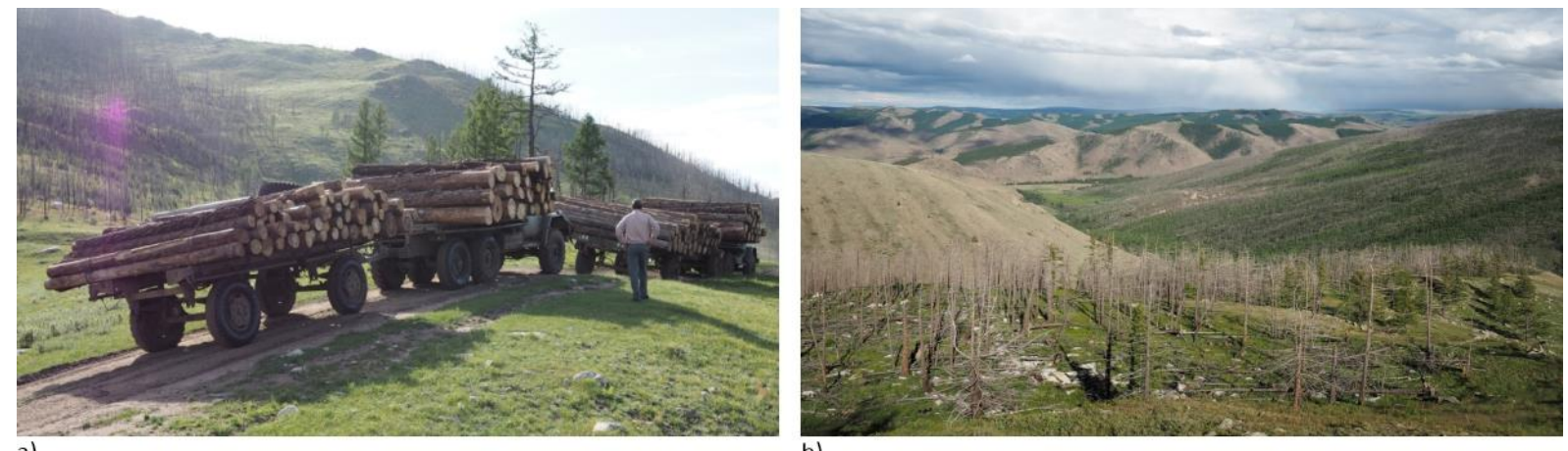

a)

b)
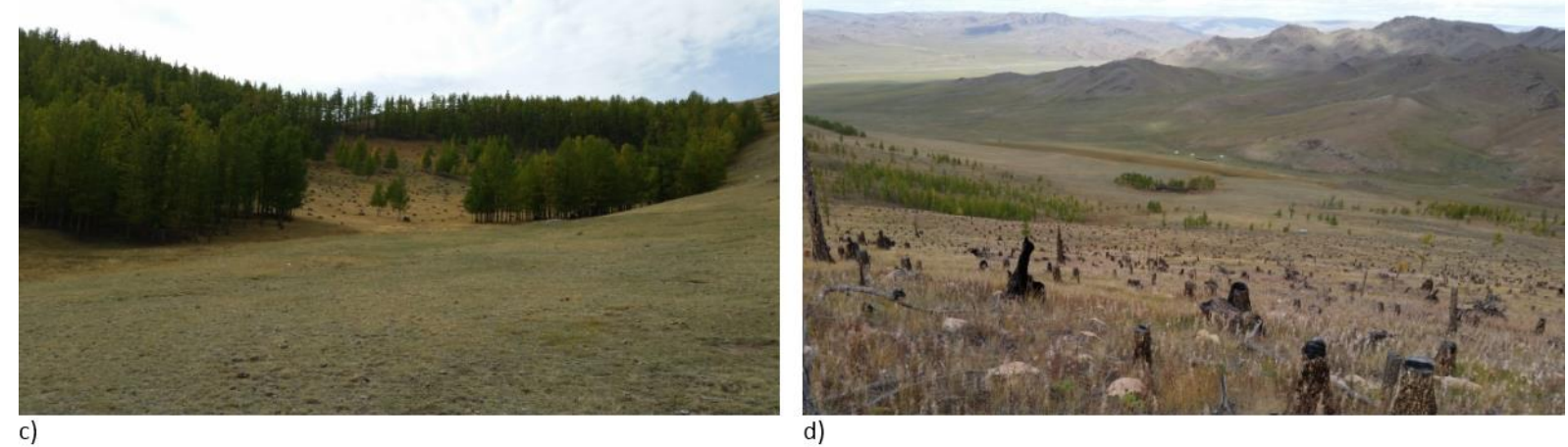

Figure 2.3.6: Photos from Khangai Mountains, Mongolia. a) Transport of illegally logged wood; b) remaining trees after extensive forest fire in the mountains; c) Logging of small forest patches; d) clear cutting after fire.

Forest management and protected areas can help to control the negative impact of human activity on the forest vegetation. The recent decline of forested areas, especially in the foreststeppe of Mongolia, requires certain regulations and management strategies for not to cause a widespread vegetation change (Tsogtbaatar 2004, 2013). Structured forest use and extensive reforestation are common practices for sustainable forestry. For example, Lobanov and Savin (2011) tested the help of shelterbelts for the development of Siberian larch trees in Siberia. The increased tree growth due to less ecological pressure proved its positive impact.

\subsubsection{Climate change}

Studies on climate development in Mongolia in the last Century indicated an increase in temperature of $1.6^{\circ} \mathrm{C}$ leading to intensified summer drought whereas the no clear shift in precipitation was recorded (Pederson et al. 2001; Batima et al. 2005; Dashkhuu et al. 2015). Tree-ring measurements proved the recent warming in Mongolia and China and a shift from 
positive correlation of growth with temperature to a negative correlation during the last decades (Jacoby et al. 1999; D'Arrigo et al. 2000b; Chen et al. 2012; Jiao et al. 2015). Trees at the upper treeline benefit from the temperature increase and will be able to establish at higher elevation (Jacoby et al. 1996; Kharuk et al. 2010). Except for the upper treeline, drought stress is the dominant consequence of climate change in central Asia and will become more severe. Beside the forests, the steppe vegetation suffers also from insufficient water supply resulting in vegetation cover decrease and degradation processes (Bat-Oyun et al. 2016).

However, climate warming proceeds faster than plants could adapt to (Tchebakova et al. 2009a). Results from investigations in Canadian boreal forests suggested that droughtaffected forests can even become a net carbon emitter due to less $\mathrm{CO}_{2}$ assimilation and increased respiration which further accelerate climate warming (Ma et al. 2012). In Mongolia, L. sibirica forests show recently a net ecosystem exchange of -85 to $-257 \mathrm{~g} \mathrm{C} \mathrm{m}^{-2} \mathrm{y}^{-1}$ but these forests can also turn to emitters because of less assimilation and more respiration under intensified drought conditions (Li et al. 2005; Miyazaki et al. 2014). Additional areas which are actually not affected can turn into drought influenced sites under a proceeding warming. In eastern and north-eastern Siberian forests of L. cajanderi and L. gmelinii, the daily evapotranspiration during the foliated period reaches 1.5 to $2.3 \mathrm{~mm}$ (Kelliher et al. 1997; Ohta et al. 2008; lida et al. 2009). In the annual sum, the evapotranspiration rate clearly exceeds the annual precipitation leading to drought stress if permafrost will disappear caused by climate warming. Thus, these forests can turn to further carbon emitters as well. Moreover, a climate induced increase of fire frequency in boreal forests will lead to further acceleration of warming processes due to more $\mathrm{CO}_{2}$ emission and less carbon stock (Ponomarev et al. 2016).

An increase of $\mathrm{CO}_{2}$ in the atmosphere is supposed to enhance the plants' carbon assimilation. This relation is proved under favourable conditions, for example for larch and pine species (DeLucia et al. 1999; Mudrik and Vil'chek 2001). Yet, the documented forest development illustrates a reverse shift. Under recent conditions, larch species are likely not to be able to 
utilize the additional amount of $\mathrm{CO}_{2}$ because other constraints, such as water and nutrient limitation, prevent enhanced growth. Yazaki et al. (2001) analysed the reaction of L. sibirica on enhanced $\mathrm{CO}_{2}$ concentrations in a greenhouse experiment. The plants were able to use the enhanced concentration under a high $\mathrm{N}$ supply but not with a low $\mathrm{N}$ treatment. Koike et al. (2010) used a similar experiment to compare the reaction of $L$. sibirica, $L$. gmelinii and $L$. kaempferi on increased $\mathrm{CO}_{2}$ concentrations. The authors found a higher nitrogen and water use efficiency with increased $\mathrm{CO}_{2}$ but a growth limitation depending on the nutrition. Therfore they assume nutrient poor permafrost soils to limit the use of increased $\mathrm{CO}_{2}$ in the athmosphere. Sidorova et al. (2009) analysed radial growth and stable isotopes of L. gmelinii in the northern part of central Siberia. The authors documented stagnation of radial growth during the last 30 years and evidences for drought stress. The interpret a water limitation as the reason for unchanged growth under increased $\mathrm{CO}_{2}$ concentration. The water supply will even shrink in future in various forested sites due to a reduction of permafrost in the foreststeppe as well as in parts of the taiga. An example is the steady degradation of the discontinuous permafrost in Mongolia (Sharkhuu 2003; Sharkhuu and Sharkhuu 2012). Furthermore, raising temperatures intensify and increase the frequency of insect outbreaks causing additional physiological stress to the vegetation (Logan et al. 2003; Pavlov and Mironov 2003).

To assess the development of forests in Siberia under climate change, different models were used in the last decade. Shuman et al. (2011) used the dynamic vegetation model FAREAST predicting a loss in dominance of larch by a further temperature increase. Dark taiga vegetation is expected to take over larger areas and larch trees will be more subjected to system disturbances, such as fire or herbivory infestations, to maintain their distribution. In opposite, Tchebakova et al. (2009b) used the Siberian BioClimatic Model (SiBCliM), which projected an expansion of light-taiga trees (larch, pine) due to climate change. Warmer and dryer conditions increase drought events and will lead to an expansion of the forest-steppe at the cost of the taiga and a displacement of dark taiga vegetation (Tchebakova et al. 2016). The second 
scenario is likely to happen, as areas with present drought conditions are already occupied by light taiga vegetation. An increase in temperature combined with similar or less precipitation causes unavoidably a further distribution of drought influenced sites, most probably covered by a forest-steppe or steppe vegetation. In addition, climate change can extend the area favourable for agriculture in Siberia which could lead to a further reduction of forests by human economy (Tchebakova et al. 2011).

\subsubsection{Conclusions}

Drought stress is a principal threat for L. sibirica, especially in the forest-steppe and the southern part of the taiga in central Asia. Several studies proved reduced tree growth caused by insufficient water supply. The regrowth of larch on disturbed sites gets decelerated or even inhibited. Furthermore, climate change will intensify the environmental pressure in a multiple way:

i) drought events will become more severe and appear more frequently due to climate warming,

ii) additional water supply by melting water from the permafrost layer will decline since the permafrost distribution decreases,

iii) herbivory infestations will intensify and raise in frequency because of more favourable conditions.

The degradation of permafrost and aggravated drought events will lead to a decline of forested areas. Without additional melting water, the soil hydrological properties, such as water storage capacity and hydraulic conductivity, will solely control the water availability related to precipitation and relief position. The distribution of forests will become addicted to favouring soil properties, more than under present conditions. Furthermore, the less water the plant receives during the growing season, the more susceptible to drought events it becomes. Thus, 
the plants ability to deal with additional disturbances, such as herbivore infestations and human impact, will be influenced by soil properties as well.

In the forest-steppe, human activities are a principal threat for the distribution of L. sibirica as well. Logging and pastural pressure reduce the forest area, fragment the forest stands, and modify the site properties. The re-establishment of larch trees gets partly inhibited, especially under frequent pastoral use. Therefore, forested areas will continuously decrease, in particular under deteriorating conditions due to climate change. An effective forest management, including logging regulations, reforestation, fire suppression, and forest stand protection against livestock browsing, is strongly needed to maintain this fragile ecosystem. The forestry application has to consider the site-specific soil properties to identify a sustainable utilisation of resources and landscape.

In the taiga, forest management has to adapt to changing site conditions. In southern Siberia, intensifying drought can displace evergreen conifers favouring larch and most probably reduce the tree's growth rates. The light demand of $L$. sibirica will decelerate the development of dense stands in the taiga. However, larch will be able to expand its distribution area at the northern treeline due to increasing temperatures. Those new developing areas can substitute the possible loss in the south. Moreover, fire will affect the forest distribution due to its increased frequency. However, the general threat by fire is supposed to be of minor influence for Siberian larch as long as in does not cause a negative change of the site conditions which disables larch regrowth. 


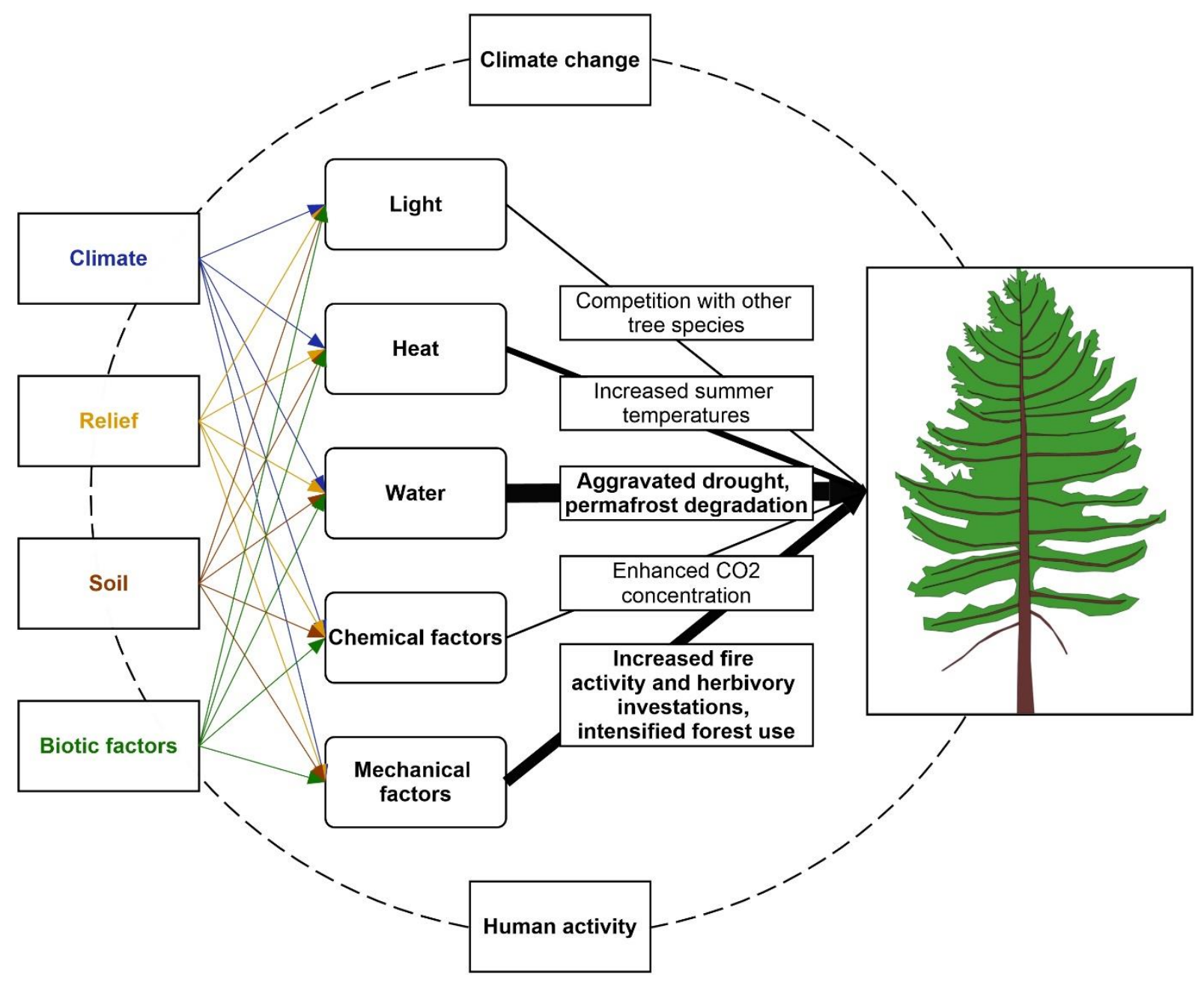

Figure 2.3.7: Schematic description of the relatively weighted environmental factors influencing the conditions of Larix sibirica. Grey Boxes and arrows sizes symbolise the environmental factors and white boxes on arrows describe the interconnected influences. Basic scheme after Glaser et al. (2017).

Figure 2.3.7 summarises the relative effects of key environmental factors on $L$. sibirica as obtained from this literature review. Despite the existing knowledge, the recent and upcoming threats on Siberian larch require to investigate and control the plants environment in an advanced manner. Forest management based on site conditions including the soil properties will be the key to obtain a certain distribution of $L$. sibirica, especially in central Asia. A reduction of human made disturbances will therefore be needed to ensure a survival of the droughtaffected forest sites. 


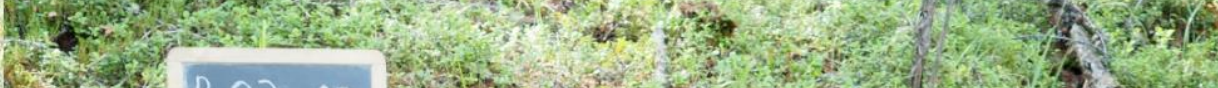

Endoskeletic Chernozem
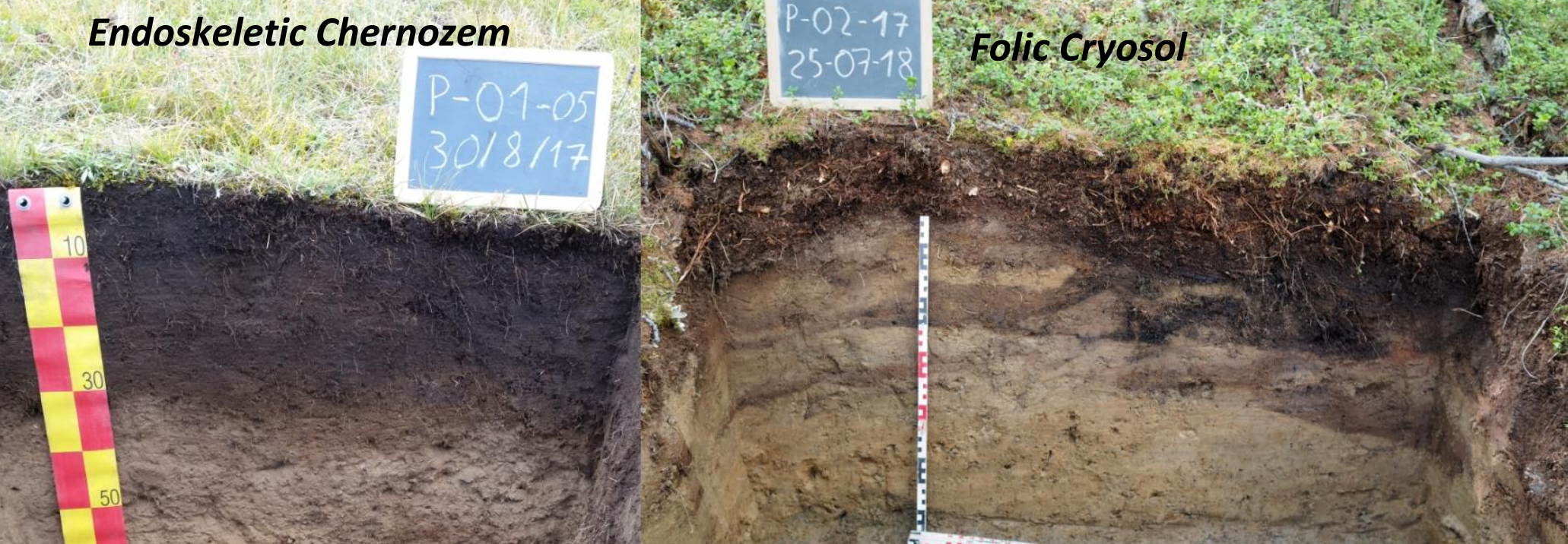

Various soils of the Khangai Mountains from the field campaigns 2017 and 2018

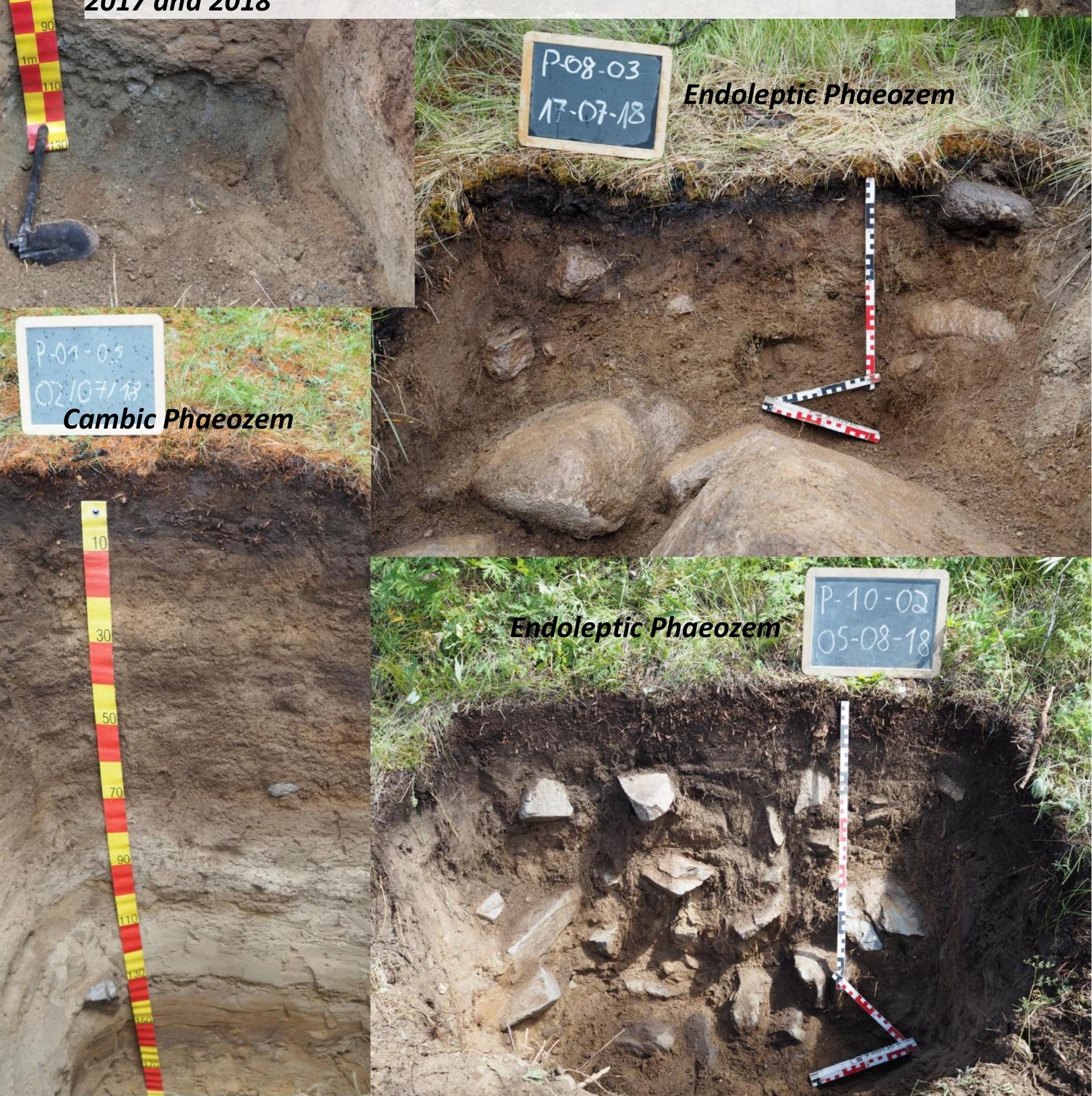




\section{CHAPTER 3: MANUSCRIPTS RELATED TO OBJECTIVE 2}

This chapter presents two scientific manuscripts in order to achieve the second objective. The studies based on the conducted field campaigns in 2017 and 2018. In the first manuscript, 54 soil profiles were analysed in the field and samples were measured on chemical, physical and hydrological soil properties. The results were used to identify differences in soil properties between disturbed forests with and without tree regrowth. The second manuscript contains gpr measurements, drillings and temperature measurements to identify the permafrost depth. The data was used to estimate the permafrost distributions and to evaluate it with respect to the vegetation pattern. 


\subsection{Hydrological soil properties control tree regrowth after forest disturbance in the forest steppe of central Mongolia}

Florian Schneider ${ }^{1}$, Michael Klinge ${ }^{1}$, Jannik Brodthuhn ${ }^{1}$, Tino Peplau², Daniela Sauer ${ }^{1}$

'Department of Physical Geography, University of Göttingen, Göttingen, 37077, Germany

${ }^{2}$ Thünen Institute of Climate-Smart Agriculture, Braunschweig, 38116, Germany

- Manuscript published in SOIL (30. August 2021)

- https://doi.org/10.5194/soil-7-563-2021

\section{Author contributions:}

Michael Klinge and Daniela Sauer designed the research project. All authors carried out the field work together. Florian Schneider, Tino Peplau and Jannik Brodthuhn carried out the laboratory work. Florian Schneider prepared the manuscript with contributions from all coauthors.

Keywords: Siberian larch, forest fire, human impact, climate change, soil hydrology, permafrost 


\section{Abstract}

The central Mongolian forest steppe forms a transition between different ecozones and is as such particularly sensitive to environmental changes. It is commonly affected by disturbances such as logging and forest fires. Intensified drought events aggravate stress on the trees that are anyway at their drier limit in the forest steppe. Climate change increases evapotranspiration and reduces the distribution of discontinuous permafrost, which leads to drier soil conditions. The motivation for this study came about through our previous observation that forest stands show great differences with respect to their recovery after disturbance by fire or logging. Sometimes, no regrowth of trees takes place at all. As water availability is the main limiting factor of forest growth in this region, we hypothesized that differences in soil hydrology control the forest-recovery pattern.

To test this hypothesis, we analysed soil properties under forests, predominantly consisting of Siberian larch (Larix sibirica Ledeb.), in the forest steppe of the northern Khangai Mountains, central Mongolia. We distinguished four vegetation categories: 1. near-natural forest (FOR), 2. steppe close to the forest (STE), 3. disturbed forest with regrowth of trees (DWIR), and 4. disturbed forest showing no regrowth of trees (DNOR). 54 soil profiles were described in the field and sampled for soil chemical, physical, and hydrological analysis. We found a significant difference in soil texture between soils under DWIR and DNOR. Sand generally dominated the soil texture, but soils under DWIR had more silt and clay compared to soils under DNOR. Soil $\mathrm{pF}$ curves showed that soils under DWIR had higher plant-available field capacity in their uppermost parts than soils under DNOR. In addition, hydraulic conductivity tended to be higher in the uppermost horizons of soils under DWIR compared to their counterparts under DNOR. Chemical properties of the soils under DWIR and DNOR showed no significant differences.

We conclude that the differences in post-disturbance tree regrowth are mainly caused by different soil hydrology. High plant-available field capacity is the key factor for forest recovery under semi-arid conditions. High hydraulic conductivity in the uppermost soil horizons can further support tree regrowth, because it reduces evaporation loss and competition of larch saplings with grasses and herbs for water. Another important factor is human impact, particularly grazing on cleared forest sites, which often keeps seedlings from growing and thus inhibits forest recovery. None of the disturbed sites (DWIR, DNOR) had permafrost. We thus conclude that permafrost is no major factor for post-disturbance tree-regrowth pattern, although it generally supports tree growth in the forest steppe by preventing meltwater from seasonal ice from seeping below the root zone, thus increasing water supply in summer.

\subsubsection{Introduction}

The forest steppe in central Mongolia represents the transition between the Siberian taiga in the north and the Gobi Desert in the south, responding sensitively to climatic, ecological and anthropogenic disturbances. Water availability is the key factor that determines, where forest patches can exist within this landscape. Climate change is a major threat for the forest steppe due to aggravated drought stress (Allen et al. 2010). In Mongolia, intensified summer droughts became more frequent over the last century (Batima et al. 2005; Dashkhuu et al. 2015). 
Siberian larch (Larix sibirica Ledeb.), which is the dominant tree species in the Mongolian forest steppe, suffers from these intensified droughts (Dulamsuren et al. 2010c; Chenlemuge et al. 2015b). Furthermore, summer droughts increase the risk of fires that disturb the vegetation structure in forests and reduce the size of the forest patches (Kharuk et al. 2008). This causes a negative effect on the forest microclimate, which in turn intensifies the sensitivity of the forest to drought stress (Khansaritoreh et al. 2017b). In addition to fire, also human impact affects the structure of the forest stands. Logging and forest pasture reduce the forest size, open the forest stand and hamper post-disturbance forest regrowth (Khishigjargal et al. 2013; Tsogtbaatar 2013; Dulamsuren et al. 2014).

Meltwater from the active layer above permafrost patches increases the soil-water availability and can thus support the survival of trees during drought events in summer (Sugimoto et al. 2002; Ishikawa et al. 2005; Churakova et al. 2016). Permafrost in Mongolia is discontinuous and especially occurs under large forests. However, climate change is currently reducing the area of permafrost in Mongolia (Sharkhuu and Sharkhuu 2012). After forest disturbance by fire or logging, permafrost degrades and may only reconstitute under certain conditions (Klinge et al. 2021). The loss of this additional water source leads to enhanced stress of trees during droughts.

Decreased water supply and increased drought stress raise the importance of soil properties in the Mongolian forest steppe even further. Soil-water distribution in the landscape after a rainfall event is generally controlled by bedrock, sediment cover, slope morphology and vegetation. In addition, plant-available field capacity and hydraulic conductivity of the soils influence the amount of water available at a site. Moreover, water repellency can reduce water infiltration, especially after fire events (DeBano 2000; Doerr et al. 2000). Several studies have been conducted on soil distribution and soil properties in the Mongolian forest steppe (Opp and Hilbig 2003; Maximovich 2004; Lehmkuhl et al. 2011). Nandintsetseg and Shinoda (2011) modelled soil moisture conditions in Mongolia based on data from meteorological stations from 
1986 until 2005. They obtained a gradient of increasing soil moisture from southwest to northeast during summer. Haase (1963) studied soils in relation to altitudinal zones in the Khangai Mountains, including particle size distribution, chemical soil properties, and water content. He reported forest vegetation on soils with higher water content and predominant steppe vegetation on soils with lower water content. However, he focused mainly on general soil description and did not report any further details on soil-vegetation relationships. Krasnoshchekov $(2008,2010)$ described physical and chemical soil properties in the East Khubsugul region and the Khangai Mountains. Sympilova and Gyninova (2012) conducted similar research in the Selenga Mountains. However, in both studies only the soils were characterised, without linking them to the vegetation pattern. Sommer (2000) analysed soils of the forest steppe of the Turgen-Charchiraa-Mountains in north-western Mongolia. He focused on soil-chemical aspects and did not find a clear relationship between forest distribution and soil properties. He concluded that forest distribution was climate-controlled and disturbed by pastoral pressure and logging. Yet, he did not analyse soil-hydrological properties.

During previous fieldwork in the Khangai Mountains, in the central Mongolian forest steppe, we observed that forest regrowth after disturbance does not proceed equally. The postdisturbance development of forest stands with apparently same site conditions ranges from spontaneous dense regrowth to no regrowth at all. As the trees are at their drier limit in this sensitive landscape, we assumed that water availability is the main factor that controls forest regrowth after disturbance, whereas nutrient availability plays a less important role. Since both factors are related to soil properties, we established the following hypotheses:

1) Silty soil texture leads to high plant-available field capacity and is thus favourable for postdisturbance tree regrowth.

2) High hydraulic conductivity in the uppermost parts of the soils supports post-disturbance forest regrowth, as rapid water infiltration to some depth reduces evaporation and groundvegetation transpiration. 
3) High nutrient stocks, for example after fire events, may support post-disturbance forest regrowth, unless nutrient stocks are anyway well above the requirements of Siberian larch. In this case, no effect is to be expected.

4) Permafrost may increase water availability for trees through the continuous water release at the melting front above the permafrost table over the summer season. As water above the permafrost table cannot infiltrate downwards, interflow may occur above the permafrost table. This process leads to increased water availability, especially in concave slope positions where interflow converges. Thus, permafrost may support post-disturbance forest regrowth also at sites with otherwise unfavourable soil-hydrological conditions for forest regrowth.

\subsubsection{Materials and methods}

\subsubsection{Study area}

The study area was located in the central Mongolian forest steppe, in the northern Khangai Mountains, near the town Tosontsengel (Fig. 3.1.1). The geological basement predominantly consists of Permian acidic plutonic and metamorphic sedimentary rock, with some occurrences of Carboniferous mafic rock (Academy of Sciences of Mongolia, Academy of Sciences of USSR 1990). Slope debris with inmixed aeolian sand and silt provides the parent material for the soils in the region. The widespread aeolian deposits originate from lacustrine sediments of big lakes that dried out during the glacial periods in the Basin of Great Lakes, located between the Mongolian Altai and the Khangai Mountains (Grunert et al. 2000; Lehmkuhl and Haselein 2000; Klinge and Lehmkuhl 2013).

The climate is cold, semi-arid, and highly continental. In the town Tosontsengel, in the northern part of the study area, mean monthly temperatures range from $-31.7^{\circ} \mathrm{C}$ in January to $14.9{ }^{\circ} \mathrm{C}$ in July (see Figure 3.1 .11 ). Mean annual precipitation is $200-500 \mathrm{~mm}$. Rainfall concentrates in summer, because of low-pressure cells that are blown in with the westerlies (Batima et al. 2005). The mean annual temperature of $-5.9^{\circ} \mathrm{C}$ supports discontinuous permafrost in the study area (Bonan and Shugart 1989). Permafrost patches occur on forested slopes, where the 
canopy protects them from solar radiation, and the organic layer insulates them from high air temperatures in summer (Dashtseren et al. 2014). In summer, the forests benefit from an additional water supply by meltwater from the active layer above the permafrost (Zhang et al. 2011).

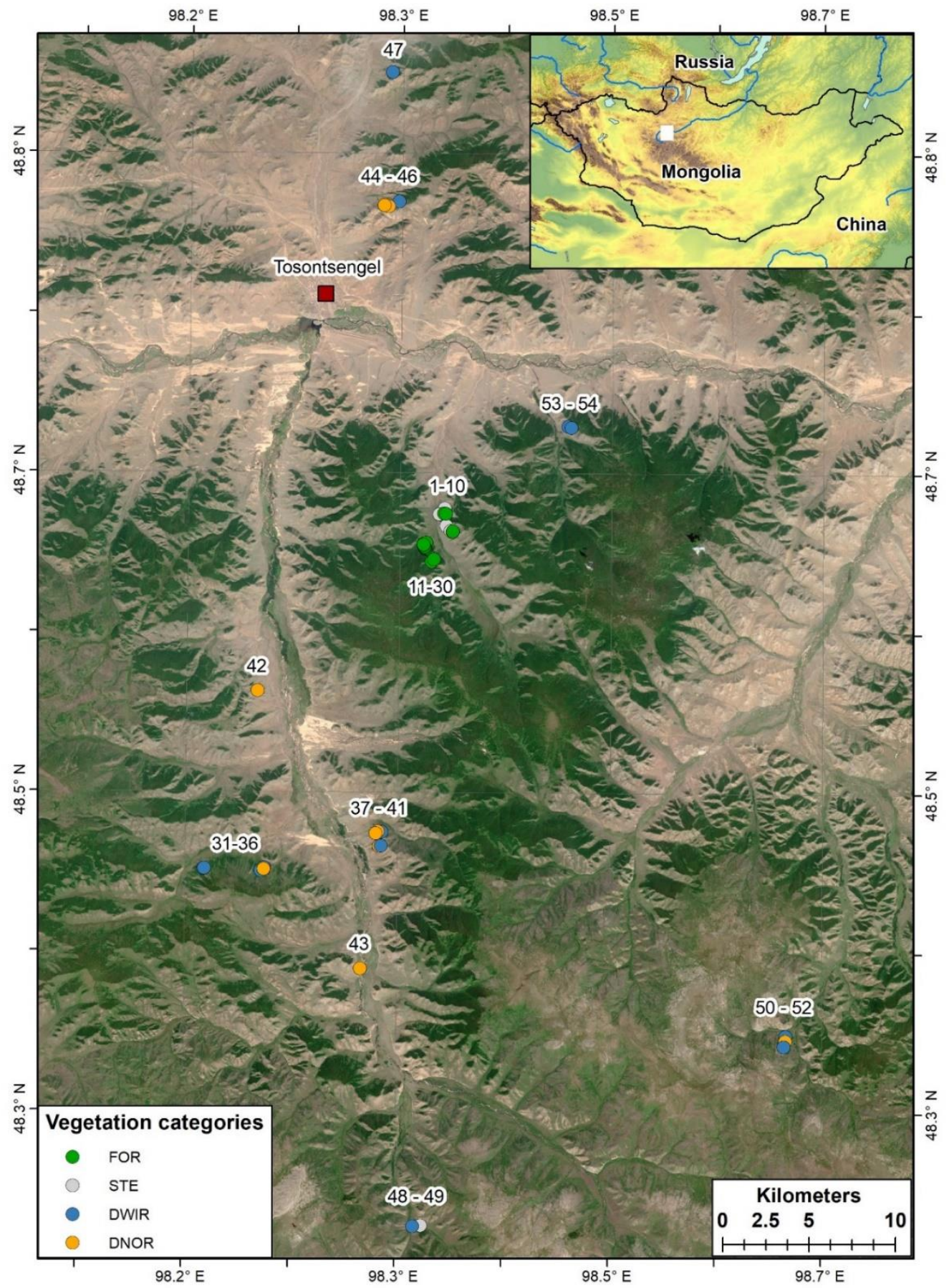

Figure 3.1.1: Sentinel image (2019/07/31) of the study area with soil profile positions. The colours indicate the four vegetation categories that were used for selecting the soil profile locations: near-natural forest (FOR, green), steppe close to forest (STE, grey), disturbed forest with regrowth of trees (DWIR, blue), and disturbed forest showing no regrowth of trees (DNOR, 
orange). The soil profiles are listed in Table 3.1.1 of the appendix. Right top: Physical map of Mongolia, showing the location of the study area (white rectangle).

The vegetation of the study area is dominated by steppe. Only north-facing slopes and some valley positions are covered by forest, predominately consisting of Siberian larch (Hilbig 1987; Tsogtbaatar 2013). The understory of these forests varies with respect to proportions of grasses, herbs, mosses and shrubs (commonly including e.g. Vaccinium vitis-idea and Lonicera altaica). High evapotranspiration combined with low precipitation and reliefdependant differences in insolation control the vegetation pattern (Schlütz et al. 2008; Hais et al. 2016). The semi-arid conditions promote frequent forest fires in this region (Goldammer 2002; Hessl et al. 2016). The last two severe fire events in the study area happened in 1996 and 2002.

A timber factory was established in the 1960s in Tosontsengel. Thus, logging strongly affected the forest stands in the study area. Since the 1990s, industrial logging is abandoned, but illegal logging is still common (Lkhagvadorj et al. 2013b). Moreover, pastoral pressure increased over the last decades (Lkhagvadorj et al. 2013b). Logging, followed by grazing, led to a reduction of the forested area, especially at its lower boundary and at the forest edges.

\subsubsection{Field work}

The site selection within the study area was based on four categories of vegetation: nearnatural forest (FOR), steppe close to forest (STE), disturbed forest with regrowth of trees (DWIR) and disturbed forest showing no regrowth of trees (DNOR) (Figs. 3.1.1 and 2). In addition, we distinguished three categories of disturbance intensity. "Low intensity" included e.g. logging of single trees. "Moderate" included logging of patches within a forest stand and fires that did not affect the whole forest stand. "Severe" included clear cutting and fires that destroyed the whole forest stand (Tab. 3.1.1). To reduce the effects of factors that were not in the focus of this study, we kept geology, exposition (only north-facing slopes), inclination, and slope morphology as similar as possible. Elevation of the studied soil profiles ranged from 1850 
to $2100 \mathrm{~m}$ a.s.I., which is well below the upper tree line of approx. $2500 \mathrm{~m}$ a.s.l. (Klinge et al. 2018). 54 soil profiles were described according to the FAO Guidelines for Soil Description (FAO 2006b) and classified according to WRB (IUSS Working Group WRB 2015). The presence of permafrost was documented as well. The soil profiles were sampled horizon-wise, whereby thick horizons were subdivided for the sampling, such that the maximum thickness included in one sample did not exceed 30 centimetres. We also carried out in situ measurements of saturated hydraulic conductivity, using a compact constant-head permeameter (Eijkelkamp) (Amoozegar and Warrick 1986; USDA 2014). The measurements were done in five replicates. In addition, soil horizons with low rock-fragment contents were sampled with $100 \mathrm{~cm}^{3}$ and $250 \mathrm{~cm}^{3}$ steel cylinders for laboratory measurements of pF curves and hydraulic conductivity, respectively. Samples for pF curves were taken during two field campaigns, whereas samples for hydraulic conductivity were taken only during one field campaign, thus not from all profiles that were sampled for $\mathrm{pF}$ measurements. The in-situ measurements of hydraulic conductivity provided additional data. Therefore, the sizes of the datasets for $\mathrm{pF}$ curves and hydraulic conductivity differ. 


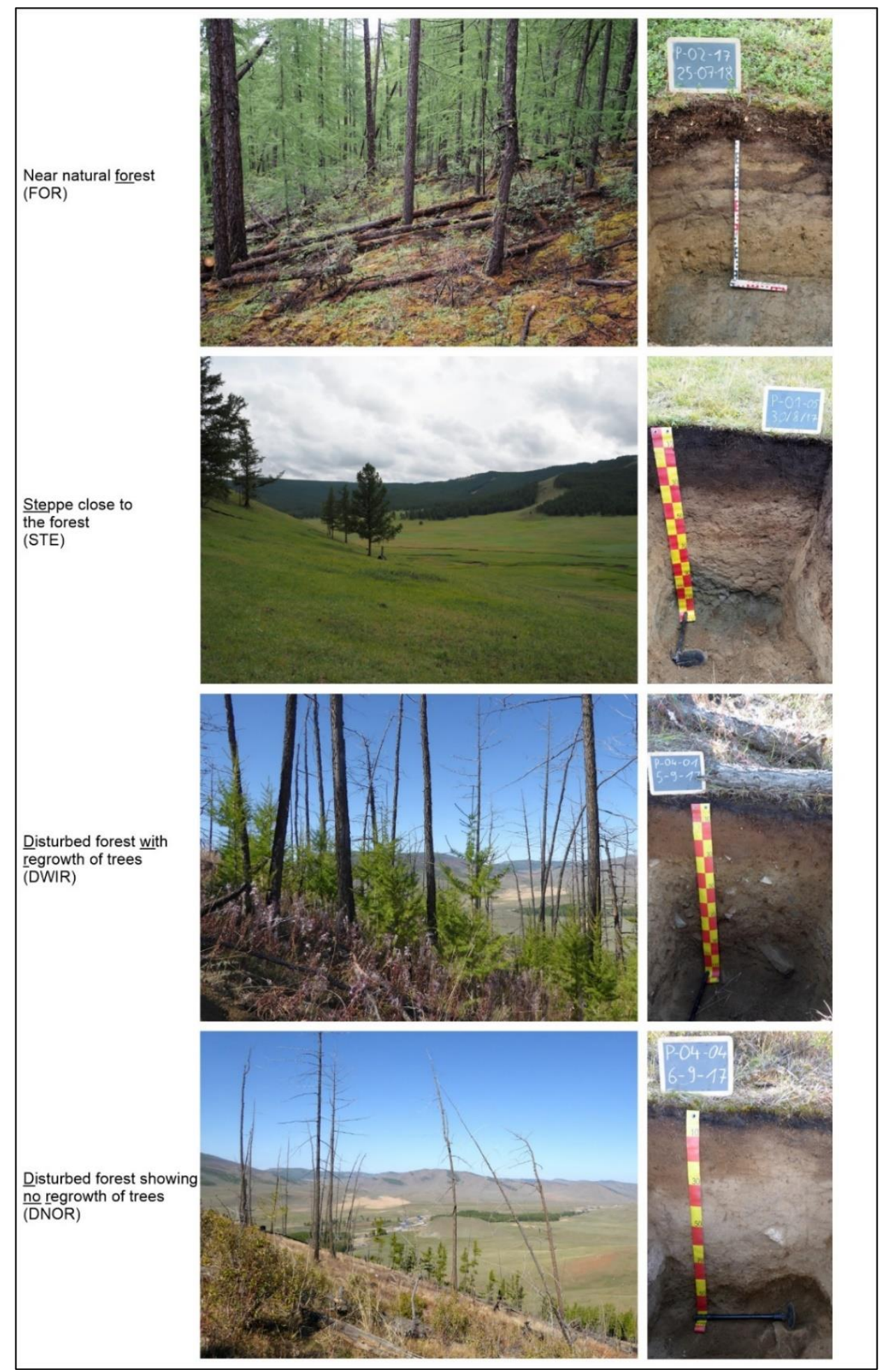

Figure 3.1.2: Typical soil profiles under the four vegetation categories.

\subsubsection{Laboratory analyses}

The soil samples were dried at $40^{\circ} \mathrm{C}$ and passed through a $2 \mathrm{~mm}$ sieve. Approximately $10 \mathrm{~g}$ of each sample was dried at $105^{\circ} \mathrm{C}$ to gravimetrically determine the remaining water contents 
for correcting all analytical data obtained from the $40{ }^{\circ} \mathrm{C}$-dried samples. An aliquot of each sample was milled. Total $\mathrm{C}$ and $\mathrm{N}$ contents were analysed on the milled samples using a $\mathrm{CHN}$ analyser (LecoTruSpec). Carbonate contents were also analysed on the milled samples using the Scheibler method. Soil organic carbon (SOC) contents were calculated by subtracting soil inorganic $\mathrm{C}$ (obtained from carbonate analysis) from total $\mathrm{C}$. Soil $\mathrm{pH}$ was measured in $1 \mathrm{M} \mathrm{KCl}$ solution at a soil:solution ratio of 1:5. Exchangeable $\mathrm{Al}, \mathrm{Fe}, \mathrm{Mn}, \mathrm{Ca}, \mathrm{Mg}, \mathrm{K}$, and $\mathrm{Na}$ were extracted with $1 \mathrm{M}$ ammonium chloride solution and measured by use of an ICP-OES (Thermo Scientific). The effective cation exchange capacity (ECEC) was calculated as the sum of negative charges occupied by these exchangeable cations. Pre-treatments for particle size distribution analysis were as follows: Soil organic matter was removed by $30 \% \mathrm{H}_{2} \mathrm{O}_{2}$, carbonates were dissolved, if necessary, by $10 \%$ hydrochloric acid, and micro-aggregates were dispersed by $0.4 \mathrm{M}$ sodium pyrophosphate. The three sand fractions were separated by sieving, and the silt and clay fractions were determined by use of a sedigraph (micromeritics). Bulk density was estimated in the field (FAO 2006b) and measured on undisturbed samples in the laboratory. All element concentrations in the fine earth were converted to element stocks per $\mathrm{m}^{2}$ considering rock-fragment content and bulk density.

Hydraulic conductivity and pF curves were determined on 41 of the soil profiles under FOR, DWIR and DNOR. Hydraulic conductivity was measured in five replicates, using a permeability device with falling water head (self-constructed device based on German norm DIN 19683-9). Soil pF curves were determined in four to five replicates, using a pressure device (ecoTech). The cylinders with the samples were carefully water saturated and placed on ceramic plates in the pressure pots. Pressures corresponding to pF 1.8, 2.5 and 4.2 were applied and the weight of the samples at each $\mathrm{pF}$ was determined. Water repellency was analysed on five replicates for each top-soil sample (Doerr 1998). The sample was placed in a petri dish and the surface was manually smoothened. The time was measured until a drop of distilled water, released from a pipette at $5 \mathrm{~cm}$ above the sample surface, infiltrated into the sample. 


\subsubsection{Data processing and statistical analysis}

We described and sampled the soil profiles down to either the bedrock or permafrost, resulting in a maximum depth of $180 \mathrm{~cm}$. According to the literature, the roots of Siberian larch can reach this depth (Kapper 1954; Albenskiy et al. 1956). Therefore, we included all soil horizons in the calculations of element stocks to evaluate the nutrient availability for larch trees at a site. To assess in addition the site conditions also for tree seedlings without fully developed root system, we only used the properties of the uppermost $10 \mathrm{~cm}$ of the soils. For this purpose, we calculated the weighted means of the following variables for the uppermost $10 \mathrm{~cm}$ of the soils: content of rock fragments, bulk density, $\mathrm{H}+$ concentration $\left(\log \left(10^{-\mathrm{pH}}\right)\right)$, carbonate content, clay content, silt content, sand content, and ECEC (first group of variables). Element contents in the fine earth of each horizon were converted to element stocks per horizon (considering rock fragment content and bulk density), and were summed up over the uppermost $10 \mathrm{~cm}$ of the soils. This was done for exchangeable Al, $\mathrm{Ca}, \mathrm{K}, \mathrm{Na}, \mathrm{Mg}, \mathrm{Mn}, \mathrm{Fe}, \mathrm{SOC}$, and total N (TN) (second group of variables).

All statistical analyses were carried out with the $\mathrm{R}$ project for statistical computing ( $\mathrm{R}$ Core Team 2014). The share of each horizon in the uppermost $10 \mathrm{~cm}$ of the soil was used for the weighting, based on formula $x 1$ (1) for the first group of variables, and formula $x 2$ (2) for the second group of variables.

$x 1=$ if (upper boundary $>10)\{N A\}$ else \{

if (lower boundary $<=10)\{($ lower boundary - upper boundary $) / 10\}$

else $\{(10-$ upper boundary $) / 10\}\}$, 
$x 2=$ if (upper boundary $>10)\{N A\}$ else \{

if (lower boundary $<=10)\{1\}$

else $\{(($ lower boundary - upper boundary $)$ - (lower boundary - 10))/

(lower boundary - upper boundary)\}\}

We conducted all statistical analyses (i) on the entire data set of each profile, and (ii) on only the data of the uppermost $10 \mathrm{~cm}$ of each profile. All analyses and graphical representations were performed with the R packages "aqp", "ggplot2" and "ggpubr" (Beaudette et al. 2013; Wickham 2016; Kassambara 2019). Principle component analyses (PCAs) were calculated and graphically depicted with the R packages "FactoMineR" and "factoextra" (Lê et al. 2008; Kassambara and Mundt 2019). The PCAs were used to identify relations between the variables and the samples. The PCA of the uppermost $10 \mathrm{~cm}$ of the soils also included inclination, exposition and elevation. Linear regression models were used to compare the data obtained for soils under DWIR and DNOR. The results, including $95 \%$ confidence intervals, described the differences between the soils under DWIR and DNOR.

We did not subject measured plant-available field capacity $\left(\mathrm{FC}_{\mathrm{pa}}\right)$ and hydraulic conductivity to statistical analysis because of their unequal representation of the vegetation groups. Although we tried to sample as many profiles as possible, high rock-fragment contents prevented equal sampling of soils under the different vegetation groups and resulted in a small number of samples. Thus, we only present the measured data in a site-wise comparison to prevent any bias.

In addition, we applied a pedo-transfer function to estimate $\mathrm{FC}_{\mathrm{pa}}$ for all soil horizons, based on other measured soil parameters that were available for all samples. We tested several transfer functions from literature and chose the function established by Gupta and Larson (1979) 
because it matched best with our measured $\mathrm{pF}$ data, is based on a large dataset (43 soils and a test run on 61 soils), and, included a wide range of different soils (0-65\% clay content, 1-72 $\%$ silt content, $5-98 \%$ sand content, $0.74-1.74 \mathrm{~g}^{*} \mathrm{~cm}^{-3}$ bulk density) (see supplement Table 3.1.2). We calculated the plant-available field capacity $\left(\mathrm{FC}_{\mathrm{pa}, \mathrm{cal}}\right)$ as follows:

$$
\begin{aligned}
& \mathrm{FC}_{\text {pa,cal }}(\text { vol. } \%)=((0.005678 * \operatorname{sand}(\%)+0.009228 * \operatorname{silt}(\%)+0.009135 * \operatorname{clay}(\%)+ \\
& \left.0.006103 * C_{\text {org }}(\%)-0.2696 * \text { bulk density }\left(g * \mathrm{~cm}^{-3}\right)\right)-(-0.000059 * \operatorname{sand}(\%)+ \\
& 0.001142 * \operatorname{silt}(\%)+0.005766 * \operatorname{clay}(\%)+0.002228 * C_{\text {org }}(\%)+0.02671 * \text { bulk density }(g * \\
& \left.\left.\mathrm{cm}^{-3}\right)\right) * 100
\end{aligned}
$$

The results were multiplied by fine-earth content [vol.\%], thus assuming that rock-fragments did not contribute to $\mathrm{FC}_{\mathrm{pa}}$. We deleted three values from the resulting $\mathrm{FC}_{\mathrm{pa} \text {,cal }}$ dataset because they exceeded a $\mathrm{FC}_{\mathrm{pa}, \mathrm{cal}}$ of 40 vol.\%, which we considered unrealistic.

\subsubsection{Results}

\subsubsection{Field observations}

The bedrock in the study area predominantly consisted of granite, with some minor occurrences of gneiss. Thick aeolian sand sheets locally covered the lower slopes and valley bottoms along west-east running valleys (Fig. 3.1.1). Thus, carbonates that were observed in some of the soils were supposed to originate from aeolian deposits.

The parent materials of the soils on the slopes generally consisted of a vertical succession of two to three sediment layers. The lowermost one was typically a solifluction layer, characterised by a high content of rock fragments with sizes ranging from fine gravel to angular stones. This layer was usually overlain by another slope deposit, consisting of a mixture of weathering products of the bedrock, and aeolian sand and silt. This slope deposit showed 
lower rock-fragment contents than the underlying one, but similar rock-fragment sizes. The proportions of sand and silt in the upper slope deposit varied both within a profile and between the profiles. In places, a Holocene colluvial deposit with varying thickness covered the slope deposits described above. Our profiles 4, 5 and 38 predominantly consisted of Holocene colluvium, whereas most of the other profiles included either no or only a thin Holocene colluvial deposit. The Holocene colluvial deposits had very low contents of rock fragments that typically consisted of fine to medium gravel. At three sites, only a thin sediment layer covered the bedrock (profiles $3,47,52$ ). As an exception, the parent material at one of the forest sites (profiles 1, 2, 7, 8, 9) consisted of a slope deposit with extremely high proportions of aeolian sand.

Phaeozems and Cambisols were the most common soils under the near-natural forests (FOR) and disturbed areas (DWIR, DNOR). In addition, Cryosols occurred above permafrost patches. Soils under steppe (STE) included Phaeozems, Chernozems, and Kastanozems. The soil structure of the A horizons was generally granular, the B horizons had subangular or angular blocky structure, and the $\mathrm{C}$ horizons had single grain, massive or rock structure. Rock fragments in several $\mathrm{C}$ horizons showed manganese or carbonate pendants (Tab. 3.1.1). Bioturbation by rodents was observed in the soils at one forest site (profiles 1, 2, 7, 8, 9), whereas cryoturbation was not found at any of the investigated sites, most likely because of insufficient moisture. Charcoal was present in most of the topsoils.

Human impact affected most of the sites, except for the near-natural forest sites (FOR) that showed either no or only minor disturbance such as cutting of single trees. Disturbance in DWIR and DNOR varied between moderate and severe. Most of the sites were impacted by both fire and logging; yet, some profiles were only affected by one type of disturbance (Tab. 3.1.1).

Permafrost was only encountered in soil profiles under near-natural forest (FOR). The depth of the permafrost table varied between $60 \mathrm{~cm}$ and $100 \mathrm{~cm}$ in soils on slope debris under closed 
forests, and between $140 \mathrm{~cm}$ and $180 \mathrm{~cm}$ in soils on sandy deposits under open forests (Tab. 3.1.1). In soils under STE, DWIR, and DNOR no permafrost was present above the bedrock that was typically encountered between $80 \mathrm{~cm}$ and $110 \mathrm{~cm}$ soil depth.

\subsubsection{Chemical and physical soil properties}

Comparison of the entire soil profiles (down to either the bedrock or permafrost) showed that soils under STE had significantly higher contents of carbonates and exchangeable Ca than soils under all other vegetation categories (Fig. 3.1.3), whereas soils under FOR had significantly higher contents of exchangeable Fe compared to soils under all other vegetation categories. There were no statistically significant differences between soils under DWIR and DNOR with respect to rock-fragment contents, $\mathrm{SOC}$ and $\mathrm{TN}$ stocks, $\mathrm{pH}$, contents of exchangeable Mg, K, Na, AI, Mn, and ECEC. However, soils under DWIR and DNOR differed significantly in their particle size distribution: Soils under DWIR had higher silt and clay contents, whereas soils under DNOR had higher sand contents. Soils under FOR had similar silt contents as soils under DWIR, whereas soils under STE had similar sand contents as soils under DNOR. Bulk density of soils under FOR and DWIR was lower than that of soils under DNOR. Yet, there was only a significant difference in bulk density between soils under FOR and DNOR but not between soils under DWIR and DNOR.

Comparison of only the uppermost $10 \mathrm{~cm}$ of each soil profile (for evaluating the soil conditions for tree seedlings) suggested that soils under DWIR had larger stocks of exchangeable Mg and $\mathrm{K}, \mathrm{SOC}$ and TN than soils under DNOR, however without significant differences (Fig. 3.1.4). The other chemical soil properties showed no differences between soils under DWIR and DNOR. In contrast, particle size distribution showed again a significant difference between soils under DWIR and DNOR. Soils under STE had the highest sand contents, followed by soils under DNOR. Soils under DWIR had the highest clay and silt contents, followed by soils 
under FOR. Bulk densities and rock-fragment contents of the soils of the four vegetation categories were similar.
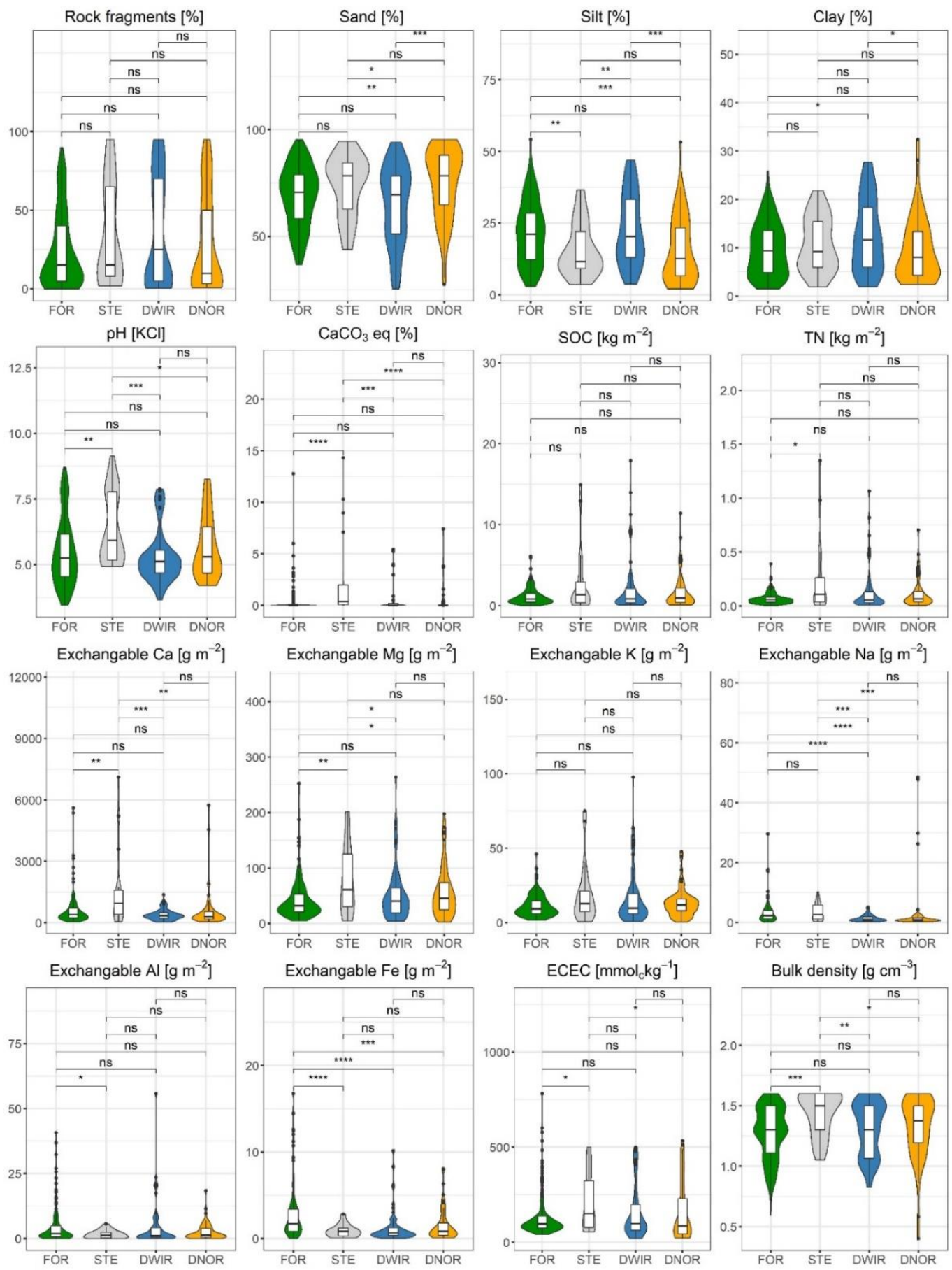

Figure 3.1.3: Properties of the entire soil profiles (down to either the bedrock or permafrost) under the four vegetation categories ( $n=305)$ : near-natural forest (FOR, green), steppe close to the forest (STE, grey), disturbed forest with regrowth of trees (DWIR, blue) and disturbed forest showing no regrowth of trees (DNOR, orange). $P$ values indicated above the plots were calculated for differences between the arithmetic means ( $n s: p>0.05$; ${ }^{*}: p \leq 0.05$; ${ }^{* *}: p \leq 0.01$; $\left.{ }^{* * *}: p \leq 0.001 ;{ }^{* * *}: p \leq 0.0001\right)$. Horizontal bars = medians, boxes = first and third quartiles, points $=$ outliers, violins $=$ data distributions. 

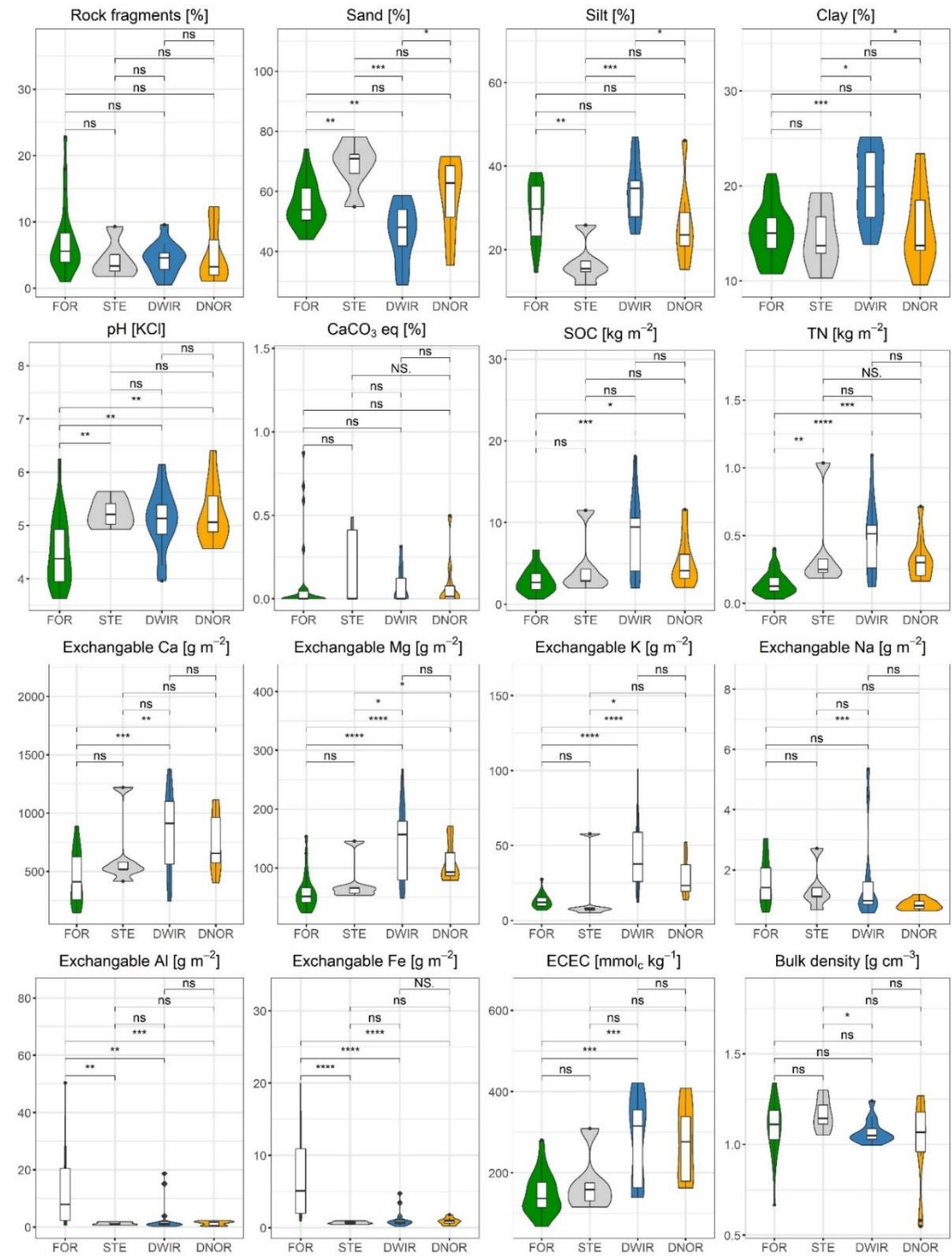

Figure 3.1.4: Properties of the uppermost $10 \mathrm{~cm}$ of the soil profiles under the four vegetation categories $(n=54)$ : near-natural forest (FOR, green), steppe close to the forest (STE, grey), disturbed forest with regrowth of trees (DWIR, blue) and disturbed forest showing no regrowth of trees (DNOR, orange). $P$ values indicated above the plots were calculated for differences between the arithmetic means (NS.: $p=1$; ns: $p>0.05$; *: $p \leq 0.05$; ${ }^{* *}: p \leq 0.01$; ${ }^{* * *}: p \leq 0.001$; $* * * *: p \leq 0.0001)$. Horizontal bars $=$ medians, boxes $=$ first and third quartiles, points $=$ outliers, violins = data distributions. 


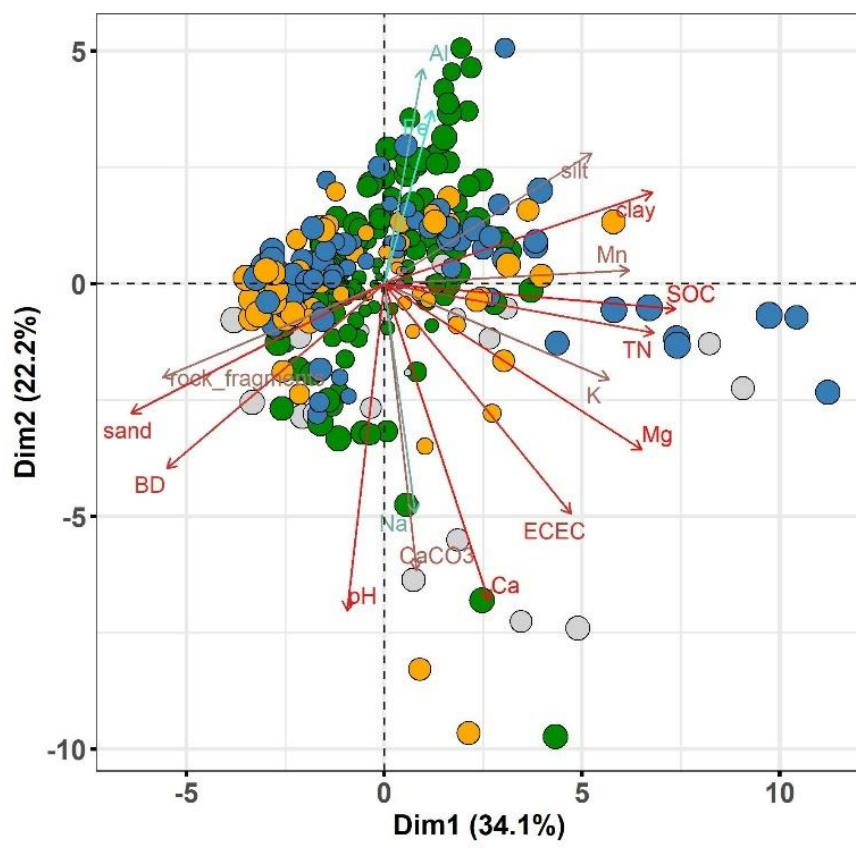

$$
\begin{aligned}
& \text { Vegetation category } \\
& \text { - FOR } \\
& \text { - STE } \\
& \text { - DWIR } \\
& \text { - DNOR }
\end{aligned}
$$

Contribution [\%]

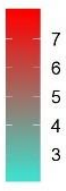

Quality of representation

O 0.2

$\begin{array}{lll}O & 0.4\end{array}$

0.6

0.8

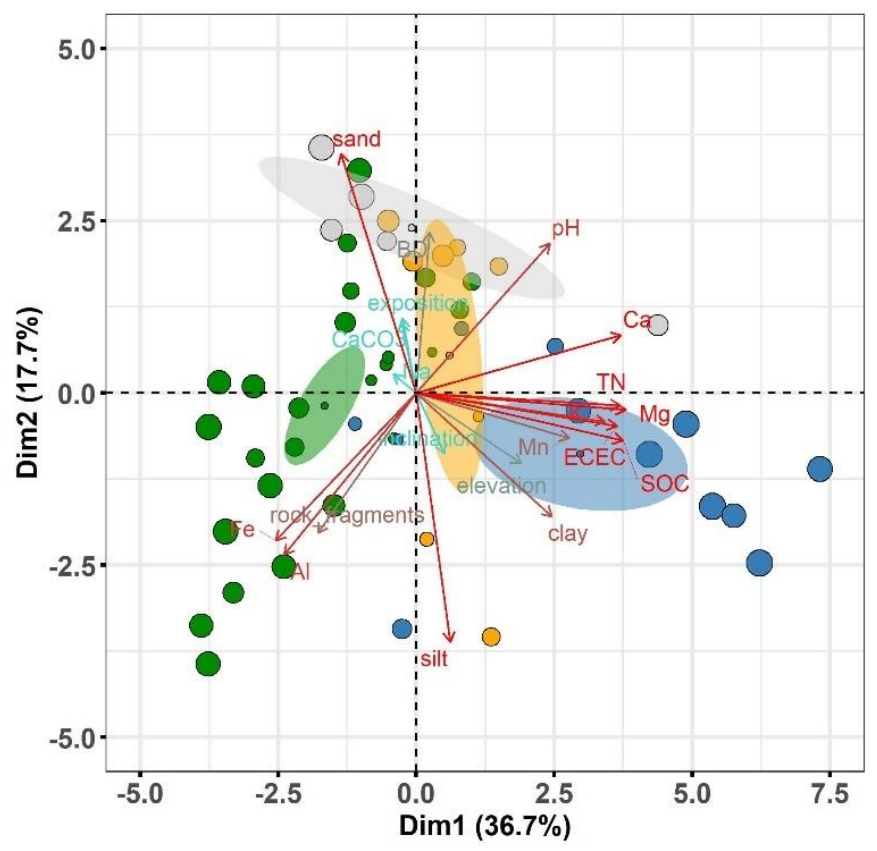

Vegetation category

- FOR

- STE

- DWIR

- DNOR

Contribution [\%]

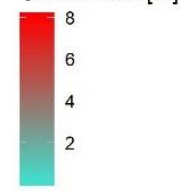

Quality of representation

0.25

0.50

0.75

Figure 3.1.5: Top: PCA of the properties of the entire soil profiles under the four vegetation categories ( $n=303)$ : near-natural forest (FOR, green), steppe close to the forest (STE, grey), disturbed forest with regrowth of trees (DWIR, blue) and disturbed forest showing no regrowth of trees (DNOR, orange). Bottom: PCA of the properties of the uppermost $10 \mathrm{~cm}$ of the soil profiles under the four vegetation categories $(n=52)$. In addition, inclination, exposition and elevation were included in the second PCA. Arithmetic means and $95 \%$ confidence intervals of the data for soils under each vegetation category are represented by a smaller circle and a shaded ellipse, respectively. SOC = soil organic carbon, $T N=$ total nitrogen, ECEC = effective cation exchange capacity, $B D=$ bulk density, and $\mathrm{Ca}, \mathrm{Mg}, \mathrm{K}, \mathrm{Na}, \mathrm{Al}, \mathrm{Fe}$, and $\mathrm{Mn}=$ exchangeable cations.

In the principle component analysis (PCA) of the data for the entire soil profiles, the first two factors explained $56.3 \%$ of the total variance (Fig. 3.1.5 top). The variables sand content, rockfragment content and bulk density on one hand, made up one axis together with clay and silt 
contents on the other hand. Most of the data scattered around this axis, regardless of vegetation category. Exchangeable $\mathrm{Al}$ and $\mathrm{Fe}$ on one hand, made up a second axis together with $\mathrm{pH}$, carbonate content, and exchangeable $\mathrm{Ca}$ and $\mathrm{Na}$ on the other hand. Exchangeable Al and Fe did not contribute much to the PCA, yet, the soils under FOR clustered around them. On the other hand, some soils under STE, DNOR and FOR clustered around $\mathrm{pH}$, carbonate content, and exchangeable $\mathrm{Ca}$ and $\mathrm{Na}$. In addition, another cluster around SOC and TN stocks, and exchangeable $\mathrm{Mg}, \mathrm{K}$ and $\mathrm{Mn}$, occurred close to the axis of clay and silt contents. Mainly soils under DWIR but also some soils under STE fell into this cluster.

In the PCA of the data for the uppermost $10 \mathrm{~cm}$ of the soil profiles, the first two factors explained $54.5 \%$ of the total variance (Fig. 3.1.5 bottom). Sand content and bulk density on one hand, made up one axis together with silt content on the other hand. Rock-fragment content and exchangeable Fe and $\mathrm{Al}$ on one hand, made up a second axis together with $\mathrm{pH}$ on the other hand. In addition, a cluster of clay content, SOC and TN stocks, ECEC, and exchangeable Mg, $\mathrm{K}$ and $\mathrm{Mn}$ occurred. The factor elevation also fell into this cluster, but with a minor contribution. The contributions of inclination, exposition, carbonate content, and exchangeable Na were negligible. In general, the data for the uppermost $10 \mathrm{~cm}$ of the soils under the four vegetation categories (lower PCA) plotted more separately from each other than those for the entire soil profiles (upper PCA). The arithmetic means and $95 \%$ confidence intervals of the data for the uppermost $10 \mathrm{~cm}$ of the soils under the four vegetation categories (smaller dots and shaded ellipses) confirmed the differences and clear separation. Soils under FOR plotted around the axes of sand and exchangeable Fe and Al. Soils under STE concentrated around sand and bulk density, thereby slightly shifting to the side of exchangeable $\mathrm{Ca}, \mathrm{Mg}, \mathrm{K}$, and SOC and TN stocks. Soils under DWIR plotted closer to silt than to sand, and mostly fell into the cluster of ECEC, exchangeable Mg, K, and SOC and TN stocks. Soils under DNOR plotted between those under STE and DWIR. The confidence interval of the soils under FOR was clearly separated from all other confidence intervals. That of the soils under DWIR was also separated 
and showed only a minor overlap with the one of soils under DNOR. The confidence intervals of the soils under STE and DNOR showed a considerable overlap.

Based on the data presented in Figures 3.1.3-5, we chose the most relevant variables for direct comparison of the soil properties under DWIR and DNOR, using multiple linear regression models (Fig. 3.1.6). We found a significant difference in particle size distribution, both for the data of the entire soil profiles (Fig. 3.1.6 top) and for the uppermost $10 \mathrm{~cm}$ of the soil profiles (Fig 3.1.6. bottom). Soils under DNOR had clearly more sand, and less silt and clay than soils under DWIR. The soils did not exhibit significant differences with respect to any other soil properties. All confidence intervals overlapped with the zero line, and all $p$ values were $>0.05$. The only relevant observation was that the uppermost $10 \mathrm{~cm}$ of the soil profiles under DNOR tended to have smaller stocks of SOC and exchangeable K, compared to those under DWIR, however without significant differences either. 

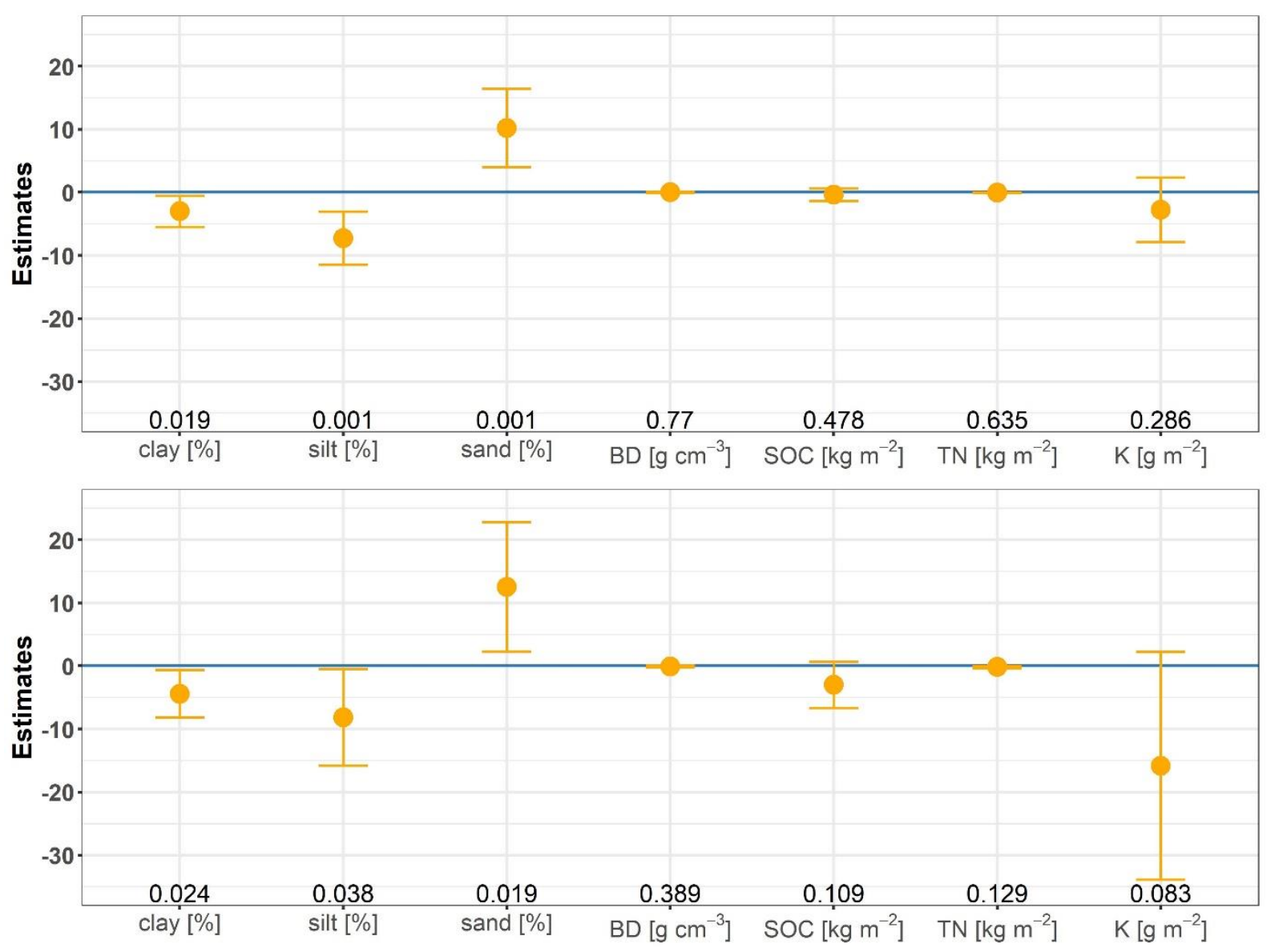

Figure 3.1.6: Top: Estimates and $95 \%$ confidence intervals of linear regression models, comparing the entire soil profiles under disturbed forest showing no regrowth of trees (DNOR, orange) to those under disturbed forest with regrowth of trees (DWIR, blue) $(n=305)$. $P$ values indicated below the plots were calculated for the differences between the estimates for soils under DNOR and DWIR. Data for exchangeable $\mathrm{Mg}$ were left out for better readability (estimate: +4.5; confidence intervals: $+21.2 /-12.2 ; p=0.596)$. Bottom: Estimates and $95 \%$ confidence intervals of linear regression models, comparing the uppermost $10 \mathrm{~cm}$ of the soil profiles under DNOR (orange) to those under DWIR (blue) $(n=54)$. P values indicated below the plots were calculated for the differences between the estimates for soils under DNOR and DWIR. Data for exchangeable $\mathrm{Mg}$ were left out for better readability (estimate: -32.2; confidence intervals: $+16.5 /-80.9 ; p=0.184$ ). $B D=$ bulk density, $S O C=$ soil organic carbon, $T N=$ total nitrogen, $K=$ exchangeable potassium.

\subsubsection{Hydrological soil properties}

In general, all soils had high hydraulic conductivities, due to their predominantly sandy texture. A site-wise comparison between soils under DWIR and DNOR showed that soils under DWIR tended to have higher hydraulic conductivities in their uppermost horizons (Fig. 3.1.7 bottom). For example, the hydraulic conductivities of soil profiles 31 and 32 (DNOR) at site 1 were below $1.510^{-3} \mathrm{~cm} \mathrm{~s}^{-1}$ whereas those of profiles $33-36$ (DWIR) ranged between 1.5 and $310^{-3} \mathrm{~cm} \mathrm{~s}^{-}$ 
1. Profiles 38 and 40 (DNOR) at site 2 showed hydraulic conductivities between $2.510^{-3} \mathrm{~cm} \mathrm{~s}^{-}$ ${ }^{1}$ and $3.510^{-3} \mathrm{~cm} \mathrm{~s}^{-1}$ in their uppermost horizons, while the hydraulic conductivities of profiles 37 and 41 (DWIR) exceeded $510^{-3} \mathrm{~cm} \mathrm{~s}^{-1}$. Soils under FOR showed similar hydraulic conductivities, with a maximum of $3.510^{-3} \mathrm{~cm} \mathrm{~s}^{-1}$ (Fig. 3.1.7 top). Soils under FOR had lower plant-available field capacities (FC $\mathrm{Fa}_{\mathrm{pa}}$ ) than soils under DWIR and DNOR (Fig. 3.1.7). Except for one subsoil horizon, $\mathrm{FC}_{\mathrm{pa}}$ ranged from 12 vol. \% to 22 vol. \% in soils under FOR, and from 12 vol. \% to 33 vol. \% in soils under DWIR and DNOR. The differences between soils under DWIR and DNOR became clearer in a site-wise comparison. For example, $\mathrm{FC}_{\mathrm{pa}}$ of profiles 39 and 40 (DNOR) at site 2 ranged between 12 vol. \% and 17 vol. \%, whereas profile 37 (DWIR) had $\mathrm{FC}_{\mathrm{pa}}$ between 17 vol. \% and 26 vol. \%. However, the limited number of samples analysed for $\mathrm{FC}_{\mathrm{pa}}$ did not allow for a final statement on differences between the sites with respect to $\mathrm{FC}_{\mathrm{pa}}$. 
a)

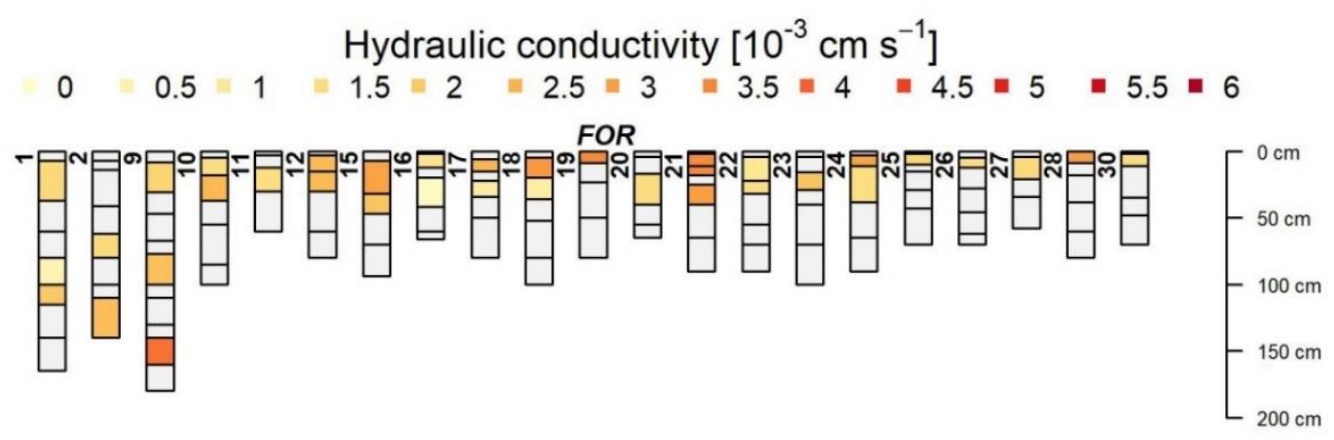

b)

Plant-available field capacity [vol. \%]

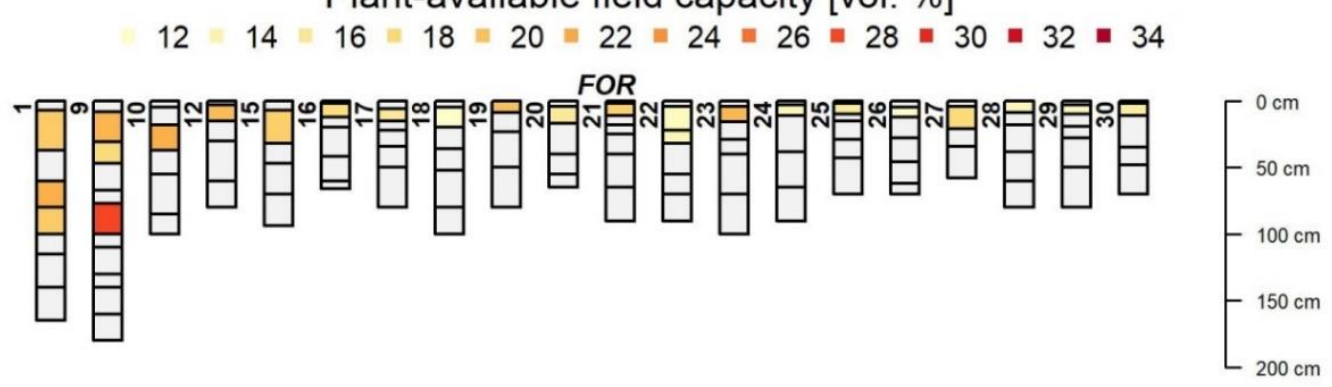

c)

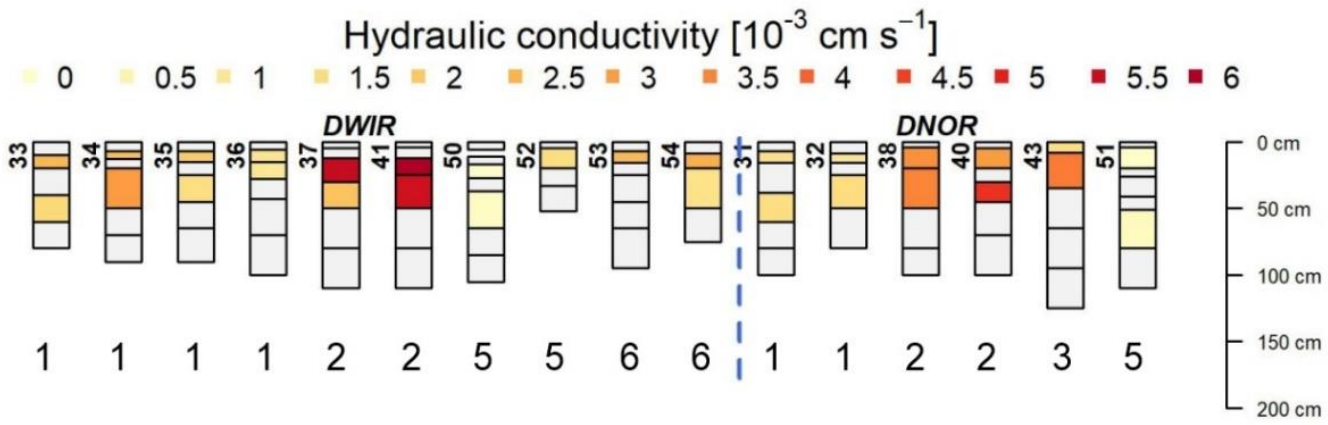

d)

Plant-available field capacity [vol. \%]

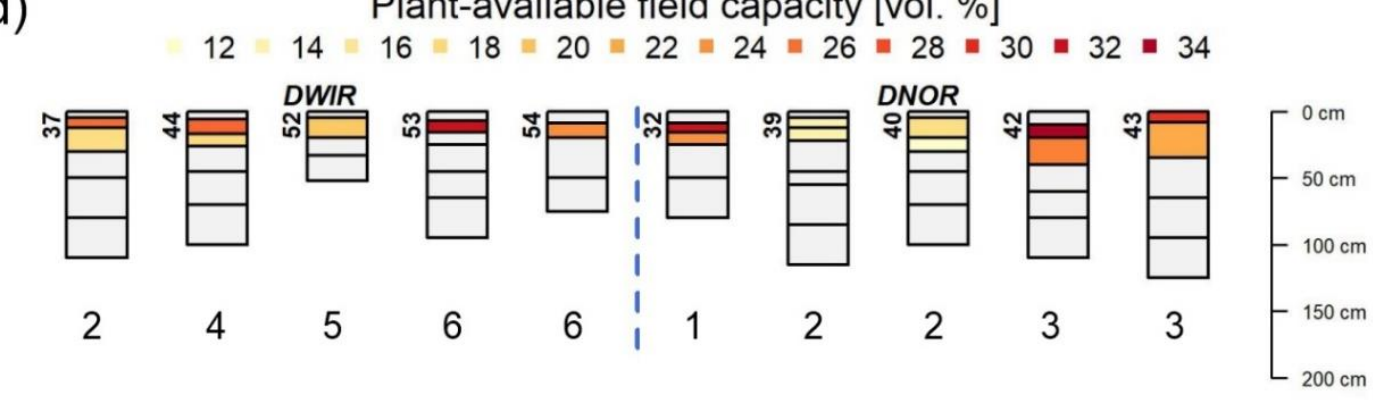

Figure 3.1.7: Hydraulic conductivities (a) and plant-available field capacities (b) of soils under near-natural forest (FOR), and hydraulic conductivities (c) and plant-available field capacities (d) of soils under disturbed forest with regrowth of trees (DWIR; left) and under disturbed forest showing no regrowth of trees (DNOR; right). Soil horizons in light grey colour were not subjected to these measurements. Same numbers under the profiles in (c) and (d) indicate that the profiles were located at the same site. 

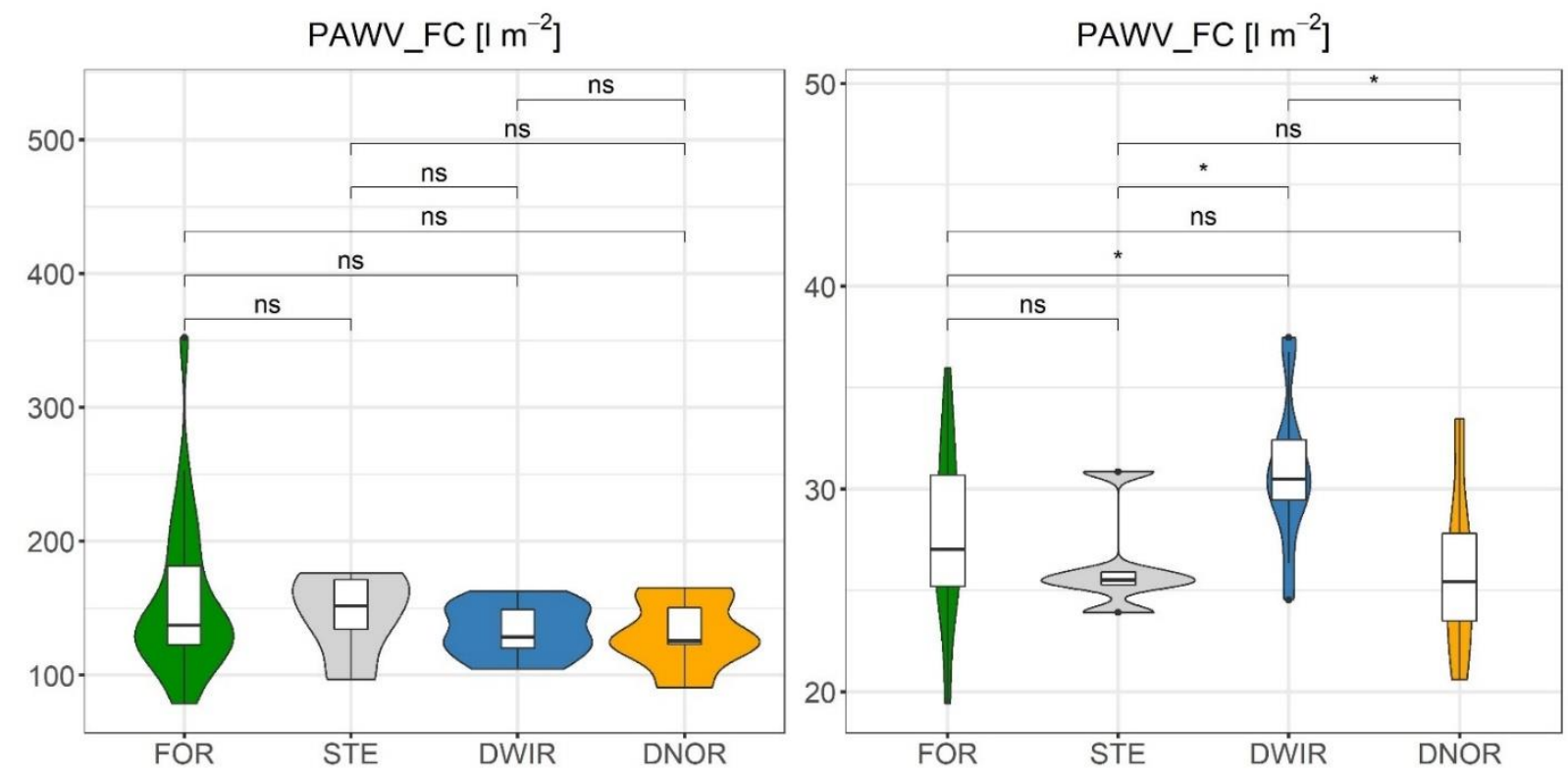

Figure 3.1.8: Calculated plant-available water volume at field capacity $\left(P A W V_{F C}\right)$ per square metre, stored in the entire soil profiles (left), and stored in only the uppermost $10 \mathrm{~cm}$ of the soil profiles (right) under the four vegetation categories: near-natural forest (FOR, green), steppe close to forest (STE, grey), disturbed forest with regrowth of trees (DWIR, blue) and disturbed forest showing no regrowth of trees (DNOR, orange). $n=49, P$ values were calculated for differences between the arithmetic means (ns: $p>0.05$; * $p \leq 0.05 ;{ }^{* *}: p \leq 0.01 ;{ }^{* *}: p \leq 0.001$; $* * * *: p \leq 0.0001)$. Horizontal bars $=$ medians, boxes $=$ first and third quartiles, points $=$ outliers, violins $=$ data distributions.

Plant-available field capacity calculated by pedo-transfer functions from the literature $\left(\mathrm{FC}_{\mathrm{pa}, \mathrm{cal}}\right)$ and measured plant-available field capacity $\left(\mathrm{FC}_{\mathrm{pa}}\right)$ did not match well, and the highest obtained $\mathrm{R}^{2}$ was only 0.195 (Table 3.1.2). We chose the pedo-transfer function of Gupta and Larson (1979), because of the wide range of soils used in their dataset, making it widely applicable. We assume that the mismatch with our measured data was due to disturbance of the samples during the transport from Mongolia to Germany, and due to high rock-fragment contents in many of our samples, creating several problems. For instance, there was a risk that rock fragments might have been hit and slightly moved by the cylinders, when these were hammered into the soil, and that moving rock fragments in turn pushed finer particles, thus slightly altering the pore-size distribution, the contribution of rock fragments to $\mathrm{FC}_{\mathrm{pa}}$ was neglected, and there was uncertainty in the calculation of rock-fragment content [vol.\%] based on soil bulk density and an assumed rock density of $2.65 \mathrm{~g} \mathrm{~cm}^{3}$. $\mathrm{FC}_{\mathrm{pa}, \mathrm{cal}}[\mathrm{vol} . \%]$ of each horizon was transformed into plant-available water volume at field capacity ( $\left.P A W V_{\mathrm{FC}}\right)$ per square metre 
in the whole soil profile (Figure 3.1.8, left), and only in the uppermost $10 \mathrm{~cm}$ of the soils (Figure 3.1.8, right). Thereby, we assumed that $P A W V_{F C}$ stored in the whole profile is the relevant factor for mature trees, whereas $P A W V_{F C}$ stored in the uppermost $10 \mathrm{~cm}$ of the soils is crucial for the reestablishment of seedlings after forest disturbance.

There were no significant differences in $\mathrm{PAWV}_{\mathrm{FC}}$ of the whole soil profiles between the four vegetation categories (Figure 3.1.8, left). In contrast, $P A W V_{F C}$ in the uppermost $10 \mathrm{~cm}$ was significantly higher in soils under DWIR compared to soils under all other vegetation categories (Figure 3.1.8, right). Soils under FOR, STE and DNOR showed no significant difference in $\mathrm{PAWV}_{\mathrm{FC}}$ in their uppermost $10 \mathrm{~cm}$. Soils under FOR exhibited a very wide range of $\mathrm{PAWV} F$ in their upper most $10 \mathrm{~cm}$.

Water repellency of topsoils under different vegetation categories did not show any differences (Figure 3.1.10). Topsoil samples from all vegetation categories included samples, on which the water drop only persisted for one or a few seconds, and samples on which the drop persisted for more than 1000 seconds.

\subsubsection{Discussion}

\subsubsection{Chemical soil properties}

In general, Siberian larch has low requirements with respect to chemical soil properties (Dylis 1947). It can grow on a wide range of soils and may colonise even rather fresh sediments (Timoshok and Skorokhodov 2014). Siberian larch can also adapt to low nutrient availability by enhanced soil nutrient exploitation (Lebedev 2012; Chernyshenko and Vasilyev 2019). Most importantly, it needs nitrogen (Lebedev 2010; Chernyshenko and Vasilyev 2019), like many

other larch species including Larix gmelinii (Schulze et al. 1995; Liang et al. 2014), Larix kaempferi (Leyton 1956; Kayama et al. 2009) and hybrids such as Larix x eurolepis (Pâques 1994). Also a lack in K and Mg may limit the growth of larch species on poor, sandy soils 
(Leyton 1956; Phu 1975), whereas growth limitation by insufficient $P$ supply has not yet been reported. Generally, differences in the vitality and growth of larch are more commonly caused by climatic or hydrological differences than by nutrient limitations (Fiedler et al. 1980; Stüber 1998; Viers et al. 2013).

Because of the low nutrient requirements of Siberian larch and since we did not detect any significant differences in the chemical properties of soils under disturbed forest with regrowth of trees (DWIR) and under disturbed forest showing no regrowth of trees (DNOR), we conclude that chemical soil properties are not responsible for the differences in post-disturbance regrowth of Siberian larch in our study area. The uppermost $10 \mathrm{~cm}$ of the soils under FOR had even significantly smaller $\mathrm{N}$ stocks and lower contents of exchangeable $\mathrm{Ca}, \mathrm{Mg}$ and $\mathrm{K}$ than the uppermost $10 \mathrm{~cm}$ of the soils under DNOR. Nevertheless, saplings and young trees were growing in the FOR areas, which confirms that the nutrient supply of all analysed soils fulfilled the needs of Siberian larch. Also, nutrient stocks were similar or even higher compared to those reported from other Siberian larch forests and from forests of other larch species (Kayama et al. 2009; Watanabe et al. 2012; Wang et al. 2014).

\subsubsection{Physical soil properties and soil hydrology}

Soils under DWIR had significantly more silt and clay, and thus higher plant-available field capacity than soils under DNOR, which were considerably sandier (Figure 3.1.4). As mean annual precipitation in Tosontsengel is only $200-250 \mathrm{~mm}$, lack of water represents a major limitation for tree growth (Dulamsuren et al. 2011; Chenlemuge et al. 2015b). Under these climatic conditions, it is plausible that silt and clay content, and corresponding plant-available field capacity are key factors controlling the post-disturbance tree regrowth pattern. The similarity in silt and clay contents of soils under DNOR and soils under STE (no significant difference in Figure 3.1.4) points to a potential risk of DNOR sites to permanently shift to steppe 
vegetation. Such potential shift has already been predicted for the forest steppe in the Khentey Mountains, Mongolia (Dulamsuren and Hauck 2008; Dulamsuren et al. 2009c).

Measured plant-available field capacities confirmed the difference between soils under DWIR and DNOR. Calculated PAWV $\mathrm{FC}_{\mathrm{FC}}$ further underscored the crucial role of soil water storage for post-disturbance tree regrowth under the given climatic conditions. With respect to $P A W V_{F C}$ of the whole soil profiles, the absence of any significant differences between the four vegetation categories (Figure 3.1.8, left) is in accordance with the fact that mature trees were originally able to grow on all of these north-facing slopes prior to a severe disturbance. With respect to the uppermost $10 \mathrm{~cm}$ of the soils, the significantly higher PAWV $\mathrm{FC}_{\mathrm{FC}}$ under DWIR compared to soils under all other vegetation categories (Figure 3.1.8, right) highlights the importance of water storage in the uppermost centimetres for the re-establishment and survival of seedlings after severe forest disturbance, which is the precondition for post-disturbance forest recovery. The very wide $P A W V_{F C}$ range in the uppermost $10 \mathrm{~cm}$ of soils under FOR suggests that these FOR sites include both, sites where seedlings will be able to re-establish after severe disturbance, and sites where this won't be possible, which means that most likely no forest regrowth will take place, if once a severe forest disturbance happens to these sites.

In the site-wise comparison, hydraulic conductivity tended to be higher in the uppermost horizons of soils under DWIR compared to their counterparts under DNOR. Trees may benefit from this difference for two reasons. Firstly, rapid infiltration through the uppermost horizons reduces evaporation loss. Secondly, grasses and herbs have a dense but shallow root system and compete with tree roots for water at shallow soil depth. As tree roots reach deeper down the soil, they benefit from rapid water infiltration below the depth of the roots of grasses and herbs. Lange et al. (2015) carried out irrigation experiments on grass-dominated south-facing slopes and forest-dominated north-facing slopes in the Mongolian forest steppe. On southfacing slopes, most of the water was either taken up by grass or evaporated, and the remaining water reached only $5 \mathrm{~cm}$ soil depth. On north-facing slopes, the water percolated down to the 
permafrost table. Although the contrasting exposition also affected this experiment, these results confirm the competitiveness of grasses for water in the upper soil horizons and the relevance of soil hydraulic conductivity for tree growth in water-limited environments.

We did not detect a positive effect of permafrost on post-disturbance tree regrowth, as permafrost was neither encountered under DWIR nor under DNOR. This is in agreement with observations by Kopp et al. (2014), who reported absence of permafrost five years after severe forest fire. The same authors moreover measured increased soil moisture in soils of burned sites, compared to soils under forest, which they attributed to the absence of tree transpiration. In contrast, Park et al. (2009) stated a decrease in soil moisture after fire and logging, arguing that evaporation loss from the bare soils and deterioration of physical soil properties exceed the decrease in transpiration. In our study area, we also observed rather decreased soil moisture at sites disturbed by fire and logging, compared to near-natural forest sites. An additional decline in soil moisture after fire can be induced by water repellency that may increase surface run off (DeBano 2000; Mataix-Solera and Doerr 2004). However, we did not observe a significant difference in water repellency between the four vegetation categories, possibly because of the high frequency of fires in in our study area, and associated enhanced erosion (Goldammer 2002; Hessl et al. 2012). As water repellency occurred irregularly across the whole study area, including DWIR and DNOR, it seemed to be not relevant for the postdisturbance tree recovery pattern in our study area.

\subsubsection{Further relevant environmental factors}

Other factors besides soil hydrology that influence the post-disturbance tree regrowth pattern, include in particular relief and human activity. Relief-induced water gains in concave positions may support tree growth even where soil properties seem to be unfavourable. Similarly, water losses through divergence in convex positions may hamper tree growth, even where soil properties seem to be suitable. Also, small tree patches that survived a disturbance, can have 
a positive influence on post-disturbance tree regrowth. In our study area, we observed enhanced fructification of trees that had survived forest fires, initiating tree regrowth in belts around small tree patches that had persisted. We explain this observation by the shading of the remaining adult trees that reduces evaporation and creates a more even microclimate on the ground, and by increased availability of intact seeds in the direct surrounding of mature trees (Dugarjav 2006).

In contrast, human activity, especially logging and pastoral pressure, may inhibit postdisturbance forest recovery (Khishigjargal et al. 2013; Dulamsuren et al. 2014; Khansaritoreh et al. 2017a). In particular, goats grazing in areas of burned forest or in forest stands that have previously been opened by partial logging, hamper the growth of seedlings and damage young trees (Sankey et al. 2006). Thus, human impact and soil hydrology are the two key factors controlling the post-disturbance tree regrowth pattern (Fig. 3.1.9). This is the outcome of this work, and relates to moderate and severe disturbances in our study area, which lead to deforested areas showing diverse tree-regrowth. Differences in tree-regrowth between moderate and severe disturbances were not detected. The observed low disturbances did not have considerable effects on the forests.

Loss of the shading by the forest canopy, of the forest microclimate and the insulating organic layer in turn lead to permafrost degradation. Also, the presently ongoing climate change accelerates permafrost decline in Mongolia. Thus, this essential soil water reservoir is likely to disappear (Sharkhuu and Sharkhuu 2012). As the meltwater from the active layer above the permafrost table can support tree growth even at sites where soil water storage is below the threshold for tree growth, permafrost decline may also contribute to the decrease in forest area in the Mongolian forest steppe. In some of our investigated sites, this has already happened.

Klinge et al. (2020) estimated that the potential forest distribution in the Khangai Mountains is three times larger than the actual forest area. This discrepancy indicates that forest fire and human activity already caused a considerable decline of forested areas. 
- High plant-available field capacity of soils

- High silt and clay contents, high SOC contents

- High hydraulic conductivity of uppermost soil horizons

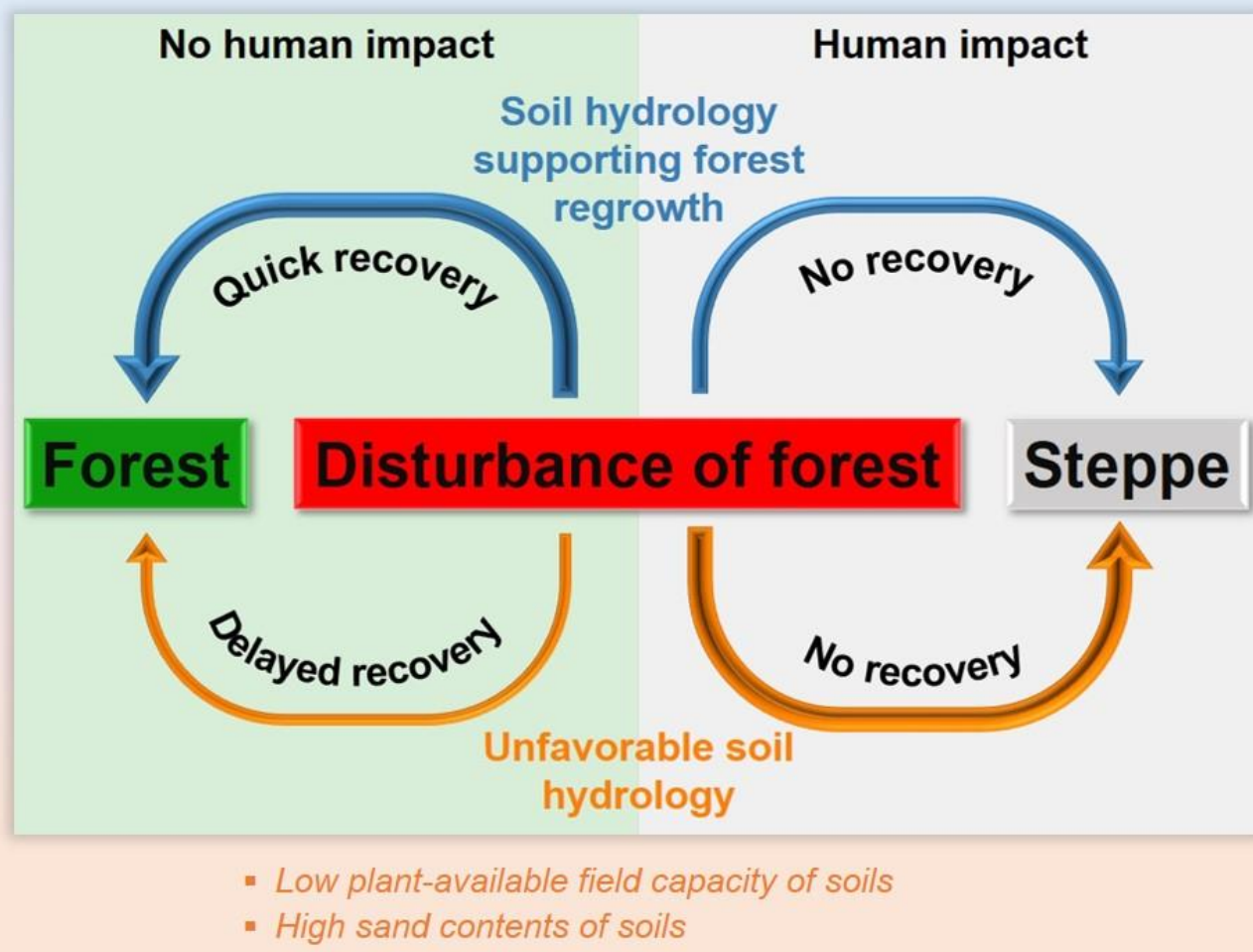

Figure 3.1.9: Possible development pathways of disturbed forests in the Mongolian forest steppe, as controlled by soil hydrology and human impact. Soil properties listed in dark blue = significant positive effect, light blue $=$ non-significant positive effect, orange = significant negative effect.

\subsubsection{Conclusions}

This study showed that the post-disturbance regrowth pattern of forests in the central Mongolian forest steppe, a highly sensitive, semi-arid landscape, is largely controlled by soil hydrology. With respect to our hypotheses established in the beginning, we conclude that:

1) Differences in post-disturbance tree regrowth depend mainly on the texture of the uppermost soil horizons. Loamy soils have high plant-available field capacity and are thus able to store sufficient amounts of water for post-disturbance re-establishment of seedlings as a precondition for forest regrowth. In contrast, sandy soils cannot store enough water for the re-establishment of seedlings and subsequent recovery of tree vegetation under the present environmental conditions.

2) Post-disturbance tree regrowth may be supported by higher hydraulic conductivity in the uppermost soil horizons, as rapid percolation through the upper soil horizons reduces 
evaporation loss. In addition, trees benefit from the reduced competition for water with grasses and herbs that results from rapid water percolation into the subsoil.

3) Nutrient limitation is not relevant for the uneven post-disturbance tree regrowth pattern in our study area, as the dominant tree species, Siberian larch, has rather low nutrient requirements.

4) Meltwater from the active layer above the permafrost table provides additional water for near-natural forests. However, it cannot be a relevant factor for the uneven post-disturbance regrowth pattern of Siberian larch in our study area, because permafrost was encountered neither under disturbed forests with nor without tree regrowth.

Under the given climatic conditions, water limitation is the predominant factor controlling tree growth in the semi-arid Mongolian forest steppe. Therefore, even small differences in soil properties that lead to an increase in the amount of plant-available water, can be decisive for post-disturbance tree regrowth.

Disturbances by severe fire or clear-cutting result in loss of permafrost and thus loss of an additional water reservoir during summer. Such additional water source can be critical at sites, where soil water storage alone is slightly below the threshold for tree growth. Therefore, such sites are particularly prone to an irreversible shift from forest to steppe after strong disturbance, involving loss of permafrost. Moreover, we expect that many sites where soil hydrology allows for post-disturbance tree regrowth under the present climatic conditions, will lose their ability for post-disturbance forest recovery in the course of the ongoing climate change, as the present conditions are very close to the threshold for forest growth, and already a minor change may lead to a fall below this threshold.

Climate projections predict that the decrease of permafrost will continue, and drought events will become both more frequent and more intensive. At the same time, it seems unlikely that the pressure on forests in the Mongolian forest steppe by fire, logging and grazing will decrease, unless explicit and effective measures are taken. Consequences of this unfavourable interplay will most likely include a decrease in the growth rates of trees, and a further considerable and irreversible decline of forested area. Therefore, regulation of human 
impact on the forests in the Mongolian forest steppe is mandatory, if a further irreversible loss of forest area shall be avoided.

\subsubsection{Appendices}


Table 3.1.1: General information on the soil profiles. Abbreviations are according to the Guidelines for Soil Description (FAO 2006b). *: If permafrost is present, the depth of the permafrost table equals the profile depth.

\begin{tabular}{|c|c|c|c|c|c|c|c|c|c|c|c|c|c|c|}
\hline \begin{tabular}{|l} 
Vegetatio \\
$n$ \\
category
\end{tabular} & $\begin{array}{l}\text { Prof } \\
\text { ile } \\
\text { ID }\end{array}$ & $\begin{array}{l}\text { Coordinate } \\
\text { s N }\end{array}$ & $\begin{array}{l}\text { Coordinate } \\
\mathrm{sE}\end{array}$ & $\begin{array}{l}\text { Elevati } \\
\text { on } \\
{[\mathrm{m}}\end{array}$ & $\begin{array}{l}\text { inclin } \\
\text { ation } \\
{[\%]}\end{array}$ & $\begin{array}{l}\text { Expos } \\
\text { ition } \\
{[0}\end{array}$ & Bedrock & $\begin{array}{l}\text { Main } \\
\text { sediment type }\end{array}$ & $\begin{array}{l}\text { Pendants } \\
\text { on rock } \\
\text { fragments }\end{array}$ & $\begin{array}{l}\text { Profile } \\
\text { depth } \\
{[\mathrm{cm}]}\end{array}$ & $\begin{array}{l}\text { Permafr } \\
\text { ost }^{\star}\end{array}$ & $\begin{array}{l}\text { Disturba } \\
\text { nce by } \\
\text { fire }\end{array}$ & $\begin{array}{l}\text { Disturban } \\
\text { ce by } \\
\text { logging }\end{array}$ & Soil type [based on WRB] \\
\hline FOR & 1 & $48^{\circ} 38.681^{\prime}$ & $98^{\circ} 22.141^{\prime}$ & 1915 & 24.5 & 320 & granite & sand sheet & no & 165 & yes & no & no & $\begin{array}{l}\text { Eutric Cambisol (Katoarenic, Bathygelic, Epiloamic, Nechic, } \\
\text { Ochric, Endoraptic) }\end{array}$ \\
\hline FOR & 2 & $48^{\circ} 38.700^{\prime}$ & $98^{\circ} 22.034^{\prime}$ & 1907 & 26.5 & 340 & granite & sand sheet & no & 140 & yes & no & no & $\begin{array}{l}\text { Eutric Cambisol (Katoarenic, Bathygelic, Amphiloamic, Nechic, } \\
\text { Ochric) }\end{array}$ \\
\hline STE & 3 & $48^{\circ} 38.929^{\prime}$ & $98^{\circ} 22.122^{\prime}$ & 1882 & 28.5 & 301 & granite & bedrock & no & 90 & no & no & no & $\begin{array}{l}\text { Skeletic Cambic Endoleptic Phaeozem (Amphiarenic, Epiloamic, } \\
\text { Nechric) }\end{array}$ \\
\hline STE & 4 & $48^{\circ} 38.377^{\prime}$ & $98^{\circ} 22.202^{\prime}$ & 1917 & 25.75 & 292 & granite & colluvium & no & 90 & no & no & no & $\begin{array}{l}\text { Endoskeletic Phaeozem (Amphiarenic, Colluvic, Epiloamic, } \\
\text { Nechric, Epiraptic) }\end{array}$ \\
\hline STE & 5 & $48^{\circ} 38.736^{\prime}$ & $98^{\circ} 21.853^{\prime}$ & 1851 & 20 & 307 & granite & colluvium & no & 110 & no & no & no & $\begin{array}{l}\text { Endoskeletic Chernozem (Katoarenic, Cambic, Colluvic, } \\
\text { Amphiloamic, Amphiraptic) }\end{array}$ \\
\hline STE & 6 & $48^{\circ} 38.216^{\prime}$ & $98^{\circ} 22.408^{\prime}$ & 1979 & 24.5 & 300 & granite/gneiss & slope deposit & no & 120 & no & no & no & $\begin{array}{l}\text { Endoskeletic Endoleptic Phaeozem (Katoarenic, Colluvic, } \\
\text { Epiloamic, Nechric, Epiraptic) }\end{array}$ \\
\hline FOR & 7 & $48^{\circ} 38.181^{\prime}$ & $98^{\circ} 22.487^{\prime}$ & 2007 & 31 & 304 & granite/gneiss & sand sheet & no & 105 & no & no & low & $\begin{array}{l}\text { Eutric Endoskeletic Cambisol (Katoarenic, Epiloamic, Nechic, } \\
\text { Ochric, Epiraptic) }\end{array}$ \\
\hline FOR & 8 & $48^{\circ} 38.206^{\prime}$ & $98^{\circ} 22.511^{\prime}$ & 2022 & 32 & 305 & granite/gneiss & sand sheet & no & 120 & no & no & low & $\begin{array}{l}\text { Eutric Endoskeletic Cambisol (Katoarenic, Amphiloamic, Nechic, } \\
\text { Ochric, Endoraptic) }\end{array}$ \\
\hline FOR & 9 & $48^{\circ} 38.770^{\prime}$ & $98^{\circ} 22.074^{\prime}$ & 1868 & 16 & 301 & granite & sand sheet & no & 180 & yes & no & moderate & $\begin{array}{l}\text { Cambic Phaeozem (Katoarenic, Colluvic, Katoloamic, Nechic, } \\
\text { Endoraptic, Bathyprotocalcic, Bathygleyic, Bathyturbic) }\end{array}$ \\
\hline FOR & 10 & $48^{\circ} 38.748^{\prime}$ & $98^{\circ} 22.169^{\prime}$ & 1900 & 26.5 & 303 & granite & slope deposit & no & 100 & no & no & moderate & $\begin{array}{l}\text { Haplic Phaeezem (Endoarenic, Colluxic, Amphiloamic, Nechric, } \\
\text { Amphiraptic) }\end{array}$ \\
\hline FOR & 11 & $48^{\circ} 37.766^{\prime}$ & $98^{\circ} 21.215^{\prime}$ & 1938 & 23.5 & 335 & granite/gneiss & slope deposit & manganese & 60 & yes & no & no & $\begin{array}{l}\text { Endoskeletic Cambic Folic Reductaquic Cryosol (Epiarenic, } \\
\text { Eutric, Amphiloamic, Nechic, Ochric, Epiraptic) }\end{array}$ \\
\hline FOR & 12 & $48^{\circ} 37.775^{\prime}$ & $98^{\circ} 21.277^{\prime}$ & 1943 & 28.5 & 317 & granite/gneiss & slope deposit & no & 80 & yes & no & no & $\begin{array}{l}\text { Endoskeletic Folic Reductaquic Cryosol (Amphiarenic, Eutric, } \\
\text { Epiloamic, Nechic, Ochric, Amphiraptic) }\end{array}$ \\
\hline FOR & 13 & $48^{\circ} 37.258^{\prime}$ & $98^{\circ} 21.517^{\prime}$ & 1974 & 27.5 & 335 & granite/gneiss & slope deposit & manganese & 60 & yes & no & no & $\begin{array}{l}\text { Endoskeletic Folic Reductaquic Cryosol (Eutric, Loamic, Nechic, } \\
\text { Ochric, Epiraptic) }\end{array}$ \\
\hline FOR & 14 & $48^{\circ} 37.322^{\prime}$ & $98^{\circ} 21.624^{\prime}$ & 1969 & 27 & 326 & granite/gneiss & slope deposit & no & 80 & yes & no & no & $\begin{array}{l}\text { Endoskeletic Folic Cryosol (Epiarenic, Eutric, Amphiloamic, } \\
\text { Nechic, Ochric, Epiraptic) }\end{array}$ \\
\hline FOR & 15 & $48^{\circ} 37.728^{\prime}$ & $98^{\circ} 21.233^{\prime}$ & 1947 & 25 & 324 & granite/gneiss & slope deposit & manganese & 94 & yes & no & no & $\begin{array}{l}\text { Endoskeletic Cambic Folic Reductaquic Cryosol (Amphiarenic, } \\
\text { Eutric, Amphiloamic, Nechic, Ochric, Epiraptic) }\end{array}$ \\
\hline FOR & 16 & $48^{\circ} 37.787^{\prime}$ & $98^{\circ} 21.210^{\prime}$ & 1913 & 23.5 & 357 & granite/gneiss & slope deposit & manganese & 66 & yes & no & low & $\begin{array}{l}\text { Cambic Folic Reductaquic Cryosol (Amphiarenic, Eutric, } \\
\text { Amphiloamic, Nechic, Ochric, Epiraptic) }\end{array}$ \\
\hline FOR & 17 & $48^{\circ} 37.816^{\prime}$ & $98^{\circ} 21.208^{\prime}$ & 1908 & 22 & 359 & granite/gneiss & slope deposit & no & 80 & yes & no & low & $\begin{array}{l}\text { Endoskeletic Cambic Reductaquic Cryosol (Endoarenic, Eutric, } \\
\text { Epiloamic, Nechic, Ochric, Amphiraptic) }\end{array}$ \\
\hline FOR & 18 & $48^{\circ} 37.755^{\prime}$ & $98^{\circ} 21.280^{\prime}$ & 1951 & 34.5 & 351 & granite/gneiss & slope deposit & manganese & 100 & yes & no & no & $\begin{array}{l}\text { Endoskeletic Cambic Reductaquic Cryosol (Epiarenic, Eutric, } \\
\text { Amphiloamic, Nechic, Ochric, Epiraptic) }\end{array}$ \\
\hline FOR & 19 & $48^{\circ} 37.799^{\prime}$ & $98^{\circ} 21.268^{\prime}$ & 1930 & 30 & 358 & granite/gneiss & slope deposit & manganese & 80 & yes & no & no & $\begin{array}{l}\text { Endoskeletic Folic Reductaquic Cryosol (Eutric, Loamic, Nechic, } \\
\text { Ochric, Epiraptic) }\end{array}$ \\
\hline FOR & 20 & $48^{\circ} 37.825^{\prime}$ & $98^{\circ} 21.271^{\prime}$ & 1914 & 24 & 1 & granite/gneiss & slope deposit & no & 65 & yes & no & no & $\begin{array}{l}\text { Endoskeletic Cambic Folic Reductaquic Cryosol (Endoarenic, } \\
\text { Eutric, Anoloamic, Nechic, Ochric, Endoraptic) }\end{array}$ \\
\hline FOR & 21 & $48^{\circ} 37.700^{\prime}$ & $98^{\circ} 21.276^{\prime}$ & 1990 & 39 & 315 & granite/gneiss & slope deposit & no & 90 & yes & no & no & $\begin{array}{l}\text { Endoskeletic Reductaquic Cryosol (Amphiarenic, Eutric, } \\
\text { Amphiloamic, Nechic, Ochric, Epiraptic) }\end{array}$ \\
\hline FOR & 22 & $48^{\circ} 37.830^{\prime}$ & $98^{\circ} 21.208^{\prime}$ & 1900 & 11 & 334 & granite/gneiss & slope deposit & no & 90 & yes & no & low & $\begin{array}{l}\text { Endoskeletic Folic Reductaquic Cryosol (Endoarenic, Eutric, } \\
\text { Amphiloamic, Nechic, Ochric, Amphiraptic) }\end{array}$ \\
\hline FOR & 23 & $48^{\circ} 37.736^{\prime}$ & $98^{\circ} 21.290^{\prime}$ & 1977 & 37 & 345 & granite/gneiss & slope deposit & no & 100 & yes & no & no & $\begin{array}{l}\text { Endoskeletic Reductaquic Cryosol (Amphiarenic, Eutric, } \\
\text { Epiloamic, Nechic, Ochric, Epiraptic) }\end{array}$ \\
\hline FOR & 24 & $48^{\circ} 37.843^{\prime}$ & $98^{\circ} 21.256^{\prime}$ & 1908 & 12 & 352 & granite/gneiss & slope deposit & no & 90 & yes & no & low & $\begin{array}{l}\text { Endoskeletic Folic Reductaquic Cryosol (Endoarenic, Eutric, } \\
\text { Amphiloamic, Nechic, Ochric, Epiraptic) }\end{array}$ \\
\hline FOR & 25 & $48^{\circ} 37.649^{\prime}$ & $98^{\circ} 21.231^{\prime}$ & 1994 & 28.5 & 336 & granite/gneiss & slope deposit & no & 70 & no & no & no & $\begin{array}{l}\text { Eutric Endoskeletic Cambisol (Gelic, Gelistagnic, Loamic, } \\
\text { Nechric, Ochric, Epiraptic) }\end{array}$ \\
\hline FOR & 26 & $48^{\circ} 37.669^{\prime}$ & $98^{\circ} 21.199^{\prime}$ & 1982 & 29 & 346 & granite/gneiss & slope deposit & no & 70 & yes & no & no & $\begin{array}{l}\text { Endoskeletic Folic Reductaquic Cryosol (Epiarenic, Eutric, } \\
\text { Amphiloamic, Nechic, Ochric, Epiraptic) }\end{array}$ \\
\hline FOR & 27 & $48^{\circ} 37.697^{\prime}$ & $98^{\circ} 21.184^{\prime}$ & 1977 & 29 & 356 & granite/gneiss & slope deposit & no & 58 & yes & no & no & Cambic Folic Cryosol (Eutric, Loamic, Nechic, Ochric, Epiraptic) \\
\hline FOR & 28 & $48^{\circ} 37.725^{\prime}$ & $98^{\circ} 21.161^{\prime}$ & 1957 & 24.5 & 352 & granite/gneiss & slope deposit & no & 80 & yes & no & no & $\begin{array}{l}\text { Endoskelettic Folic Reductaquic Cryosol (Amphiarenic, Eutric, } \\
\text { Amphiloamic, Nechic, Ochric, Epiraptic) }\end{array}$ \\
\hline FOR & 29 & $48^{\circ} 37.768^{\prime}$ & $98^{\circ} 21.135^{\prime}$ & 1943 & 25.5 & 353 & granite/gneiss & slope deposit & no & 80 & yes & no & no & $\begin{array}{l}\text { Endoskeletic Folic Reductaquic Cryosol (Epiarenic, Eutric, } \\
\text { Amphiloamic, Nechic, Ochric, Epiraptic) }\end{array}$ \\
\hline FOR & 30 & $48^{\circ} 37.787^{\prime}$ & $98^{\circ} 21.127^{\prime}$ & 1915 & 15 & 351 & granite/gneiss & slope deposit & no & 70 & yes & no & low & $\begin{array}{l}\text { Endoskeletic Cambic Folic Reductaquic Cryosol (Eutric, Loamic, } \\
\text { Nechic, Ochric, Epiraptic) }\end{array}$ \\
\hline DNOR & 31 & $48^{\circ} 27.636^{\prime}$ & $98^{\circ} 13.686^{\prime}$ & 2046 & 22 & 316 & granite/gneiss & slope deposit & $\begin{array}{l}\text { calcium } \\
\text { carbonate }\end{array}$ & 100 & no & severe & moderate & $\begin{array}{l}\text { Eutric Endoskeletic Cambisol (Endoarenic, Amphiloamic, } \\
\text { Nechric, Ochric, Amphiraptic) }\end{array}$ \\
\hline DNOR & 32 & $48^{\circ} 27.640^{\prime}$ & $98^{\circ} 13.730^{\prime}$ & 2055 & 25.5 & 344 & granite/gneiss & slope deposit & $\begin{array}{l}\text { calcium } \\
\text { carbonate }\end{array}$ & 80 & no & severe & moderate & $\begin{array}{l}\text { Eutric Endoskeletic Cambisol (Endoarenic, Colluric, Epiloamic, } \\
\text { Nechric, Ochric, Epiraptic) }\end{array}$ \\
\hline DWIR & 33 & $48^{\circ} 27.549^{\prime}$ & $98^{\circ} 13.576^{\prime}$ & 2055 & 25 & 312 & granite/gneiss & slope deposit & $\begin{array}{l}\text { calcium } \\
\text { carbonate }\end{array}$ & 80 & no & severe & moderate & $\begin{array}{l}\text { Eutric Endoskeletic Cambisol (Colluvic, Loamic, Nechric, Ochric, } \\
\text { Epiraptic) }\end{array}$ \\
\hline DWIR & 34 & $48^{\circ} 27.595^{\prime}$ & $98^{\circ} 13.723^{\prime}$ & 2079 & 32.5 & 332 & granite/gneiss & slope deposit & $\begin{array}{l}\text { manganese } \\
\text {, calcium }\end{array}$ & 90 & no & severe & moderate & $\begin{array}{l}\text { Eutric Endoskeletic Cambisol (Protocalcic, Colluvic, Loamic, } \\
\text { Nechric, Ochric, Amphiraptic) }\end{array}$ \\
\hline DWIR & 35 & $48^{\circ} 27.597^{\prime}$ & $98^{\circ} 10.886^{\prime}$ & 2077 & 26.5 & 322 & granite/gneiss & slope deposit & no & 90 & no & severe & moderate & $\begin{array}{l}\text { Eutric Endoskeletic Cambisol (Loamic, Nechric, Ochric, } \\
\text { Epiraptic) }\end{array}$ \\
\hline DWIR & 36 & $48^{\circ} 27.609^{\prime}$ & $98^{\circ} 10.914^{\prime}$ & 2069 & 29.5 & 320 & granite/gneiss & slope deposit & no & 100 & no & severe & moderate & $\begin{array}{l}\text { Eutric Endoskeletic Cambisol (Loamic, Nechric, Ochric, } \\
\text { Epiraptic) }\end{array}$ \\
\hline DWIR & 37 & $48^{\circ} 28.784^{\prime}$ & $98^{\circ} 19.246^{\prime}$ & 2088 & 35 & 324 & granite/gneiss & slope deposit & no & 110 & no & severe & moderate & $\begin{array}{l}\text { Eutric Endoskeletic Cambisol (Amphiarenic, Colluvic, Epiloamic, } \\
\text { Nechric, Ochric, Epiraptic) }\end{array}$ \\
\hline DNOR & 38 & $48^{\circ} 28.790^{\prime}$ & $98^{\circ} 19.074^{\prime}$ & 2004 & 41 & 328 & granite/gneiss & colluvium & no & 100 & no & severe & moderate & $\begin{array}{l}\text { Endoskeletic Phae ozem (Amphiarenic, Colluvic, Epiloamic, } \\
\text { Nechric, Ochric, Amphiraptic) }\end{array}$ \\
\hline DNOR & 39 & $48^{\circ} 28.732^{\prime}$ & $98^{\circ} 18.980^{\prime}$ & 2018 & 36 & 328 & granite/gneiss & slope deposit & $\begin{array}{l}\text { calcium } \\
\text { carbonate }\end{array}$ & 115 & no & severe & severe & $\begin{array}{l}\text { Eutric Endoskeletic Cambisol (Amphiarenic, Colluvic, Epiloamic, } \\
\text { Nechric, Ochric, Amphiraptic) }\end{array}$ \\
\hline DNOR & 40 & $48^{\circ} 28.335^{\prime}$ & $98^{\circ} 19.140^{\prime}$ & 2040 & 36.5 & 320 & granite/gneiss & slope deposit & $\begin{array}{l}\text { manganese } \\
\text { calcium }\end{array}$ & 100 & no & severe & moderate & $\begin{array}{l}\text { Eutric Endoskeletic Cambisol (Amphiarenic, Colluvic, Epiloamic, } \\
\text { Nechric, Ochric, Amphiraptic) }\end{array}$ \\
\hline DWIR & 41 & $48^{\circ} 28.345^{\prime}$ & $98^{\circ} 19.228^{\prime}$ & 2053 & 42.5 & 330 & granite/gneiss & slope deposit & $\begin{array}{l}\text { calcium } \\
\text { carbonate }\end{array}$ & 110 & no & severe & moderate & $\begin{array}{l}\text { Eutric Endoskeletic Cambisol (Amphiarenic, Colluvic, Epiloamic, } \\
\text { Nechric, Ochric, Amphiraptic) }\end{array}$ \\
\hline DNOR & 42 & $48^{\circ} 33.181^{\prime}$ & $98^{\circ} 13.362^{\prime}$ & 1893 & 23 & 330 & granite & slope deposit & no & 110 & no & no & severe & $\begin{array}{l}\text { Haplic Kastanozem (Amphiarenic, Cambic, Collunic, Epiloamic, } \\
\text { Nechric, Epiraptic) }\end{array}$ \\
\hline DNOR & 43 & $48^{\circ} 24.506^{\prime}$ & $98^{\circ} 18.295^{\prime}$ & 1912 & 35 & 17 & granite & slope deposit & no & 125 & no & no & severe & $\begin{array}{l}\text { Skeletic Phaeozem (Katoarenic, Colluvic, Amphiloamic, Nechric, } \\
\text { Amphiraptic) }\end{array}$ \\
\hline DWIR & 44 & $48^{\circ} 48.525^{\prime}$ & $98^{\circ} 19.850^{\prime}$ & 2093 & 25.5 & 320 & granite/gneiss & slope deposit & no & 100 & no & severe & severe & $\begin{array}{l}\text { Eutric Endoskeletic Cambisol (Amphiarenic, Epiloamic, Nechric, } \\
\text { Ochric, Amphiraptic) }\end{array}$ \\
\hline DNOR & 45 & $48^{\circ} 48.371^{\prime}$ & $98^{\circ} 19.351^{\prime}$ & 2059 & 23 & 324 & granite/gneiss & slope deposit & no & 90 & no & severe & severe & $\begin{array}{l}\text { Eutric Endoskeletic Cambisol (Amphiarenic, Epiloamic, Nechric, } \\
\text { Ochric, Epiraptic) }\end{array}$ \\
\hline DNOR & 46 & $48^{\circ} 48.400^{\prime}$ & $98^{\circ} 19.136^{\prime}$ & 2002 & 28 & 330 & granite/gneiss & slope deposit & manganese & 105 & no & severe & severe & $\begin{array}{l}\text { Eutric Endoskeletic Cambisol (Katoarenic, Epiloamic, Nechric, } \\
\text { Ochric, Amphiraptic) }\end{array}$ \\
\hline DWIR & 47 & $48^{\circ} 52.582^{\prime}$ & $98^{\circ} 19.482^{\prime}$ & 2006 & 32.5 & 315 & granite/gneiss & bedrock & manganese & 80 & no & moderate & moderate & $\begin{array}{l}\text { Eutric Endoskeletic Endoleptic Cambisol (Amphiarenic, } \\
\text { Amphiloamic. Nechric OOChric Epiraptic) }\end{array}$ \\
\hline STE & 48 & $48^{\circ} 16.462^{\prime}$ & $98^{\circ} 21.224^{\prime}$ & 2045 & 3 & 305 & granite & slope deposit & $\begin{array}{l}\text { calcium } \\
\text { carbonate }\end{array}$ & 130 & no & no & no & Haplic Kastanozem (Cambic, Loamic, Amphiraptic) \\
\hline DWIR & 49 & $48^{\circ} 16.438^{\prime}$ & $98^{\circ} 20.856^{\prime}$ & 2043 & 26.5 & 325 & granite & slope deposit & manganese & 90 & no & severe & moderate & $\begin{array}{l}\text { Eutric Endoskeletic Cambisol (Amphiarenic, Epiloamic, Nechric, } \\
\text { Ochric, Epiraptic) }\end{array}$ \\
\hline DWIR & 50 & $48^{\circ} 22.427^{\prime}$ & $98^{\circ} 38.329^{\prime}$ & 2039 & 23 & 357 & granite & slope deposit & no & 105 & no & severe & moderate & $\begin{array}{l}\text { Endoskeletic Phaeozem (Katoarenic, Colluvic, Amphiloamic, } \\
\text { Nechric, Amphiraptic) }\end{array}$ \\
\hline DNOR & 51 & $48^{\circ} 22.293^{\prime}$ & $98^{\circ} 38.313^{\prime}$ & 2098 & 34 & 4 & granite & slope deposit & no & 110 & no & severe & moderate & $\begin{array}{l}\text { Endoskeletic Phaeozem (Katoarenic, Colluvic, Amphiloamic, } \\
\text { Nechric, Amphiraptic) }\end{array}$ \\
\hline DWIR & 52 & $48^{\circ} 22.113^{\prime}$ & $98^{\circ} 38.247^{\prime}$ & 2213 & 30.5 & 355 & granite & bedrock & no & 52 & no & severe & no & Endoskeletic Endoleptic Phaeozem (Loamic, Nechric, Epiraptic) \\
\hline DWIR & 53 & $48^{\circ} 41.506^{\prime}$ & $98^{\circ} 27.930^{\prime}$ & 1934 & 45 & 290 & gneiss & slope deposit & manganese & 95 & no & moderate & moderate & $\begin{array}{l}\text { Skeletic Endoleptic Phaeozem (Amphiarenic, Epiloamic, Nechric, } \\
\text { Epiraptic) }\end{array}$ \\
\hline DWIR & 54 & $48^{\circ} 41.471^{\prime}$ & $98^{\circ} 28.073^{\prime}$ & 2033 & 44.5 & 291 & gneiss & slope deposit & manganese & 75 & no & moderate & moderate & $\begin{array}{l}\text { Endoskeletic Endoleptic Phaeozem (Amphiarenic, Epiloamic, } \\
\text { Nechric, Epiraptic) }\end{array}$ \\
\hline
\end{tabular}



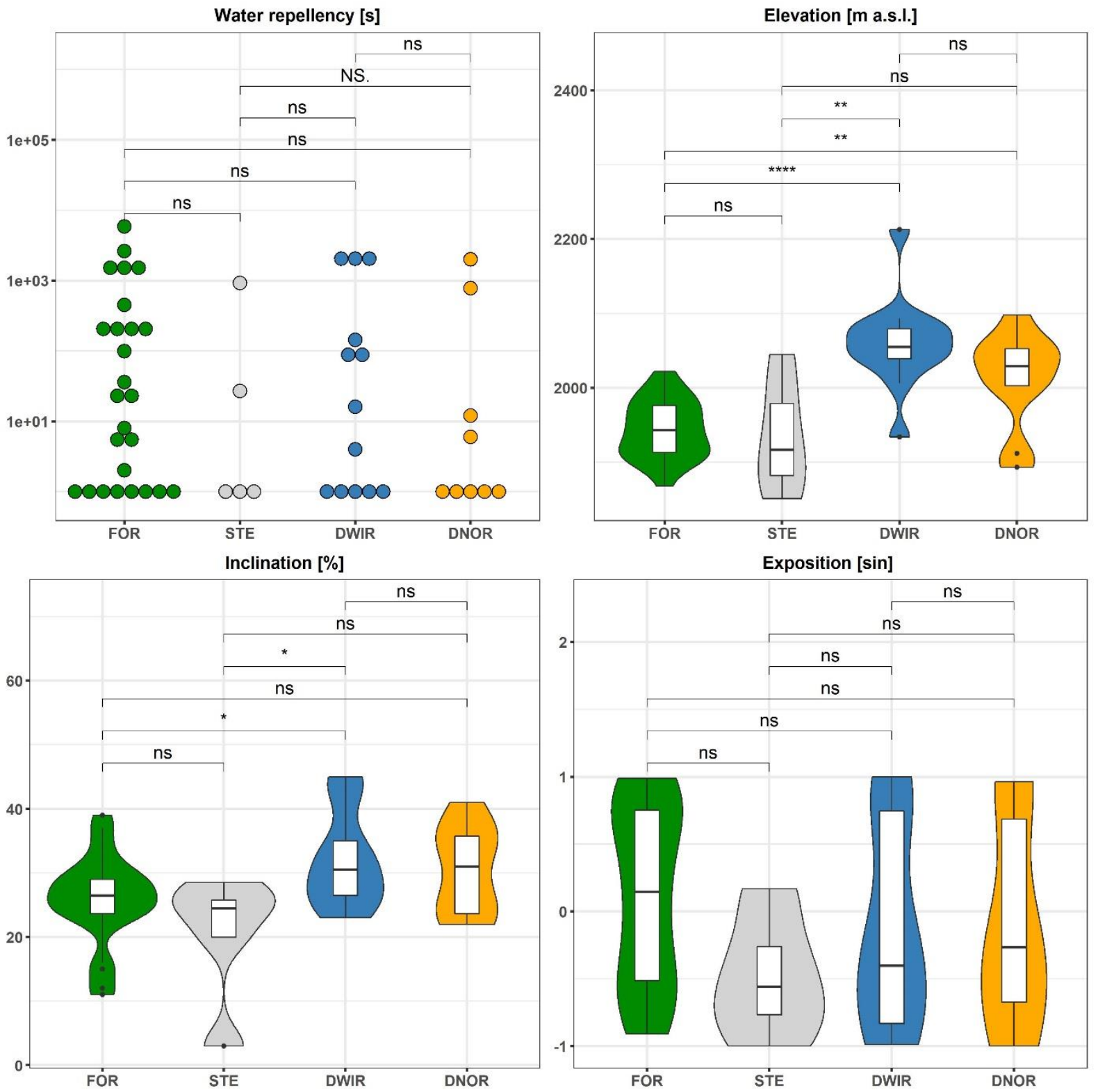

Figure 3.1.10: Scatter plots for water repellency (expressed as water drop infiltration time in seconds; $n=53)$, and violin plots and boxplots elevation $(n=54)$, inclination $(n=54)$, and exposition ( $n=54$ ) of the soils under the four vegetation categories near-natural forest (FOR, green), steppe close to forest (STE, grey), disturbed forest with regrowth of trees (DWIR, blue) and disturbed forest showing no regrowth of trees (DNOR, orange). $P$ values were calculated for differences between the arithmetic means (NS.: $p=1 ; n s: p>0.05 ;{ }^{*}: p \leq 0.05$; ${ }^{* *}: p \leq 0.01$; $\left.{ }^{* * *}: p \leq 0.001 ;{ }^{* * *}: p \leq 0.0001\right)$. Horizontal bars $=$ medians, boxes = first and third quartiles, points $=$ outliers, violins $=$ data distributions. 


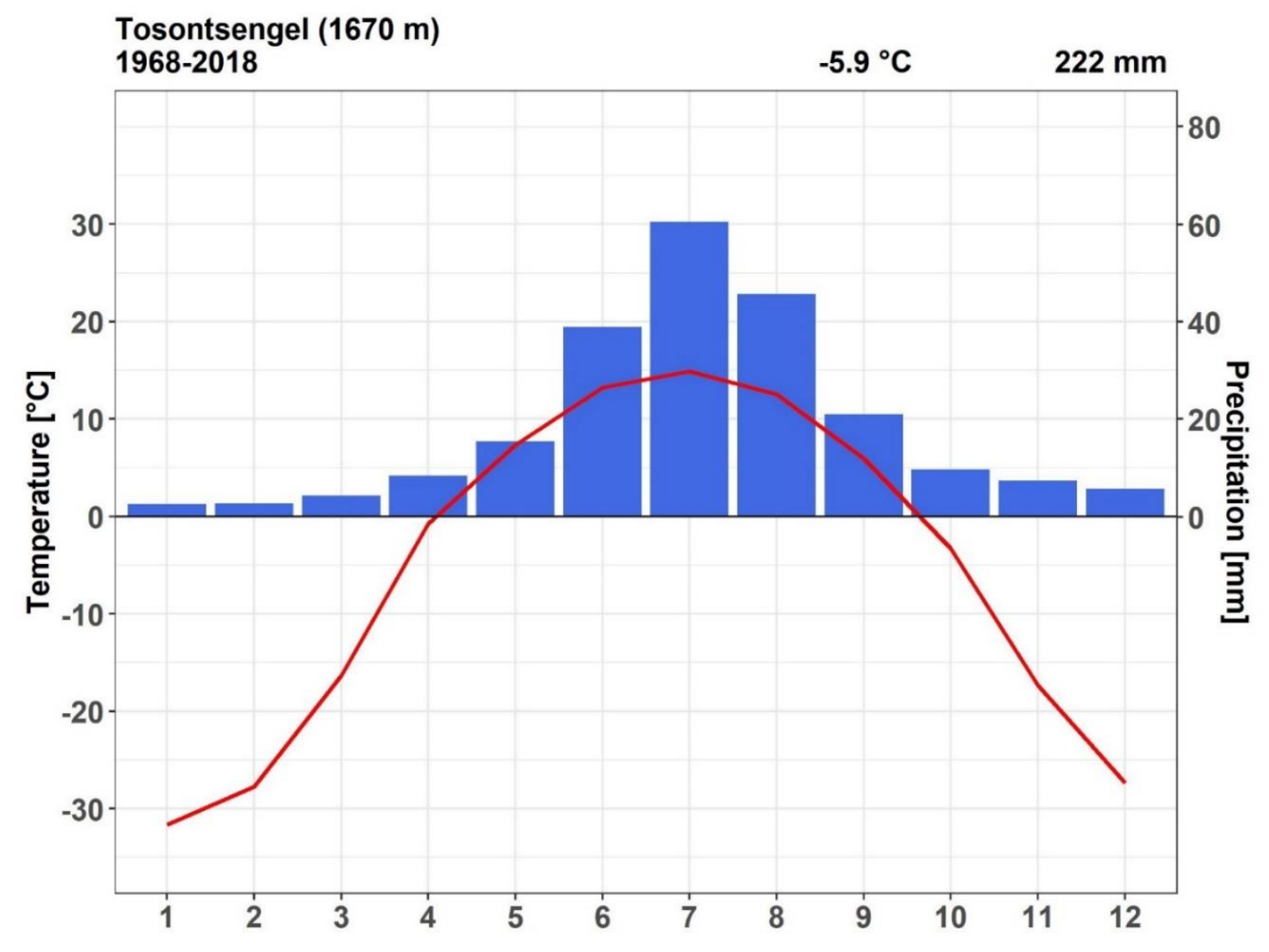

Figure 3.1.11: Climate diagram for Tosontsengel, Mongolia (data source: meteorological station of Tosontsengel, Mongolia; National Statistical Office of Mongolia). 
Table 3.1.2: Applied pedotransfer functions with references.

\begin{tabular}{|c|c|c|c|}
\hline Puplication & $\begin{array}{l}\text { Gupta and Larson (1979): } \\
\text { Estimating Soil Water } \\
\text { Retention Characteristics } \\
\text { From Particle Size } \\
\text { Distribution, Organic } \\
\text { Matter Percent, and Bulk } \\
\text { Density }\end{array}$ & $\begin{array}{l}\text { Ostovati et al. (2015): } \\
\text { Performance Evaluation of } \\
\text { Pedotransfer Functions } \\
\text { to Predict Field Capacity } \\
\text { and Permanent Wilting } \\
\text { Point Using UNSODA and } \\
\text { HYPRES Datasets }\end{array}$ & $\begin{array}{l}\text { Ghanbarian-Alavijeh and } \\
\text { Millán (2010): Point } \\
\text { pedotransfer functions for } \\
\text { estimating soil water } \\
\text { retention curve }\end{array}$ \\
\hline Source & $\begin{array}{l}\frac{\text { https:// }}{\text { citeseerx.ist.psu.edu/ }} \\
\text { viewdoc/download? } \\
\text { doi=10.1.1.475.497\&rep }= \\
\text { rep1\&type=pdf }\end{array}$ & $\begin{array}{l}\frac{\text { https:// }}{\text { www.tandfonline.com/ }} \\
\frac{\text { doi/abs/ }}{10.1080 / 15324982.2015} \\
.1029649 \\
\end{array}$ & $\begin{array}{l}\frac{\text { https:// }}{\text { wwww.researchgate.net/ }} \\
\text { profile/Humberto Millan/ } \\
\text { publication/ } \\
\frac{236134790}{\text { Point pedotra }} \\
\text { nsfer functions for estima } \\
\text { ing soil water retention c } \\
\text { urve/links/ } \\
\text { 55e45ee908aecb1a7ccae1 } \\
\text { 4e/Point-pedotransfer- } \\
\text { functions-for-estimating- } \\
\text { soil-water-retention- } \\
\text { curve.pdf }\end{array}$ \\
\hline $\begin{array}{l}\text { Correlation }\left(R^{2}\right) \text { with } \\
\text { measured plant-available } \\
\text { field capacity, entire data } \\
(n=42) \\
\text { Correlation }\left(R^{2}\right) \text { with } \\
\text { measured plant-available } \\
\text { field capacity, all samples } \\
\text { with low rock-fragment } \\
\text { content }(\leq 5.2 \%)(n=22)\end{array}$ & 0,065 & 0,024 & 0,006 \\
\hline
\end{tabular}

Data set online available: https://soil.copernicus.org/articles/7/563/2021/soil-7-563-2021supplement.zip 


\subsection{Interrelations between relief, vegetation, disturbances, and permafrost in the forest-steppe of central Mongolia}

Michael Klinge ${ }^{1}$, Florian Schneider ${ }^{1}$, Choimaa Dulamsuren ${ }^{2}$, Kim Arndt ${ }^{1}$, Uudus

Bayarsaikhan $^{3}$, Daniela Sauer ${ }^{1}$

1 Department of Physical Geography, Institute of Geography, University of Göttingen, Goldschmidtstraße 5, 37077 Göttingen, Germany

${ }^{2}$ Applied Vegetation Ecology, Faculty of Environment and Natural Resources, University of Freiburg, Tennenbacher Str. 4, 79106 Freiburg, Germany

${ }^{3}$ Department of Biology, School of Arts and Sciences, National University of Mongolia, Baga toiruu 47, Sukhbaatar duureg, Ulaanbaatar, Mongolia

- Manuscript published in Earth Surface Processes and Landforms (15. March 2021)

- $\quad$ https://doi.org/10.1002/esp.5116

\section{Author contributions:}

Michael Klinge and Daniela Sauer designed the research project. All authors carried out the field work together. Michael Klinge prepared the manuscript with contributions from all coauthors.

Keywords: Permafrost, Mongolia, forest-steppe, soil, ground-penetrating radar (GPR), geomorphology, forest fire 


\section{Abstract}

In semi-arid central Asia, relief has a strong impact on the distribution of vegetation and discontinuous permafrost. Our aim was to analyse causal chains and interrelationships that control the spatial patterns of forest and permafrost in the forest-steppe of the northern Khangai Mountains in Mongolia. For this purpose, we conducted soil-profile descriptions, groundpenetrating radar sounding, and vegetation mapping to gain information about forest and permafrost distribution. We integrated remote-sensing analysis and field-mapping data, including soil properties, vegetation cover, forest fires and anthropogenic forest use. We developed and applied a technique for spatial delineation of permafrost distribution, based on the parameters Topographic Wetness Index (TWI), incoming solar radiation and Normalized Difference Vegetation Index (NDVI). Key outcomes of this study are that the occurrence of discontinuous permafrost within $1 \mathrm{~m}$ depth is limited to forest stands larger than 100 ha on north-facing slopes. Dense ground vegetation supports permafrost, whereas sandy soil texture leads to greater depth of the permafrost table. As the seasonal ice in the active layer progressively melts down during summer, meltwater interflow above the permafrost table provides additional soil moisture downslope. This process is reflected in enhanced vitality of the steppe vegetation on toe slopes below forests with permafrost. This effect can in turn be used to indirectly detect permafrost in forest stands by remote sensing. Permafrost mostly disappears after forest fires and other severe disturbances, but it may re-establish during forest regrowth. However, climate warming is presently leading to a loss of permafrost regeneration potential after disturbance, and to a shift from climate-induced and ecosystem-driven permafrost to entirely ecosystem-protected permafrost. These trends will result in a further decrease of permafrost area after forest disturbance.

\subsubsection{Introduction}

The forest-steppe of Mongolia represents an ecotone at the northern edge of the central-Asian dry belt. It is thus highly sensitive to climate change (Dulamsuren et al. 2010a). Water is the main limiting factor for forest distribution in this semi-arid region. As a result of topographically induced differences of solar radiation and evapotranspiration, forests, consisting of Siberian larch (Larix sibirica), are limited to north-facing slopes, whereas mountain steppe covers southfacing slopes (Schlütz et al. 2008). In these semi-arid regions, forest distribution on slopes is controlled by temperature at the upper treeline and by moisture at the lower treeline (Klinge et al. 2015). The Mongolian forest-steppe is characterized by discontinuous permafrost (Dashtseren et al. 2014). Permafrost also influences soil moisture, as was already highlighted by Richter et al. (1963), Kowalkowski and Starkel (1984), and Starkel (1998). Based on results of ecological studies in the forest-steppe of Mongolia, several authors suppose that soil moisture on slopes is supplemented by meltwater released from seasonal ice above the permafrost table (Dulamsuren 2004; Dulamsuren and Hauck 2008; Dulamsuren et al. 2010a; Kopp et al. 2014). During drought events, this additional water source can be crucial for forests in semi-arid regions (Sugimoto et al. 2002; 2003; Kopp et al. 2014). Moreover, slope aspect and solar radiation lead to topographic asymmetries in soil moisture and vegetation cover that 
cause different geoecological conditions between north- and south-facing slopes (Pelletier et al. 2018). lijima et al. (2012) showed that precipitation on south-facing steppe-covered slopes is completely consumed by evapotranspiration. In contrast, precipitation on north-facing forested slopes with permafrost is only partially consumed by evapotranspiration and partially contributes to river discharge. Therefore, the mountain-forest ecosystems of Mongolia represent substantial water reservoirs (Karthe et al. 2013).

The mountain forests of Mongolia are currently threatened, as the trees are suffering from enhanced drought stress (Dulamsuren et al. 2010c; 2014). In addition, insufficient forest management and extensive forest exploitation by logging and wood pasture have led to forest fragmentation and deforestation (Tsogtbaatar 2004). Fragmented forests are more sensitive to climate warming and less resilient than large forests (Khansaritoreh et al. 2017b). Moreover, fires destroyed large forest areas in Mongolia over the past decades (Goldammer 2002; Nyamjav et al. 2007; Hansen et al. 2013). Given the role of the forest ecosystems as important water reservoir, a continuation of the decrease in forest area would lead to shortage of potable water for people and livestock.

As pointed out above, additional water supply related to permafrost patches can make the decisive difference for tree growth in the semi-arid Mongolian forest-steppe. Therefore, permafrost distribution and the factors controlling the permafrost-distribution pattern, need to be considered in order to understand the spatial differences in water supply and tree growth. Shur and Jorgenson (2007) identified vegetation, soil and hydrological conditions as the main factors controlling permafrost distribution in the region of discontinuous permafrost of Alaska. Sharkhuu (2003) as well as (Sharkhuu and Sharkhuu 2012) showed (spatially differentiated) trends of permafrost degradation in Mongolia. The authors found an increase in the activelayer thickness of 0.1-0.6 mm yr ${ }^{-1}$ (1969-2002) that accelerated between 1980 and 2005. The main cause for this trend is global warming, as the mean annual air temperature (MAAT) in Mongolia increased by $1.9 \mathrm{~K}$ over the period 1940-2006 (Dagvadorj et al. 2009). In addition, degradation of the vegetation cover by fires, logging, and overgrazing contribute to the permafrost degradation as well (Sharkhuu and Sharkhuu 2012).

Understanding the causal chains and interrelations between the factors that control the permafrost pattern in the Mongolian forest-steppe is essential, because of the role of permafrost for the growth of forests in this sensitive ecotone and in turn, the importance of forests in the water cycle. Therefore, we performed geomorphological field investigations and GIS analyses in the forest-steppe of the Khangai Mountains in central Mongolia (Figure 3.2.1) in order to test the following hypotheses: 
$\mathrm{H}_{1}$ : Large forest stands on north-facing slopes (NW-NE) favour permafrost, whereas permafrost is absent under small fragmented forests.

$\mathrm{H}_{2}$ : Meltwater from seasonal ice above the permafrost table enhances vegetation growth and vigour during summer.

$\mathrm{H}_{3}$ : Forest use leads to opening of forest stands, which in turn causes deepening of the permafrost table.

$\mathrm{H}_{4}$ : Permafrost disappears after extensive forest fire, but may reconstitute during tree regrowth.

$\mathrm{H}_{5}$ : Remote sensing data can be used to locate permafrost patches and to estimate the depth of the permafrost table (corresponding to the thickness of the active layer).

Proving the hypotheses $\mathrm{H}_{1}$ to $\mathrm{H}_{4}$ was important, because these geoecological relationships have been postulated by several researchers before, but have not yet been proven in detail. Proving hypothesis $\mathrm{H}_{5}$ was relevant, as it provided the base for spatial delineation of the depth of the permafrost table based on empirical data, as an alternative approach to the use of deterministic top-down models based on climate parameters for assessing zonal permafrost distribution (Böhner and Lehmkuhl 2005; Gruber 2012).

\subsubsection{Study area}

The study area is situated at the northern edge of the Khangai Mountains in central Mongolia, south of Tosontsengel $\left(98^{\circ} 16^{\prime} \mathrm{E} / 48^{\circ} 46^{\prime} \mathrm{N}, 1670 \mathrm{~m}\right.$ a.s.I.) (Figure 3.2.1). It is characterized by a cold, semi-arid continental climate, with mean annual air temperature of $-6{ }^{\circ} \mathrm{C}$ and monthly mean temperatures between $-31.7^{\circ} \mathrm{C}$ in January and $14.7^{\circ} \mathrm{C}$ in July (Tosontsengel). Most of the precipitation ( $220 \mathrm{~mm} \mathrm{yr}^{-1}$ ) falls from May to September, with a maximum in July. It is related to low pressure cells that are driven across the region by the westerlies (Batima et al. 2005). Winters are generally dry, as an effect of the Siberian high. The given climatic conditions result in the presence of discontinuous permafrost. Permafrost mainly occurs in valley bottoms, higher mountain areas, and on north-facing slopes. Ground ice in permafrost forms only where some soil moisture is available. Otherwise, dry permafrost, i.e., permanently frozen ground without ice, occurs.

The highest mountains within the study area, reaching up to 3,200 $\mathrm{m}$ a.s.l., are situated in the southern part of the study area. Mountain plateaus with cryoplanation terraces are widespread at these altitudes (Richter et al. 1963; Kowalkowski and Starkel 1984). There, the upper 
treeline is at about 2,500 $\mathrm{m}$ a.s.I. (Klinge et al. 2018). This elevation also represents the lower limit of the periglacial zone with continuous permafrost. The mountains in the northern part of the study area are lower. Their north-facing slopes are completely covered by mountain foreststeppe up to the summits. The major valleys run from south to north. At an elevation of 1,600 $\mathrm{m}$ a.s.l., they discharge into the valley of the river Ider Gol that runs west-east. The geological basement of the study area is composed of Permian metamorphosed sedimentary and acidic plutonic rock, and Carboniferous mafic rock (Academy of Sciences of Mongolia, Academy of Sciences of USSR 1990). Debris composed of these rock types largely covers the slopes. Sandy to silty aeolian sediments are often mixed into the rock debris, forming cover beds, that overly the rock debris.

The area south of the river Ider Gol is characterized by large, dense forests, whereas further north, steppe vegetation predominates, and forests are more fragmented (Dulamsuren et al. 2019a). Forests (made up of Larix sibirica) are generally limited to north-facing slopes, whereas steppe covers south-facing slopes. This clear spatial vegetation pattern is characteristic for the forest-steppe of Mongolia (Hilbig 1995). It is the result of low precipitation (<300 mm), high evapotranspiration and the strong difference in insolation between north- and south-facing slopes in the mid-latitudes (Schlütz et al. 2008; Hais et al. 2016). In addition, groundwater-fed riparian forests occur, which are less dependent on local precipitation. Riparian woody vegetation includes willow (Salix), poplar (Populus), and larch (L. sibirica). Moreover, scattered, single old larch trees occur on Pleistocene dune fields that are widespread in the basins. During summer, there are many local forest fires (Nyamjav et al. 2007; Hessl et al. 2012). Large forest areas were destroyed by fires in 1996 and 2002. Also, anthropogenic activity causes disturbance of forests. In addition to the extraction of firewood and wood pasture by the local population, intensive forest exploitation in the study area started in the 1960s, when also a timber factory was built in Tosontsengel. In the early 1990s, industrial logging was abandoned. However, in the meantime, logging has restarted to some extent. 


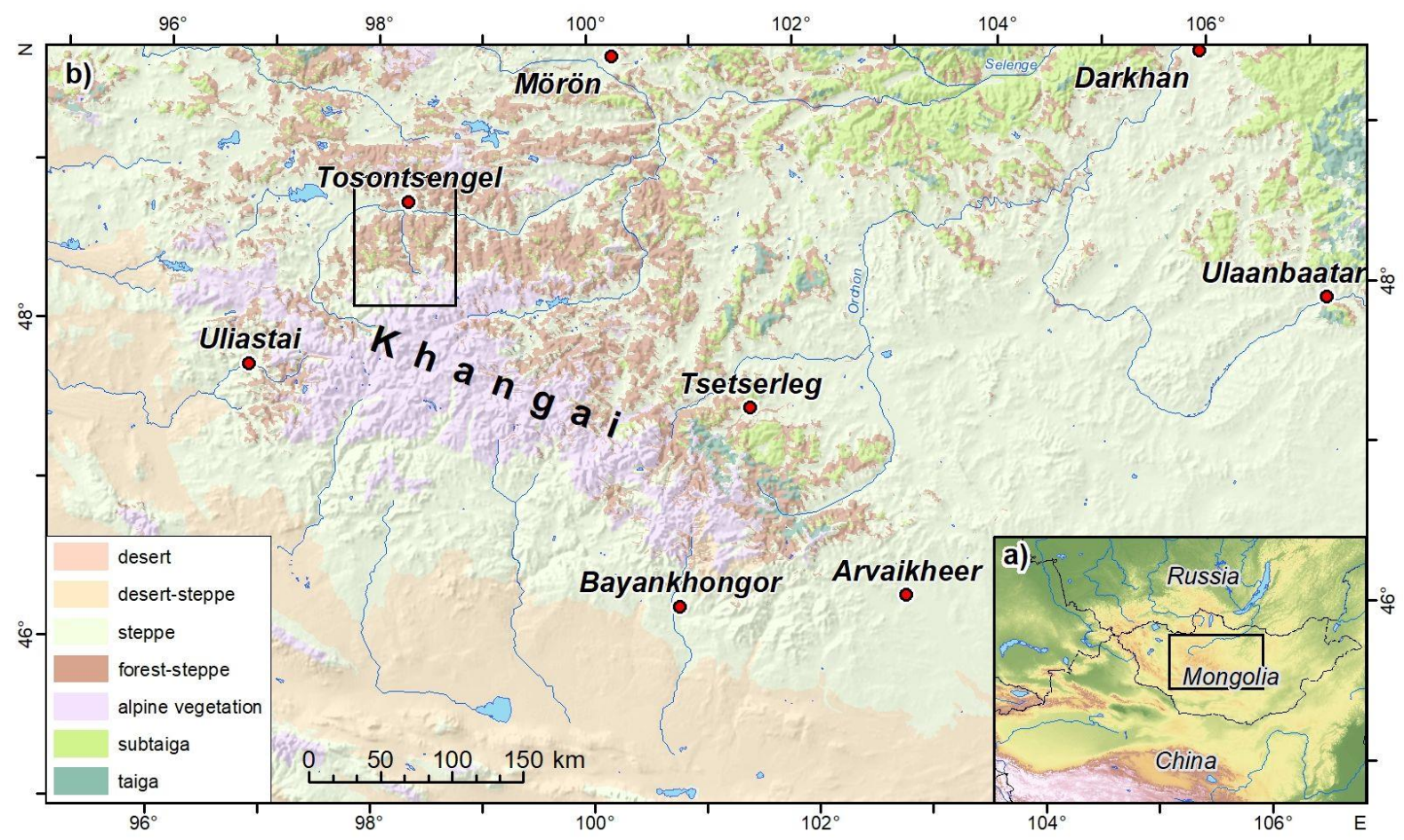

Figure 3.2.1: Study area. a) Overview of Mongolia. The black frame shows the position of the map b). b) Location of the study area in the forest-steppe of central Mongolia. The vegetation zones were adapted from Klinge and Sauer (2019). The digital elevation model (DEM) was created from SRTM (Shuttle Radar Topography Mission) data. The black frame in b) indicates the location of the study area.

\subsubsection{Methods}

Two approaches were combined. Fieldwork provided site information about permafrost distribution and the depth of the permafrost table. Remote sensing and statistical correlations were used to analyse geoecological parameters and to evaluate permafrost distribution.

\subsubsection{Fieldwork}

In July and August of the years 2017 and 2018, we dug 76 soil pits down to either the permafrost table or bedrock. Vertical soil-temperature profiles were measured at $10 \mathrm{~cm}$ intervals in the profile walls of 30 soil pits immediately after digging. We used a thermometer (Greisinger, G 1700) with a $10 \mathrm{~cm}$ robust insertion probe (Greisinger, GES 175). Sediment layers and soil horizons were described according to the FAO Guidelines for Soil Description (FAO 2006b), and the soils were classified according to the World Reference Base for Soil Resources (IUSS Working Group WRB 2015). The sub-surface structure was recorded by use of ground-penetrating radar (GPR) along 30 transects, covering different vegetation, relief and 
soil types. The recording tracks were positioned to run across forest boundaries, dense and open forests, as well as burned, remaining, and re-growing forests. The aim was to evaluate the differences of the permafrost-table depth between different vegetation units, as previous investigations showed the suitability of GPR for detecting permafrost in Alaska, Canada, and Mongolia (Hinkel et al. 2001; Moorman et al. 2003; Pascale et al. 2008; Wu et al. 2009; 2012). We used a GPR SIR-4000 system by Geophysical Survey Systems Inc. (GSSI) equipped with a $400 \mathrm{MHz}$ antenna (Type: 50400S). Data editing and generation of GPR images was performed using the RADAN 7 software of GSSI. The exact transect positions were determined by GPS (Garmin Montana 680T). The GPR tracks were previously cleaned from stones, branches and dead trees. They were supplemented by up to $2 \mathrm{~m}$ deep soil pits and up to $1 \mathrm{~m}$ deep manual drillings in which soil temperature was measured. Depending on soil characteristics and moisture, the maximum GPR recording depth was 3-5 m.

\subsubsection{Remote sensing and statistical analysis}

The workflow of GIS (geographic information system) analysis, generation of a DEM (digital elevation model), and remote sensing analyses is shown in Figure 3.2.7. The DEM was based on TanDEM-X data (resolution 10x10 m). We integrated four supervised image classifications from Landsat 8 (2013.05.14; 2015.06.20) and Sentinel 2 (2016.09.14; 2017.09.19) satellite images and visually checked and edited the forest polygons to obtain a robust forest representation. The forest area was then used to eliminate topographic distortion caused by forest from the DEM. The elevation data was gradually reduced by $3 \mathrm{~m}$ from the forest edges to the interiors, and a smoothing filter was applied on the elevation data inside the forest polygons. The resulting DEM was used to compute various topographic datasets (Figure 3.2.7):

- Relief parameters were calculated by the GIS module "Basic Terrain Analysis" integrated into the SAGA 2.3.2 software (Conrad et al. 2015).

- The potential incoming annual solar radiation (ASRI) was calculated for the year 2017 by use of the GIS tool "Area Solar Radiation" implemented in ArcMap 10.7 (ESRI).

- A hydrographic catchment delineation based on the DEM was combined with the forestclassification map to distinguish hydrologically differing forest units.

The study area was subdivided into different landscape units:

- Based on the proportions of forest and steppe, we distinguished forest- and steppedominated areas (FDA, SDA).

- The area above the upper treeline was defined as high-mountain area. 
- Flat areas $\left(<2^{\circ}\right.$ slope angle) at low relative elevations were classified as alluvial plains and basins.

In addition, we mapped sand dunes and sand sheets that locally occur across the study area, because they modify soil moisture and temperature, and thus the depth of the permafrost table. Sand dunes can be easily detected in satellite images, whereas sand sheets are mostly masked by vegetation. The latter were recorded exemplarily by GPS-tracking when observed in the field. In addition, the light colour of unpaved roads was used for detecting sand sheets in satellite images.

In a first step, we assigned potential permafrost occurrence to certain landscape units, based on the results of our fieldwork combined with NDVI (normalized differentiated vegetation index) analysis (chapter 3.2.4.4). We used the NDVIs of three satellite images of midsummer to determine individual NDVI threshold values (TV) for steppe below forests with and without permafrost (Sentinel 2: 2019.07.31, TV=0.7; 2018.06.11, TV=0.45; Landsat 8: 2015.07.23, $\mathrm{TV}=0.7$ ) (Figure 3.2.7).

In a second step, we included the depth of the permafrost table in various landscape units. Stepwise regression analyses were carried out to identify correlations between the depth of the permafrost table as measured in the field, relief parameters and NDVI. We chose those parameters that showed the highest correlations and obtained specific linear regression models for different landscape units with potential occurrence of permafrost. Finally, we calculated multivariate regression terms to establish a linear model for the spatial delineation of the depth of the permafrost table. This model was validated by comparing the model-output data to the empirical input data from the study area (Figure 3.2.8).

\subsubsection{Results}

\subsubsection{Field observations on the interrelations between relief, permafrost, and water supply to forests}

Usually no permafrost was observed in fragmented forests. Such forests showed no or very slow regrowth after extensive forest fire. Large forest stands on north-facing slopes usually grew on permafrost. Steppe vegetation on toe slopes below such forests was more vital, denser and greener than below forests without permafrost (Figure 3.2.9). Thus, the steppe vegetation below forests with permafrost reflected the additional moisture supply by meltwater from seasonal ice above the permafrost table during summer. We assumed that this was due 
to lateral meltwater flow above the permafrost table that supplemented soil moisture downslope. In addition, shrubs and deciduous trees like willow and birch occurred at these sites. This difference in vegetation vigour during summer enabled us to indirectly identify forests with permafrost also by remote sensing, based on enhanced NDVI of steppe vegetation on toe slopes below forests in satellite images taken in summer (see chapter 3.2.4.4).

\subsubsection{Soil-temperature depth curves and depth of the permafrost table}

Soil-temperature depth curves were measured in the profile walls of 30 soil pits on north-facing slopes (Figure 3.2.2). These measurements were carried out during July-August, when the thawing depth approaches its maximum (Yershov and Williams 2009; French 2018). Therefore, the depth where the temperature reached $0^{\circ} \mathrm{C}$ may serve as an approximation of the depth of the permafrost table. A generally steep temperature decrease in the upper $10 \mathrm{~cm}$ was followed by a more gradual decrease further down. The upper $10 \mathrm{~cm}$ were rich in soil organic matter and were in places covered by an organic layer, insulating the soil from the above-ground air temperature. We grouped the curves into four classes, corresponding to different site conditions (Figure 3.2.2), and calculated mean temperature gradients (excluding the upper $10 \mathrm{~cm}$ ) for these four classes (Table 3.2.1).

Soils developed in slope debris under forest showed the lowest soil temperatures and steepest gradients $\left(\sim 0.09 \mathrm{~K} \mathrm{~cm}^{-1}\right)$ (Figure 3.2.2). The permafrost table usually occurred at a depth of $50-100 \mathrm{~cm}$ (on average at a depth of $70 \mathrm{~cm}$ ). Sandy soils under forest showed higher temperatures and a less steep temperature gradient $\left(\sim 0.07 \mathrm{~K} \mathrm{~cm}^{-1}\right)$. The temperature reached $0^{\circ} \mathrm{C}$ at $110-170 \mathrm{~cm}$ (mean: $160 \mathrm{~cm}$ ) depth, thus on average $90 \mathrm{~cm}$ deeper compared to soils developed in slope debris under forest. Sandy soils under forest showed the highest surface temperatures, reaching up to $15^{\circ} \mathrm{C}$. In all soil profiles under steppe and burned forest, the bedrock occurred at $80-120 \mathrm{~cm}$ depth, and a temperature of $0{ }^{\circ} \mathrm{C}$ was not reached within this depth. Temperature decrease with depth was much more gradual in soils without forest than in soils under forests $\left(\sim 0.03-0.04 \mathrm{~K} \mathrm{~cm}^{-1}\right)$. Soil temperatures at sites without forest did not seem to approach $0{ }^{\circ} \mathrm{C}$, making the presence of permafrost unlikely. 


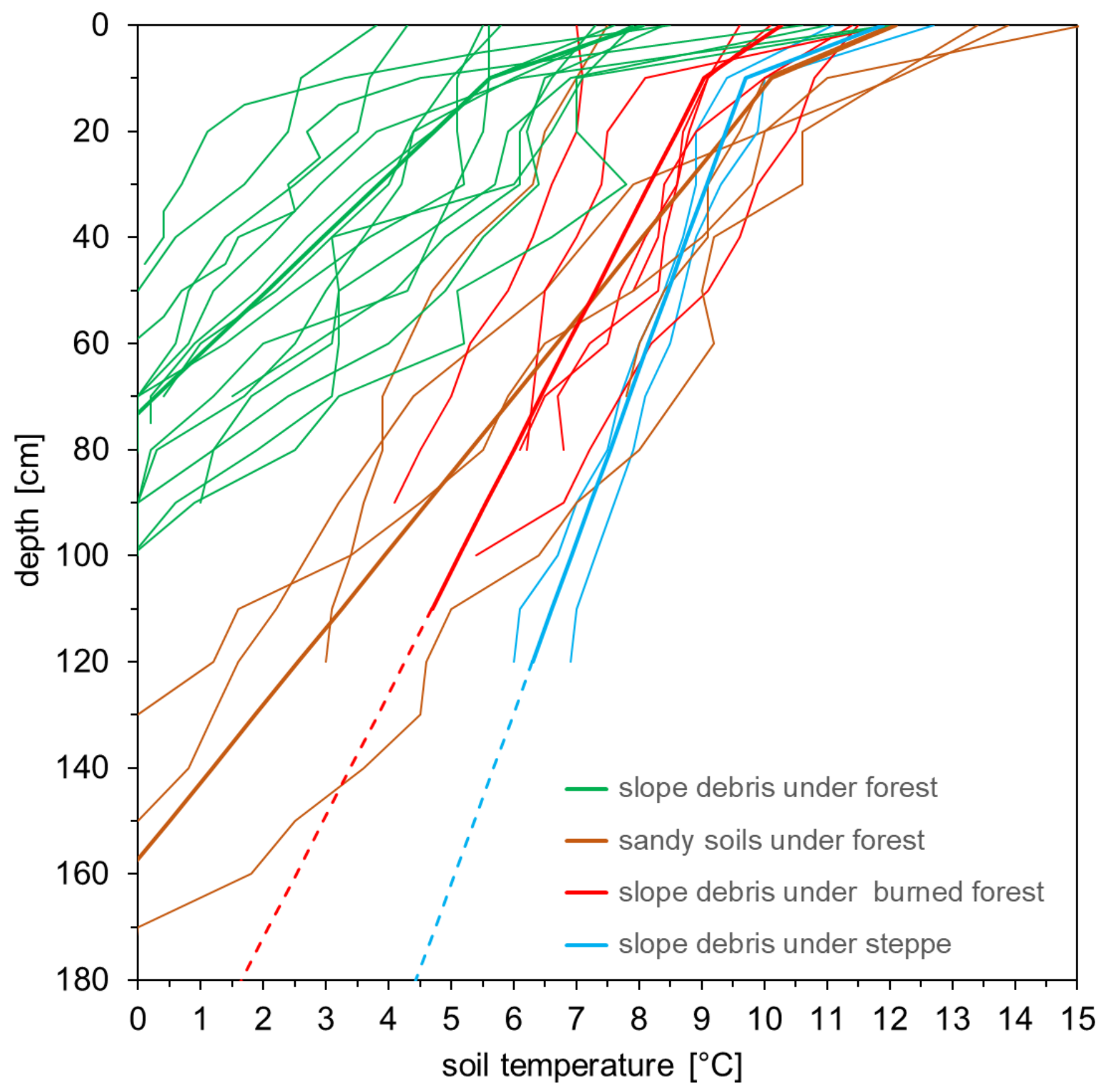

Figure 3.2.2: Soil-temperature depth curves of different geoecological units, measured in profile walls of soil pits on north-facing slopes in July-August 2017 and 2018. Thin lines indicate individual soil-temperature depth curves, whereas bold lines represent mean soil-temperature gradients of each class. Broken lines represent estimated mean gradients where no data are available. 
Table 3.2.1: Average soil-temperature characteristics for different geoecological units.

Arithmetic means

Sandy soilsSlope debrisSoils underSoils under

(standard deviation) under forest underforest steppe burned forest

Surface temperature $\left[{ }^{\circ} \mathrm{C}\right]$

$12.1(2.5)$

$8.1(2.6)$

$11.9 \quad(0.8) \quad 10.3 \quad(1.7)$

Soil temperature at $10 \mathrm{~cm}$ depth $\left[{ }^{\circ} \mathrm{C}\right] 10.1$ (1.8)

$5.6(1.5)$

$9.7(0.3)$

$9.0(1.2)$

Gradient $>10 \mathrm{~cm}$ depth [K dm$\left.{ }^{-1}\right]$

$0.69(0.43)$

$0.89(0.51)$

$0.31(0.15) \quad 0.43(0.30)$

Number of soil pits [n] 6 16 6

The insulating effect of $O$ horizons and moss covers led to considerably shallower depth of the permafrost table (Figure 3.2.3). As a mutual feedback, low soil temperatures and high permafrost table decreased biological activity and thus led to thick $O$ horizons (and thin $A$ horizons resulting from reduced bioturbation).

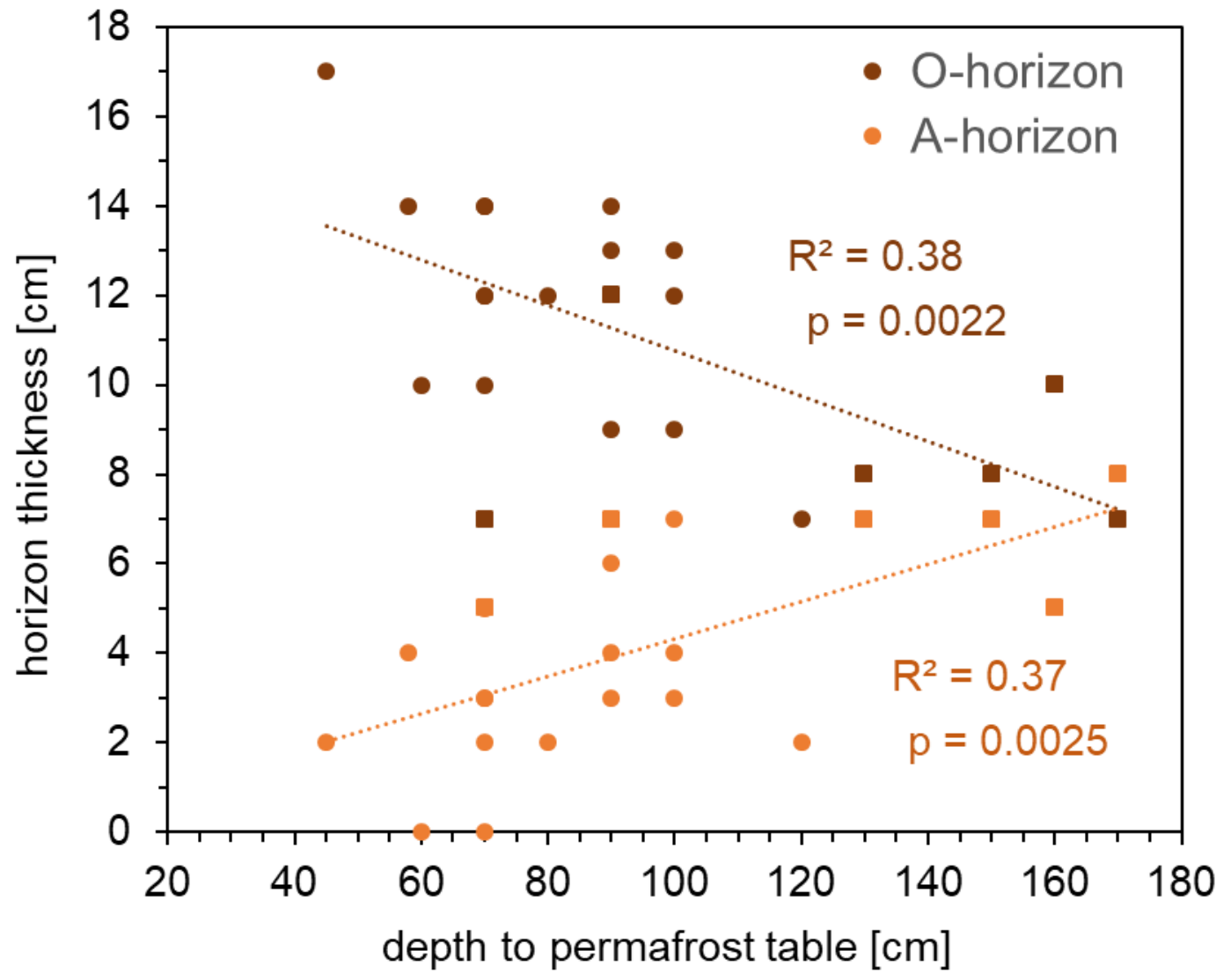

Figure 3.2.3: Correlations and $p$ values between O-horizon (and A-horizon) thickness and the depth of the permafrost table in 22 soil pits. Circles indicate soils developed in slope debris; squares indicate soils developed in sand. 


\subsubsection{Permafrost distribution and sedimentological information obtained by ground-penetrating radar (GPR)}

Linear reflectors in GPR images indicate distinct sedimentary boundaries. The permafrost table produces a continuous reflection that cuts through any sedimentary structures (Figure 3.2.4, 3.2.11). Ground-ice attenuates the radar signal below the permafrost table. A reflector above the permafrost table that was running approximately parallel to the permafrost table, was interpreted as the upper limit of a moist zone. Linear reflectors that approached the soil surface in downslope direction indicated an imbricated structure of colluvial deposits and solifluction layers. Surface-parallel structures below the permafrost table pointed to the transition zone to the bedrock. The depth of the permafrost table increased with decreasing tree density.

Two examples of GPR images (transects $A$ and $B$ ) and their interpretation are shown in Figure 3.2.4 (transects $C$ to $F$ are provided in Figure 3.2.11). These transects were located on slope debris of metamorphic rock under forest. Transect $A$ was in a pristine forest with dense ground vegetation consisting of mosses, herbs and shrubs. Logging was limited to few patches at the lower forest boundary. Deadwood and windthrown trees were widespread. Ice-rich permafrost was found at less than $1 \mathrm{~m}$ depth in many soil pits. The soils were generally moist. The shallow depth of the permafrost table of $<0.8 \mathrm{~m}$ was clearly visible in the GPR image. It increased to $\sim 1 \mathrm{~m}$ where the forest had been opened. Moisture and ice strongly attenuated the GPR signal. Transect $B$ was in an area of intense logging that had led to opening of the lower part of the forest stand. As captured in the GPR image, the depth of the permafrost table increased downslope, from $\sim 1.5 \mathrm{~m}$ under dense forest to $3 \mathrm{~m}$ under steppe. The depth of the moist zone above the permafrost table increased from $<1 \mathrm{~m}$ depth under dense forest to more than $1.8 \mathrm{~m}$ depth under steppe. This trend already started in the lower part of the forest that had been opened by logging. 


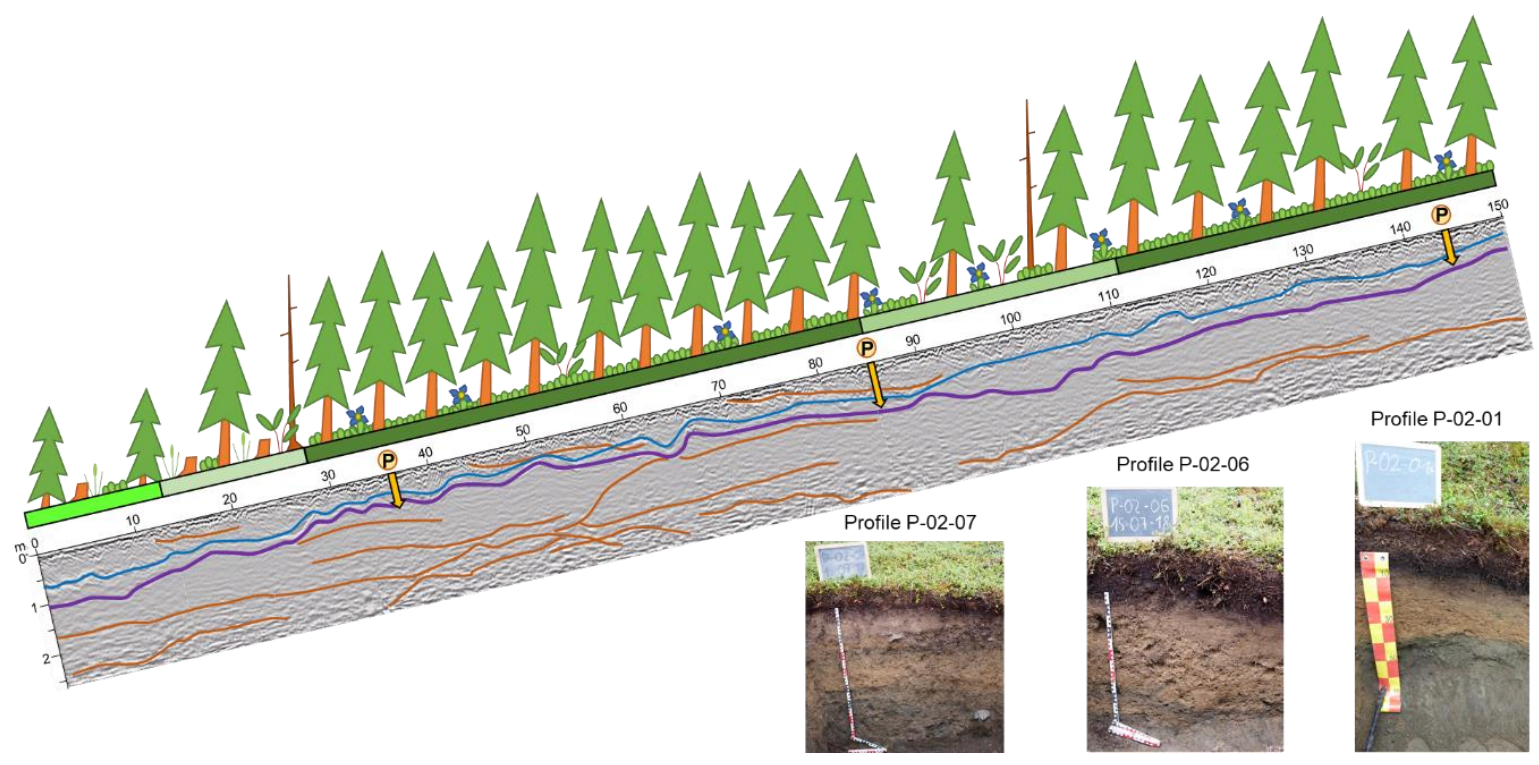

B

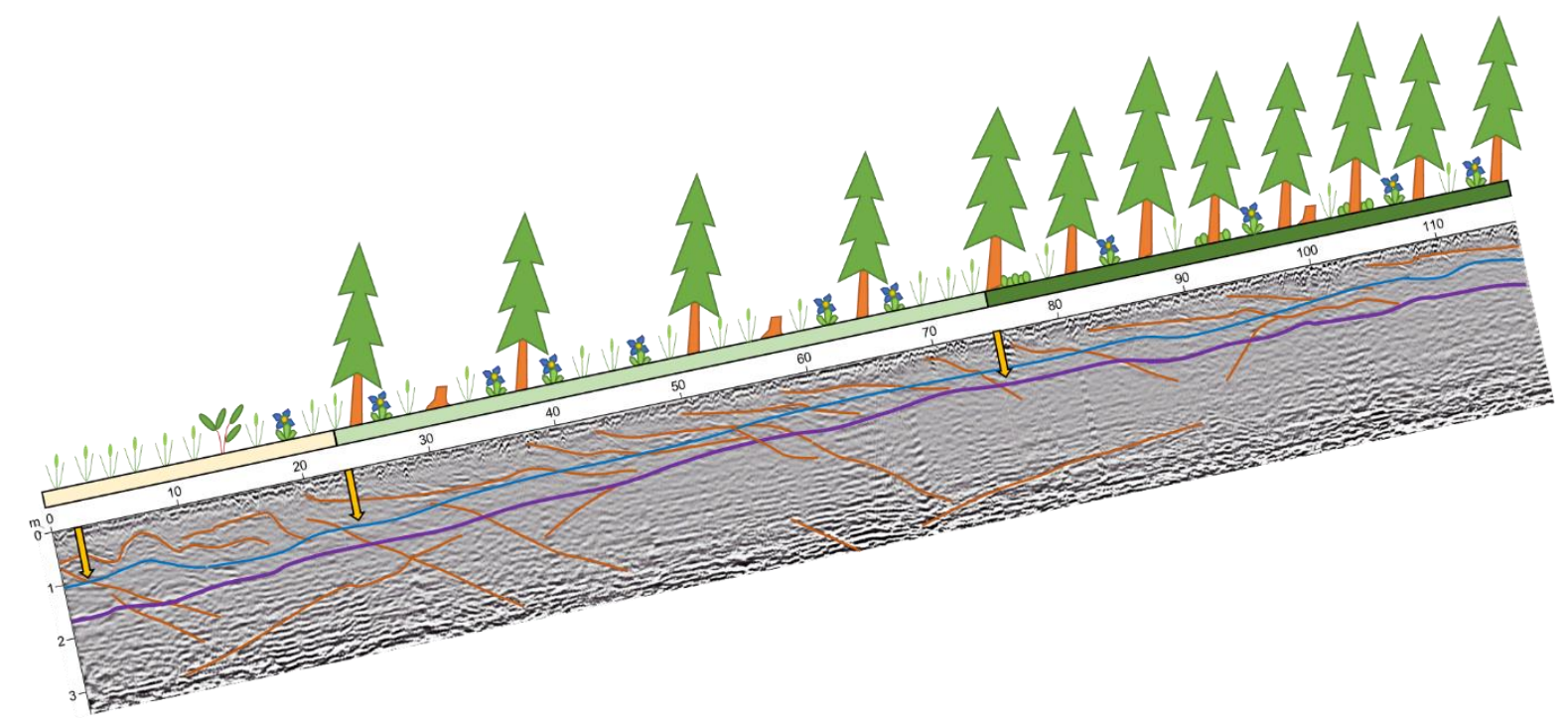




\begin{tabular}{|lll} 
steppe \\
\hline open forest \\
dense forest
\end{tabular}

Figure 3.2.4 GPR images with interpretation of sedimentary structures, permafrost distribution and vegetation cover. The transects ran along slopes at the lower forest boundary. The inclinations of the GPR images were adjusted to the mean gradient of the slopes. A: pristine forest on soils developed in slope debris, $B$ : forest affected by logging on soils developed in slope debris. Additional GPR images are provided in the appendix (Figure 3.2.11).

\subsubsection{GIS-based delineation of vegetation and permafrost patterns}

We had observed in the field (cf. Chapter 3.2.4.1) that steppe vegetation on toe slopes below forests with permafrost benefitted from additional soil moisture (Figure 3.2.9). Therefore, we compared the NDVI of steppe vegetation below forests in which we had detected / not detected permafrost during fieldwork, and found a clear difference. We used three suitable satellite images to determine individual NDVI thresholds for steppe vegetation below forest stands with and without permafrost. Where steppe NDVI values from all three satellite images exceeded the respective thresholds, we classified the forests above these steppe sites as forests growing on permafrost (Figure 3.2.5). In addition, we checked forest stands for the presence of sandy sediments, as these reduced soil moisture and decreased the NDVI of the adjacent steppe below the defined thresholds, even where ice-poor permafrost was present.

This approach pointed to permafrost in $<5 \%$ of the forests in the steppe-dominated area (SDA), and in $>55 \%$ of the forests of the forest-dominated area (FDA) (Figure 3.2.5; Table 3.2.4). The north-western part of the study area belongs to the SDA, whereas the north-eastern part is FDA. In both areas, we found no permafrost during fieldwork. In agreement with these field observations, also the NDVI-based approach indicated permafrost only in a few cases (Figure 3.2.5). In the central part of the study area, the sand-layer distribution substantially affected soil moisture and permafrost distribution. Sandy deposits also occurred in the western part of the FDA but not in the eastern part of the SDA. 


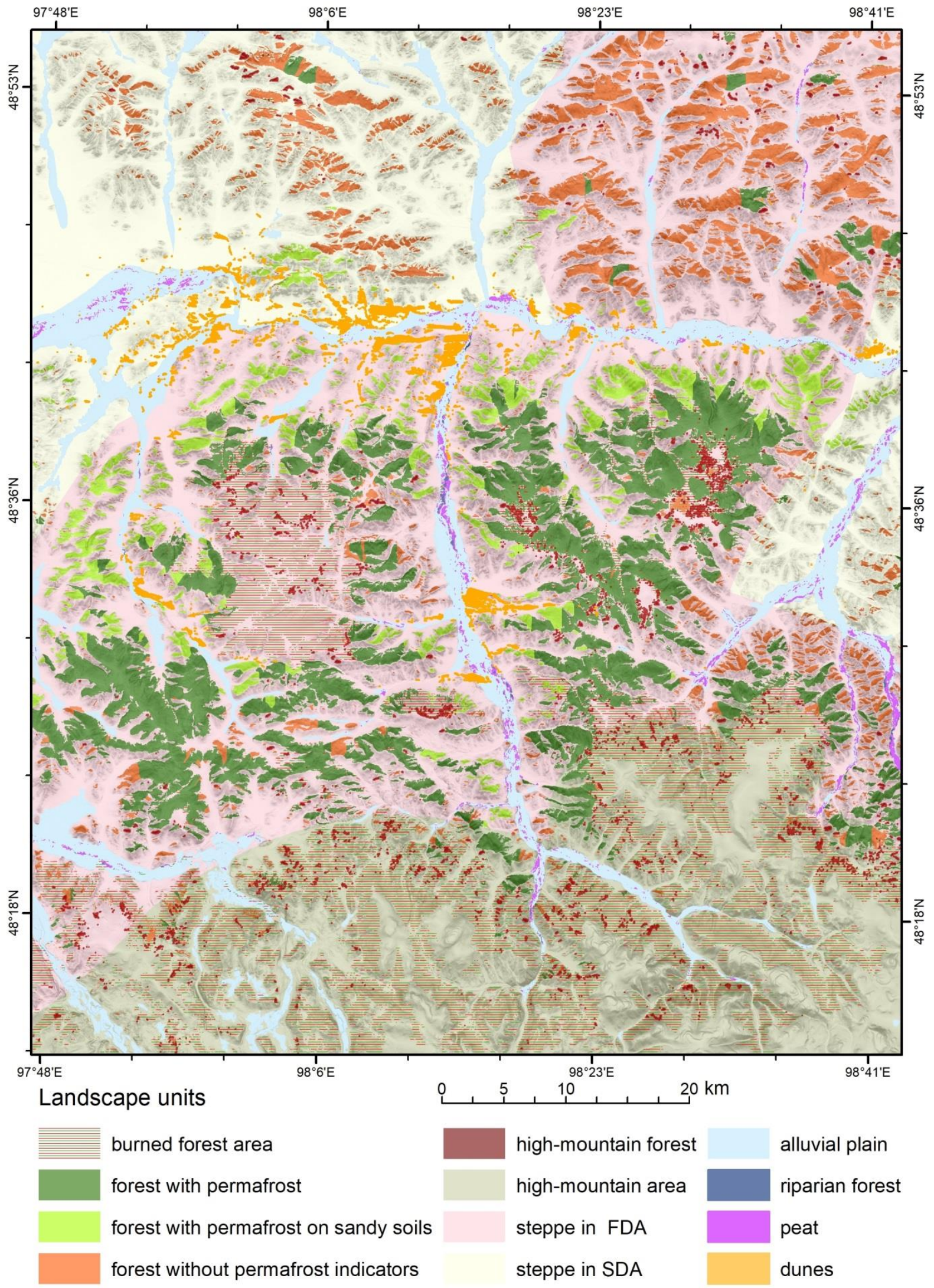

Figure 3.2.5: Landscape classification. The shaded relief is based on TanDEM-X data. The burned area was adapted from Klinge et al. (2020). FDA = forest-dominated area, SDA = steppe-dominated area. 
The combination of temperature measurements in soil pits with permafrost information from GPR measurements led to a database of 115 plots with empiric data for the depth of the permafrost table.

Stepwise regression analyses showed the closest relationships with the depth of the permafrost table for the following three parameters (Table 3.2.2):

- Topographic Wetness Index (TWI), a topographic parameter that depicts the accumulation of soil water and slope deposits in the relief;

- Potential incoming annual solar radiation (ASRI), used for estimating diurnal warming intensity as influenced by topography;

- Mean NDVI of 16 multispectral satellite images (2013-2018), integrating site-specific vegetation conditions for the entire growing season, and interannual variability in moisture availability.

These three parameters represent independent variables. They were derived from different databases and relate to ecological conditions favouring permafrost. The applicability of these three parameters for permafrost delineation is in agreement with findings reported by Etzelmüller et al. (2006). The strongest correlation with NDVI was obtained by using the average NDVI of 16 satellite images from the growing seasons of the period 2013-2018, whereas individual NDVI datasets from Landsat 8 and Sentinel 2 yielded weaker correlations.

Table 3.2.2: Correlation statistics of multivariate regressions between depth of the permafrost table and the parameters ASRI (potential incoming annual solar radiation), TWI (Topographic Wetness Index), and mean NDVI (mean Normalized Difference Vegetation Index of 16 satellite images) of different geoecological units $\left(F_{1-4}\right)$. Root mean square error (RMSE) refers to the relationship between measured and calculated depths of the permafrost table.

\begin{tabular}{lccccc}
\multicolumn{1}{c}{ Geoecological unit: } & $F_{1}$ : Sites & & & $F_{4}$ : All sites \\
Correlation statistics & without forest & under forest & under forest & forest \\
\hline Number of samples [n] & 34 & 53 & 28 & 81 \\
Determination coefficient [ $\left.\mathrm{r}^{2}\right]$ & 0.58 & 0.26 & 0.06 & 0.06
\end{tabular}

\section{Permafrost table depth}

Arithmetic mean $[\mathrm{cm}]$

184

96

160

118 
Maximum / minimum [cm]

RMSE [cm]
$380 / 75$

40.4
$200 / 40$

$200 / 73$

$200 / 40$

\section{Mean NDVI}

$p$ value

0.00

0.00

0.31

0.39

Mean value / standard deviation

$0.43 / 0.05$
23.3

40.3

\begin{tabular}{llll} 
& $0.51 / 0.02$ & $0.52 / 0.02$ & $0.51 / 0.02$ \\
\hline
\end{tabular}

\section{ASRI}

$p$ value

0.01

0.02

0.32

0.04

Mean value / standard deviation

[kW H m${ }^{-2}$ ]

$1141 / 57 \quad 1045 / 47 \quad 1064 / 85 \quad 1051 / 63$

\section{TWI}
$p$ value
0.04
0.01
0.27
0.24

Mean value / standard deviation

Two multivariate regression terms were used for delineating the depth of the permafrost table in areas with $\left(F_{2}\right)$ and without forest $\left(F_{1}\right)$. A multiple correlation coefficient of $\mathrm{r}^{2}=0.58\left(F_{1}\right.$, Table 3.2.2) was determined for sites without forest (including the classes steppe, burned forest and areas with ongoing tree succession). The correlation for the 81 forested sites was much weaker $\left(F_{4}\right.$, Table 3.2.2). Excluding forests on sandy soils resulted in an increase of the multiple correlation coefficient to $\mathrm{r}^{2}=0.26\left(F_{2}\right)$. The lacking correlation for forests on sandy soils $\left(F_{3}\right)$ indicated that factors not considered here controlled the depth of the permafrost table at these sites. Therefore, we generally applied the regression for forests on slope debris $F_{2}$ for estimating the depth of the permafrost table in forests and then added $1 \mathrm{~m}$ to the permafrosttable depth for forests on sandy soils. This adjustment was based on our field observation that the permafrost table was $1 \mathrm{~m}$ deeper in sandy soils compared to soils in slope debris (cf. 
Chapter 3.2.4.2). Subsequent validation of the delineated depth of the permafrost table including all 115 plots yielded a correlation coefficient of $r^{2}=0.58$ between empirical and modelled data (Figure 3.2.8). 


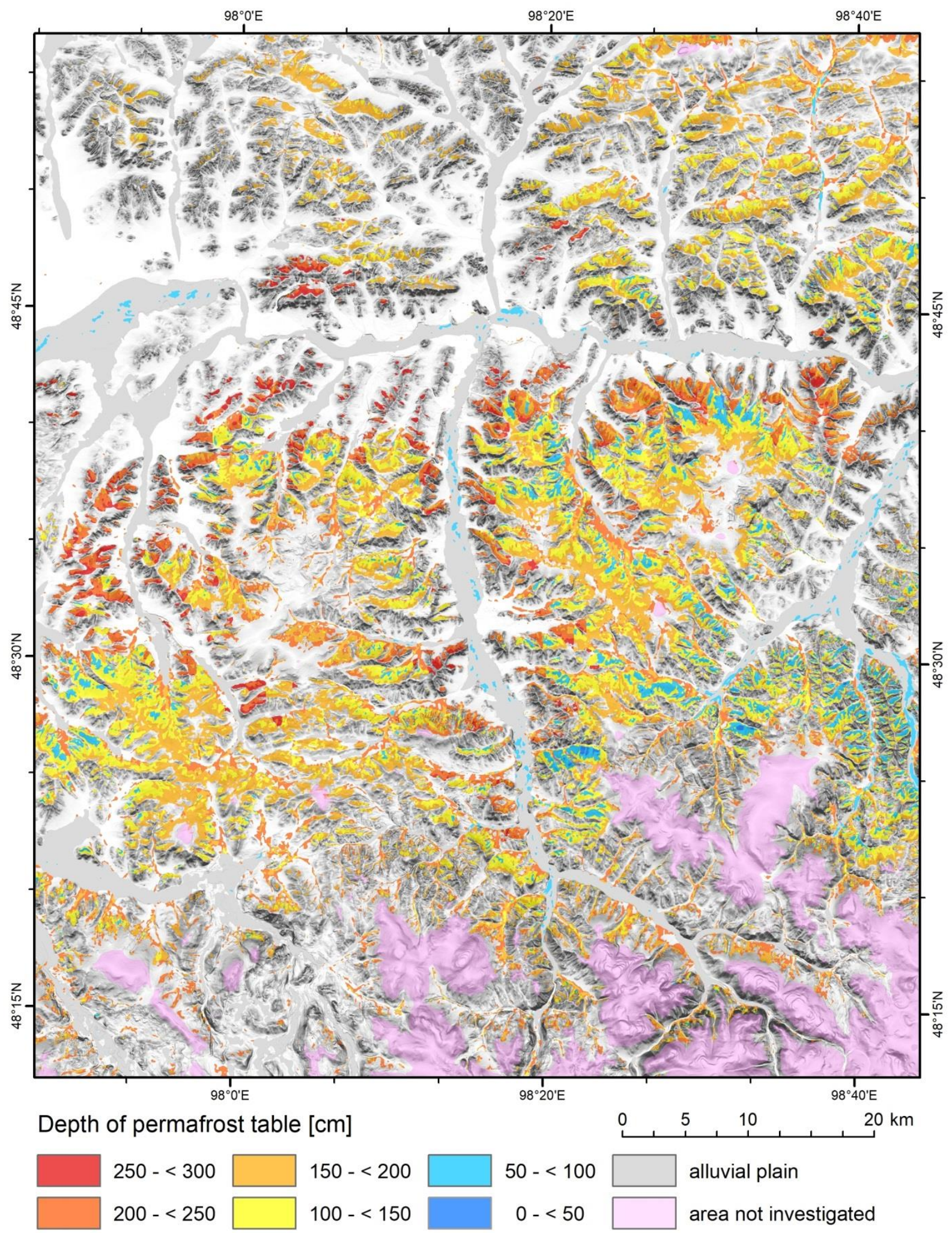

Figure 3.2.6: Delineated permafrost distribution and calculated depth of the permafrost table in the study area. The shaded relief is based on TanDEM-X data. No permafrost was identified in the non-coloured areas.

The final delineation of permafrost distribution and depth of the permafrost table was achieved by combining the qualitative relationship between forests with permafrost (Figure 3.2.5) and the quantitative results of the linear regression terms for landscape units in which permafrost 
occurs (Figure 3.2.6). The maximum depth was set to $300 \mathrm{~cm}$, as this depth represented the maximum penetration depth of the $400 \mathrm{MHz}$ GPR antenna and the maximum sediment thickness on the slopes. Thus, possible occurrences of permafrost at more than $300 \mathrm{~cm}$ depth were not considered.

Permafrost in the steppe area was limited to the direct vicinity of large forests. The depth of the permafrost table there was between 200 and $>300 \mathrm{~cm}$. Permafrost was absent on southfacing slopes and in most basin areas. North of Tosontsengel, permafrost was scarce. Under fragmented forests, permafrost occasionally occurred below $150 \mathrm{~cm}$. Sandy soils under forest had permafrost starting between 200 and $300 \mathrm{~cm}$. Inside large and dense forests, the depth of the permafrost table generally decreased downslope, from $200 \mathrm{~cm}$ on the upper slopes to $<50$ $\mathrm{cm}$ at the lower forest boundary. On the mountain crests in the FDA, the permafrost delineation pointed to absence of permafrost or deep permafrost table $(\sim 300 \mathrm{~cm})$.

Permafrost was widespread under peat and swampy meadows in the alluvial plains. This is in accordance to observations by Shur and Jorgenson (2007) in the zone of discontinuous permafrost of Alaska. However, no permafrost was found in floodplains near rivers and under riparian forests. Dunes in the basins, and the periglacial zone in the highest mountains were not included in this study.

\subsubsection{Discussion}

\subsubsection{Soil properties and vegetation controlling permafrost distribution and depth of the permafrost table}

The observed influence of relief and soil texture on the depth of the permafrost table can be explained as follows. Three soil-physical parameters control permafrost-table depth in the region of discontinuous permafrost in semi-arid environments. These are thermal conductivity, thermal capacity and water content. Soil moisture and ground ice increase thermal conductivity. The high thermal capacity of ground ice makes ice-rich permafrost more resilient to thawing, compared to dry permafrost, because of the heat that is required to melt the ice. Soil texture is important, too, as water can easily infiltrate into sandy material, but sand has a low water holding capacity. Thus, the upper $10 \mathrm{~cm}$ of a dry, sandy soil quickly warm up, whereas the low thermal conductivity of dry sand limits soil-temperature changes at greater depth. 
The influence of vegetation cover was also investigated by Dashtseren et al. (2014). Based on soil-temperature measurements in the forest-steppe region of the Khentei Mountains in northern Mongolia, they suggested that mountain-steppe supports only seasonally frozen ground, whereas a forest cover maintains permafrost, as it reduces soil exposure to insolation, and thick organic layers occurring under forest additionally insulate the soils from high summer air temperatures. The authors concluded that active-layer thickness is controlled by summer temperatures. Thermal conductivity of organic layers and mosses substantially changes with their water content. During winter, a wet organic layer (having high thermal conductivity) promotes soil freezing. During summer, a dry organic layer (having low thermal conductivity) reduces soil warming. In winter, the insulating effect of a snow cover controls soil temperature in seasonally frozen ground (Lehmkuhl and Klinge 2000; Zhang 2005; Dashtseren et al. 2014). Zhang (2005) suggested a snow-cover thickness of $40 \mathrm{~cm}$ as optimum thickness for insulating soils from low air temperatures. A thinner snow cover allows for propagation of low temperatures into the soils in winter, whereas a thicker snow cover persists longer during spring, delaying the beginning of insolation of the soil. Due to the stable Siberian high-pressure cell during winter, snow-cover thickness in Mongolia does generally not exceed 10-15 cm (Nyamjav et al. 2007), and its spatial distribution in Mongolia is limited (Middleton et al. 2015). However, in certain years an extensive snow cover occurs, leading to episodic hazardous events known as Dzuud.

Ishikawa et al. (2018) calculated a mean active-layer thickness of 300-400 cm for the zones of continuous and discontinuous permafrost in Mongolia. Wu et al. (2009; 2012) used GPR to detect the permafrost table under steppe in a basin near Ulaanbaatar, where it occurred at depths between 200 and $400 \mathrm{~cm}$. In the forest-steppe of northern Mongolia, Kopp et al. (2014) reported permafrost at $70 \mathrm{~cm}$ depth under forest on north-facing slopes, whereas permafrost was absent on south-facing slopes under steppe and in burned forest areas. Our observations of a permafrost-table depth between 50 and $>300 \mathrm{~cm}$ in the northern Khangai Mountains match well with these findings.

\subsubsection{Influence of fire and forest exploitation on permafrost}

The main factors controlling permafrost and their effects in the various geoecological units of the forest-steppe are summarized in Table 3.2.3. As discussed in the previous chapter, forests promote permafrost. As a positive feedback mechanism, meltwater released from seasonal ice above the permafrost supports them to persist through droughts and fire events. Selective logging and non-lethal forest fire lead to a lowering of the permafrost table, whereas clearcutting and severe forest fires lead to permafrost degradation (Shur and Jorgenson 2007). 
Fires destroyed many of the large forests in the high-mountain area (Figure 3.2.5). In the burned areas, permafrost has largely disappeared. In contrast to large closed forests, forest fires can less easily propagate across small, fragmented forests. This explains why forest fires are less extensive in the steppe-dominated area. Relief strongly controls the pattern of forest disturbance and regrowth after fire (Figure 3.2.10a). For instance, larch trees on toe slopes and in depressions, where soil moisture is enhanced, often survive forest fires (Dorjsuren 2009). Such patches of remaining trees form nuclei of forest regrowth. They are often surrounded by belts of different tree generations (Figure 3.2.10a). From there, forest regeneration slowly proceeds into the burned area, as larch seeds do not spread very far, and seedlings mainly grow near their parent trees (Dugarjav 2006). The shading effect and moist soils under deadwood and remaining living trees improve the conditions for saplings (Figure 3.2.10d).

Because of the mutual positive feedback between forest and permafrost, the speed and spatial pattern of this forest regeneration process also controls permafrost reestablishment. Fedorov et al. (2017) showed for a disturbed larch forest in the zone of continuous permafrost in Yakutia that permafrost regenerates with the succession of vegetation. According to Nyamjav et al. (2007), it may take up to 200 years until a forest regenerates to its state prior to the fire. In the semi-arid environment of our study area, larch seedlings require several consecutive moist years, allowing them to root deep enough to survive also a drier year. This explains the strong age grouping of larch forests in the Altai Mountains reported by Sommer and Treter (1999). They argued that dry years and fires often destroy several generations of seedlings, before a tree generation can finally establish.

Soil moisture plays a decisive role for both, forest regrowth and permafrost reestablishment. In Alaska, Jorgenson et al. (2013) found that permafrost in silty soils even persisted after forest fire, due to high water capacity and ice content of these soils, whereas permafrost in sandy and gravely soils mostly disappeared after fire. Kopp et al. (2014) and Lange et al. (2015) compared soil moisture and water fluxes under pristine forests, burned forests and steppes on south-facing slopes in the Khentei Mountains. They found high infiltration of precipitation into soils under intact and burned forests. The permafrost layer under intact forests retained the moisture in the soils. Without permafrost, the water was lost through deep percolation. The authors assumed a short-term water loss under burned forests due to permafrost degradation. On south-facing steppe-covered slopes, Lange et al. (2015) observed that water infiltrated only a few centimetres into the soil and then evaporated. 
Table 3.2.3: Geoecological factors controlling soil moisture and permafrost distribution in different vegetation units.

\begin{tabular}{|c|c|c|c|c|c|}
\hline \multirow[b]{2}{*}{ Ecological parameter } & Pristine forest & Degraded forest & Steppe & Burned forest & $\begin{array}{c}\text { Forest } \\
\text { succession }\end{array}$ \\
\hline & & & 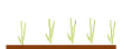 & & 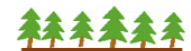 \\
\hline Canopy shading & high & low & no & no & high \\
\hline Ground vegetation & $\begin{array}{c}\text { dense } \\
\text { mosses, grasses, shrubs }\end{array}$ & $\begin{array}{l}\text { sparse } \\
\text { grasses }\end{array}$ & $\begin{array}{l}\text { sparse } \\
\text { grasses }\end{array}$ & $\begin{array}{c}\text { sparse } \\
\text { grasses, herbs, shrubs }\end{array}$ & $\begin{array}{l}\text { sparse } \\
\text { grasses }\end{array}$ \\
\hline Organic layer & thick & shallow & missing & missing & shallow \\
\hline Thermal insulation & high & medium & low & low & medium \\
\hline Permafrost table & shallow & deep & missing & missing & deep / missing \\
\hline Physical soil conditions & cool / wet & warm / dry & hot / dry & hot / dry & cool / dry \\
\hline
\end{tabular}

Permafrost reestablishment after forest disturbance differs considerably between the zones of discontinuous and continuous permafrost. In the zone of continuous permafrost, soils usually have high water and ice contents. After forest disturbance, the soils warm up. The released meltwater is perched above the permafrost table, increasing the thermal conductivity of the soil, which in turn results in partial permafrost degradation (Fedorov et al. 2017). In the region of discontinuous permafrost in semi-arid Mongolia, soil moisture is limited, with strong reliefcontrolled differences, leading to spatially differing permafrost reestablishment after forest disturbance.

Based on our field observations, we suggest the following causal chains: Abundant deadwood maintains soil moisture, allowing for dense tree succession after fire, in turn supporting permafrost reestablishment. Without deadwood, tree regrowth and, thus, permafrost reestablishment, are hampered (Figure 3.2.10c). Hence, with respect to the permafrost formation-degradation scheme of Shur and Jorgenson (2007), discontinuous permafrost in our study area is in-between climate-induced, ecosystem-driven and ecosystem-protected. Under natural conditions without climate warming, permafrost would re-establish contemporaneously with forest regrowth. However, permafrost already disappeared in small fragmented forests. Dead-tree margins at the edges of many forest stands point to ongoing soil-moisture decrease, induced by climate warming (Figure 3.2.10b). With climate warming, permafrost in this region will become totally ecosystem-protected and will thus not regenerate after forest disturbance any longer. Zhang et al. (2011) modelled the larch-taiga permafrost system in Siberia under climate warming. They predicted that this coupled system cannot persist if warming exceeds $2{ }^{\circ} \mathrm{C}$. Tchebakova et al. (2009b) modelled potential vegetation changes across Siberia based on climate-change scenarios, predicting a decrease of forest areas and a northward shift of 
the present Siberian biomes. Aridity and increased tree mortality would trigger more frequent and more severe wildfires, in turn accelerating permafrost disappearance.

\subsubsection{Conclusions}

Combining remote sensing, field measurements and statistical analyses enabled us to locate permafrost patches and to estimate the depth of the permafrost table in the central-Mongolian forest-steppe. The most significant correlations were found between permafrost-table depth and Topographic Wetness Index (TWI), potential incoming annual solar radiation input (ASRI), and mean NDVI. These parameters allow for predicting permafrost-table depth. Sandy soil texture, however, may lead to a $100 \mathrm{~cm}$ deeper permafrost table, contributing to drier conditions in sandy soils under forest compared to soils developed in slope debris.

The hypothesis that discontinuous permafrost in our study area is limited to large forests on north-facing slopes and directly adjacent steppes was verified. Permafrost was not encountered in small fragmented forests, even on north-facing slopes. We found that scattered patches of peat support permafrost, whereas no permafrost occurs in riparian forests.

Forests and permafrost form a mutually interlinked ecological system in the cold, semi-arid forest-steppe environment. Canopy shading of forests, and insulation of soils by organic layers and moss covers favour permafrost formation and preservation in large forest stands. Shallow depth of the permafrost table prevents deep percolation of meltwater from seasonal ice, thus keeping this important moisture reservoir available for tree roots. Progressive melting of ground ice replenishes soil moisture over summer and may support trees especially during summer droughts. Lateral meltwater flow above the permafrost table also enhances the vitality of steppe and broadleaf vegetation on the toe slopes, below the forests.

Opening of forest stands by logging decreases the shading effect and the amount of tree litter. This leads in turn to thinning of the insulating organic layer, enhanced soil warming and drying, and thus, deepening of the permafrost table and potential loss of permafrost. Thus, intense forest exploitation leads to drier conditions and increases the forests' vulnerability to drought and risk of fire. At sites with unfavourable soil conditions, clear cutting may lead to irreversible loss of permafrost and a shift to permanent steppe vegetation.

We found that permafrost has mostly disappeared after extensive forest fires in the study area. Tree regrowth and permafrost reconstitution, however, are highly variable, depending on the site conditions. At sites with favourable geoecological conditions, such as concave relief positions, permafrost and some trees may persist after fire. These sites form nuclei, from where 
dense tree succession may take place where large forests existed previously. In contrast, disturbed forests in the steppe-dominated area, where no permafrost is present today, hardly recover after fire. Under the currently ongoing climate warming, permafrost in the centralMongolian forest-steppe is in transition from climate- and ecosystem-triggered (active formation) to ecosystem-preserved (passive). Fragmented forests in the steppe-dominated area still persist without permafrost, but they will most likely disappear after fire or logging. Large forest stands still enable permafrost reconstitution after disturbance, but they will lose this ability in the course of climate warming.

\subsubsection{Appendices}

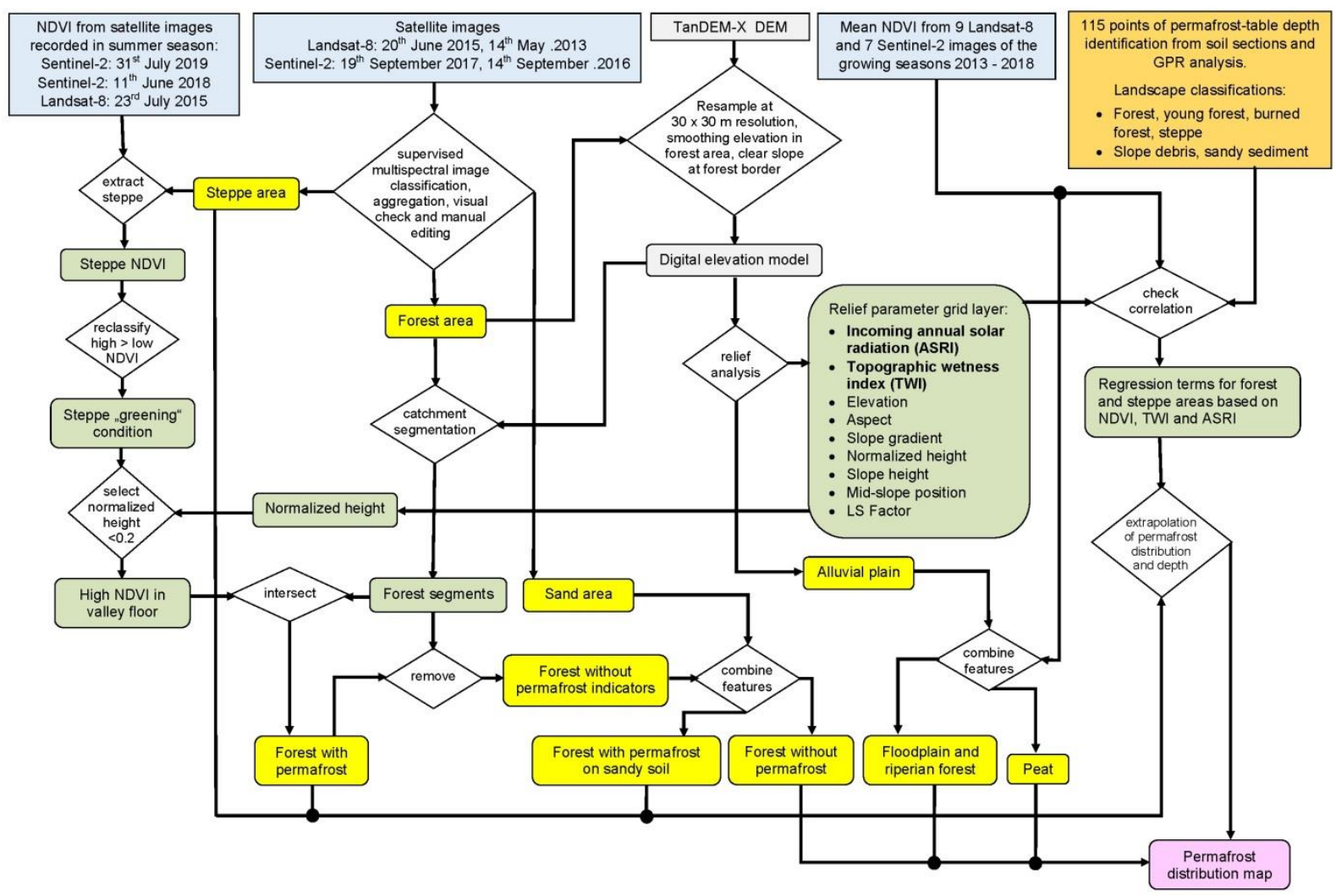

Figure 3.2.7: Flowchart illustrating input and output data, and the GIS-analysis process flows. The uppermost boxes list all data sources. Multispectral satellite images (blue), digital elevation data (grey), intermediate data (green), output data (yellow), final delineation of permafrost occurrence (pink). 


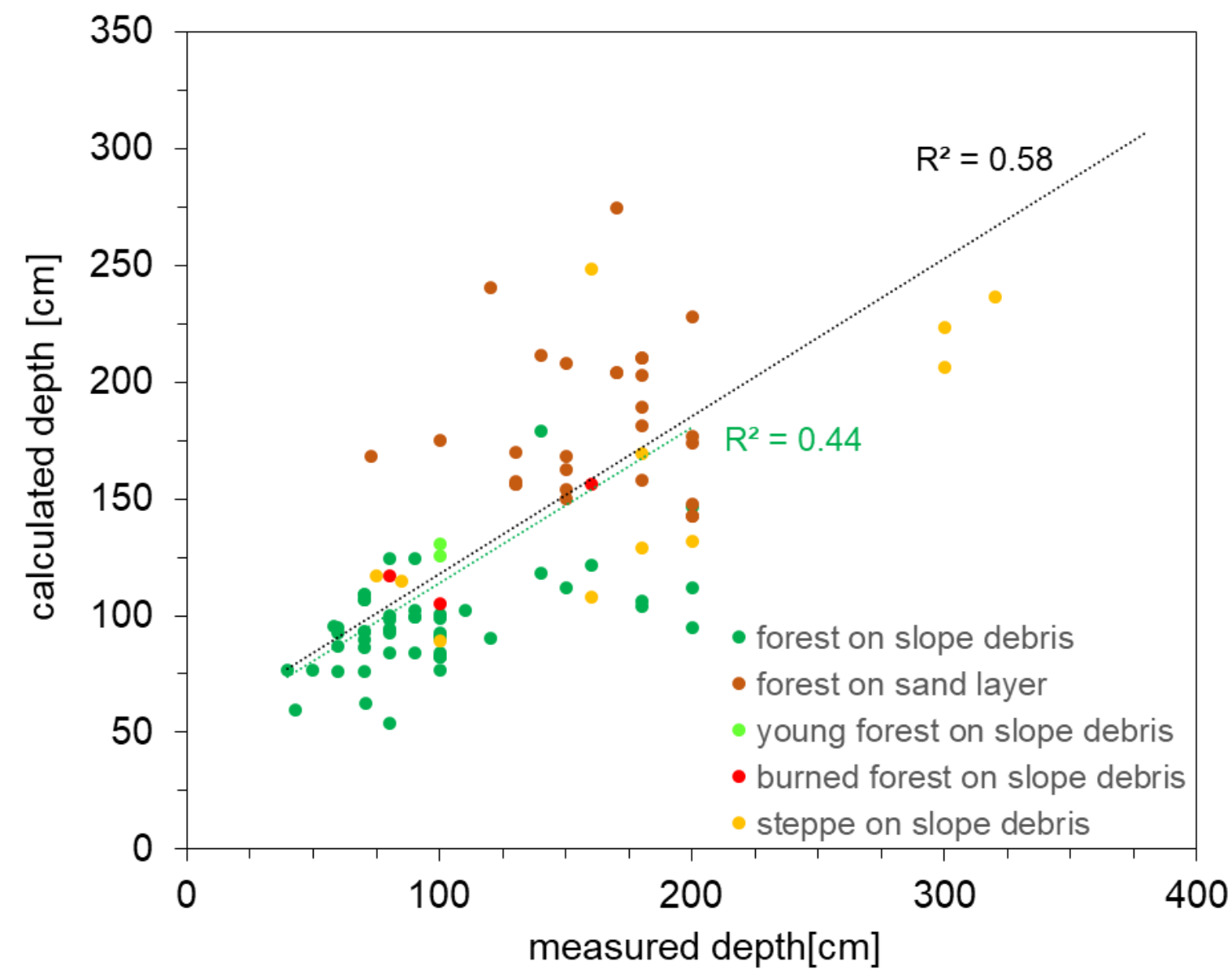

Figure 3.2.8: Relation between measured and calculated depths of the permafrost table. Depths of the permafrost table under steppe and under forest were calculated by the equations obtained for steppe $\left(F_{1}\right)$ and for forest on slope debris $\left(F_{2}\right) .100 \mathrm{~cm}$ were added for the 28 forest plots on sandy soils, because our field observations had revealed a generally deeper permafrost table for sandy soils. The black dotted line indicates the linear regression of all 115 plots and the correlation coefficient ( $p<0.005)$; the green dotted line indicates the linear regression of the 81 forest plots and the correlation coefficient $(p<0.005)$. 

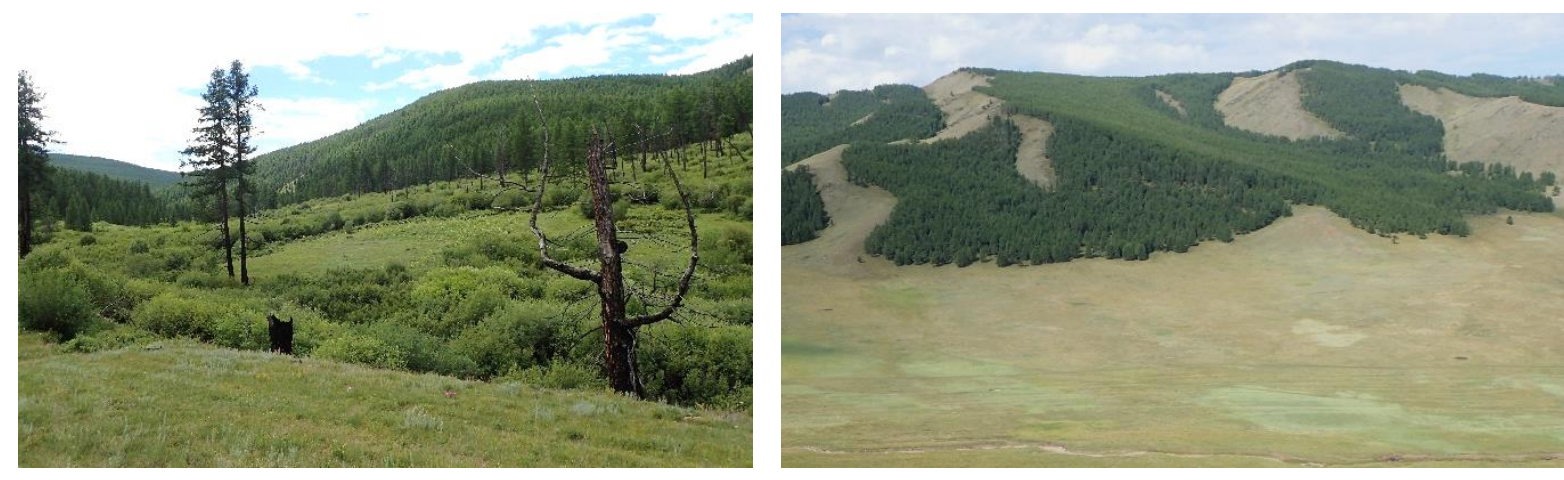

Figure 3.2.9: (a) Forest with permafrost. The permafrost is indicated by dense, green vegetation with shrubs on the lower slope, below the forest; (b) forest without permafrost, indicated by dry, yellowish-brownish steppe vegetation on the lower slope, below the forest.
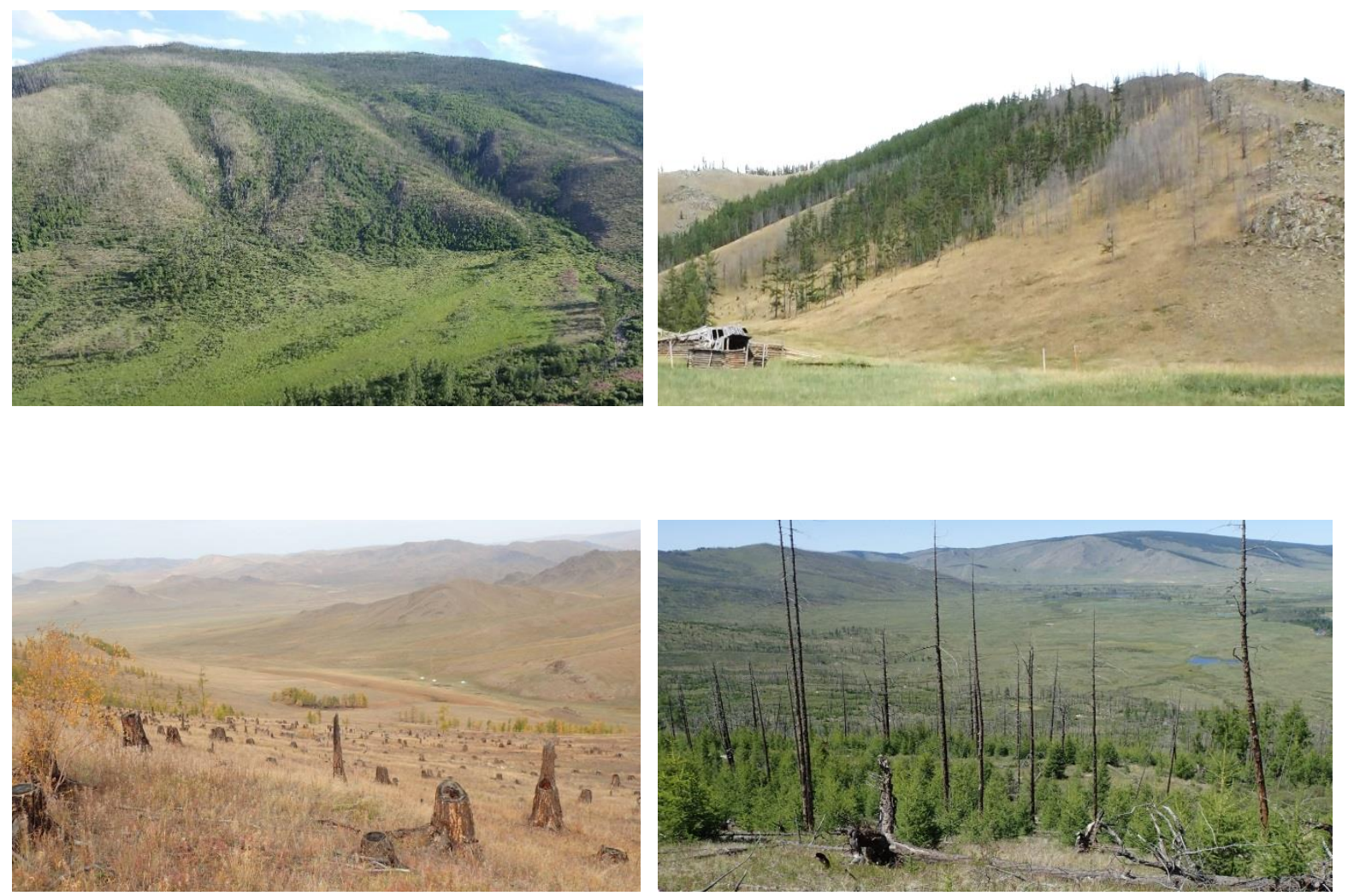

Figure 3.2.10: (a) Forest-regrowth pattern after fire: Remaining trees that survived in concave positions and on toe slopes are surrounded by young trees of different generations. Convex positions show no tree regrowth yet. (b) Dead-tree margins beside and above a fragmented forest. (c) Burned forest area with deadwood exploitation, without tree regrowth. (d) Burned forest area with remaining deadwood and abundant tree regrowth. 


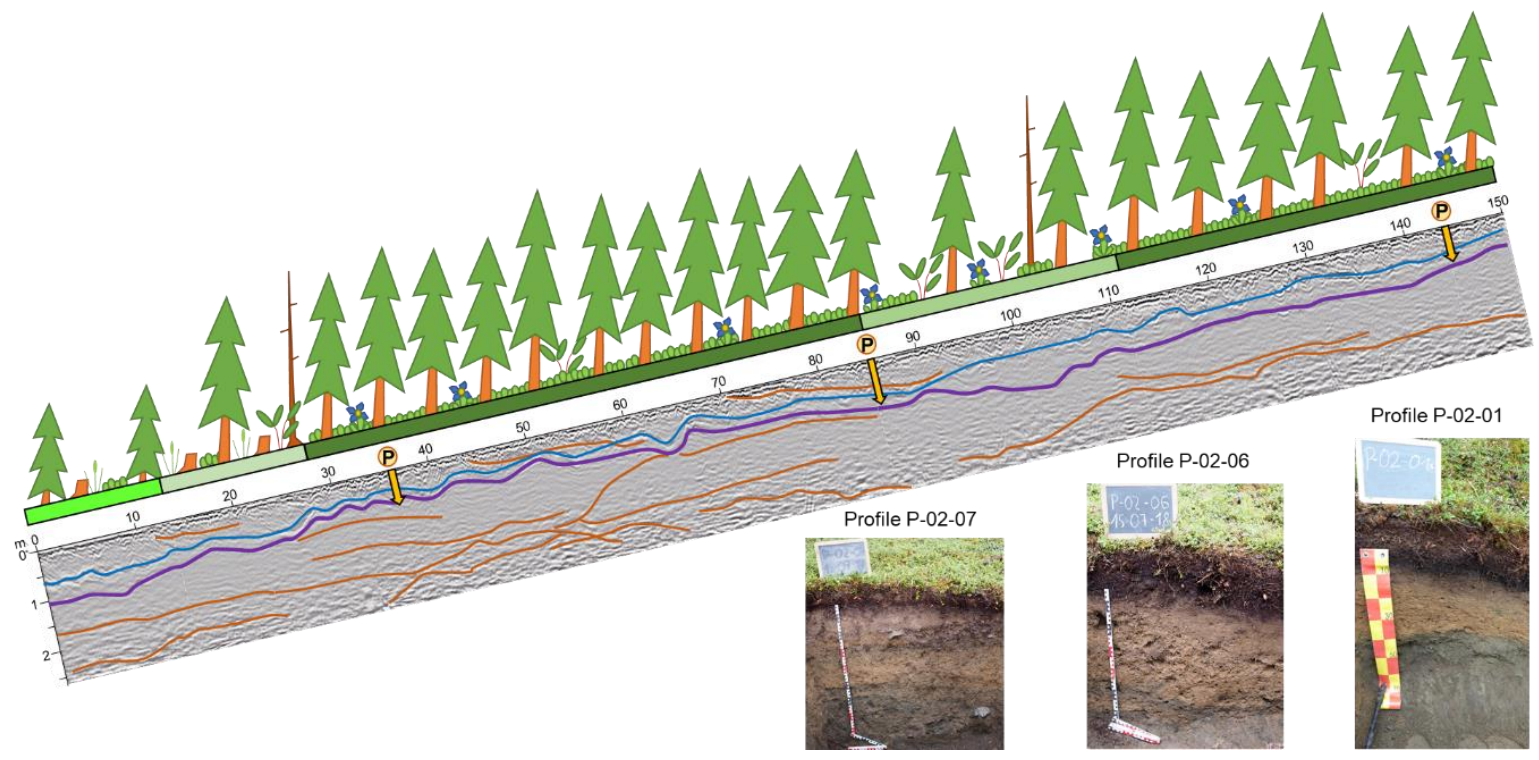

B

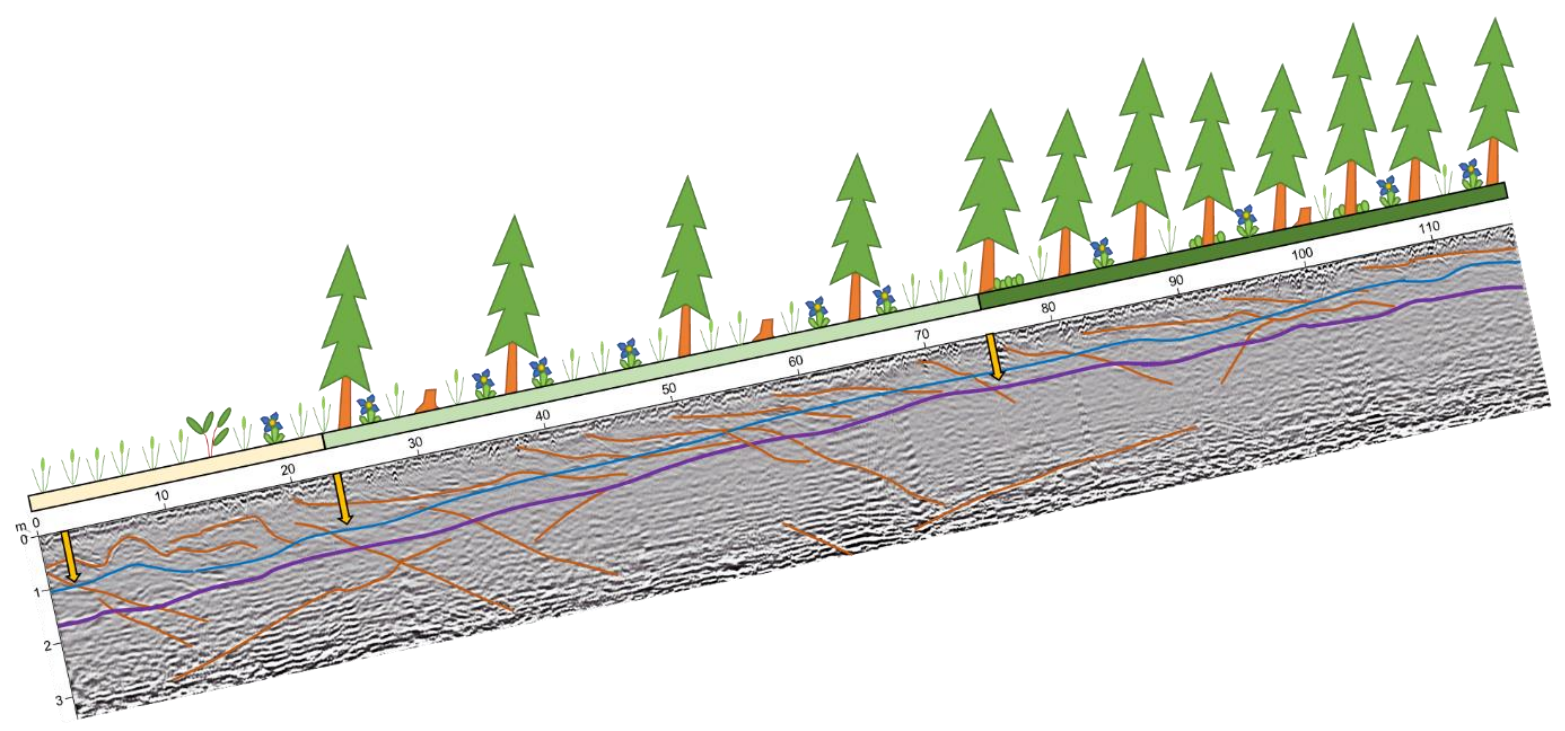


C

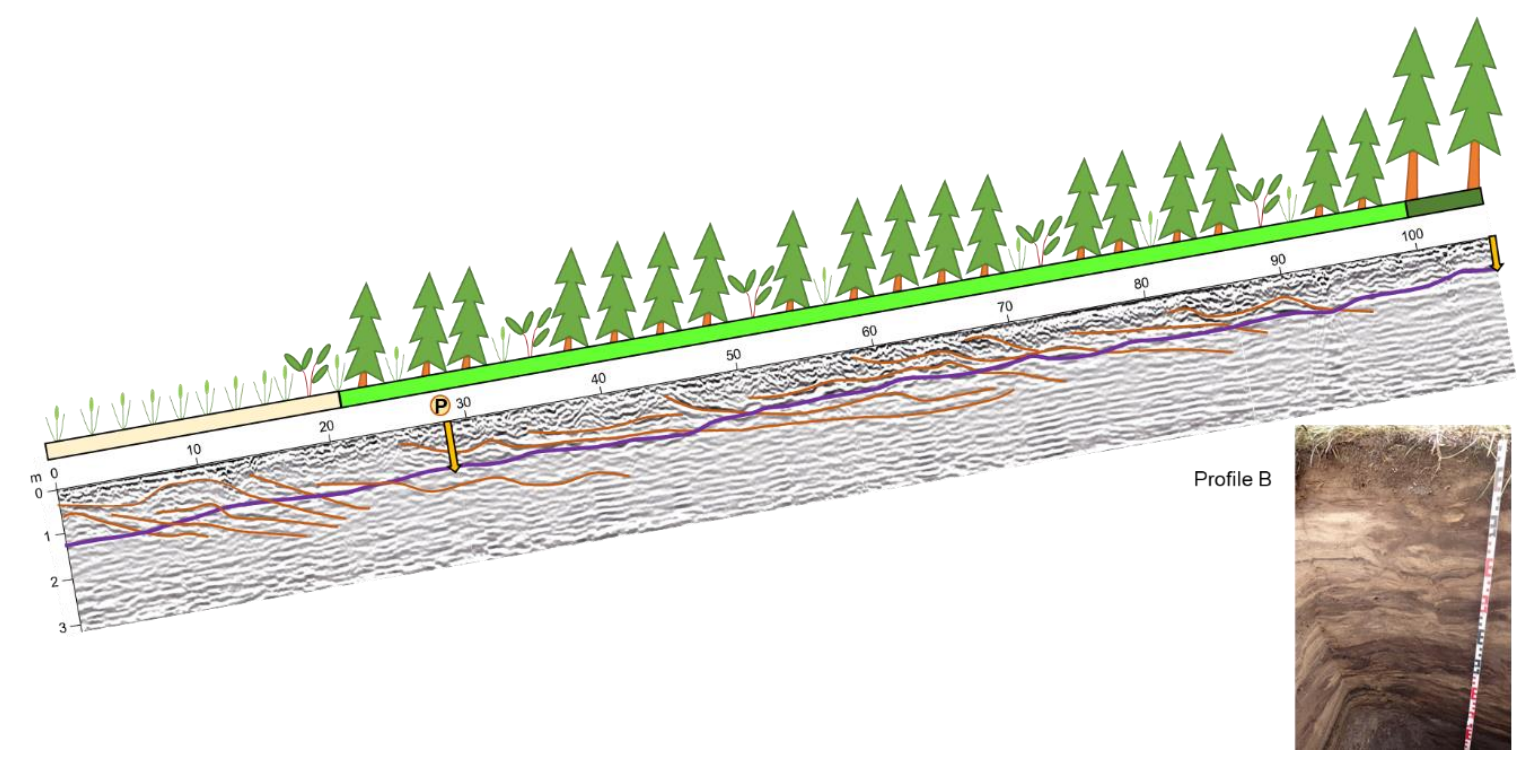

D

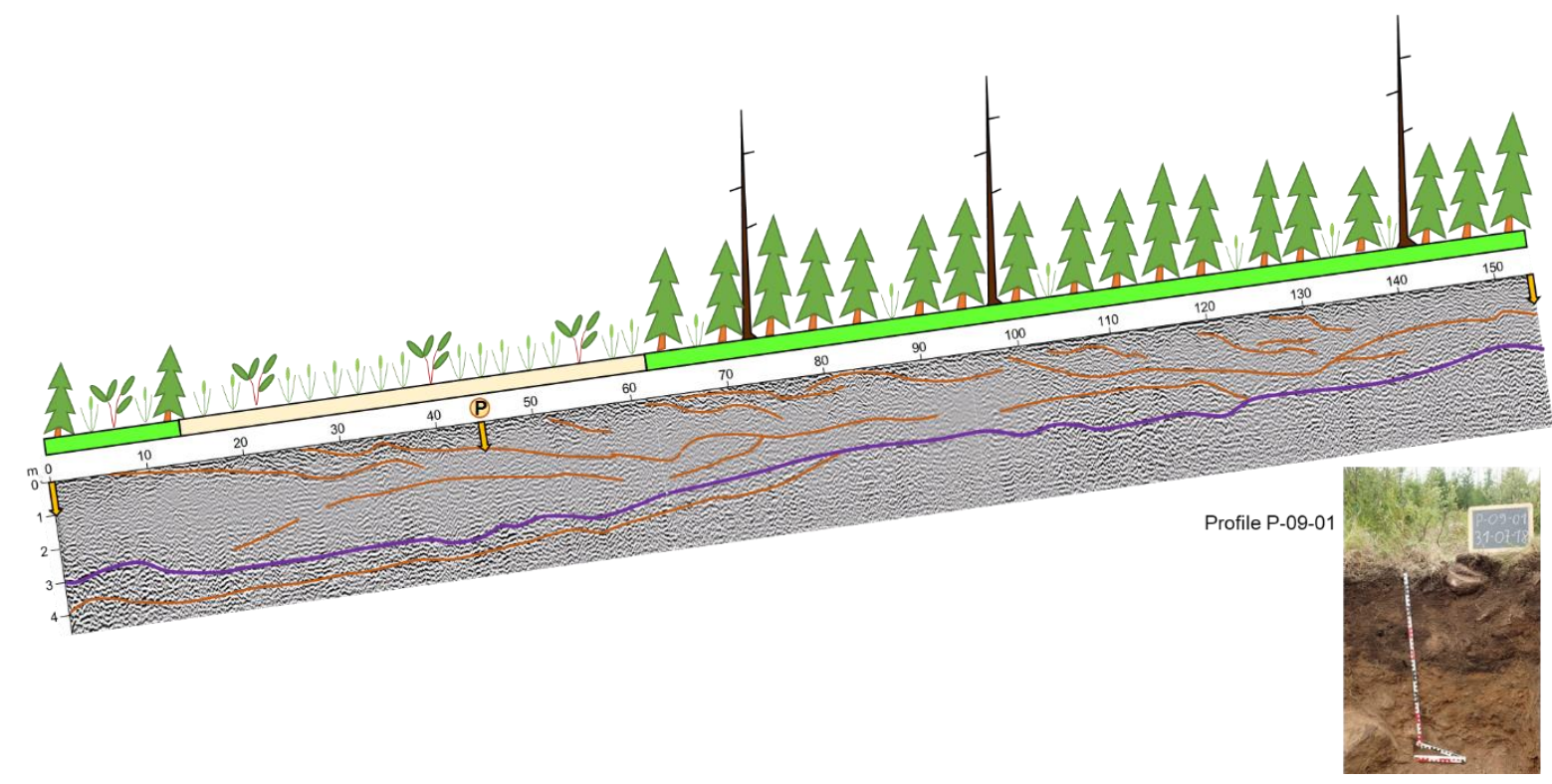




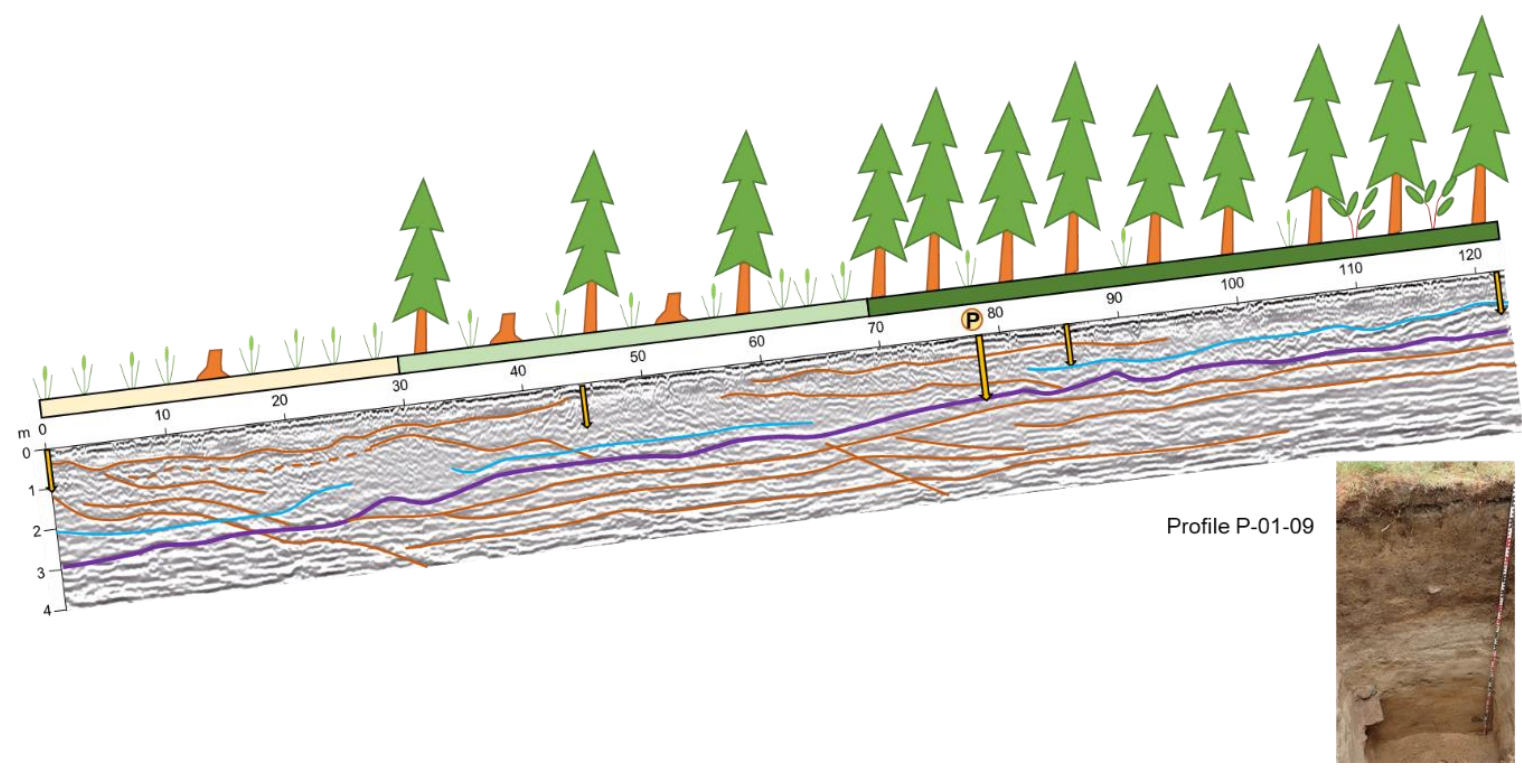

F

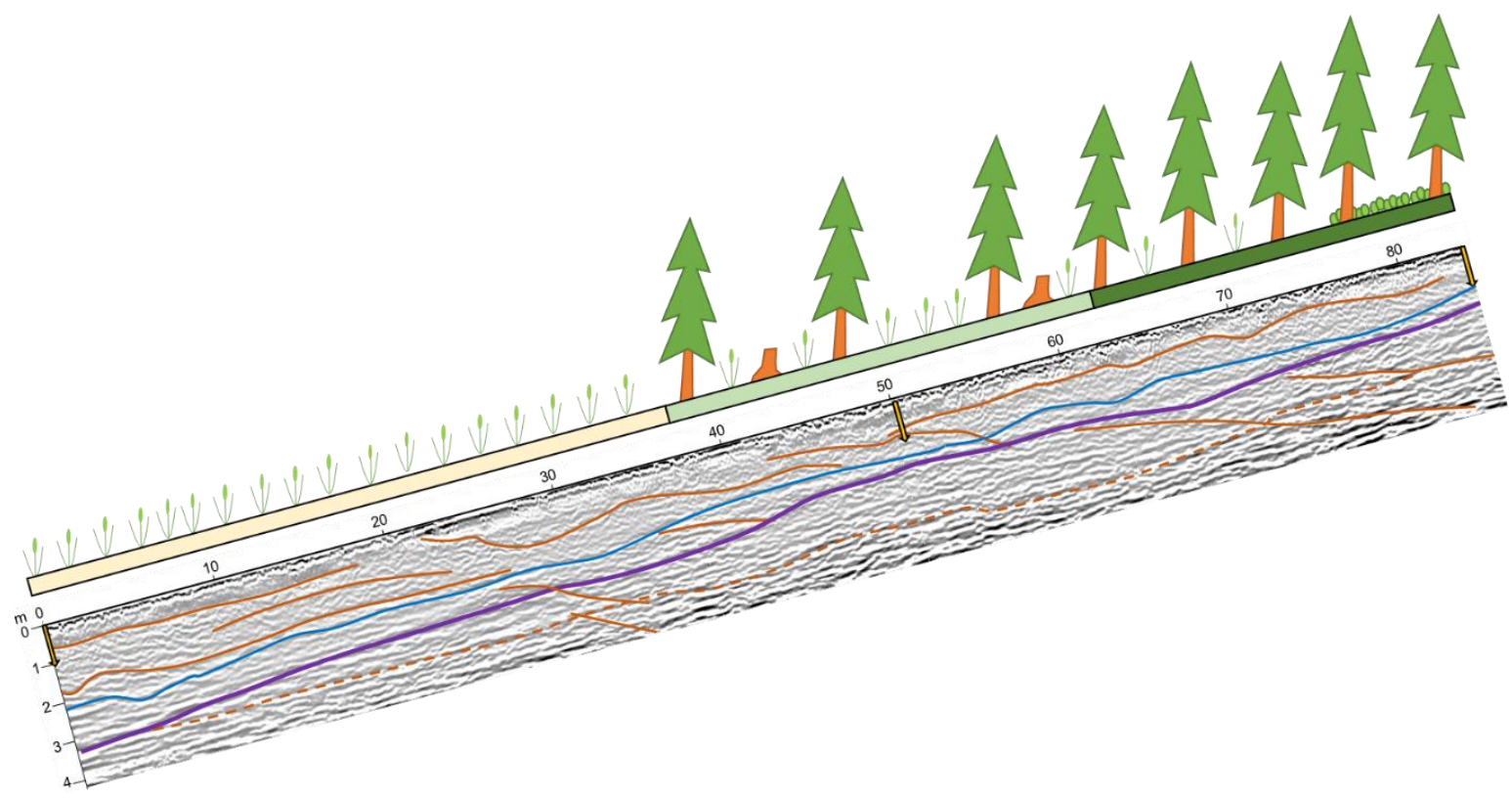




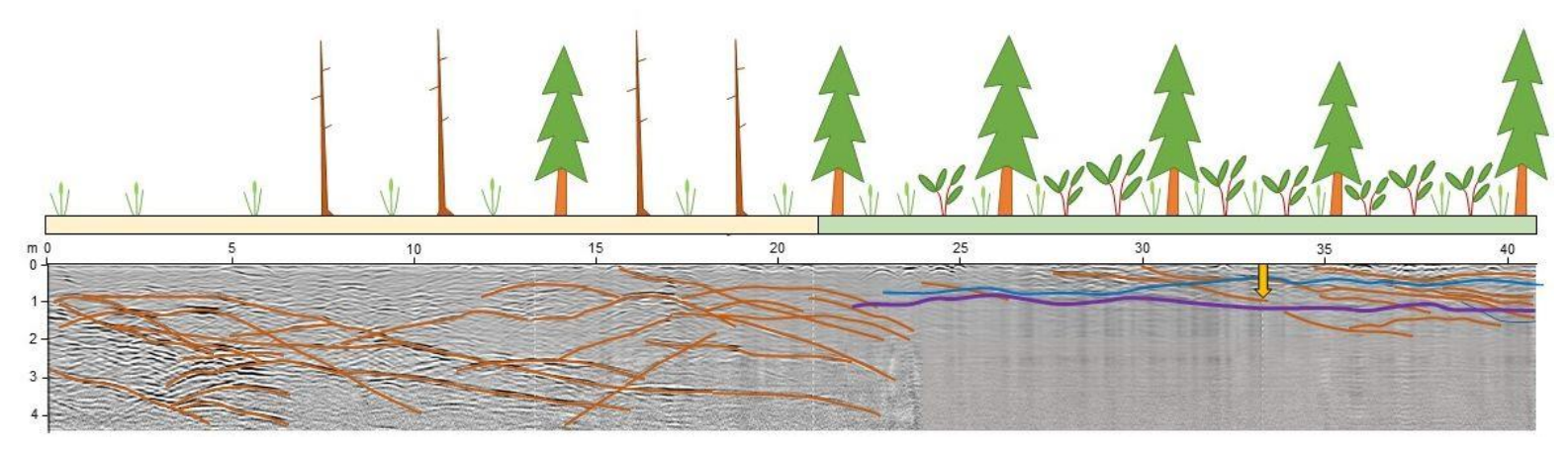

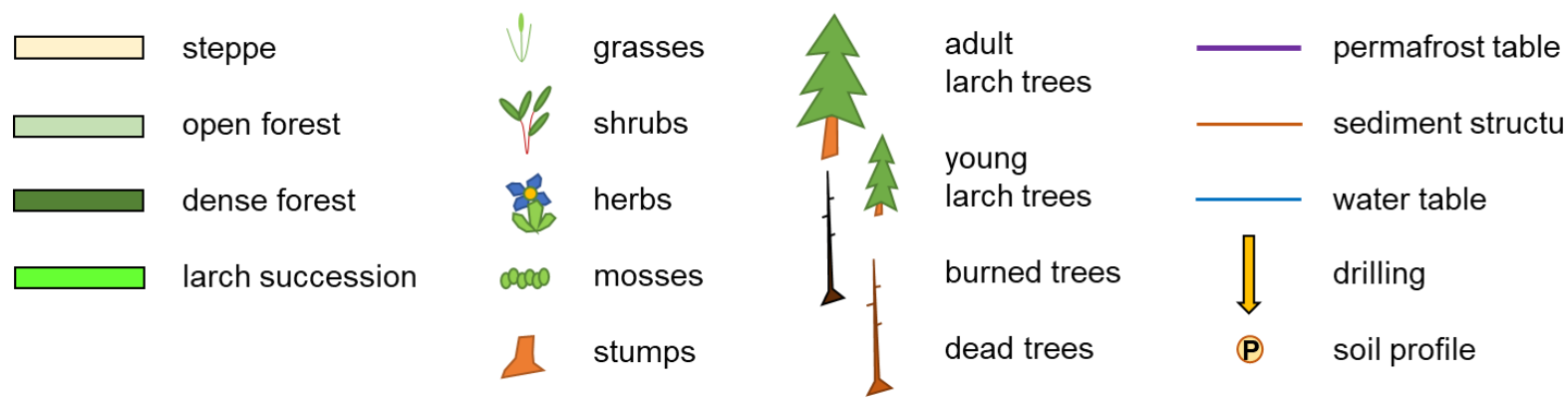

Figure 3.2.11: GPR images with interpretation of sedimentary structures, permafrost table and vegetation cover. The transects run along slopes at the lower forest boundary. The inclinations of the GPR images were adjusted to the mean gradient of the slopes. A: pristine forest on soils developed in slope debris, B: forest with logging on soils developed in slope debris, $C$ : forest on sandy soils, in the process of regrowth after forest fire, D: forest on glacial till, in the process of regrowth after forest fire, $E$ and F: forest on sandy soils influenced by logging, $G$ : horizontal transect from a dead-tree margin into a forest.

\section{Results of GPR analyses}

In the GPR images, the depth of the permafrost table is detectable as a distinct continuous reflector cutting through any sedimentary structures (Figure 3.2.11). The depth of the permafrost table increases with decreasing tree density. Transects $A$ and $B$ in Figure S1 are on slope debris of metamorphic rock under forest. Transect $A$ lies in a pristine forest with dense ground vegetation consisting of mosses, herbs and shrubs. Logging is limited to a few patches at the lower forest boundary. Deadwood and windthrown trees are widespread. Ice-rich permafrost was found at less than $1 \mathrm{~m}$ depth in many soil pits. The soils were generally moist. The shallow active layer of $<0.8 \mathrm{~m}$ under the dense forest is also visible in the GPR image. The depth of the permafrost table increases to about $1 \mathrm{~m}$ where the forest has been opened. The high water and ice content strongly attenuate the GPR signal. Transect B is in an area of 
intense logging that caused an opening of the forest stand in the lower part. As shown in the GPR image, the depth of the permafrost table, as well as the depth of the moist zone above it, decreases downslope from $<1 \mathrm{~m}$ depth under the dense forest along the open forest to more than $1.8 \mathrm{~m}$ depth under steppe. The reflector signals in the sediment display an imbricated structure of several colluvial layers.

Transects $C$ and $D$ are located on a toe slope with regrowth of young and dense-growing larch trees after a forest fire 20 year ago (Hansen et al. 2013). Transect $C$ is on sandy material, which shows imbricated sediment structures and a development similar to transects $A$ and $B$. The permafrost table in profile $B$ is at $1 \mathrm{~m}$ depth. The corresponding reflector in the GPR image slightly shifts from $0.8 \mathrm{~m}$ depth under the remaining forest along the young forest to more than $1.2 \mathrm{~m}$ depth under steppe. The soil above the permafrost table was dry at the time the soil pits were dug. High ice content attenuates the radar signal below the permafrost table. Transect $D$ is situated on glacial till, which contains abundant granite boulders causing numerous hyperbolas in the GPR image. Few distinct reflectors might indicate different moraine layers in the lower part and colluvial layers in the upper part. The permafrost table was identified at 2$2.5 \mathrm{~m}$ depth under forest regrowth and at $>3 \mathrm{~m}$ depth in the area where no tree regrowth takes place yet.

Transects $E$ and $F$ in Figure 3.2.11 are on sandy soil, in the transition zone from forest to steppe. The depth of the permafrost table increases from $\sim 1.5 \mathrm{~m}$ under dense forest to $3 \mathrm{~m}$ under steppe. This trend already starts with the opening of the forest at the lower forest boundary. An approximately parallel reflector occurs above the permafrost table. It can be interpreted as the upper limit of a moist zone. Although the soils predominately consist of aeolian sand, the sediment includes colluvial sandy and stony layers and horizons with carbonate accumulation. In the GPR image, the reflectors that approach the soil surface in downslope direction indicate an imbricated structure of colluvial layers. Periglacial processes during the late Pleistocene and early Holocene, and slope-wash processes after destructive fire events led to the formation of cover beds and colluvial layers on the slopes. Surface-parallel structures below the permafrost table indicate the transition zone to the bedrock.

Transect G runs horizontally from a rocky ridge with shallow, stony soils, bordering a small forest stand with dead-tree margin, into a slope depression in the centre of the small open forest. In the left part of the GPR image, reflector signals indicate bedrock. Wide hyperbolas point to boulders, but no permafrost table can be identified. In the right part of the image, layered slope sediments, a permafrost table, and a moist zone above the permafrost table are indicated by respective reflector signals and signal attenuation below. Due to the absence of permafrost that would provide a supplementary water reservoir and due to the low soil water 
capacity, trees growing on the shallow stony soils at the forest margins are seriously affected by droughts.

Table 3.2.4: Dimensions $\left(\mathrm{km}^{2}\right)$ of the calculated landscape units in the study area. SDA: steppe-dominated area, FDA: forest-dominated area; HMA: high-mountain area.

\begin{tabular}{lrrrrr}
\hline & SDA & FDA & HMA & \multicolumn{2}{r}{ Alluvial plain } \\
\hline Forest without permafrost & 79 & 387 & 11 & Forest & 7 \\
Forest with permafrost & 4 & 487 & 75 & Peat & 26 \\
Steppe & 1050 & 2034 & 1709 & Steppe & 464 \\
\hline Sum & 1133 & 2908 & 1795 & & 497 \\
\hline
\end{tabular}





\section{CHAPTER 4: SYNTHESIS AND OUTLOOK}

\subsection{Synthesis and conclusions}

From 1990 until 2015, climate change reduced the global forested area of about $3 \%$ (Keenan et al. 2015). Climate change, forest fires and human impact affected the central Mongolian forest-steppe resulting in a forest loss $13.5 \%$ from 2000 to 2013 (Hansen et al. 2013). Intensified drought events (Batima et al. 2005; Dulamsuren et al. 2010c) and forest fires (Goldammer 2002; Hessl et al. 2016) principally drive this development, yet, human impact additionally diminishes the forest distribution by logging and forest grazing (Tsogtbaatar 2004; Lkhagvadorj et al. 2013a). This thesis aimed to investigate the geo-ecological factors controlling the forest distribution and post-disturbance tree regrowth pattern to achieve a precise understanding concerning the future development and distribution of forest stands in the Mongolian forest-steppe. This general aim was divided into two objectives, which were elaborated in the previous two chapters. Chapter 2 focused on the present and potential forest distribution and vitality, as well as on the requirements and limitations of tree growth in this ecotone with particular attention on Siberian larch. Chapter 3 concentrated on soil properties and permafrost distribution in the study area and their differences connected to the documented tree regrowth pattern after disturbances. In these studies, multiple methods on different spatial scales were used to identify the relevance of relief, slope morphology, soil properties, permafrost, fire, climate change and human activity for the vegetation pattern.

For study one, remote sensing techniques and field measurements of tree biomass were used to identify the present and potential forest distribution in the northern Khangai Mountains. The results proved that the potential forest area could be up to three times larger than the present distribution. Forest fires and human impact dominantly caused this considerable difference, yet, the influence of climate change remains unclear. However, the semi-arid conditions limit the present and potential forest distribution to northern slopes due to less evapotranspiration. 
Study two combined field measurements of tree ring growth with NDVI time series from Landsat data. Due to a $30 \mathrm{~m}$ spatial resolution of the satellite data, a correlation of forest NDVI and steppe NDVI data with tree ring growth was conducted to testify the applicability of highresolution remote sensing analyses on the forest-steppe. The better correlation of forest NDVI with tree ring growth compared to steppe NDVI proved that the common use of steppe NDVI in this environment lacks in precision. Furthermore, forest NDVI time series can be used to accurately determine changes in forest vitality in the central Asian forest-steppe.

Study three based on a comprehensive review of English, German, and Russian literature concerning the ecological requirements of Siberian larch, supplemented by GIS techniques. Aggravated drought stress appeared to be the principal threat for this tree species in the central Asian forest-steppe. Furthermore, logging and forest grazing diminish forest stands and increase their sensitivity to other disturbances. Fire events seem to be of minor relevance for Siberian larch forests due to the species adaptation to fire disturbances. However, frequent fire disturbances accompanied by forest use will hamper tree regrowth, and if, thereby, the site properties underly severe changes, tree vegetation may not recover.

Study four and five were based on field descriptions and laboratory measurements from two field campaigns in 2017 and 2018. In study four, chemical, physical and hydrological soil properties of 54 soil profiles were analysed. The differences between areas with regrowth and without regrowth of trees after disturbances were of particular interest for this investigation. Areas with regrowth showed significantly higher silt contents, whereas areas without regrowth were considerably sandier. The resulting difference in plant-available field capacity is decisive for tree growth under the semi-arid climate. Furthermore, high hydraulic conductivity in the uppermost horizons supports tree regrowth due to a faster infiltration to the subsoil and, therefore, less evaporation loss. These findings confirm the importance of hydrological soil properties for the tree regrowth pattern in the study area. In contrast, chemical soil properties 
could not prove a significant difference between the disturbed areas with and without regrowth. Therefore, soil nutrients are not responsible for the post-disturbance tree regrowth.

Study five concentrated on ground-penetrating radar measurements combined with borehole analyses and soil-temperature measurements to analyse the permafrost distribution in the study area. The examined permafrost table was encountered under forest stands with a varying depth between $50-200 \mathrm{~cm}$. Permafrost has vanished at the severely disturbed forest stands and, therefore, an influence of permafrost on the observed tree regrowth pattern has to be rejected. A recovery of permafrost after forest disturbances was only documented in geoecologically favourable positions, receiving more water due to a beneficial slope morphology, and being already covered by dense tree succession.

In summary, Figure 4.1.1 illustrates the crucial findings from all five studies which are embodied in this thesis. Water availability stands out to be the key factor for the forest distribution and post-disturbance tree regrowth pattern in the central Mongolian forest-steppe. Therefore, all factors which increase the amount of available water support tree growth and regrowth, especially after disturbances. In this regard, slope morphology and hydrological soil properties are of dominant importance for tree regrowth in the investigated area. However, climate variations strongly influence the regrowth pattern due to a perennial increase or decrease in precipitation. These variations can enable tree regrowth under unfavourable site conditions and, vice versa, hamper it under favourable conditions. Furthermore, forest stands benefit from the presence of permafrost due to an additional water supply from the meltwater of the active layer. However, tree regrowth after severe disturbances appears without the presence of permafrost and succeeds with respect to the site properties. Remnant tree vegetation favours this process through reduced evapotranspiration by shading and through sufficient seed supply. 


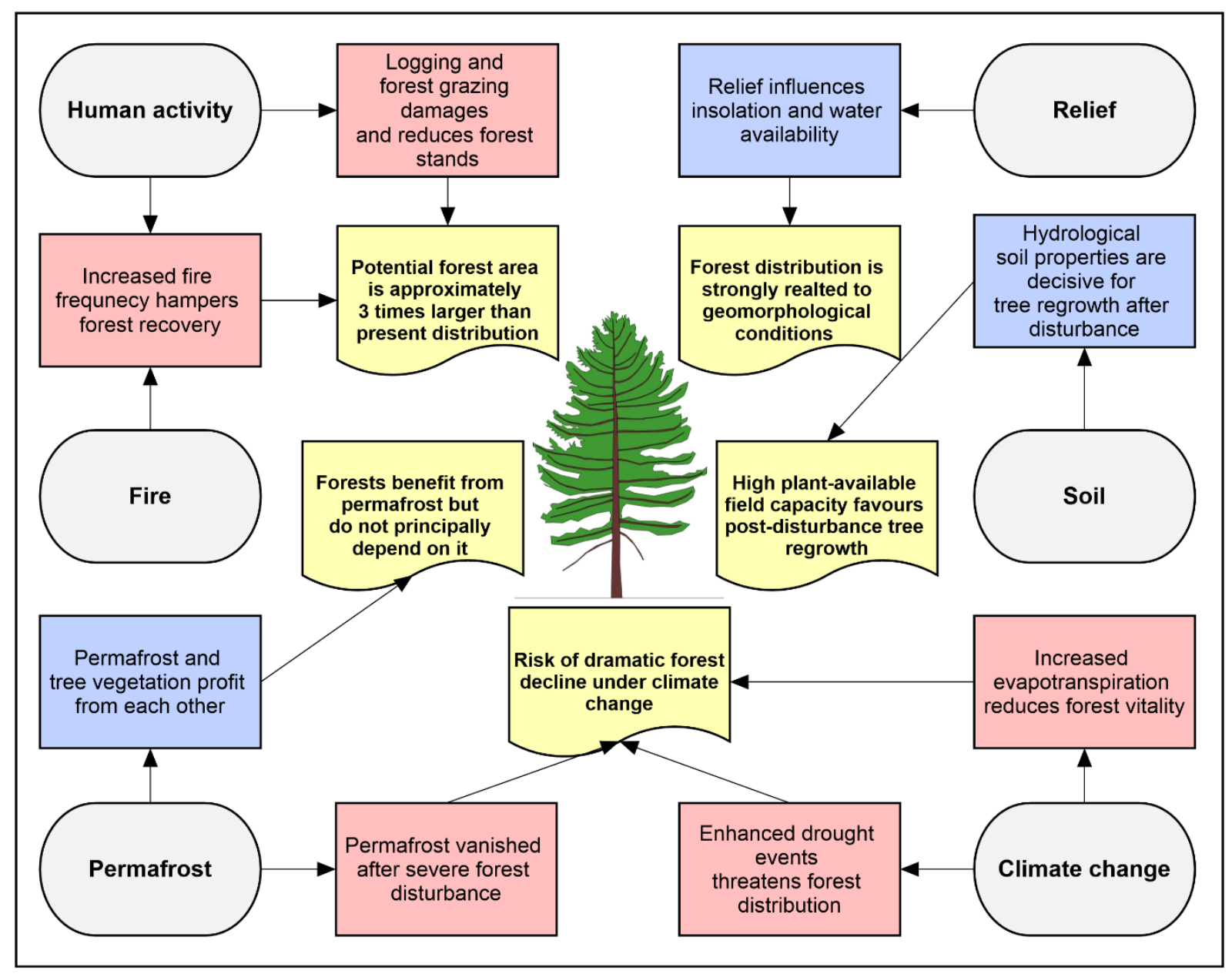

Figure 4.1.1: Key findings of the conducted studies. Grey boxes represent environmental factors, blue boxes show advantages for tree growth, red boxes show disadvantages for tree growth, yellow boxes represent consequences for L. sibirica.In contrast, enhanced drought

events and increased evapotranspiration, caused by climate change, principally threaten the present forest distribution. A lack of water might disable tree regrowth on severely disturbed forest areas with unfavourable soil properties and reduced water supply caused by the permafrost decline. Moreover, intensive forest use, in particular logging and forest grazing, disturbs the forest microclimate and causes an increased vulnerability of trees to other disturbances, e.g. drought events and herbivory infestations. In addition, forest use diminishes the post-disturbance tree regrowth, especially by grazing of goats, causing a considerable lack in forest reestablishment. 


\subsection{Outlook}

The post-disturbance tree regrowth in the central Asian forest-steppe is primarily limited by water availability and hampered by human activity. Under intensified droughts due to climate change, soil hydrological properties become decisive for tree growth in this region. Thus, structured and sustainable forest management is mandatory to prevent a dramatic loss of forested areas due to the consequences of climate change and human impact. An extensive investigation of site properties, in particular soil texture and slope morphology, will be necessary to define the possible use for forests and disturbed areas. Without regulation of human impact on the fragile Mongolian forest-steppe, a further considerable and irreversible loss of forested areas cannot be avoided.

The impact of climate change on the southern boundary of the Siberian taiga remains unclear. Due to a continuous forest- and permafrost distribution, this ecotone has a principle ability to buffer detrimental influences. However, intensified drought will affect the vegetation vitality and permafrost depth as well. A comprehensive investigation of the boreal zone of central Asia is therefore needed to supply necessary insights into the present and future development of this ecozone. 


\section{REFERENCES}

Abaimov, Anatoly P.; Lesinski, Jerzy A.; Martinsson, Owe; Milyutin, Leonid I. (1998): Variability and ecology of Siberian larch species. $43^{\text {rd }}$ ed. Umea: Swedish University of Agricultural Science.

Abaimov, Anatoly P. (2010): Geographical Distribution and Genetics of Siberian Larch Species. In Akira Osawa, Olga A. Zyryanova, Yojiro Matsuura, Takuya Kajimoto, Ross W. Wein (Eds.): Permafrost Ecosystems. Siberian Larch Forests. Dordrecht: Springer (Ecological studies, 209), pp. 41-58.

Abramenko, O. V. (2015): The Use of Siberian Larch (Larix sibirica Ledeb.) as the Bioindicator of the Urban Planting State in the Conditions of the Forest-Steppe zone in the Khakass-Minusinsk Hollow (in Russian). In Bulletin of Krasnoyarsk Agrarian University (1), pp. 184-188 [in Russian].

Academy of Sciences of Mongolia, Academy of Sciences of USSR (1990): National Atlas of the Peoples Republic of Mongolia. Ulaanbaatar, Moscow.

Albenskiy, A. V.; Krylov, G. V.; Logginov, B. J.; Scherlin, J. D. (1956): Usage of fast growing breeds in field protection forest cultivation (in Russian). Moskow [in Russian].

Alexander, Heather D.; Natali, Susan M.; Loranty, Michael M.; Ludwig, Sarah M.; Spektor, Valentin V.; Davydov, Sergey et al. (2018): Impacts of increased soil burn severity on larch forest regeneration on permafrost soils of far northeastern Siberia. In Forest Ecology and Management 417, pp. 144-153. DOI: 10.1016/j.foreco.2018.03.008.

Allen, Craig D.; Macalady, Alison K.; Chenchouni, Haroun; Bachelet, Dominique; McDowell, Nate; Vennetier, Michel et al. (2010): A global overview of drought and heat-induced tree mortality reveals emerging climate change risks for forests. In Forest Ecology and Management 259 (4), pp. 660-684. DOI: 10.1016/j.foreco.2009.09.001.

Amoozegar, A.; Warrick, A. W. (1986): Hydraulic Conductivity of Saturated Soils: Field Methods. In American Socienty of Agronomy-Soil Science Society of America, pp. 735-770.

Anenkhonov, Oleg A.; Korolyuk, Andrey Yu.; Sandanov, Denis V.; Liu, Hongyan; Zverev, Andrei A.; Guo, Dali (2015): Soil-moisture conditions indicated by field-layer plants help identify vulnerable forests in the forest-steppe of semi-arid Southern Siberia. In Ecological Indicators 57, pp. 196-207. DOI: 10.1016/j.ecolind.2015.04.012.

Antonova, Galina F.; Stasova, Victoria V. (1997): Effects of environmental factors on wood formation in larch (Larix sibirica Ldb.) stems. In Trees 11, pp. 462-468.

Avdeeva, E. V.; Kuzmichev, V. V. (2007): Specificity of the Ontogenesis and Indicator Role of Siberian Larch (Larix sibirica Ledeb.) in the Conditions of Urban Environment (in Russian). In Conifers of the boreal zone 24 (4-5), pp. 362-367 [in Russian].

Babushkina, Elena A.; Belokopytova, Liliana V. (2014): Climatic Signal in Radial Increment of Conifers in Forest-Steppe of Southern Siberia and Its Dependence on Local Growing Conditions. In Russ J Ecol 45 (5), pp. 325-332. DOI: 10.1134/S1067413614050038.

Babushkina, Elena A.; Belokopytova, Liliana V.; Grachev, Alexi M.; Meko, David M.; Vaganov, Eugene A. (2017): Variation of the hydrological regime of Bele-Shira closed basin in Southern Siberia and its reflection in the radial growth of Larix sibirica. In Reg Environ Change 17 (6), pp. 1725-1737. DOI: 10.1007/s10113-017-1137-1. 
Barchenkov, A. P.; Milyutin, Leonid I.; Zhamyansuren, S. (2012): Morphological Variability of Generative Organs of Larix sibirica Growing in East Siberia and North-East Mongolia (in Russian). In Conifers of the boreal zone 30, pp. 16-20 [in Russian].

Batima, P.; Natsagdorj, L.; Gombluudev, P.; Erdenetsetseg, B. (2005): Observed climate change in Mongolia. In Assessments of Impacts and Adaptations of Climate Change (12), pp. 1-26.

Batkhuu, Nyam-Osor; Lee, Don Koo; Tsogtbaatar, Jamsran; Park, Yeong Dae (2010): Seed quality of Siberian larch (Larix sibirica Ldb.) from geographically diverse seed sources in Mongolia. In Scandinavian Journal of Forest Research 25 (sup8), pp. 101-108. DOI: 10.1080/02827581.2010.485815.

Bat-Oyun, Tserenpurev; Shinoda, Masato; Cheng, Yunxiang; Purevdorj, Yadamjav (2016): Effects of grazing and precipitation variability on vegetation dynamics in a Mongolian dry steppe. In JPECOL 9 (5), pp. 508-519. DOI: 10.1093/jpe/rtv083.

Battulga, Purevragchaa; Tsogtbaatar, Jamsran; Dulamsuren, Choimaa; Hauck, Markus (2013): Equations for estimating the above-ground biomass of Larix sibirica in the foreststeppe of Mongolia. In J. Forestry. Res. 24 (3), pp. 431-437. DOI: 10.1007/s11676-0130375-4.

Bazha, S. N.; Gunin, Petr D.; Danzhalova, E. V.; Drobyshev, Yu. I.; Prishcepa, A. V. (2012): Pastoral Degradation of Steppe Ecosystems in Central Mongolia. In Marinus J.A. Werger, Marja A. van Staalduinen (Eds.): Eurasian Steppes. Ecological Problems and Livelihoods in a Changing World. Dordrecht: Springer Netherlands (Plant and Vegetation), pp. 289-319.

Bazha, S. N.; Baldanov, B. Ts.; Baskhaeva, T. G.; Danzhalova, E. V.; Drobyshev, Yu. I.; Dugarjav, Chultamiin et al. (2016): Diagnostic Features of Reforestation Potential of Larix sibirica Ledeb. in Ecosystems at the Southern Boundary of the Boreal Belt in Asia. In Arid Ecosyst 6 (3), pp. 169-176. DOI: 10.1134/S2079096116030033.

Beaudette, D. E.; Roudier, P.; O'Geen, A. T. (2013): Algorithms for quantitative pedology: A toolkit for soil scientists. In Computers \& Geosciences 52, pp. 258-268. DOI:

10.1016/j.cageo.2012.10.020.

Beck, Pieter S. A.; Juday, Glenn P.; Alix, Claire; Barber, Valerie A.; Winslow, Stephen E.; Sousa, Emily E. et al. (2011): Changes in forest productivity across Alaska consistent with biome shift. In Ecology Letters 14 (4), pp. 373-379. DOI: 10.1111/j.1461-0248.2011.01598.x [in eng].

Benkova, Anna V.; Rubtsov, Alexey V.; Benkova, Vera E.; Shashkin, Alexander V. (2019): Seasonal Sap Flow Dynamics in Larix sibirica Trees Growing in the Krasnoyarsk ForestSteppe (in Russian). In J. Sib. Fed. Univ., Biol. 12 (1), pp. 32-47. DOI: 10.17516/1997-13890071 [in Russian].

Bjarnadottir, Brynhildur; Sigurdsson, Bjarni D.; Lindroth, Anders (2007): Estimate of annual carbon balance of a young Siberian larch (Larix sibirica) plantation in Iceland. In Tellus $B$ : Chemical and Physical Meteorology 59 (5), pp. 891-899. DOI: 10.1111/j.16000889.2007.00300.x.

Bocharov, Anatoly Yu. (2009): Climatogenetic Radial Growth of Conifers in the Upper Forest Belt of the Seminsky Range (the Central Altai Mountains) (in Russian). In Journal of Siberian Federal University 1 (2), pp. 30-37 [in Russian].

Böhner, Jürgen; Lehmkuhl, Frank (2005): Environmental change modelling for Central and High Asia: Pleistocene, present and future scenarios. In Boreas 34 (2), pp. 220-231. DOI: 10.1080/03009480510012917. 
Bonan, Gordon B.; Shugart, Herman Henry (1989): Environmental Factors and Ecological Processes in Boreal Forests. In Annu. Rev. Syst. 20, pp. 1-28.

Brehaut, Lucas; Danby, Ryan K. (2018): Inconsistent relationships between annual tree ringwidths and satellite-measured NDVI in a mountainous subarctic environment. In Ecological Indicators 91, pp. 698-711. DOI: 10.1016/j.ecolind.2018.04.052.

Buermann, Wolfgang; Parida, Bikash; Jung, Martin; MacDonald, Glen M.; Tucker, Compton J.; Reichstein, Markus (2014): Recent shift in Eurasian boreal forest greening response may be associated with warmer and drier summers. In Geophys. Res. Lett. 41 (6), pp. 19952002. DOI: 10.1002/2014GL059450.

Bumann, Evan (2017): Assessing Responses of Betula papyrifera (Paper Birch) to Climate Variability in a Remnant Population Along the Niobrara River in Nebraska Through Dendroecological and Remote Sensing Techniques. Lincoln, Nebraska (Dissertations \& Theses in Natural Resources, 161). Available online at http://digitalcommons.unl.edu/natresdiss/161, checked on 10/26/2018.

Bunn, Andrew G.; Hughes, Malcolm K.; Kirdyanov, Alexander V.; Losleben, Mark; Shishov, Vladimir V.; Berner, Logan T. et al. (2013): Comparing forest measurements from tree rings and a space-based index of vegetation activity in Siberia. In Environ. Res. Lett. 8 (3), p. 35034. DOI: $10.1088 / 1748-9326 / 8 / 3 / 035034$.

Carter, M. R. (1980): Effects of sulphate and chloride soil salinity on growth and needle composition of Siberian larch. In Canadian Journal of Plant Science 60, pp. 903-910.

Chen, Dong; Loboda, Tatiana V.; Krylov, Alexander; Potapov, Peter V. (2016): Mapping stand age dynamics of the Siberian larch forests from recent Landsat observations. In Remote Sensing of Environment 187, pp. 320-331. DOI: 10.1016/j.rse.2016.10.033.

Chen, Feng; Yuan, Yu-jiang; Wei, Wen-shou; Fan, Zi-ang; Zhang, Tong-wen; Shang, Huaming et al. (2012): Climatic response of ring width and maximum latewood density of Larix sibirica in the Altay Mountains, reveals recent warming trends. In Annals of Forest Science 69 (6), pp. 723-733. DOI: 10.1007/s13595-012-0187-2.

Chen, Feng; Yuan, Yu-jiang; Yu, Shu-long; Zhang, Tong-wen; Shang, Hua-ming; Zhang, Ruibo et al. (2015): A 225-year long drought reconstruction for east Xinjiang based on Siberia larch (Larix sibirica) tree-ring widths: Reveals the recent dry trend of the eastern end of Tien Shan. In Quaternary International 358, pp. 42-47. DOI: 10.1016/j.quaint.2014.11.055.

Chenlemuge, Tselmeg; Hertel, Dietrich; Dulamsuren, Choimaa; Khishigjargal, Mookhor; Leuschner, Christoph; Hauck, Markus (2013): Extremely low fine root biomass in Larix sibirica forests at the southern drought limit of the boreal forest. In Flora - Morphology, Distribution, Functional Ecology of Plants 208 (8-9), pp. 488-496. DOI: 10.1016/j.flora.2013.08.002.

Chenlemuge, Tselmeg; Dulamsuren, Choimaa; Hertel, Dietrich; Schuldt, Bernhard; Leuschner, Christoph; Hauck, Markus (2015a): Hydraulic properties and fine root mass of Larix sibirica along forest edge-interior gradients. In Acta Oecologica 63, pp. 28-35. DOI: 10.1016/j.actao.2014.11.008.

Chenlemuge, Tselmeg; Schuldt, Bernhard; Dulamsuren, Choimaa; Hertel, Dietrich; Leuschner, Christoph; Hauck, Markus (2015b): Stem increment and hydraulic architecture of a boreal conifer (Larix sibirica) under contrasting macroclimates. In Trees 29 (3), pp. 623636. DOI: 10.1007/s00468-014-1131-x. 
Chernyshenko, O. V.; Vasilyev, S. B. (2019): Mineral nutrition specificity of coniferous trees on industrial waste discharge of Egorievsk phosphorite deposit (in Russian). In FB (135), pp. 46-53. DOI: 10.18698/2542-1468-2019-5-46-53 [in Russian].

Churakova, Olga V.; Shashkin, Alexander V.; Siegwolf, Rolf T. W.; Spahni, Renato; Launois, Thomas; Saurer, Matthias et al. (2016): Application of eco-physiological models to the climatic interpretation of $\delta 13 \mathrm{C}$ and $\delta 180$ measured in Siberian larch tree-rings. In Dendrochronologia 39, pp. 51-59. DOI: 10.1016/j.dendro.2015.12.008.

Chu, Thuan; Guo, Xulin; Takeda, Kazuo (2016a): Remote sensing approach to detect postfire vegetation regrowth in Siberian boreal larch forest. In Ecological Indicators 62, pp. 3246. DOI: 10.1016/j.ecolind.2015.11.026.

Chu, Thuan; Guo, Xulin; Takeda, Kazuo (2016b): Temporal dependence of burn severity assessment in Siberian larch (Larix sibirica) forest of northern Mongolia using remotely sensed data. In Int. J. Wildland Fire 25 (6), p. 685. DOI: 10.1071/WF15182.

Conrad, Olaf; Bechtel, B.; Bock, M.; Dietrich, H.; Fischer, E.; Gerlitz, L. et al. (2015): System for Automated Geoscientific Analyses (SAGA) v. 2.1.4. In Geosci. Model Dev. 8 (7), pp. 1991-2007. DOI: 10.5194/gmd-8-1991-2015.

Coops, Nicholas; Bi, Huiquan; Barnett, Paul; Ryan, Phil (1999): Estimating Mean and Current Annual Increments of Stand Volume in a Regrowth Eucalypt Forest Using Historical Landsat Multi Spectral Scanner Imagery. In Journal of Sustainable Forestry 9 (3-4), pp. 149-168. DOI: 10.1300/J091v09n03_07.

Dagvadorj, D.; Natsagdorj, L.; Dorjpurev, J.; Namkhainyam, B. (2009): Mongolia Assessment Report on Climate Change 2009. Ulaanbaatar, Mongolia, checked on 1/22/2021.

Danilin, I. M. (1995): Structure and biomass of larch stands regenerating naturally after clearcut logging. In Water, Air and Soil Pollution 82, pp. 125-131. DOI: 10.1007/978-94-0170942-2_14 [in en].

Danilin, I. M.; Tsogt, Z. (2014): Dynamics of Structure and Biological Productivity of Post-Fire Larch Forests in the Northern Mongolia. In Contemp. Probl. Ecol. 7 (2), pp. 158-169. DOI: $10.1134 /$ S1995425514020036.

D'Arrigo, Rosanne D.; Malmstrom, C. M.; Jacoby, Gordon C.; Los, S. O.; Bunker, D. E. (2000a): Correlation between maximum latewood density of annual tree rings and NDVI based estimates of forest productivity. In Int. J. Remote Sens. 21 (11), pp. 2329-2336. DOI: $10.1080 / 01431160050029611$.

D'Arrigo, Rosanne D.; Jacoby, Gordon C.; Pederson, Neil; Frank, David; Buckley, Brendan M.; Nachin, Baatarbileg et al. (2000b): Mongolian tree-rings, temperature sensitivity and reconstructions of Northern Hemisphere temperature. In The Holocene 10, pp. 669-672.

D'Arrigo, Rosanne D.; Kaufmann, Robert K.; Davi, Nicole; Jacoby, Gordon C.; Laskowski, Cheryl; Myneni, Ranga B.; Cherubini, Paolo (2004): Thresholds for warming-induced growth decline at elevational tree line in the Yukon Territory, Canada. In Global Biogeochem. Cycles 18 (3), n/a-n/a. DOI: 10.1029/2004GB002249 [in en].

Dashkhuu, Dulamsuren; Kim, Jong Pil; Chun, Jong Ahn; Lee, Woo-Seop (2015): Long-term trends in daily temperature extremes over Mongolia. In Weather and Climate Extremes 8, pp. 26-33. DOI: 10.1016/j.wace.2014.11.003.

Dashtseren, Avirmed; Ishikawa, Mamoru; lijima, Yoshihiro; Jambaljav, Yamkhin (2014): Temperature Regimes of the Active Layer and Seasonally Frozen Ground under a ForestSteppe Mosaic, Mongolia. In Permafrost and Periglac. Process. 25 (4), pp. 295-306. DOI: 10.1002/ppp.1824. 
Davi, Nicole; Jacoby, Gordon C.; Curtis, A. E.; Baatarbileg, Nachin (2006): Extension of Drought Records for Central Asia Using Tree Rings: West-Central Mongolia. In Journal of Climate (19), pp. 288-299.

Davi, Nicole; Jacoby, Gordon C.; Fang, K.; Li, J.; D'Arrigo, Rosanne D.; Baatarbileg, Nachin; Robinson, D. (2010): Reconstructing drought variability for Mongolia based on a large-scale tree ring network: 1520-1993. In J. Geophys. Res. 115 (D22), p. 535. DOI:

10.1029/2010JD013907.

Davis, Robert; Holmgren, Peter (2000): Global ecological zoning for the global forest resources assessment. Available online at http://www.fao.org/3/ad652e/ad652e00.htm\#TopOfPage, updated on 1/4/2007, checked on 11/7/2019.

DeBano, L.F (2000): The role of fire and soil heating on water repellency in wildland environments: a review. In Journal of Hydrology 231-232, pp. 195-206. DOI: 10.1016/S00221694(00)00194-3.

Deluca, T. H.; Boisvenue, C. (2012): Boreal forest soil carbon: distribution, function and modelling. In Ecosystems 85 (2), pp. 161-184. DOI: 10.1093/forestry/cps003.

DeLucia, Evan H.; Hamilton, Jason G.; Naidu, Shawna L.; Thomas, Richard B.; Andrews, Jeffrey A.; Finzi, Adrien et al. (1999): Net Primary Production of a Forest Ecosystem with Experimental CO2 Enrichment. In Science (New York, N.Y.) 284 (5417), pp. 1177-1179. DOI: $10.1126 /$ science.284.5417.1177.

Dinerstein, Eric; Olson, David; Joshi, Anup; Vynne, Carly; Burgess, Neil D.; Wikramanayake, Eric et al. (2017): An Ecoregion-Based Approach to Protecting Half the Terrestrial Realm. In BioScience 67 (6), pp. 534-545. DOI: 10.1093/biosci/bix014.

Doerr, Stefan H. (1998): On standardizing the 'Water Drop Penetration Time' and the 'Molarity of an Ethanol Droplet' techniques to classify soil hydrophobicity: A case study using medium textured soils. In Earth Surface Processes and Landforms 23 (7), pp. 663-668. DOI: 10.1002/(SICI)1096-9837(199807)23:7<663::AID-ESP909>3.0.CO;2-6.

Doerr, Stefan H.; Shakesby, R. A.; Walsh, R.P.D. (2000): Soil water repellency: its causes, characteristics and hydro-geomorphological significance. In Earth-Science Reviews 51 (1-4), pp. 33-65. DOI: 10.1016/S0012-8252(00)00011-8.

Dorjsuren, Ch. (2009): Anthropogenic succession in larch forests of Mongolia (in Russian). In Biological Resources and Natural Conditions of Mongolia 50, pp. 1-260.

Dugarjav, Chultamiin (2006): Larch forests of Mongolia (in Mongolian). Ulan Bator: Bembi San.

Dulamsuren, Choimaa (2004): Floristische Diversität, Vegetation und Standortbedingungen in der Gebirgstaiga des Westkhentej, Nordmongolei. In Berichte des Forschungszentrums Waldökosysteme, Reihe A 191, pp. 1-290.

Dulamsuren, Choimaa; Hauck, Markus; Mühlenberg, Michael (2005): Vegetation at the taiga forest-steppe borderline in the western Khentey Mountains, northern Mongolia. In Ann. Bot. Fennici 42, pp. 411-426.

Dulamsuren, Choimaa; Hauck, Markus; Mühlenberg, Michael (2008): Insect and small mammal herbivores limit tree establishment in northern Mongolian steppe. In Plant Ecol 195 (1), pp. 143-156. DOI: 10.1007/s11258-007-9311-z. 
Dulamsuren, Choimaa; Hauck, Markus (2008): Spatial and seasonal variation of climate on steppe slopes of the northern Mongolian mountain taiga. In Grassland Science 54 (4), pp. 217-230. DOI: 10.1111/j.1744-697X.2008.00128.x.

Dulamsuren, Choimaa; Hauck, Markus; Nyambayar, Suran; Bader, Martin; Osokhjargal, Dalaikhuu; Oyungerel, Shagjjav; Leuschner, Christoph (2009a): Performance of Siberian elm (Ulmus pumila) on steppe slopes of the northern Mongolian mountain taiga: Drought stress and herbivory in mature trees. In Environmental and Experimental Botany 66 (1), pp. 18-24. DOI: 10.1016/j.envexpbot.2008.12.020.

Dulamsuren, Choimaa; Hauck, Markus; Bader, Martin; Oyungerel, Shagjjav; Osokhjargal, Dalaikhuu; Nyambayar, Suran; Leuschner, Christoph (2009b): The different strategies of Pinus sylvestris and Larix sibirica to deal with summer drought in a northern Mongolian forest-steppe ecotone suggest a future superiority of pine in a warming climate. In Canadian Journal of Plant Science 39 (12), pp. 2520-2528. DOI: 10.1139/X09-156.

Dulamsuren, Choimaa; Hauck, Markus; Bader, Martin; Osokhjargal, Dalaikhuu; Oyungerel, Shagjjav; Nyambayar, Suran et al. (2009c): Water relations and photosynthetic performance in Larix sibirica growing in the forest-steppe ecotone of northern Mongolia. In Tree physiology 29 (1), pp. 99-110. DOI: 10.1093/treephys/tpn008.

Dulamsuren, Choimaa; Hauck, Markus; Khishigjargal, Mookhor; Leuschner, Hanns Hubert; Leuschner, Christoph (2010a): Diverging climate trends in Mongolian taiga forests influence growth and regeneration of Larix sibirica. In Oecologia 163 (4), pp. 1091-1102. DOI: 10.1007/s00442-010-1689-y.

Dulamsuren, Choimaa; Hauck, Markus; Leuschner, Hanns Hubert; Leuschner, Christoph (2010b): Gypsy moth-induced growth decline of Larix sibirica in a forest-steppe ecotone. In Dendrochronologia 28 (4), pp. 207-213. DOI: 10.1016/j.dendro.2009.05.007.

Dulamsuren, Choimaa; Hauck, Markus; Leuschner, Christoph (2010c): Recent drought stress leads to growth reductions in Larix sibirica in the western Khentey, Mongolia. In Global Change Biology 95, 3024-3035. DOI: 10.1111/j.1365-2486.2009.02147.x.

Dulamsuren, Choimaa; Hauck, Markus; Leuschner, Hanns Hubert; Leuschner, Christoph (2011): Climate response of tree-ring width in Larix sibirica growing in the drought-stressed forest-steppe ecotone of northern Mongolia. In Annals of Forest Science 68 (2), pp. 275-282. DOI: 10.1007/s13595-011-0043-9.

Dulamsuren, Choimaa; Wommelsdorf, Tobias; Zhao, Fengjun; Xue, Yaoqin; Zhumadilov, Bulat Z.; Leuschner, Christoph; Hauck, Markus (2013a): Increased Summer Temperatures Reduce the Growth and Regeneration of Larix sibirica in Southern Boreal Forests of Eastern Kazakhstan. In Ecosystems 16 (8), pp. 1536-1549. DOI: 10.1007/s10021-013-9700-1.

Dulamsuren, Choimaa; Hauck, Markus; Leuschner, Christoph (2013b): Seedling emergence and establishment of Pinus sylvestris in the Mongolian forest-steppe ecotone. In Plant Ecol 214 (1), pp. 139-152. DOI: 10.1007/s11258-012-0152-z.

Dulamsuren, Choimaa; Khishigjargal, Mookhor; Leuschner, Christoph; Hauck, Markus (2014): Response of tree-ring width to climate warming and selective logging in larch forests of the Mongolian Altai. In Journal of Plant Ecology 7 (1), pp. 24-38. DOI: 10.1093/jpe/rtt019.

Dulamsuren, Choimaa; Klinge, Michael; Degener, Jan; Khishigjargal, Mookhor; Chenlemuge, Tselmeg; Bat-Enerel, Banzragch et al. (2016): Carbon pool densities and a first estimate of the total carbon pool in the Mongolian forest-steppe. In Global Change Biology 22 (2), pp. 830-844. DOI: 10.1111/gcb.13127. 
Dulamsuren, Choimaa; Klinge, Michael; Bat-Enerel, Banzragch; Ariunbaatar, Tumurbaatar; Tuya, Daramragchaa (2019a): Effects of forest fragmentation on organic carbon pool densities in the Mongolian forest-steppe. In Forest Ecology and Management 433, pp. 780788. DOI: $10.1016 /$ j.foreco.2018.10.054.

Dulamsuren, Choimaa; Abilova, Sholpan B.; Bektayeva, Madina; Eldarov, Mahammad; Schuldt, Bernhard; Leuschner, Christoph; Hauck, Markus (2019b): Hydraulic architecture and vulnerability to drought-induced embolism in southern boreal tree species of Inner Asia. In Tree physiology 39 (3), pp. 463-473. DOI: 10.1093/treephys/tpy116.

Dylis, N. V. (1947): Siberian larch (in Russian). Moskow.

Eckert, Sandra; Hüsler, Fabia; Liniger, Hanspeter; Hodel, Elias (2015): Trend analysis of MODIS NDVI time series for detecting land degradation and regeneration in Mongolia. In J. Arid Environ. 113, pp. 16-28. DOI: 10.1016/j.jaridenv.2014.09.001.

Eitel, Jan U. H.; Griffin, Kevin L.; Boelman, Natalie T.; Maguire, Andrew J.; Meddens, Arjan J. H.; Jensen, Johanna et al. (2020): Remote sensing tracks daily radial wood growth of evergreen needleleaf trees. In Global Change Biology 26 (7), pp. 4068-4078. DOI: $10.1111 / \mathrm{gcb} .15112$ [in eng].

Erasmi, Stefan; Klinge, Michael; Dulamsuren, Choimaa; Schneider, Florian; Hauck, Markus (2021): Modelling the productivity of Siberian larch forests from Landsat NDVI time series in fragmented forest stands of the Mongolian forest-steppe. In Environmental monitoring and assessment 193 (4), p. 200. DOI: 10.1007/s10661-021-08996-1 [in eng].

Etzelmüller, Bernd; Heggem, Eva S. Flo; Sharkhuu, Natsagdorj; Frauenfelder, Regula; Kääb, Andreas; Goulden, Clyde E. (2006): Mountain permafrost distribution modelling using a multicriteria approach in the Hövsgöl area, northern Mongolia. In Permafrost and Periglac.

Process. 17 (2), pp. 91-104. DOI: 10.1002/ppp.554.

FAO (2006a): Global Forest Resources Assessment 2005 - Report on fires in the Central Asian Region and adjacent countries. In Fire Management Working Paper 16.

FAO (2006b): Guidelines for soil description. With assistance of Reinhold Jahn. 4., [rev.] ed. Rome: FAO.

Fedorov, Alexander N.; Iwahana, Go; Konstantinov, Pavel Y.; Machimura, Takashi; Argunov, Radomir N.; Efremov, Peter V. et al. (2017): Variability of Permafrost and Landscape Conditions Following Clear Cutting of Larch Forest in Central Yakutia. In Permafrost and Periglac. Process. 28 (1), pp. 331-338. DOI: 10.1002/ppp.1897.

Feldmann, Eike; Glatthorn, Jonas; Hauck, Markus; Leuschner, Christoph (2018): A novel empirical approach for determining the extension of forest development stages in temperate old-growth forests. In Eur. J. Forest Res. 137 (3), pp. 321-335. DOI: 10.1007/s10342-0181105-4.

Fensholt, Rasmus; Proud, Simon R. (2012): Evaluation of Earth Observation based global long term vegetation trends - Comparing GIMMS and MODIS global NDVI time series. In Remote Sensing of Environment 119, pp. 131-147. DOI: 10.1016/j.rse.2011.12.015.

Fiedler, H. J.; Hunger, W.; Müller, K.; Skodawessely, K. (1980): Zu den Beziehungen zwischen Boden, Ernährungszustand und Wuchsleistung bei Lärche (Larix decidua Mill.) (in German). In Flora 170 (1-2), pp. 1-19. DOI: 10.1016/S0367-2530(17)31187-8 [in German].

Fonti, Patrick; Bryukhanova, Marina V.; Myglan, Vladimir S.; Kirdyanov, Alexander V.; Naumova, Oksana V.; Vaganov, Eugene A. (2013): Temperature-induced responses of xylem structure of Larix sibirica (Pinaceae) from the Russian Altay. In American journal of botany 100 (7), pp. 1332-1343. DOI: 10.3732/ajb.1200484. 
Fonti, Patrick; Babushkina, Elena A. (2016): Tracheid anatomical responses to climate in a forest-steppe in Southern Siberia. In Dendrochronologia 39, pp. 32-41. DOI:

10.1016/j.dendro.2015.09.002.

Forkel, Matthias; Thonicke, Kirsten; Beer, Christian; Cramer, Wolfgang; Bartalev, Sergey; Schmullius, Christiane (2012): Extreme fire events are related to previous-year surface moisture conditions in permafrost-underlain larch forests of Siberia. In Environ. Res. Lett. 7 (4), p. 44021. DOI: 10.1088/1748-9326/7/4/044021.

Forkel, Matthias; Carvalhais, Nuno; Verbesselt, Jan; Mahecha, Miguel; Neigh, Christopher; Reichstein, Markus (2013): Trend Change Detection in NDVI Time Series: Effects of InterAnnual Variability and Methodology. Remote Sensing, 5(5), 2113-2144. DOI: 10.3390/RS5052113.

French, Hugh M. (2018): The periglacial environment. Fourth edition. Hoboken, NJ: Wiley Blackwell [in eng].

Furyaev, Valentin V. (1996): Pyrological Regimes and Dynamics of the Southern Taiga Forests in Siberia. In Johann Georg Goldammer, Valentin V. Furyaev (Eds.): Fire in Ecosystems of Boreal Eurasia. Dordrecht: Kluwer (Forestry sciences, 48), pp. 168-185.

Furyaev, Valentin V.; Vaganov, Eugene A.; Tchebakova, Nadejda M.; Valendik, Erik N. (2001): Effects of Fire and Climate on Successions and Structural Changes in The Siberian Boreal Forest. In Eurasian J. For. Res. 2, pp. 1-15.

Gavrilova, O. I. (1996): The main laws of the formation of the root system of Siberian larch sproots in the condition of southern Karelia (in Russian). In Resources and Technology (1), pp. 11-15 [in Russian].

Glaser, Rüdiger; Hauter, Christiane; Faust, Dominik; Glawion, Rainer; Saurer, Helmut; Schulte, Achim; Sudhaus, Dirk (2017): Physische Geographie kompakt. Berlin: Springer Spektrum [in ger].

Goldammer, Johann Georg (2002): Fire Situation in Mongolia (IFFN No. 26) | GFMC. Available online at http://gfmc.online/iffn/country/mn/mn_11.html, checked on 10/14/2019.

Goldammer, Johann Georg (Ed.) (2007): International Forest Fire News (36), checked on 2/9/2017.

Goodale, Christine L.; Apps, Michael J.; Birdsey, Richard A.; Field, Christopher B.; Heath, Linda S.; Houghton, Richard A. et al. (2002): Forest carbon sinks in the northern hemisphere. In Ecol. Appl. 12 (3), pp. 891-899. DOI: 10.1890/10510761(2002)012[0891:FCSITN]2.0.CO;2.

Gower, Stith T.; Richards, James H. (1990): Larches: Deciduous Conifers in an Evergreen World. In BioScience 40 (11), pp. 818-826.

Gradel, Alexander; Haensch, Christina; Ganbaatar, Batsaikhan; Dovdondemberel, Batdorj; Nadaldorj, Ochirragchaa; Günther, Björn (2017): Response of white birch (Betula platyphylla Sukaczev) to temperature and precipitation in the mountain forest steppe and taiga of northern Mongolia. In Dendrochronologia 41, pp. 24-33. DOI: 10.1016/j.dendro.2016.03.005.

Grandpré, Louis de; Tardif, Jacques C.; Hessl, Amy E.; Pederson, Neil; Conciatori, France; Green, Timothy R. et al. (2011): Seasonal shift in the climate responses of Pinus sibirica, Pinus sylvestris, and Larix sibirica trees from semi-arid, north-central Mongolia. In Canadian Journal of Plant Science 41 (6), pp. 1242-1255. DOI: 10.1139/x11-051.

Gruber, Stephan (2012): Derivation and analysis of a high-resolution estimate of global permafrost zonation. In The Cryosphere 6 (1), pp. 221-233. DOI: 10.5194/tc-6-221-2012. 
Grunert, Jörg; Lehmkuhl, Frank; Walther, Michael (2000): Paleoclimatic evolution of the Uvs Nuur basin and adjacent areas (Western Mongolia). In Quaternary International 65-66, pp. 171-192. DOI: 10.1016/S1040-6182(99)00043-9.

Gupta, S. C.; Larson, W. E. (1979): Estimating soil water retention characteristics from particle size distribution, organic matter percent, and bulk density. In Water Resources Research 15 (6), pp. 1633-1635. DOI: 10.1029/WR015i006p01633.

Gurskaya, M. A. (2019): Effect of Summer Monthly Temperatures on Light Tree Ring Formation in Three Larch Species (Larix) in the Northern Forest-Tundra of Siberia. In Russ J Ecol 50 (4), pp. 343-351. DOI: 10.1134/S1067413619040088.

Haase, Günter (1963): Die Höhenstufen der Böden im Changai (MVR) (in German). In Z. Pflanzenernaehr. Dueng. Bodenk. 102 (2), pp. 113-127. DOI: 10.1002/jpln.19631020205 [in German].

Hais, Martin; Chytrý, Milan; Horsák, Michal (2016): Exposure-related forest-steppe: A diverse landscape type determined by topography and climate. In Journal of Arid Environments 135, pp. 75-84. DOI: 10.1016/j.jaridenv.2016.08.011.

Hansen, Matt; Potapov, Peter V.; Moore, Rebecca; Hancher, M.; Turubanova, Svetlana; Tyukavina, Alexandra et al. (2013): High-resolution global maps of 21st-century forest cover change. In Science (New York, N.Y.) 342 (6160), pp. 850-853. DOI:

10.1126/science.1244693.

Hantemirov, R. M.; Surkov, A. Yu.; Gorlanova, L. A. (2008): Climate Changes and Overstory Recruitment of Larch at the Northern Timberline in the Yamal Peninsula. In Russ J Ecol 39 (5), pp. 305-309. DOI: 10.1134/S1067413608050019.

Hauck, Markus; Dulamsuren, Choimaa; Heimes, Christine (2008): Effects of insect herbivory on the performance of Larix sibirica in a forest-steppe ecotone. In Environmental and Experimental Botany 62 (3), pp. 351-356. DOI: 10.1016/j.envexpbot.2007.10.025.

Hauck, Markus; Javkhlan, Samjaa; Lkhagvadorj, Dorjburgedaa; Bayartogtokh, Badamdorj; Dulamsuren, Choimaa; Leuschner, Christoph (2012): Edge and land-use effects on epiphytic lichen diversity in the forest-steppe ecotone of the Mongolian Altai. In Flora - Morphology, Distribution, Functional Ecology of Plants 207 (6), pp. 450-458. DOI: 10.1016/j.flora.2012.03.008.

Hauck, Markus; Dulamsuren, Choimaa; Bayartogtokh, Badamdorj; Ulykpan, Kaman; Burkitbaeva, Ulzhan D.; Otgonjargal, Erdenechuluun et al. (2014): Relationships between the diversity patterns of vascular plants, lichens and invertebrates in the Central Asian foreststeppe ecotone. In Biodivers Conserv 23 (5), pp. 1105-1117. DOI: 10.1007/s10531-0140648-z [in En;en].

Hauck, Markus; Dulamsuren, Choimaa; Leuschner, Christoph (2016): Anomalous Increase in Winter Temperature and Decline in Forest Growth Associated with Severe Winter Smog in the Ulan Bator Basin. In Water Air Soil Pollut 227 (8), p. 137. DOI: 10.1007/s11270-0162957-1.

Hauck, Markus; Leuschner, Christoph; Homeier, Jürgen (2020): Klimawandel und Vegetation - Eine globale Übersicht. [S.I.]: Springer Spektrum.

He, Jicheng; Shao, Xuemei (2006): Relationships between tree-ring width index and NDVI of grassland in Delingha. In CHINESE SCI BULL 51 (9), pp. 1106-1114. DOI: 10.1007/s11434006-1106-4. 
Hessl, Amy E.; Ariya, Uyanga; Brown, Peter; Byambasuren, Oyunsannaa; Green, Timothy R.; Jacoby, Gordon C. et al. (2012): Reconstructing fire history in central Mongolia from treerings. In Int. J. Wildland Fire 21 (1), p. 86. DOI: 10.1071/WF10108.

Hessl, Amy E.; Brown, Peter; Byambasuren, Oyunsannaa; Cockrell, Shawn; Leland, Caroline; Cook, Edward R. et al. (2016): Fire and climate in Mongolia (1532-2010 Common Era). In Geophys. Res. Lett. 43 (12), pp. 6519-6527. DOI: 10.1002/2016GL069059.

Hilbig, Werner (1987): Zur Problematik der ursprünglichen Waldverbreitung in der Mongolischen Volksrepublik Ergebnisse der Mongolisch - Deutschen Biologischen Expeditionen seit 1962, Nr. 181 (in German). In Flora 179 (1), pp. 1-15. DOI: 10.1016/S0367-2530(17)30213-X [in German].

Hilbig, Werner (1995): The vegetation of Mongolia. Amsterdam: SPB Acad. Publ [in eng]. Hinkel, K. M.; Doolittle, J. A.; Bockheim, J. G.; Nelson, F. E.; Paetzold, R.; Kimble, John M.; Travis, R. (2001): Detection of subsurface permafrost features with ground-penetrating radar, Barrow, Alaska. In Permafrost and Periglac. Process. 12 (2), pp. 179-190. DOI: 10.1002/ppp.369.

Holben, Brent N. (1986): Characteristics of maximum-value composite images from temporal AVHRR data. In Int. J. Remote Sens. 7 (11), pp. 1417-1434. DOI: 10.1080/01431168608948945.

lida, Shin'ichi; Ohta, Takeshi; Matsumoto, Kazuho; Nakai, Taro; Kuwada, Takashi; Kononov, Alexander V. et al. (2009): Evapotranspiration from understory vegetation in an eastern Siberian boreal larch forest. In Agricultural and Forest Meteorology 149 (6-7), pp. 11291139. DOI: 10.1016/j.agrformet.2009.02.003.

lijima, Y.; Ishikawa, M.; Jambaljav, Yamkin (2012): Hydrological cycle in relation to permafrost environment in forest-grassland ecotone in Mongolia. (in Japanese with English abstract). In Journal of Japanese Association of Hydrological Sciences 42, pp. 119-130, checked on 12/12/2019.

lijima, Yoshihiro; Ohta, Takeshi; Kotani, Ayumi; Fedorov, Alexander N.; Kodama, Yuji; Maximov, Trofim C. (2014): Sap flow changes in relation to permafrost degradation under increasing precipitation in an eastern Siberian larch forest. In Ecohydrol. 7 (2), pp. 177-187. DOI: 10.1002/eco.1366.

IPCC (2013): Climate Change 2013 - The Physical Science Basis. Cambridge: Cambridge University Press.

IPCC (Ed.) (2014): Climate Change 2014: Synthesis Report. Contribution of Working Groups I, II and III to the Fifth Assessment Report of the Intergovernmental Panel on Climate Change. With assistance of R. K. Pachauri, L. A. Meyer. Intergovernmental Panel on Climate Change. Geneva, Switzerland: Intergovernmental Panel on Climate Change.

Ishikawa, Mamoru; Sharkhuu, Natsagdorj; Zhang, Yinsheng; Kadota, Tsutomu; Ohata, Tetsuo (2005): Ground Thermal and Moisture Conditions at the Southern Boundary of Discontinuous Permafrost, Mongolia. In Permafrost and Periglac. Process. 16 (2), pp. 209216. DOI: $10.1002 / p p p .483$.

Ishikawa, Mamoru; Jamvaljav, Yamkhin; Dashtseren, Avirmed; Sharkhuu, Natsagdorj; Davaa, Gamboo; lijima, Yoshihiro et al. (2018): Thermal states, responsiveness and degradation of marginal permafrost in Mongolia. In Permafrost and Periglac. Process. 29 (4), pp. 271-282. DOI: 10.1002/ppp.1990. 
IUSS Working Group WRB (2015): World reference base for soil resources 2014.

International soil classification system for naming soils and creating legends for soil maps.

Rome: FAO (World soil resources reports, 106).

Ivanova, G. A.; Ivanov, V. A.; Kukavskaya, E. A.; Soja, A. J. (2010): The frequency of forest fires in Scots pine stands of Tuva, Russia. In Environ. Res. Lett. 5 (1), p. 15002. DOI:

10.1088/1748-9326/5/1/015002.

Ivanova, Yulia; Kovalev, Anton; Soukhovolsky, Vlad (2021): Modeling the Radial Stem Growth of the Pine (Pinus sylvestris L.) Forests Using the Satellite-Derived NDVI and LST (MODIS/AQUA) Data. In Atmosphere 12 (1), p. 12. DOI: 10.3390/atmos12010012.

Jacob, Mascha; Bade, Claudia; Calvete, Héctor; Dittrich, Sebastian; Leuschner, Christoph; Hauck, Markus (2013): Significance of Over-Mature and Decaying Trees for Carbon Stocks in a Central European Natural Spruce Forest. In Ecosystems 16 (2), pp. 336-346. DOI: 10.1007/s10021-012-9617-0.

Jacoby, Gordon C.; D'Arrigo, Rosanne D.; Davaajamts, Tsevegyn (1996): Mongolian Tree Rings and 20th-Century Warming. In Science (New York, N.Y.) 273 (5276), pp. 771-773. DOI: 10.1126/science.273.5276.771.

Jacoby, Gordon C.; D'Arrigo, Rosanne D.; Pederson, Neil; Buckley, Brendan M.; Dugarjav, Chultamiin; Mijiddorj, R. (1999): Temperature and Precipitation in Mongolia based on Dendroclimatic Investigations. In IAWA Journal (20), pp. 339-350.

James, Thomas M. (2011): Temperature sensitivity and recruitment dynamics of Siberian larch (Larix sibirica) and Siberian spruce (Picea obovata) in northern Mongolia's boreal forest. In Forest Ecology and Management 262 (4), pp. 629-636. DOI:

10.1016/j.foreco.2011.04.031.

Jarvis, PG.; Saugier, B.; Schulze, E-D. (2001): Productivity of boreal forests. In J. Roy, B. Saugier, H. Mooney (Eds.): Terrestrial global productivity. San Diego: Academic Press, pp. 211-244.

Jiao, Liang; Jiang, Yuan; Zhang, Wen-Tao; Wang, Ming-Chang; Zhang, Ling-Nan; Zhao, Shou-Dong (2015): Divergent responses to climate factors in the radial growth of Larix sibirica in the eastern Tianshan Mountains, northwest China. In Trees 29 (6), pp. 1673-1686. DOI: 10.1007/s00468-015-1248-6.

Jorgenson, M. Torre; Harden, Jennifer; Kanevskiy, Mikhail; O’Donnell, Jonathan; Wickland, Kim; Ewing, Stephanie et al. (2013): Reorganization of vegetation, hydrology and soil carbon after permafrost degradation across heterogeneous boreal landscapes. In Environ. Res. Lett. 8 (3), p. 35017. DOI: 10.1088/1748-9326/8/3/035017.

Kajimoto, Takuya; Matsuura, Yojiro; Osawa, Akira; Prokushkin, Anatoliy S.; Sofronov, Mark A.; Abaimov, Anatoly P. (2003): Root system development of Larix gmelinii trees affected by micro-scale conditions of permafrost soils in central Siberia. In Plant and Soil 255, pp. 281292.

Kajimoto, Takuya; Matsuura, Yojiro; Osawa, Akira; Abaimov, Anatoly P.; Zyryanova, Olga A.; Isaev, Alexander P. et al. (2006): Size-mass allometry and biomass allocation of two larch species growing on the continuous permafrost region in Siberia. In Forest Ecology and Management 222 (1-3), pp. 314-325. DOI: 10.1016/j.foreco.2005.10.031.

Kajimoto, Takuya; Osawa, Akira; Matsuura, Yojiro; Abaimov, Anatoly P.; Zyryanova, Olga A.; Kondo, Kazuma et al. (2007): Individual-based measurement and analysis of root system development: case studies for Larix gmelinii trees growing on the permafrost region in 
Siberia. In Journal of Forest Research 12 (2), pp. 103-112. DOI: 10.1007/s10310-006-0259y.

Kalinina, E. V.; Knorre, Anastasia A.; Fonti, M. V.; Vaganov, Eugene A. (2019): Seasonal Formation of Tree Rings in Siberian Larch and Scots Pine in the Southern Taiga of Central Siberia. In Russ J Ecol 50 (3), pp. 227-233. DOI: 10.1134/S1067413619030068.

Kapper, O. G. (1954): Conifer Species (in Russian). Forestry Characteristics. Moskow, Leningrad [in Russian].

Karaseva, M. A.; Karasev, B. H.; Matorkin, A. A. (2003): Physiological Assessment Stability of Larix sibirica Growing in Middle Volga Region (in Russian). In Conifers of the boreal zone (1), pp. 1-8 [in Russian].

Karger, Dirk Nikolaus; Conrad, Olaf; Böhner, Jürgen; Kawohl, Tobias; Kreft, Holger; SoriaAuza, Rodrigo Wilber et al. (2017): Climatologies at high resolution for the earth's land surface areas. In Scientific data 4, p. 170122. DOI: 10.1038/sdata.2017.122 [in eng].

Karthe, D.; Malsy, M.; Kopp, B. J.; Minderlein, S.; Hülsmann, L. (2013): Assessing water availability and its drivers in the context of an Integrated Water Resources Management (IWRM): a case study from the Kharaa River Basin, Mongolia. In Geoöko 34 (5-26), checked on $2 / 5 / 2020$.

Kassambara, A.; Mundt, F. (2019): factoextra: Extract and Visualize the Results of. Version $\mathrm{R}$ package version 1.0.6. Available online at https://CRAN.R-project.org/package=factoextra.

Kassambara, A. (2019): ggpubr: 'ggplot2' Based Publication Ready Plots. Version R package version 0.2.4. Available online at https://CRAN.R-project.org/package=ggpubr.

Kaufmann, Robert K.; D'Arrigo, Rosanne D.; Laskowski, Cheryl; Myneni, Ranga B.; Zhou, L.; Davi, Nicole (2004): The effect of growing season and summer greenness on northern forests. In Geophys. Res. Lett. 31 (9). DOI: 10.1029/2004GL019608.

Kayama, Masazumi; Makoto, Kobayashi; Nomura, Mutsumi; Satoh, Fuyuki; Koike, Takayoshi (2009): Nutrient dynamics and carbon partitioning in larch seedlings (Larix kaempferi) regenerated on serpentine soil in northern Japan. In Landscape Ecol Eng 5 (2), pp. 125-135. DOI: 10.1007/s11355-009-0069-4.

Keenan, Rodney J.; Reams, Gregory A.; Achard, Frédéric; Freitas, Joberto V. de; Grainger, Alan; Lindquist, Erik (2015): Dynamics of global forest area: Results from the FAO Global Forest Resources Assessment 2015. In Forest Ecology and Management 352, pp. 9-20. DOI: 10.1016/j.foreco.2015.06.014.

Kelliher, F. M.; Hollinger, D. Y.; Schulze, E.-D.; Vygodskaya, N. N.; Byers, J. N.; Hunt, J. E. et al. (1997): Evaporation from an eastern Siberian larch forest. In Agricultural and Forest Meteorology (85), pp. 135-147.

Khansaritoreh, Elmira; Eldarov, Mahammad; Ganbaatar, Kherlenchimeg; Saindovdon, Davaadorj; Leuschner, Christoph; Hauck, Markus; Dulamsuren, Choimaa (2017a): Age structure and trends in annual stem increment of Larix sibirica in two neighboring Mongolian forest-steppe regions differing in land use history. In Trees 31 (6), pp. 1973-1986. DOI: 10.1007/s00468-017-1601-z.

Khansaritoreh, Elmira; Dulamsuren, Choimaa; Klinge, Michael; Ariunbaatar, Tumurbaatar; Bat-Enerel, Banzragch; Batsaikhan, Ganbaatar et al. (2017b): Higher climate warming sensitivity of Siberian larch in small than large forest islands in the fragmented Mongolian forest steppe. In Global Change Biology 23 (9), pp. 3675-3689. DOI: 10.1111/gcb.13750. 
Khansaritoreh, Elmira; Schuldt, Bernhard; Dulamsuren, Choimaa (2018): Hydraulic traits and tree-ring width in Larix sibirica Ledeb. as affected by summer drought and forest fragmentation in the Mongolian forest steppe. In Annals of Forest Science 75 (30), pp. 1-12. DOI: 10.1007/s13595-018-0701-2.

Kharuk, Viacheslav I.; Ranson, Kenneth J.; Dvinskaya, Maria L. (2008): Wildfires dynamic in the larch dominance zone. In Geophys. Res. Lett. 35 (L01402), pp. 1-6. DOI: 10.1029/2007GL032291.

Kharuk, Viacheslav I.; Ranson, Kenneth J.; Im, Sergey T.; Vdovin, Alexander S. (2010): Spatial distribution and temporal dynamics of high-elevation forest stands in southern Siberia. In Global Ecology and Biogeography 19 (6), pp. 822-830. DOI: 10.1111/j.14668238.2010.00555.x.

Kharuk, Viacheslav I.; Ranson, Kenneth J.; Dvinskaya, Maria L.; Im, Sergey T. (2011): Wildfires in northern Siberian larch dominated communities. In Environ. Res. Lett. 6 (045208), pp. 1-6. DOI: 10.1088/1748-9326/6/4/045208.

Kharuk, Viacheslav I.; Ponomarev, Evgenii (2017): Spatiotemporal Characteristics of Wildfire Frequency and Relative Area Burned in Larch- Dominated Forests of Central Siberia. In Russ J Ecol 48 (6), pp. 507-512. DOI: 10.1134/S1067413617060042.

Khishigjargal, Mookhor; Dulamsuren, Choimaa; Lkhagvadorj, Dorjburgedaa; Leuschner, Christoph; Hauck, Markus (2013): Contrasting responses of seedling and sapling densities to livestock density in the Mongolian forest-steppe. In Plant Ecol 214 (11), pp. 1391-1403. DOI: 10.1007/s11258-013-0259-x.

Khishigjargal, Mookhor; Dulamsuren, Choimaa; Leuschner, Hanns Hubert; Leuschner, Christoph; Hauck, Markus (2014): Climate effects on inter- and intra-annual larch stemwood anomalies in the Mongolian forest-steppe. In Acta Oecologica 55, pp. 113-121. DOI: 10.1016/j.actao.2013.12.003.

Klinge, Michael; Lehmkuhl, Frank (2013): Geomorphology of the Tsetseg Nuur basin, Mongolian Altai - lake development, fluvial sedimentation and aeolian transport in a semiarid environment. In Journal of Maps 9 (3), pp. 361-366. DOI: 10.1080/17445647.2013.783513.

Klinge, Michael; Böhner, Jürgen; Erasmi, Stefan (2015): Modeling forest lines and forest distribution patterns with remote-sensing data in a mountainous region of semiarid central Asia. In Biogeosciences 12 (10), pp. 2893-2905. DOI: 10.5194/bg-12-2893-2015.

Klinge, Michael; Dulamsuren, Choimaa; Erasmi, Stefan; Karger, Dirk Nikolaus; Hauck, Markus (2018): Climate effects on vegetation vitality at the treeline of boreal forests of Mongolia. In Biogeosciences 15 (5), pp. 1319-1333. DOI: 10.5194/bg-15-1319-2018.

Klinge, Michael; Sauer, Daniela (2019): Spatial pattern of Late Glacial and Holocene climatic and environmental development in Western Mongolia - A critical review and synthesis. In Quaternary Science Reviews 210, pp. 26-50. DOI: 10.1016/j.quascirev.2019.02.020.

Klinge, Michael; Dulamsuren, Choimaa; Schneider, Florian; Erasmi, Stefan; Hauck, Markus; Bayarsaikhan, Uudus; Sauer, Daniela (2020): Modelled potential forest area in the foreststeppe of central Mongolia is about three times of actual forest area.

Klinge, Michael; Schneider, Florian; Dulamsuren, Choimaa; Arndt, K.; Bayarsaikhan, Uudus; Sauer, Daniela (2021): Interrelations between relief, vegetation, disturbances, and permafrost in the forest-steppe of central Mongolia. In Earth Surface Processes and Landforms. DOI: 10.1002/esp.5116. 
Koike, Takayoshi; Yazaki, Kenichi; Eguchi, N.; Kitaoka, S.; Funada, R. (2010): Effects of Elevated CO2 on Ecophysiological Responses of Larch Species Native to Northeast Eurasia. In Akira Osawa, Olga A. Zyryanova, Yojiro Matsuura, Takuya Kajimoto, Ross W. Wein (Eds.): Permafrost Ecosystems. Siberian Larch Forests. Dordrecht: Springer (Ecological studies, 209), pp. 447-458.

Kopp, Benjamin Johannes; Minderlein, Stefanie; Menzel, Lucas (2014): Soil Moisture Dynamics in a Mountainous Headwater Area in the Discontinuous Permafrost Zone of northern Mongolia. In Arctic, Antarctic, and Alpine Research 46 (2), pp. 459-470. DOI: 10.1657/1938-4246-46.2.459.

Körner, Christian (2012): Alpine treelines. Functional ecology of the global high elevation tree limits. Basel [u.a.]: Springer.

Korovin, G. N. (1996): Analysis of the Distribution of Forest Fires in Russia. In Johann Georg Goldammer, Valentin V. Furyaev (Eds.): Fire in Ecosystems of Boreal Eurasia. Dordrecht: Kluwer (Forestry sciences, 48), pp. 112-128.

Kovacs, Katalin; Ranson, Kenneth J.; Sun, Guoqing; Kharuk, Viacheslav I. (2004): The Relationship of the Terra MODIS Fire Product and Anthropogenic Features in the Central Siberian Landscape. In Earth Interactions (8), pp. 1-25.

Kovalev, A. A.; Erdenebaatar, D. (2009): Discovery of new cultures of the Bronze Age in Mongolia according to the data obtained by the international Central Asian Archaeological Expedition. In J. Bemmann, H. Parzinger, E. Pohl, D. Tseveendorj (Eds.): Current archaeological research in Mongolia. Bonn, pp. 149-170, checked on 10/17/2018.

Kovylina, O. P.; Kovylin, N. V.; Terekhova, S. A.; Sychev, N. N.; Zhikhar, A. A. (2013a): Natural Regeneration of Siberian Larch (Larix sibirica LDB.) in the Steppe Artificial Phytocenosis (in Russian). In Bulletin of Krasnoyarsk Agrarian University 11, pp. 206-210 [in Russian].

Kovylina, O. P.; Kovylin, N. V.; Zhikhar, A. A.; Sychev, N. N. (2013b): The Assessment of Siberian Larch State and Growth in the Steppe Pure and Mixed Artificial Phytocenosis (in Russian). In Bulletin of Krasnoyarsk Agrarian University 5, pp. 137-142 [in Russian].

Kowalkowski, K.; Starkel, L. (1984): Altitudinal belts of geomorphic processes in the southern Changai Mts. (Mongolia). In Studia Geomorphologica Carpatho-Balcanica 18, pp. 95-115.

Krasnoshchekov, Yu. N. (2008): Soil cover of mountain forests in the East Khubsugul region of Mongolia. In Eurasian Soil Sc. 41 (7), pp. 694-703. DOI: 10.1134/S106422930807003X.

Krasnoshchekov, Yu. N. (2010): Soils and the Soil Cover of Mountainous Tundra and Forest Landscapes in the Central Khangai of Mongolia. In Eurasian Soil Sc. 43 (2), pp. 117-126. DOI: 10.1134/S1064229310020018.

Kuosmanen, Niina; Fang, Keyan; Bradshaw, Richard H. W.; Clear, Jennifer L.; Seppä, Heikki (2014): Role of forest fires in Holocene stand-scale dynamics in the unmanaged taiga forest of northwestern Russia. In The Holocene 24 (11), pp. 1503-1514. DOI:

$10.1177 / 0959683614544065$.

Kuznetsova, Ekaterina P.; Kozlov, Daniil N. (2011): Tree-Ring Variability of Larch (Larix sibirica Ledeb.) in Different Landscape Positions of the Terekhol Depression, Tuva, Russia in the 20th Century (in Russian). In J. Sib. Fed. Univ., Biol. 4, pp. 325-337 [in Russian].

Lange, Jens; Kopp, Benjamin Johannes; Bents, Matthias; Menzel, Lucas (2015): Tracing variability of run-off generation in mountainous permafrost of semi-arid north-eastern Mongolia. In Hydrol. Process. 29 (6), pp. 1046-1055. DOI: 10.1002/hyp.10218. 
Lebedev, E. V. (2010): Impact of nitrogen forms on photosynthesis, mineral nutrition and biological productivity of plants as Siberian larch and European spruce (in Russian). In Forestry Bulletin 6, pp. 14-18 [in Russian].

Lebedev, E. V. (2012): Quantitative Measurements of Net Productivity of Photosynthesis, Mineral Nutrition and Biological Productivity of Larix sibirica During Ontogenesis in the Areal of Southern Altai (in Russian). In Herald of Altai state agricultural university 12 (98), pp. 6166 [in Russian].

Lebedev, E. V. (2013): The Forest Vegetation Condition Type Influence on the Root System Absorbing Activity and on Siberian Larch Biological Productivity at the Organism Level in Ontogenesis (in Russian). In Bulletin of Krasnoyarsk Agrarian University 1, pp. 68-74 [in Russian].

Lehmkuhl, Frank; Klinge, Michael (2000): Bodentemperaturmessungen aus dem Mongolischen Altai als Indikatoren für periglaziale Geomorphodynamik in hochkontinentalen Gebirgsräumen. (in German with English abstract). In Zeitschrift für Geomorphologie N.F. 44 (1), pp. 75-102, checked on 12/12/2019.

Lehmkuhl, Frank; Haselein, Frank (2000): Quaternary paleoenvironmental change on the Tibetan Plateau and adjacent areas (Western China and Western Mongolia). In Quaternary International 65-66, pp. 121-145. DOI: 10.1016/S1040-6182(99)00040-3.

Lehmkuhl, Frank; Hilgers, Alexandra; Fries, Susanne; Hülle, Daniela; Schlütz, Frank; Shumilovskikh, Lyudmila et al. (2011): Holocene geomorphological processes and soil development as indicator for environmental change around Karakorum, Upper Orkhon Valley (Central Mongolia). In CATENA 87 (1), pp. 31-44. DOI: 10.1016/j.catena.2011.05.005.

Lê, S.; Josse, J.; Husson, F. (2008): FactoMineR: An R Package for Multivariate Analysis. In Journal of Statistical Software 25 (1), pp. 1-18.

Leyton, L. (1956): The relationship between the growth and mineral composition of the foliage of Japanese larch (Larix leptolepis, Murr.). In Plant Soil 7 (2), pp. 167-177. DOI: 10.1007/BF01343725.

Liang, Maochang; Sugimoto, Atsuko; Tei, Shunsuke; Bragin, Ivan V.; Takano, Shinya; Morozumi, Tomoki et al. (2014): Importance of soil moisture and $\mathrm{N}$ availability to larch growth and distribution in the Arctic taiga-tundra boundary ecosystem, northeastern Siberia. In Polar Science 8 (4), pp. 327-341. DOI: 10.1016/j.polar.2014.07.008.

Li, Sheng-Gong; Asanuma, Jun; Kotani, Ayumi; Eugster, Werner; Davaa, Gombo; Oyunbaatar, Dambaravjaa; Sugita, Michiaki (2005): Year-round measurements of net ecosystem CO 2 flux over a montane larch forest in Mongolia. In J. Geophys. Res. 110 (D09303), pp. 1-14. DOI: 10.1029/2004JD005453.

Li, Sheng-Gong; Tsujimura, Maki; Sugimoto, Atsuko; Sasaki, Lisa; Yamanaka, Tsutomu; Davaa, Gombo et al. (2006): Seasonal variation in oxygen isotope composition of waters for a montane larch forest in Mongolia. In Trees 20 (1), pp. 122-130. DOI: 10.1007/s00468-0050019-1.

Liu, Hongyan; He, Siyuan; Anenkhonov, Oleg A.; Hu, Guozheng; Sandanov, Denis V.; Badmaeva, Natalya K. (2012): Topography-Controlled Soil Water Content ans the Coexistence of Forest and Steppe in Northern China. In Physical Geography 33 (5), pp. 113.

Liu, Hongyan; Williams, A. Park; Allen, Craig D.; Guo, Dali; Wu, Xiuchen; Anenkhonov, Oleg A. et al. (2013): Rapid warming accelerates tree growth decline in semi-arid forests of Inner Asia. In Global Change Biology 19 (8), pp. 2500-2510. DOI: 10.1111/gcb.12217. 
Liu, Liangyun (2016): Opportunities of Mapping Forest Carbon Stock and its Annual Increment Using Landsat Time-Series Data. In Geoinfor Geostat: An Overview 04 (04). DOI: 10.4172/2327-4581.1000151.

Lkhagvadorj, Dorjburgedaa; Hauck, Markus; Dulamsuren, Choimaa; Tsogtbaatar, Jamsran (2013a): Pastoral nomadism in the forest-steppe of the Mongolian Altai under a changing economy and a warming climate. In Journal of Arid Environments 88, pp. 82-89. DOI: 10.1016/j.jaridenv.2012.07.019.

Lkhagvadorj, Dorjburgedaa; Hauck, Markus; Dulamsuren, Choimaa; Tsogtbaatar, Jamsran (2013b): Twenty Years After Decollectivization: Mobile Livestock Husbandry and Its Ecological Impact in the Mongolian Forest-Steppe. In Hum Ecol 41 (5), pp. 725-735. DOI: 10.1007/s10745-013-9599-3.

Lobanov, A. I.; Savin, E. N. (2011): Larix sibirica Ledeb. in Pature Forest Belts (in Russian). In Conifers of the boreal zone 24 (3-4), pp. 237-243 [in Russian].

Logan, Jesse A.; Régnière, Jaques; Powell, James A. (2003): Assessing the impacts of global warming on forest pest dynamics. In Frontiers in Ecology and the Environment 1 (3), pp. $130-137$.

Lu, Dengsheng; Chen, Qi; Wang, Guangxing; Liu, Lijuan; Li, Guiying; Moran, Emilio (2015): A survey of remote sensing-based aboveground biomass estimation methods in forest ecosystems. In Int. J. Digit. Earth 9 (1), pp. 63-105. DOI: 10.1080/17538947.2014.990526.

Lukkarinen, Antti J.; Ruotsalainen, Seppo; Nikkanen, Teijo; Peltola, Heli (2009): The Growth Rhythm and Height Growth of Seedlings of Siberian (Larix sibirica Ledeb.) and Dahurian (Larix gmelinii Rupr.) Larch Provenances in Greenhouse Conditions. In Silva Fennica 43 (1), pp. 5-20.

Lukkarinen, Antti J.; Ruotsalainen, Seppo; Nikkanen, Teijo; Peltola, Heli (2010): Survival, Height Growth and Damages of Siberian (Larix sibirica Ledeb.) and Dahurian (Larix gmelinii Rupr.) Larch Provenances in Field Trials Located in Southern and Northern Finland. In Silva Fennica 44 (5), pp. 727-747.

Luyssaert, S.; Inglima, I.; Jung, Martin; Richardson, Andrew D.; Reichstein, Markus; Papale, D. et al. (2007): CO2 balance of boreal, temperate, and tropical forests derived from a global database. In Glob. Change Biol. 13 (12), pp. 2509-2537. DOI: 10.1111/j.1365-

2486.2007.01439.x.

Main-Knorn, Magdalena; Cohen, Warren B.; Kennedy, Robert E.; Grodzki, Wojciech; Pflugmacher, Dirk; Griffiths, Patrick; Hostert, Patrick (2013): Monitoring coniferous forest biomass change using a Landsat trajectory-based approach. In Remote Sensing of Environment 139, pp. 277-290. DOI: 10.1016/j.rse.2013.08.010.

Maksis, O. A.; Haruk, E. B. (2002): Special Aspects Extractives of Wood of Larix Growing in Different Eco-Geographical Circumstances (in Russian). In Chemistry of plant fibre 4, pp. 39-41 [in Russian].

Mataix-Solera, J.; Doerr, Stefan H. (2004): Hydrophobicity and aggregate stability in calcareous topsoils from fire-affected pine forests in southeastern Spain. In Geoderma 118 (1-2), pp. 77-88. DOI: 10.1016/S0016-7061(03)00185-X.

Maximovich, Stanislav V. (2004): Geography and Ecology of Cryogenic Soils of Mongolia. In John M. Kimble (Ed.): Cryosols. Permafrost-Affected Soils. Berlin, Heidelberg: Springer, pp. 253-274.

Ma, Zhihai; Peng, Changhui; Zhu, Qiuan; Chen, Huai; Yu, Guirui; Li, Weizhong et al. (2012): Regional drought-induced reduction in the biomass carbon sink of Canada's boreal forests. 
In Proceedings of the National Academy of Sciences of the United States of America 109 (7), pp. 2423-2427. DOI: 10.1073/pnas.1111576109.

Middleton, Nick; Rueff, Henri; Sternberg, Troy; Batbuyan, Batjav; Thomas, David (2015): Explaining spatial variations in climate hazard impacts in western Mongolia. In Landscape Ecol 30 (1), pp. 91-107. DOI: 10.1007/s10980-014-0091-2.

Miehe, Georg; Miehe, Sabine (2000): Comparative High Mountain Research on the Treeline Ecotone under Human Impact. In Erdkunde (54), pp. 34-50.

Miehe, Georg; Miehe, Sabine; Will, Martin; Opgenoorth, Lars; La Duo; Dorgeh, Tsering; Liu, Jianquan (2007a): An inventory of forest relicts in the pastures of Southern Tibet (Xizang A.R., China). In Plant Ecol 194 (2), pp. 157-177. DOI: 10.1007/s11258-007-9282-0.

Miehe, Georg; Schlütz, Frank; Miehe, Sabine; Opgenoorth, Lars; Cermak, Jan; Samiya, Ravčigijn et al. (2007b): Mountain forest islands and Holocene environmental changes in Central Asia: A case study from the southern Gobi Altay, Mongolia. In Palaeogeography, Palaeoclimatology, Palaeoecology 250, pp. 150-166. DOI: 10.1016/j.palaeo.2007.03.022.

Miehe, Georg; Miehe, Sabine; Böhner, Jürgen; Kaiser, Knut; Hensen, Isabel; Madsen, David et al. (2014): How old is the human footprint in the world's largest alpine ecosystem? A review of multiproxy records from the Tibetan Plateau from the ecologists' viewpoint. In Quaternary Sci. Rev. 86, pp. 190-209. DOI: 10.1016/j.quascirev.2013.12.004.

Miyahara, Mie; Takenaka, Chisato; Tomioka, Rie; Ohta, Takeshi (2011): Root responses of Siberian larch to different soil water conditions. In Hydrological Research Letters 5, pp. 9397. DOI: 10.3178/hrl.5.93.

Miyazaki, Shin; Ishikawa, Mamoru; Baatarbileg, Nachin; Damdinsuren, Sodov; Ariuntuya, Nymsambuu; Jambaljav, Yamkhin (2014): Interannual and seasonal variations in energy and carbon exchanges over the larch forests on the permafrost in northeastern Mongolia. In Polar Science 8 (2), pp. 166-182. DOI: 10.1016/j.polar.2013.12.004.

Mongolian Ministry of Environment and Tourism (2019): Mongolian Multipurpose National Forest Inventory 2014-2017. 2nd edn. Ulaanbaatar.

Moorman, Brian J.; Robinson, Stephen D.; Burgess, Margo M. (2003): Imaging periglacial conditions with ground-penetrating radar. In Permafrost and Periglac. Process. 14 (4), pp. 319-329. DOI: 10.1002/ppp.463.

Mudrik, V. A.; Vil'chek, G. E. (2001): Ecophysiological Responses of Larix sibirica Ledeb. and Pinus sibirica Du Tour Undergrowth to Climate Change. In Russ J Ecol (32), pp. 243-248.

Mukhortova, L.; Schepaschenko, Dmitry; Shvidenko, Anatoly Z.; McCallum, I.; Kraxner, F. (2015): Soil contribution to carbon budget of Russian forests. In Agr. Forest Meteorol. 200, pp. 97-108. DOI: 10.1016/j.agrformet.2014.09.017.

Müller, Michael; Schwab, Niels; Schickhoff, Udo; Böhner, Jürgen; Scholten, Thomas (2016): Soil Temperature and Soil Moisture Patterns in a Himalayan Alpine Treeline Ecotone. In Arctic, Antarctic, and Alpine Research 48 (3), pp. 501-521. DOI: 10.1657/AAAR0016-004.

Nandintsetseg, Banzragch; Shinoda, Masato (2011): Seasonal change of soil moisture in Mongolia: its climatology and modelling. In Int. J. Climatol. 31 (8), pp. 1143-1152. DOI: 10.1002/joc.2134.

National Statistical Office of Mongolia: Mongolian Statistical Information Service. Available online at http://1212.mn/, checked on 11/6/2019.

Noskova, N. E.; Romanova, L. I. (2013): Structural and Functional Properties of the Male Generative Organs of Siberian larch and Scotch pine in the Conditions of Climate Change in 
Siberia (in Russian). In Bulletin of Krasnoyarsk Agrarian University 7, pp. 175-180 [in Russian].

Nyamjav, Bayartaa; Goldammer, G.J.; Uibrig, H. (2007): Fire situation in Mongolia. In : International Forest Fire News, 36, vol. 36 (36), pp. 46-66, checked on 1/5/2017.

Ohta, Takeshi; Maximov, Trofim C.; Dolman, A. Johannes; Nakai, Taro; van der Molen, Michiel K.; Kononov, Alexander V. et al. (2008): Interannual variation of water balance and summer evapotranspiration in an eastern Siberian larch forest over a 7-year period (19982006). In Agricultural and Forest Meteorology 148 (12), pp. 1941-1953. DOI:

10.1016/j.agrformet.2008.04.012.

Ohta, Takeshi; Kotani, Ayumi; lijima, Yoshihiro; Maximov, Trofim C.; Ito, Syogo; Hanamura, Miho et al. (2014): Effects of waterlogging on water and carbon dioxide fluxes and environmental variables in a Siberian larch forest, 1998-2011. In Agricultural and Forest Meteorology 188, pp. 64-75. DOI: 10.1016/j.agrformet.2013.12.012.

Opp, C.; Hilbig, Werner (2003): Regular distribution patterns of soils and plant communities in northern Central Asia with special consideration of the Uvs-Nuur-Basin (in German). In Petermanns Geographische Mitteilungen 147 (5), pp. 16-23.

Pan, Yude; Birdsey, Richard A.; Fang, Jingyun; Houghton, Richard A.; Kauppi, Pekka E.; Kurz, Werner A. et al. (2011): A large and persistent carbon sink in the world's forests. In Science (New York, N.Y.) 333 (6045), pp. 988-993. DOI: 10.1126/science.1201609 [in eng].

Pâques, L. E. (1994): Relationship between foliar nutrient concentrations and growth of hybrid larch (Larix $\times$ eurolepsis Henry). In Forest Ecology and Management 63 (2-3), pp. 153-167. DOI: 10.1016/0378-1127(94)90108-2.

Park, Yeong Dae; Lee, Don Koo; Stanturf, John A.; Woo, Su Young; Zoyo, Damdinjav (2009): Ecological Indicators of Forest Degradation after Forest Fire and Clear-cutting in the Siberian Larch (Larix sibirica) Stand of Mongolia. In Jour. Korean For. Soc. 98 (5), pp. 609617.

Pascale, Gregory P.; Pollard, Wayne H.; Williams, Kevin K. (2008): Geophysical mapping of ground ice using a combination of capacitive coupled resistivity and ground-penetrating radar, Northwest Territories, Canada. In J. Geophys. Res. 113 (F2), p. 68. DOI: 10.1029/2006JF000585.

Pavlov, I. N.; Mironov, A. G. (2003): Dynamics of Sowing Qualities of Seeds from Larix sibirica Ledeb. Growing in an Areal of Siberia from 1936 to 2000 (in Russian). In Conifers of the boreal zone (1), pp. 9-16 [in Russian].

Pederson, Neil; Jacoby, Gordon C.; D’Arrigo, Rosanne; Cook, Edward R.; Buckley, Brendan M. (2001): Hydrometerological Reconstructions for Northeastern Mongolia Derived from Tree Rings: 1651-1995. In Journal of Climate 14, pp. 872-881.

Pelletier, Jon D.; Barron-Gafford, Greg A.; Gutiérrez-Jurado, Hugo; Hinckley, Eve-Lyn S.; Istanbulluoglu, Erkan; McGuire, Luke A. et al. (2018): Which way do you lean? Using slope aspect variations to understand Critical Zone processes and feedbacks. In Earth Surf. Process. Landforms 43 (5), pp. 1133-1154. DOI: 10.1002/esp.4306 [in en].

Peng, Changhui; Ma, Zhihai; Lei, Xiangdong; Zhu, Qiuan; Chen, Huai; Wang, Weifeng et al. (2011): A drought-induced pervasive increase in tree mortality across Canada's boreal forests. In Nature Clim Change 1 (9), pp. 467-471. DOI: 10.1038/nclimate1293.

Phu, Truong Dinh (1975): Nutrient requirements of planted European larch in Quebec. In Plant Soil 42 (1), pp. 109-117. DOI: 10.1007/BF02186977. 
Ponomarev, Evgenii; Kharuk, Viacheslav I.; Ranson, Kenneth J. (2016): Wildfires Dynamics in Siberian Larch Forests. In Forests 7 (125), pp. 1-9. DOI: 10.3390/f7060125.

Poulter, Benjamin; Pederson, Neil; Liu, Hongyan; Zhu, Zaichun; D’Arrigo, Rosanne; Ciais, Philippe et al. (2013): Recent trends in Inner Asian forest dynamics to temperature and precipitation indicate high sensitivity to climate change. In Agricultural and Forest Meteorology 178-179, pp. 31-45. DOI: 10.1016/j.agrformet.2012.12.006.

Powell, Scott L.; Cohen, Warren B.; Healey, Sean P.; Kennedy, Robert E.; Moisen, Gretchen G.; Pierce, Kenneth B.; Ohmann, Janet L. (2010): Quantification of live aboveground forest biomass dynamics with Landsat time-series and field inventory data. A comparison of empirical modeling approaches. In Remote Sensing of Environment 114 (5), pp. 1053-1068. DOI: 10.1016/j.rse.2009.12.018.

R Core Team (2014): R: A language and environment for statistical computing. Vienna: R Foundation for Statistical. Available online at http://www.R-project.org/.

Richter, H.; Haase, G.; Barthel, H. (1963): Die Golezterrassen. In Petermanns Geographische Mitteilungen 107, pp. 183-192 [in German].

Rigling, Andreas; Waldner, Philipp O.; Forster, Theodor; Bräker, Otto U.; Pouttu, Antti (2001): Ecological interpretation of tree-ring width and intraannual density fluctuations in Pinus sylvestris on dry sites in the central Alps and Siberia. In Canadian Journal of Plant Science 31 (1), pp. 18-31. DOI: 10.1139/cjfr-31-1-18.

Ripple, William J.; Wolf, Christopher; Newsome, Thomas M.; Barnard, Phoebe; Moomaw, William R. (2019): World Scientists' Warning of a Climate Emergency. In BioScience 5, p. 969. DOI: 10.1093/biosci/biz088.

Rodríguez-Veiga, Pedro; Quegan, Shaun; Carreiras, Joao; Persson, Henrik J.; Fransson, Johan E.S.; Hoscilo, Agata et al. (2019): Forest biomass retrieval approaches from earth observation in different biomes. In Int. J. Appl. Earth Obs. 77, pp. 53-68. DOI: 10.1016/j.jag.2018.12.008.

Rouse, J. W.; Hass, R.; Schell, J. A.; Deering, D. W. (1974): Monitoring vegetation systems in the Great Plains with ERTS. In NASA. Goddard Space Flight Center (Ed.): 3rd ERTS-1 Symposium, pp. 309-317.

Roy, D. P.; Kovalskyy, V.; Zhang, H. K.; Vermote, E. F.; Yan, L.; Kumar, S. S.; Egorov, A. (2016): Characterization of Landsat-7 to Landsat-8 reflective wavelength and normalized difference vegetation index continuity. In Remote Sensing of Environment 185, pp. 57-70. DOI: 10.1016/j.rse.2015.12.024.

Sakamoto, Keiji; Tomonari, Misaki; Ariya, Uyanga; Nakagiri, Erika; Matsumoto, Tetsuya K.; Akaji, Yasuaki et al. (2021): Effects of large-scale forest fire followed by illegal logging on the regeneration of boreal forests in Mongolia. In Landscape Ecol Eng 17 (3), pp. 267-279. DOI: 10.1007/s11355-021-00457-8 [in En;en].

Saladyga, Thomas; Hessl, Amy E.; Nachin, Baatarbileg; Pederson, Neil (2013): Privatization, Drought, and Fire Exclusion in the Tuul River Watershed, Mongolia. In Ecosystems 16 (6), pp. 1139-1151. DOI: 10.1007/s10021-013-9673-0.

Sangüesa-Barreda, Gabriel; Camarero, J. Julio; García-Martín, Alberto; Hernández, Rodolfo; La Riva, Juan (2014): Remote-sensing and tree-ring based characterization of forest defoliation and growth loss due to the Mediterranean pine processionary moth. In Forest Ecology and Management 320, pp. 171-181. DOI: 10.1016/j.foreco.2014.03.008.

Sankey, Temuulen Tsagaan; Montagne, Cliff; Graumlich, Lisa; Lawrence, Rick; Nielsen, Jerry (2006): Lower forest-grassland ecotones and 20th Century livestock herbivory effects 
in northern Mongolia. In Forest Ecology and Management 233 (1), pp. 36-44. DOI: 10.1016/j.foreco.2006.05.070.

Schlütz, Frank; Dulamsuren, Choimaa; Wieckowska, Magdalena; Mühlenberg, Michael; Hauck, Markus (2008): Late Holocene vegetation history suggests natural origin of steppes in the northern Mongolian mountain taiga. In Palaeogeography, Palaeoclimatology, Palaeoecology 261 (3-4), pp. 203-217. DOI: 10.1016/j.palaeo.2007.12.012.

Schulze, E.-D.; Schulze, W.; Koch, H.; Arneth, A.; Bauer, G.; Kelliher, F. M. et al. (1995): Aboveground biomass and nitrogen nutrition in a chronosequence of pristine Dahurian Larix stands in eastern Siberia. In Canadian Journal of Plant Science 25 (6), pp. 943-960. DOI: 10.1139/x95-103.

Schulze, E.-D.; Wirth, C.; Mollicone, D.; Ziegler, W. (2005): Succession after stand replacing disturbances by fire, wind throw, and insects in the dark Taiga of Central Siberia. In Oecologia 146 (1), pp. 77-88. DOI: 10.1007/s00442-005-0173-6.

Sharkhuu, Anarmaa; Plante, Alain F.; Enkhmandal, Orsoo; Gonneau, Cédric; Casper, Brenda B.; Boldgiv, Bazartseren; Petraitis, Peter S. (2016): Soil and ecosystem respiration responses to grazing, watering and experimental warming chamber treatments across topographical gradients in northern Mongolia. In Geoderma 269, pp. 91-98. DOI: 10.1016/j.geoderma.2016.01.041.

Sharkhuu, Natsagdorj (2003): Recent changes in the permafrost of Mongolia. In Marcia Phillips, Sarah M. Springman, Lukas U. Arenson (Eds.): Permafrost. Proceedings of the 8th International Conference on Permafrost, 21-25 July 2003, Zurich, Switzerland. Lisse: Balkema, pp. 1029-1034.

Sharkhuu, Natsagdorj; Sharkhuu, Anarmaa (2012): Effects of Climate Warming and Vegetation Cover on Permafrost of Mongolia. In Marinus J.A. Werger, Marja A. van Staalduinen (Eds.): Eurasian Steppes. Ecological Problems and Livelihoods in a Changing World, vol. 6. Dordrecht: Springer Netherlands (Plant and Vegetation), pp. 445-472.

Shuman, Jacquelyn Kremper; Shugart, Herman Henry; O'Halloran, Thoma Liam (2011): Sensitivity of Siberian larch forests to climate change. In Global Change Biology 17 (7), pp. 2370-2384. DOI: 10.1111/j.1365-2486.2011.02417.x.

Shur, Y. L.; Jorgenson, M. Torre (2007): Patterns of permafrost formation and degradation in relation to climate and ecosystems. In Permafrost and Periglac. Process. 18 (1), pp. 7-19. DOI: 10.1002/ppp.582.

Shvidenko, A. Z.; Schepaschenko, Dmitry (2014): Carbon balance of Russian forests. In Siberian Forest Journal 1, pp. 69-92, checked on 8/21/2019.

Sidorova, Olga Vladimirovna; Siegwolf, Rolf T. W.; Saurer, Matthias; Naurzbaev, Mukhtar M.; Vaganov, Eugene A. (2008): Isotopic composition ( $\delta 13 \mathrm{C}, \delta 18 \mathrm{O})$ in wood and cellulose of Siberian larch trees for early Medieval and recent periods. In J. Geophys. Res. 113 (G02019), 1-13. DOI: 10.1029/2007JG000473.

Sidorova, Olga Vladimirovna; Siegwolf, Rolf T. W.; Saurer, Matthias; Shashkin, Alexander V.; Knorre, Anastasia A.; Prokushkin, Anatoliy S. et al. (2009): Do centennial tree-ring and stable isotope trends of Larix gmelinii (Rupr.) Rupr. indicate increasing water shortage in the Siberian north? In Oecologia 161 (4), pp. 825-835. DOI: 10.1007/s00442-009-1411-0.

Sidorova, Olga Vladimirovna; Siegwolf, Rolf T. W.; Saurer, Matthias; Naurzbaev, Mukhtar M.; Shashkin, Alexander V.; Vaganov, Eugene A. (2010): Spatial patterns of climatic changes in the Eurasian north reflected in Siberian larch tree-ring parameters and stable isotopes. In Global Change Biology 16 (3), pp. 1003-1018. DOI: 10.1111/j.1365-2486.2009.02008.x. 
Sommer, Martin; Treter, Uwe (1999): Die Lärchenwälder der Gebirgswaldsteppe in den Randgebieten des Uvs Nuur- Beckens. In Die Erde 130, pp. 173-188, checked on 7/11/2019.

Sommer, Martin (2000): Die Lärchenwälder der Gebirgs-Waldsteppe im Nordwesten der Mongolei (in German). Ökologische Bestandsaufnahmen und Synthese. Dissertation [in German].

Starkel, L. (1998): Geomorphic response to climatic and environmental changes along a Central Asian transect during the Holocene. In Geomorphology 23, pp. 293-305, checked on 12/11/2019.

Stolbovoi, Vladimir (2000): Soils of Russia: correlated with the revised legend of the FAO soil map of the world and world reference base for soil resources. International Institute for Applied Systems Analysis. Laxenburg (Research report / International Institute for Applied Systems Analysis, RR-00-13).

Stüber, Volker (1998): Untersuchungen zum standortbezogenen Jugendwachstum der europäischen Lärche (Larix europaea, Dc.; Larix decidua, L.) (in German). Zugl.: Göttingen, Univ., Diss., 1998. 1. Aufl. Göttingen: Cuvillier [in ger].

Sudachkova, Nina E.; Milyutina, Inna L.; Semenova, Galina P. (2003): Specificity of Metabolism of Larix sibirica and Larix Gmelinii under Different Ecological Conditions (in Russian). In Conifers of the boreal zone 1, pp. 17-23 [in Russian].

Sugimoto, Atsuko; Yanagisawa, Nao; Naito, Daisuke; Fujita, Noboru; Maximov, Trofim C. (2002): Importance of permafrost as a source of water for plants in east Siberian taiga. In Ecological Research 17, pp. 493-593.

Sugimoto, Atsuko; Naito, Daisuke; Yanagisawa, Nao; Ichiyanagi, K.; Kurita, N.; Kubota, J. et al. (2003): Characteristics of soil moisture in permafrost observed in East Siberian taiga with stable isotopes of water. In Hydrol. Process. 17 (6), pp. 1073-1092. DOI: 10.1002/hyp.1180.

Suvorova, Galina G.; Yankova, Ludmila S.; Kopytova, Lidia D. (2009): Photosynthetic Productivity of Three Coniferous Species in Baikal Siberia, Eastern Russia. In Eurasian J. For. Res. 12 (1), pp. 47-56.

Sympilova, D. P.; Gyninova, A. B. (2012): Soils of the subtaiga landscapes on the northern spurs of the Tsagan-Daban Ridge in the Selenga Mountains. In Eurasian Soil Sc. 45 (3), pp. 231-236. DOI: 10.1134/S1064229312030118.

Takenaka, Chisato; Miyahara, Mie; Ohta, Takeshi; Maximov, Trofim C. (2016): Response of larch root development to annual changes of water conditions in eastern Siberia. In Polar Science 10 (2), pp. 160-166. DOI: 10.1016/j.polar.2016.04.012.

Taynik, Anna V.; Barinov, Valentin V.; Oidupaa, Orlan Ch.; Myglan, Vladimir S.; Reinig, Frederick; Büntgen, Ulf (2016): Growth coherency and climate sensitivity of Larix sibirica at the upper treeline in the Russian Altai-Sayan Mountains. In Dendrochronologia 39, pp. 1016. DOI: $10.1016 /$ j.dendro.2015.12.003.

Tchebakova, Nadejda M.; Blyakharchuk, T. A.; Parfenova, E. I. (2009a): Reconstruction and prediction of climate and vegetation change in the Holocene in the Altai-Sayan mountains, Central Asia. In Environ. Res. Lett. 4 (4), pp. 1-11. DOI: 10.1088/1748-9326/4/4/045025.

Tchebakova, Nadejda M.; Parfenova, E. I.; Soja, A. J. (2009b): The effects of climate, permafrost and fire on vegetation change in Siberia in a changing climate. In Environ. Res. Lett. 4 (4), pp. 1-9. DOI: 10.1088/1748-9326/4/4/045013. 
Tchebakova, Nadejda M.; Parfenova, E. I.; Lysanova, G. I.; Soja, A. J. (2011): Agroclimatic potential across central Siberia in an altered twenty-first century. In Environ. Res. Lett. 6 (4), pp. 1-11. DOI: 10.1088/1748-9326/6/4/045207.

Tchebakova, Nadejda M.; Parfenova, E. I.; Korets, M. A.; Conard, S. G. (2016): Potential change in forest types and stand heights in central Siberia in a warming climate. In Environ. Res. Lett. 11 (3), pp. 1-16. DOI: 10.1088/1748-9326/11/3/035016.

Tei, Shunsuke; Sugimoto, Atsuko; Yonenobu, Hitoshi; Ohta, Takeshi; Maximov, Trofim C. (2014): Growth and physiological responses of larch trees to climate changes deduced from tree-ring widths and $\delta 13 \mathrm{C}$ at two forest sites in eastern Siberia. In Polar Science 8 (2), pp. 183-195. DOI: 10.1016/j.polar.2013.12.002.

Testa, S.; Soudani, K.; Boschetti, L.; Borgogno Mondino, E. (2018): MODIS-derived EVI, NDVI and WDRVI time series to estimate phenological metrics in French deciduous forests. In International Journal of Applied Earth Observation and Geoinformation 64, pp. 132-144. DOI: 10.1016/j.jag.2017.08.006.

Thomas, Nancy E.; Huang, Chengquan; Goward, Samuel N.; Powell, Scott L.; Rishmawi, Khaldoun; Schleeweis, Karen; Hinds, Adrienne (2011): Validation of North American Forest Disturbance dynamics derived from Landsat time series stacks. In Remote Sensing of Environment 115 (1), pp. 19-32. DOI: 10.1016/j.rse.2010.07.009.

Thurner, Martin; Beer, Christian; Santoro, Maurizio; Carvalhais, Nuno; Wutzler, Thomas; Schepaschenko, Dmitry et al. (2014): Carbon stock and density of northern boreal and temperate forests. In Global Ecol. Biogeogr. 23 (3), pp. 297-310. DOI: 10.1111/geb.12125.

Timoshok, E. N.; Skorokhodov, S. N. (2014): Ecology of Siberian Stone Pine (Pinus sibirica Du Tour) and Siberian Larch (Larix sibirica Ledeb.) in the Altai Mountain Glacial Basins. In Russ J Ecol 45 (3), pp. 194-200. DOI: 10.1134/S1067413614030138.

Treter, Uwe (1996): Gebirgs-Waldsteppe in der Mongolei. In Geographische Rundschau 48 (11), pp. 655-661.

Tsogtbaatar, Jamsran (2004): Deforestation and reforestation needs in Mongolia. In Forest Ecology and Management 201 (1), pp. 57-63. DOI: 10.1016/j.foreco.2004.06.011.

Tsogtbaatar, Jamsran (2013): Deforestation and Reforestation of Degraded Forestland in Mongolia. In Norio Yamamura, Noboru Fujita, Ai Maekawa (Eds.): The Mongolian Ecosystem Network. Environmental Issues Under Climate and Social Changes. Tokyo: Springer Japan; Imprint; Springer (Ecological Research Monographs), pp. 83-98.

Tucker, Compton J. (1979): Red and photographic infrared linear combinations for monitoring vegetation. In Remote Sensing of Environment 8 (2), pp. 127-150, checked on 8/26/2019.

Turco, M.; Palazzi, E.; Hardenberg, J.; Provenzale, A. (2015): Observed climate change hotspots. In Geophys. Res. Lett. 42 (9), pp. 3521-3528. DOI: 10.1002/2015GL063891.

U.S. Geological Survey (2019a): Landsat 4-7 Surface Reflectance (LEDAPS) Product Guide. Version 2.0. Sioux Falls, South Dakota (LSDS-1370). Available online at https://www.usgs.gov/media/files/landsat-4-7-surface-reflectance-code-ledaps-product-guide, checked on 8/23/2019.

U.S. Geological Survey (2019b): Landsat 8 Surface Reflectance Code (LASRC) Product Guide. Version 2.0. Sioux Falls, South Dakota (LSDS-1368). Available online at https://www.usgs.gov/media/files/landsat-8-surface-reflectance-code-lasrc-product-guide, checked on 8/23/2019. 
U.S. Geological Survey (2019c): Landsat Collection 1 Level 1 Product Definition. Sioux Falls, South Dakota (LSDS-1656). Available online at https://www.usgs.gov/land-

resources/nli/landsat/landsat-collection-1?qt-science_support_page_related_con=1\#qtscience_support_page_related_con, checked on 8/27/2019.

Umbanhowar, Charles E.; Shinneman, Avery L.C.; Tserenkhand, Gundsambuu; Hammon, Elizabeth R.; Lor, Pao; Nail, Kelly (2009): Regional fire history based on charcoal analysis of sediments from nine lakes in western Mongolia. In The Holocene 19 (4), pp. 611-624. DOI: 10.1177/0959683609104039.

Undarmaa, J.; Tamura, K.; Natsagdorj, L.; Yamanaka, N. (2018): Rangeland Ecosystems of Mongolia. Ulaanbaatar: Munkhiin Useg.

Unkelbach, Julia; Dulamsuren, Choimaa; Punsalpaamuu, Gaadan; Saindovdon, Davaadorj; Behling, Hermann (2017): Late Holocene vegetation, climate, human and fire history of the forest-steppe-ecosystem inferred from core G2-A in the 'Altai Tavan Bogd' conservation area in Mongolia. In Veget. Hist. Archaeobot. 27 (5), pp. 665-677. DOI: 10.1007/s00334-0170664-5.

Unkelbach, Julia; Kashima, K.; Enters, D.; Dulamsuren, Choimaa; Punsalpaamuu, Gaadan; Behling, Hermann (2019): Late Holocene (Meghalayan) palaeoenvironmental evolution inferred from multi-proxy-studies of lacustrine sediments from the Dayan Nuur region of Mongolia. In Palaeogeography, Palaeoclimatology, Palaeoecology 530, pp. 1-14. DOI: 10.1016/j.palaeo.2019.05.021.

USDA (2014): Soil Survey Field and Laboratory Methods Manual. oil Survey Investigations Report No. 51, Version 2.0. R. With assistance of Soil Survey Staff, Burt and Soil Survey Staff (ed.).

Vaganov, Eugene A.; Schulze, Ernst-Detlef; Skomarkova, Marina V.; Knohl, Alexander; Brand, Willi A.; Roscher, Christiane (2009): Intra-annual variability of anatomical structure and $\delta 13 \mathrm{C}$ values within tree rings of spruce and pine in alpine, temperate and boreal Europe. In Oecologia 161 (4), pp. 729-745. DOI: 10.1007/s00442-009-1421-y [in eng].

Vaganov, Eugene A.; Kirdyanov, Alexander V. (2010): Dendrochronology of Larch Trees Growing on Siberian Permafrost. In Akira Osawa, Olga A. Zyryanova, Yojiro Matsuura, Takuya Kajimoto, Ross W. Wein (Eds.): Permafrost Ecosystems. Siberian Larch Forests. Dordrecht: Springer (Ecological studies, 209), pp. 347-363.

Valendik, Erik N. (1996): Temporal and Spatial Distribution of Forest Fires in Siberia. In Johann Georg Goldammer, Valentin V. Furyaev (Eds.): Fire in Ecosystems of Boreal Eurasia. Dordrecht: Kluwer (Forestry sciences, 48), pp. 129-138.

van Lierop, Pieter; Lindquist, Erik; Sathyapala, Shiroma; Franceschini, Gianluca (2015): Global forest area disturbance from fire, insect pests, diseases and severe weather events. In Forest Ecology and Management 352, pp. 78-88. DOI: 10.1016/j.foreco.2015.06.010.

van Staalduinen, Marja A.; During, Heinjo; Werger, Marinus J.A. (2007): Impact of grazing regime on a Mongolian forest steppe. In Applied Vegetation Science (10), pp. 299-306.

Velisevich, Svetlana N.; Kozlov, Daniil N. (2006): Effects of Temperature and Precipitation on Radial Growth of Siberian Larch in Ecotopes with Optimal, Insufficient, and Excessive Soil Moistening. In Russ J Ecol 37 (4), pp. 241-246. DOI: 10.1134/S1067413606040047.

Velisevich, Svetlana N.; Khutornoy, Oleg V. (2009): Effects of Climatic Factors on Radial Growth of Siberian Stone Pine and Siberian Larch in Sites with Different Soil Humidity in the South of Western Siberia (in Russian). In Journal of Siberian Federal University 1 (2), pp. 117-132 [in Russian]. 
Venables, W. N.; Ripley, Brian D. (2011): Modern applied statistics with S. 4th ed. New York, London: Springer (Statistics and computing).

Venäläinen, Martti; Harju, Anni M.; Terziev, Nasko; Laakso, Tapio; Saranpää, Pekka (2006): Decay resistance, extractive content, and water sorption capacity of Siberian larch (Larix sibirica Lebed.) heartwood timber. In Holzforschung 60 (1), pp. 99-103. DOI: 10.1515/HF.2006.017.

Vicente-Serrano, Sergio M.; Camarero, J. Julio; Olano, José M.; Martín-Hernández, Natalia; Peña-Gallardo, Marina; Tomás-Burguera, Miquel et al. (2016): Diverse relationships between forest growth and the Normalized Difference Vegetation Index at a global scale. In Remote Sensing of Environment 187, pp. 14-29. DOI: 10.1016/j.rse.2016.10.001.

Viers, J.; Prokushkin, Anatoliy S.; Pokrovsky, O. S.; Auda, Y.; Kirdyanov, Alexander V.; Beaulieu, E. et al. (2013): Seasonal and spatial variability of elemental concentrations in boreal forest larch foliage of Central Siberia on continuous permafrost. In Biogeochemistry 113 (1-3), pp. 435-449. DOI: 10.1007/s10533-012-9770-8.

Villalba, Ricardo; Velben, Thomas T. (1997): Spatial and temporal variation in Austrocedrus growth along the forest-steppe ecotone in northern Patagonia. In Canadian Journal of Plant Science 27, pp. 580-597.

Walter, Heinrich; Breckle, Siegmar-Walter (1999): Vegetation und Klimazonen (in German). Grundriß der globalen Ökologie. 7., völlig neu bearb. und erw. Aufl. Stuttgart: Ulmer (UTB für Wissenschaft Uni-Taschenbücher, 14) [in German].

Wang, Hui-Mei; Wang, Wen-Jie; Chen, Huanfeng; Zhang, Zhonghua; Mao, Zijun; Zu, YuanGang (2014): Temporal changes of soil physic-chemical properties at different soil depths during larch afforestation by multivariate analysis of covariance. In Ecology and evolution 4 (7), pp. 1039-1048. DOI: 10.1002/ece3.947 [in eng].

Wang, J.; Rich, P. M.; Price, K. P.; Kettle, W. D. (2004): Relations between NDVI and tree productivity in the central Great Plains. In Int. J. Remote Sens. 25 (16), pp. 3127-3138. DOI: $10.1080 / 0143116032000160499$.

Watanabe, Makoto; Ryu, Koharu; Kita, Kazuhito; Takagi, Kentaro; Koike, Takayoshi (2012): Effect of nitrogen load on growth and photosynthesis of seedlings of the hybrid larch $\mathrm{F} 1$ (Larix gmelinii var. japonica $\times$ L. kaempferi) grown on serpentine soil. In Environmental and Experimental Botany 83, pp. 73-81. DOI: 10.1016/j.envexpbot.2012.04.011.

Wecking, Anne (2017): Managing Forest Ecosystems in Mongolia - the Crucial Role of Soil. Unpublished. Gottfried Wilhelm Leibniz Universität, Hannover. Institute of Physical Geography and Landscape Ecology.

Wickham, Hadley (2016): ggplot2. Elegant graphics for data analysis. Cham: Springer (Use R!). Available online at http://dx.doi.org/10.1007/978-3-319-24277-4 [in eng].

Wu, Tonghua; Wang, Qinxue; Watanabe, Masataka; Chen, Ji; Battogtokh, Dorjgotov (2009): Mapping vertical profile of discontinuous permafrost with ground penetrating radar at Nalaikh depression, Mongolia. In Environ Geol 56 (8), pp. 1577-1583. DOI: 10.1007/s00254-0081255-7.

Wu, Tonghua; Wang, Qinxue; Zhao, Lin; Du, Erji; Wang, Wu; Batkhishig, Ochirbat et al. (2012): Investigating internal structure of permafrost using conventional methods and ground-penetrating radar at Honhor basin, Mongolia. In Environ Earth Sci 67 (7), pp. 18691876. DOI: 10.1007/s12665-012-1629-8. 
Xu, Peipei; Fang, Wei; Zhou, Tao; Zhao, Xiang; Luo, Hui; Hendrey, George R.; Yi, Chuixiang (2019): Spatial Upscaling of Tree-Ring-Based Forest Response to Drought with Satellite Data. In Remote Sensing 11 (20), p. 2344. DOI: 10.3390/rs11202344.

Yang, Yue; Wang, Zhaoqi; Li, Jianlong; Gang, Chencheng; Zhang, Yanzhen; Zhang, Ying et al. (2016): Comparative assessment of grassland degradation dynamics in response to climate variation and human activities in China, Mongolia, Pakistan and Uzbekistan from 2000 to 2013. In J. Arid Environ. 135, pp. 164-172. DOI: 10.1016/j.jaridenv.2016.09.004.

Yazaki, Kenichi; Funada, Ryo; Mori, Shigeta; Maruyama, Yutaka; Abaimov, Anatoly P.; Kayama, Masazumi; Koike, Takayoshi (2001): Growth an annual ring structure of Larix sibirica grown at different carbon dioxide concentrations and nutrient supply rates. In Tree physiology 21, pp. 1223-1229.

Yershov, E. D.; Williams, Peter J. (2009): General Geocryology: Cambridge University Press.

Zhang, Ningning; Yasunari, Tetsuzo; Ohta, Takeshi (2011): Dynamics of the larch taigapermafrost coupled system in Siberia under climate change. In Environ. Res. Lett. 6 (2), p. 24003. DOI: 10.1088/1748-9326/6/2/024003.

Zhang, Tingjun (2005): Influence of the seasonal snow cover on the ground thermal regime: An overview. In Rev. Geophys. 43 (4), p. 1. DOI: 10.1029/2004RG000157.

Zhou, Yang; Yi, Yujun; Jia, Wenfei; Cai, Yanpeng; Yang, Wei; Li, Zhiwei (2020): Applying dendrochronology and remote sensing to explore climate-drive in montane forests over space and time. In Quaternary Science Reviews 237, p. 106292. DOI:

10.1016/j.quascirev.2020.106292. 